\title{
73-Allyl carbonyl complexes of group 6 metals: structural aspects, isomerism, dynamic behaviour and reactivity
}

Article

Accepted Version

Creative Commons: Attribution-Noncommercial-No Derivative Works 4.0

Ryan, D. E., Cardin, D. and Hartl, F. (2017) ฤ3-Allyl carbonyl complexes of group 6 metals: structural aspects, isomerism, dynamic behaviour and reactivity. Coordination Chemistry Reviews, 335. pp. 103-149. ISSN 0010-8545 doi: https://doi.org/10.1016/j.ccr.2016.12.018 Available at https://centaur.reading.ac.uk/68547/

It is advisable to refer to the publisher's version if you intend to cite from the work. See Guidance on citing.

To link to this article DOI: http://dx.doi.org/10.1016/j.ccr.2016.12.018

Publisher: Elsevier

All outputs in CentAUR are protected by Intellectual Property Rights law, including copyright law. Copyright and IPR is retained by the creators or other copyright holders. Terms and conditions for use of this material are defined in the End User Agreement.

www.reading.ac.uk/centaur 
Central Archive at the University of Reading

Reading's research outputs online 


\title{
$\eta^{3}$-Allyl Carbonyl Complexes of Group 6 Metals: Structural Aspects, Isomerism, Dynamic Behaviour and Reactivity
}

\author{
David E. Ryan, David J. Cardin, František Hart1*
}

Department of Chemistry, University of Reading, Whiteknights, Reading RG6 6AD, UK

E-mail: f.hartl@ reading.ac.uk

\section{Contents}

1. Introduction

2. Complexes $\left[\mathrm{CpM}(\mathrm{CO})_{2}\left(\eta^{3}\right.\right.$-allyl $\left.)\right]$ and related compounds

2.1. Synthetic strategies

2.2. Exo $\rightleftharpoons$ endo isomerism

2.3. ${ }^{95} \mathrm{Mo}$ and ${ }^{183} \mathrm{~W}$ NMR spectroscopy

2.4. Oxidized cationic complexes - reactivity, fluxionality, structural features

2.5. Mixed nitrosyl carbonyl complexes $\left[\mathrm{CpM}(\mathrm{CO})(\mathrm{NO})\left(\eta^{3} \text {-allyl }\right)\right]^{+}(\mathrm{M}=\mathrm{Mo}, \mathrm{W})$

3. Complexes $\left[\mathrm{M}(\mathrm{CO})_{2}\left(\eta^{3}\right.\right.$-allyl $)(\alpha$-diimine $\left.) \mathrm{X}\right](\mathrm{X}=$ anionic monodentate ligand $)$ and related compounds

3.1. Synthetic strategies

3.2. Mechanistic features, structural aspects, and dynamic behaviour

3.3. Monodentate ligands bound to $\mathrm{M}(\mathrm{CO})_{2}\left(\eta^{3}\right.$-allyl $)\left(\mathrm{L}^{\frown} \mathrm{L}\right)$ : reactivity and intermediacy in allylic alkylations

3.4. Redox Properties and Electrocatalysis

4. Amidinato and pyrazolato complexes related to $\left[\mathrm{M}(\mathrm{CO})_{2}\left(\eta^{3}\right.\right.$-allyl $)(\alpha$-diimine $\left.) \mathrm{X}\right]$

4.1. Synthesis and dynamic behaviour

4.2. Coordinatively unsaturated species and their reactivity

5. Summary and outlook

Acknowledgement

References 


\section{ABSTRACT}

Transition metal complexes with $\pi$-allylic ligands remain an attractive topic in organometallic chemistry, given the numerous reports of a wide variety of synthetic routes, dynamic behaviour and reactivity, structural (including isomerism), spectroscopic and redox properties, and applications in organic synthesis and catalysis. Surprisingly, despite the considerable interest in the rich and varied chemistry of this family of organometallic compounds, there is no recent review. This review is focused on $\pi$-allylic representatives of low-cost Group- 6 metals bearing one or more carbonyl ligand, the coordination sphere being complemented with $\eta^{5}$ cyclopentadienyl (Section 2), chelating ligands, including redox active $\alpha$-diimines and various complementary diphosphine (Section 3) and novel anionic amidinate or pyrazolate (Section 4) ligands. In Section 1 particular attention is paid to rearrangements of the $\pi$-allylic ligand, namely exo and endo isomerism, interconversion mechanisms, fluxionality, and agostic interactions. In addition, the application of multinuclear NMR spectroscopy to the elucidation of such isomerism, and the effect of the metal centre oxidation state on the bonding, dynamic behaviour and reactivity of the $\pi$-allylic ligand are described. The detailed mechanistic description of the synthetic routes and dynamic behaviour of selected representatives of $\alpha$ diimine complexes in Section 2 is followed by a description of the $\left[\mathrm{M}(\mathrm{CO})_{2}\left(\eta^{3}\right.\right.$-allyl-H,R $)(\alpha-$ diimine) $]^{0 /+}$ fragment as a convenient scaffold for diverse monodentate ligands participating in a range of substitution, insertion, intramolecular migration and $\mathrm{C}-\mathrm{C}$ coupling reactions frequently involving also the $\pi$-allylic ligand, such as allylic alkylation. Special attention is devoted to selected examples of redox and acid-base reactivity of the $\alpha$-diimine complexes with emphasis on prospects in electrocatalysis. The amidinate (and related pyrazolate) ligands treated in Section 4 may directly replace the $\pi$-allylic ligand in some cyclopentadienyl complexes (Section 2) or the $\alpha$-diimine ligand in some dicarbonyl $\pi$-allylic complexes (Section 3). The brief description of their synthetic routes is complemented by intriguing examples of 
fluxionality and characteristic reactivity encountered for these unusual four-electron donor ligands.

\section{Keywords:}

Group 6 metal; $\pi$-Allylic ligand; $\alpha$-Diimine; Amidinate; Fluxionality; Reactivity

\section{Introduction}

The $\mathrm{M}(\mathrm{CO})_{2}\left(\eta^{3}\right.$-allyl $)$ moiety has been extensively explored in the organometallic chemistry of Group 6 metals since the advent of this family of complexes in the 1960s. [1] A considerable variety of stable 18 valence electron complexes may be furnished by installation of monodentate, chelating or $\pi$ bound neutral $(\mathrm{L})$ and anionic $(\mathrm{X})$ ligands that constitute the complementary $\mathrm{L}_{2} \mathrm{X}$ component (or $\mathrm{L}_{3}$ in the case of cationic analogues); the composition of which prescribes the structure of this review. The cyclopentadienyl $(\mathrm{Cp})$ ligand, $\eta^{5}$-bound to the metal centre, is perhaps the most fundamental unit in this context, and complexes $\left[\mathrm{CpM}(\mathrm{CO})_{2}\left(\eta^{3}\right.\right.$-allyl $\left.)\right]$, along with derivatives thereof, are the topic of Section 2. Whereas throughout this realm of Group 6 organometallic chemistry, complexes of molybdenum and tungsten comprise the large majority, the small number of cyclopentadienylchromium allyl compounds exhibit novel chemical properties, including the formation of thermally stable 17 valence electron $\mathrm{Cr}(\mathrm{III})$ species (Section 2.4). Cationic allylmolybdenum and tungsten complexes $\left[\mathrm{CpM}(\mathrm{CO})(\mathrm{NO})\left(\eta^{3}-\right.\right.$ allyl) $]^{+}$are subject to nucleophilic attack at the allyl ligand; the regio- and stereochemical- outcome being controlled by an ubiquitous fluxional interconversion of isomers (Section 2.2).

The construction of the $\mathrm{L}_{2} \mathrm{X}$ component from chelating ligands $\mathrm{L}^{\frown} \mathrm{L}$, typically bound to the metal centre through nitrogen or phosphorus donor atoms, and monodentate anionic ligands $\mathrm{X}$, is a widespread feature amongst Group 6 allyl carbonyl complexes. A treatment of these complexes, generalised as $\left[\mathrm{M}(\mathrm{CO})_{2}\left(\eta^{3}\right.\right.$-allyl $\left.)\left(\mathrm{L}^{\frown} \mathrm{L}\right) \mathrm{X}\right]$, is provided in Section 3, accompanied by relevant examples that manifest alternative chelate motifs and donor atoms, as well as cationic complexes coordinated by 
neutral donors $\mathrm{L}$ in place of the anionic ligands. The variety within this family of complexes is accompanied by complex isomerism, which is acutely influenced by the composition of the coordination sphere (i.e., the steric and electronic structure of the ligands that constitute the $\mathrm{L}_{2} \mathrm{X}$ component), and further diversified by various substitution motifs borne by the allyl ligand. An additional complexity arises from discrete dynamic processes operant in solution, which interconvert the various isomers. A comprehensive discussion surrounding this isomerism is raised in Section 3, and continued in Section 4 in the context of amidinato complexes. Herein, the consolidation of data pertaining to the solid state and solution-based isomerism of these complexes, and the surrounding discussion, is designed to provide some insight into the effect of various ligands and their substituents, such that ligand optimisation may be approached in a more pragmatic manner to promote the desired dynamic behaviour and subsequent reactivity.

Section 4 is devoted to pyrazolate and amidinate ligands, the latter more pertinently belonging to a family of ligands with a heteroatomic allylic backbone. Whilst amidinate ligands are closer neighbours to the chelating $\mathrm{L}^{\frown} \mathrm{L}$ ligands introduced in Section 3, azaallyl and silaallyl ligands mimic the $\eta^{3}$-coordination mode of the unadorned allyl ligand, serving as direct replacements thereto. However the alternative bonding properties induced by the presence of the heteroatom(s) within the allylic backbone give rise to unique reactivity with novel intermediate species.

The various organometallic complexes explored herein are readily characterised by a range of analytical techniques that are frequently alluded to throughout the entirety of this text. Infrared spectroscopic measurements are routine in this realm, since the almost invariably present cis-dicarbonyl moiety engenders two distinct $v(\mathrm{CO})$ absorption bands, which may be conveniently tracked by IR spectro-electrochemical techniques to study the redox behaviour of electroactive compounds. [2,3] NMR spectroscopy, including variable-temperature and multinuclear studies (pertinently ${ }^{91} \mathrm{Mo}$ and ${ }^{183} \mathrm{~W}$ nuclei; Section 2.3), provides an invaluable means for the characterisation of structure and dynamic behaviour.

Amongst the various classes of Group 6 allyl carbonyl complexes, there are many examples displaying, or promising, catalytic activity; and the aforementioned fluxional phenomena have 
important consequences on the regio- and stereochemical course of the elementary reactions that constitute a given catalytic process. While many catalytic applications, such as allylic alkylations (Section 3.3) have been known for some time, mechanistic features still remain to be elucidated in order to pragmatically optimise the process. Contemporary interest in complexes containing the $\mathrm{M}(\mathrm{CO})_{2}\left(\eta^{3}-\right.$ allyl) fragment as a generality is in their suitability as precursors for catalytic olefin epoxidation. This topic is not explored in detail within this text, since it has only recently received a thorough treatment elsewhere. [4] Largely in its infancy, the pursuit of redox-active $\alpha$-diimine complexes $\left[\mathrm{M}(\mathrm{CO})_{3}\left(\eta^{3}\right.\right.$ allyl $)(\alpha$-diimine $) \mathrm{X}]$ as electrocatalysts for the reduction of carbon dioxide to carbon monoxide and potentially other useful species is particularly attractive, and stems from the moderate success of Group 6 tetracarbonyl $\alpha$-diimine complexes, as well as their Group-7 (Mn, Re) counterparts (Section 3.4).

Finally, whereas the ligation of carbonyl ligands and $\pi$-allyl moieties amongst these formally M(II) complexes suggests a character commensurate with late transition metal organometallic compounds, a surprising oxophilicity and general affinity for 'hard Lewis donor' atoms is frequently demonstrated in various reaction mechanisms, which is the case even for low-valent complexes of molybdenum and tungsten (Section 3.3). Such an intermediate behaviour offers unique strategies for the activation of small molecules and subsequent regio- and stereoselective transformations, and suggests catalytic applications for these abundant and relatively low-cost metals.

\section{Complexes $\left[\mathrm{CpM}(\mathrm{CO})_{2}\left(\eta^{3}\right.\right.$-allyl $\left.)\right]$ and related compounds}

\subsection{Synthetic strategies}

The synthesis of the complex $\left[\mathrm{CpMo}(\mathrm{CO})_{2}\left(\eta^{3}-\mathrm{C}_{3} \mathrm{H}_{5}\right)\right]\left(\mathrm{Cp}=\eta^{5}-\mathrm{C}_{5} \mathrm{H}_{5} ; 3\right)$ (Scheme 1) reported in 1963 by Cousins and Green [1] employed the anionic piano stool precursor $\left[\mathrm{CpMo}(\mathrm{CO})_{3}\right]^{-}(\mathbf{1})$ as its sodium salt. When added slowly to excess allyl chloride, the $\sigma$-allyl complex $\left[\mathrm{Cp}(\mathrm{Mo})(\mathrm{CO})_{3}\left(\eta^{1}-\mathrm{C}_{3} \mathrm{H}_{5}\right)\right]$ (2) is prepared via oxidative addition. UV irradiation then furnishes the $\pi$-allyl complex via photochemical dissociation of one of the carbonyl ligands. The tungsten analogue, $\left[\mathrm{CpW}(\mathrm{CO})_{2}\left(\eta^{3}-\right.\right.$ 
$\mathrm{C}_{3} \mathrm{H}_{5}$ )] (4) has been similarly obtained. [5,6] An improved synthesis (Scheme 2) requiring just two steps from the readily available hexacarbonyl precursor 5 was reported by Hayter in 1968. [7] The product of oxidative addition with allyl chloride, $\left[\mathrm{Mo}(\mathrm{CO})_{2}(\mathrm{MeCN})_{2}\left(\eta^{3}-\mathrm{C}_{3} \mathrm{H}_{5}\right) \mathrm{Cl}\right](\mathbf{6})$, typifies a precursor to another family of allyl carbonyl compounds of interest; a treatment of these complexes is presented in Section 3. The acetonitrile ligands are readily displaced along with the halide from intermediate 6 , upon treatment with a solution of lithium cyclopentadienide in tetrahydrofuran, introducing the Cp moiety as a ligand. This synthetic route has been employed for analogues of intermediate $\mathbf{6}$, including, but not limited to, $\left[\mathrm{M}(\mathrm{CO})_{2}(\mathrm{MeCN})_{2}\left(\eta^{3}\right.\right.$-allyl $\left.) \mathrm{X}\right]\left(\mathrm{M}=\mathrm{Mo}, \mathrm{W}\right.$; allyl $=\mathrm{C}_{3} \mathrm{H}_{5}, \mathrm{C}_{3} \mathrm{H}_{4} \mathrm{Me}, \mathrm{C}_{3} \mathrm{H}_{4} \mathrm{Cl}, \mathrm{C}_{6} \mathrm{H}_{9} ; \mathrm{X}=\mathrm{Cl}$, $\mathrm{Br}$, NCS). However, this method only appears to be applicable to compounds of molybdenum and tungsten, [7-9] and no $\pi$-allyl complexes of chromium have been prepared from $\left[\mathrm{Cr}(\mathrm{CO})_{3}(\mathrm{MeCN})_{3}\right]$ (7), using this strategy. The latter complex itself is far less stable than the molybdenum and tungsten tris(acetonitrile) tricarbonyl analogues. [10]

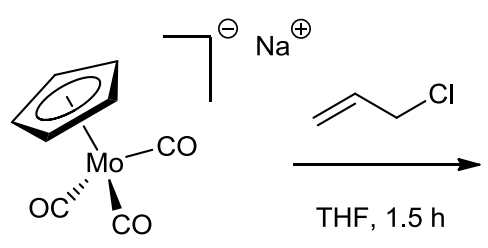

1

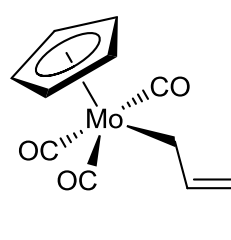

2

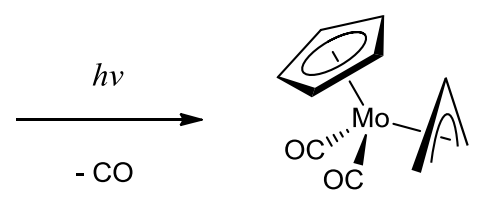

3

\section{Scheme 1.}

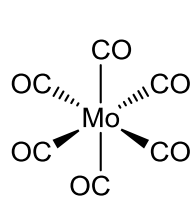

5
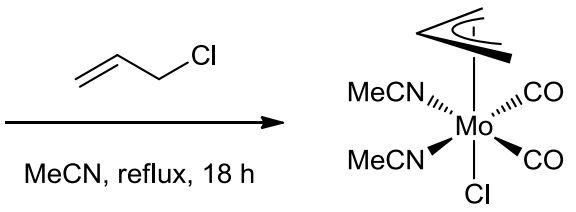

6

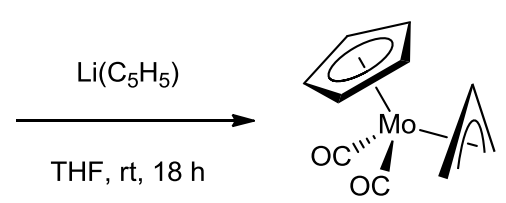

3

\section{Scheme 2.}


A general trend amongst the Group- 6 allyl carbonyls is, indeed, that the chromium analogues are significantly more challenging to prepare, with the resultant $\eta^{3}$-allyl products being often less stable. [11-16] However, recently a modification to the method shown in Scheme 2 provided a synthetic strategy for a variety of chromium analogues of $\mathbf{3}$ (Scheme 3). [8] Tris(acetonitrile) complex 7 undergoes oxidative addition to allyl bromide in acetonitrile, forming the intermediate $\left[\mathrm{Cr}(\mathrm{CO})_{2}(\mathrm{MeCN})_{2}\left(\eta^{3}-\mathrm{C}_{3} \mathrm{H}_{5}\right) \mathrm{Br}\right](\mathbf{8})$, which is analogous to $\mathbf{6}$ in Scheme 2. Intermediate $\mathbf{8}$ is temperaturesensitive; warming up the reaction mixture prior to the addition of $\mathrm{NaCp}$ yields intractable decomposition products. Appropriate choice of reagents affords a wide range of compounds 9a-e, some of which are shown in Scheme 3. However, the reaction does not proceed with allyl chlorides, presumably on account of the stronger $\mathrm{C}-\mathrm{Cl}$ bond which resists the oxidative addition step. The relatively low yield of $\mathbf{9 d}$ is perhaps attributable to the necessity of oxidative addition at a secondary carbon (Section 3.2).

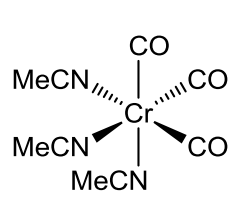

7

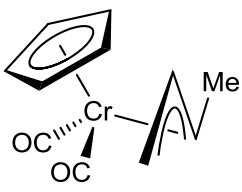

9b $73 \%$
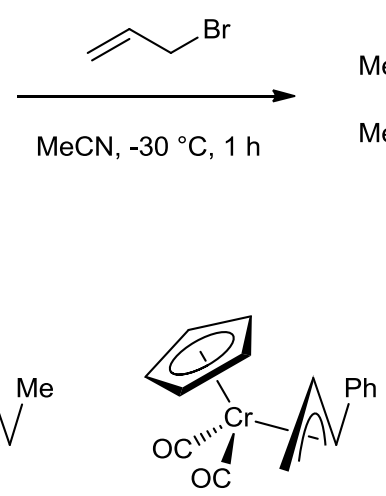

9c $61 \%$

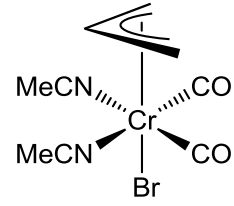

8
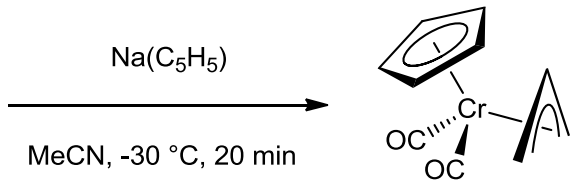

9a $75 \%$

Scheme 3. Synthetic route to $\left[\mathrm{CpCr}(\mathrm{CO})_{2}\left(\eta^{3}-\mathrm{C}_{3} \mathrm{H}_{5}\right)\right]$ 9a; derivatives 9b-e may also be prepared with an appropriate choice of reagents. [8]

The foregoing comments suggest that perhaps the smaller size of the chromium centre in comparison to that of molybdenum and tungsten for a given oxidation state, and the subsequent steric shielding imposed by the ligands, are at least in part responsible for the rather diminished reactivity of various chromium precursors towards oxidative addition to an allylic substrate. [12] As expected, 
cyclopentadienylchromium allyls generally have shorter $\mathrm{M}-\mathrm{C}_{\text {allyl }}$ distances compared to molybdenum and tungsten analogues. [17] On this assumption, one might discount an $S_{N} 2$ '-type mechanism of chromium precursor $\mathbf{7}$ on the allylic substrate, since the yields are similar for 9a-c where oxidative addition to a primary carbon is a common feature - yet the same synthetic route to $9 \mathbf{d}$ affords a comparatively low conversion. The details of the mechanism by which the oxidative addition to allylic substrates occurs have not yet been fully elucidated, and it is postulated that in fact differing mechanisms are applicable amongst the variety of complexes of topic throughout this review, see Section 3.2.

The indenyl ligand in 9e warrants some further discussion, since it exhibits a lower energetic barrier to the $\eta^{5} \rightarrow \eta^{3}$ haptotropic rearrangement in comparison to that of the cyclopentadienyl ligand. $[18,19]$ This feature, born of the tendency of the fused benzene ring to maintain aromaticity, provides a means by which the indenyl moiety can be installed as an allylic ligand itself. The molybdenum analogue of 9e serves as a precursor in a novel synthetic route to such compounds (Scheme 4). Treatment of $\left[\mathrm{Mo}(\mathrm{CO})_{2}\left(\eta^{5}\right.\right.$-indenyl $)\left(\eta^{3}\right.$-allyl $\left.)\right](\mathbf{1 0})$, prepared via the corresponding method to that shown in Scheme 3, with $\mathrm{HCl}$ gas yields chloride-bridged dimer 11. Incorporation of the cyclopentadienyl moiety induces a haptotropic shift of the $\eta^{5}$-coordinated indenyl ligand to furnish $\eta^{3}$ indenyl complex 12. The reaction is reported to also be successful for methyl-functionalised indenyl moieties 2- $\mathrm{MeC}_{9} \mathrm{H}_{6}$ and 4,7- $\mathrm{Me}_{2}-\mathrm{C}_{9} \mathrm{H}_{5} .[20]$

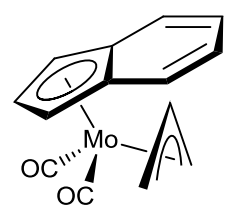

10

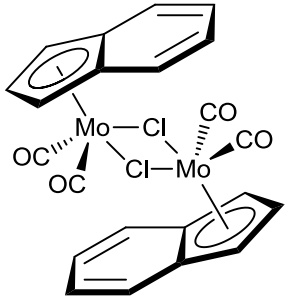

11

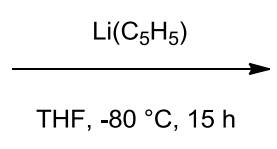

Scheme 4. Synthetic route to $\left[\mathrm{CpMo}(\mathrm{CO})_{2}\left(\eta^{3}\right.\right.$-indenyl) $(\mathbf{1 2})$; this reaction is also suited for various substituted indenyl derivatives. [20] 


\subsection{Exo $\rightleftharpoons$ endo isomerism}

The tendency of $\left[\mathrm{CpM}(\mathrm{CO})_{2}\left(\eta^{3}\right.\right.$-allyl $\left.)\right](\mathrm{M}=\mathrm{Cr}, \mathrm{Mo}, \mathrm{W})$ to form exo or endo isomers $\mathbf{A}$ and $\mathbf{B}$ (Chart 1) with regard to the arrangement of the allylic moiety, is a distinguishing feature of this family of complexes. The preference towards one rotameric conformation of the allyl ligand and the energetic barrier for interconversion between the two isomers, are seemingly a function of numerous steric and electronic variables. This phenomenon was first characterised on account of $\left[\mathrm{CpMo}(\mathrm{CO})_{2}\left(\eta^{3}-\mathrm{C}_{3} \mathrm{H}_{5}\right)\right](\mathbf{3})$ solutions exhibiting four IR $\mathrm{v}(\mathrm{CO})$ absorption bands, initially misidentified as the presence of $c i s$ and trans isomers; [21] the latter suggestion was later disregarded on account of steric unfeasibility, supported by the appearance two pairs of $\mathrm{v}(\mathrm{CO})$ bands at very similar wavenumbers. [22] Indeed, such a similarity in wavenumber often leads to the observation of just two $\mathrm{v}(\mathrm{CO})$ bands for compounds of this type, attributed to line broadening as a result of solvent effects. [23] Variable-temperature ${ }^{1} \mathrm{H} N M R$ studies further rationalised the presence of the exo and endo isomers and their interconversion in the solution. [22,24] The proton resonances pertaining to the allyl moiety do not collapse to an $\mathrm{A}_{4} \mathrm{X}$ motif in the spectrum on increasing the temperature, which is characteristic of a haptotropic interconversion through a $\sigma$-allyl intermediate; [25] rapid internal rotation of the $\eta^{1}$-allyl intermediate during the haptotropic rearrangement interconverts the syn and anti protons in the latter process. Instead, at low temperature, where the interconversion between exo and endo rotamers is sufficiently slow on the NMR timescale, the ${ }^{1} \mathrm{H}$ NMR spectrum of $\mathbf{3}$ (Figure 1) features two $\eta^{5}$-cyclopentadienyl resonances and two sets of superimposed allylic $\mathrm{AM}_{2} \mathrm{X}_{2}$ spectra consistent with 3-A and 3-B. On increasing the temperature, the rotameric interconversion becomes rapid on the NMR timescale; the peaks belonging to each of the conformations then coalesce and produce a weighted-average $\mathrm{A}_{2} \mathrm{M}_{2} \mathrm{X}$ spectrum. Since the syn and anti protons are shown not to interconvert, a $\eta^{3} \rightarrow \eta^{1} \rightarrow \eta^{3}$ mechanism to the rearrangement may be dismissed. [23,24] Instead, a $\eta^{3} \rightarrow \eta^{3} \rightarrow \eta^{3}$ mechanism is applicable (vide infra). Here, the complex $\left[\mathrm{CpMo}(\mathrm{CO})_{2}\left(\eta^{3}-\mathrm{C}_{3} \mathrm{H}_{5}\right)\right]$ (3) behaves differently to analogous compounds of Group-8 metals $\left[\mathrm{CpM}(\mathrm{CO})\left(\eta^{3}-\mathrm{C}_{3} \mathrm{H}_{5}\right)\right](\mathrm{M}=\mathrm{Fe}, \mathrm{Ru})$, which have been shown to interconvert between exo and endo conformations via the aforementioned $\eta^{3} \rightarrow \eta^{1} \rightarrow \eta^{3}$ mechanism. [26,27] A rationale for this observation was not offered until much later, whereby DFT calculations showed that the additional d-electron count 
of 2 in complexes of $\mathrm{Fe}$ and $\mathrm{Ru}$ occupies a high-lying orbital of a metal-Cp antibonding character in the transition state, pertaining to a half-rotated gauche arrangement of the allyl ligand (Figure 2b). [28] This renders the energy barrier to the $\eta^{3} \rightarrow \eta^{3} \rightarrow \eta^{3}$ interconversion of $\left[\mathrm{CpRu}(\mathrm{CO})\left(\eta^{3}-\mathrm{C}_{3} \mathrm{H}_{5}\right)\right]$ some 108 $\mathrm{kJ} \mathrm{mol}^{-1}$ higher than that of $\left[\mathrm{CpMo}(\mathrm{CO})_{2}\left(\eta^{3}-\mathrm{C}_{3} \mathrm{H}_{5}\right)\right]$ (Figure 2a). Another possible mechanistic pathway was also considered, which resembles a 'ring-flip', proceeding via a metallacyclobutane-type transition state where the allyl moiety is $\kappa^{2}$-bound. This transition state was calculated to be too high in energy due to both the conformational strain of the four membered metallacycle, and a lifting of the metalallyl $\Psi_{3}$ retrodative bonding; indeed, this mechanism would also stipulate the interconversion of syn and anti substituents at the allylic termini. Instead, the mechanism delineated in Figure 2 is applicable for complexes $\left[\mathrm{CpM}(\mathrm{CO})_{2}\left(\eta^{3}\right.\right.$-allyl $\left.)\right]$, whereby the allylic ligand rotates in a plane normal to the metalligand axis. The barrier to the $\eta^{3} \rightarrow \eta^{3} \rightarrow \eta^{3}$ interconversion for $\mathbf{3}$ has been estimated from variabletemperature NMR studies to reach ca. $51 \mathrm{~kJ} \mathrm{~mol}^{-1}$, [24] which is comparable to the calculated energy barrier shown in Figure 2.

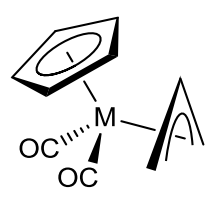

A exo

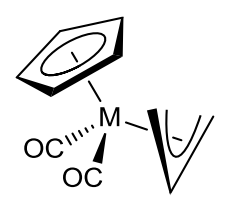

B endo

Chart 1. The exo $\mathbf{A}$ and endo $\mathbf{B}$ rotameric forms adopted by complexes $\left[\mathrm{CpM}(\mathrm{CO})_{2}\left(\eta^{3}\right.\right.$-allyl $\left.)\right](\mathrm{M}=\mathrm{Cr}, \mathrm{Mo}, \mathrm{W})$, and various derivatives thereof. 

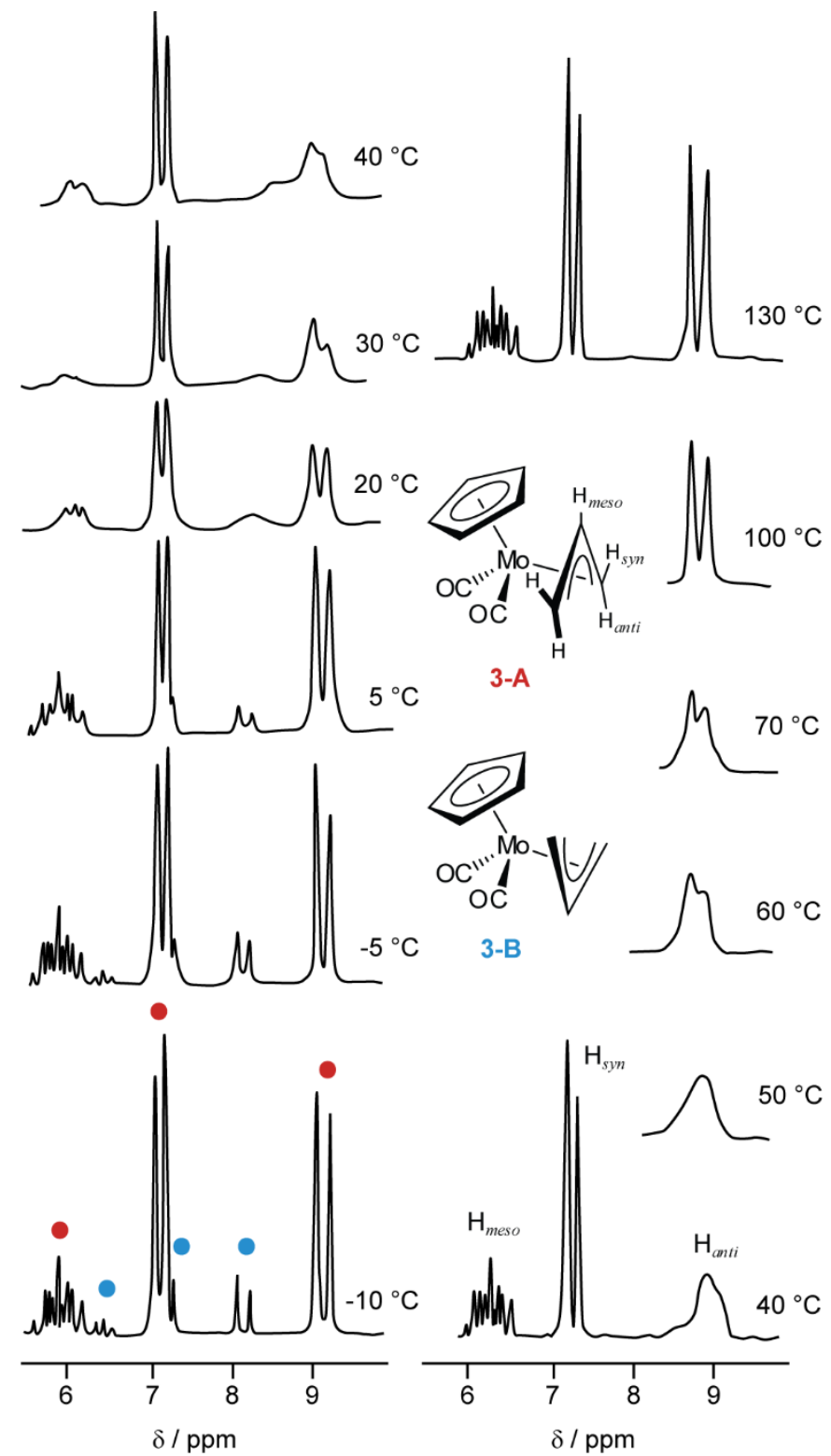

Figure 1. Variable-temperature ${ }^{1} \mathrm{H}$ NMR spectra of 3 recorded at $60 \mathrm{MHz}$ (ppm upfield from the benzene reference standard). The low-temperature spectra (left) were recorded in chloroform- $d_{3}$. Due to decomposition at $T>50{ }^{\circ} \mathrm{C}$ in chlorinated solvents, benzene- $d_{6}$ was used to record spectra in the temperature range of $40-130{ }^{\circ} \mathrm{C}$ (right). Adapted from [22]. 


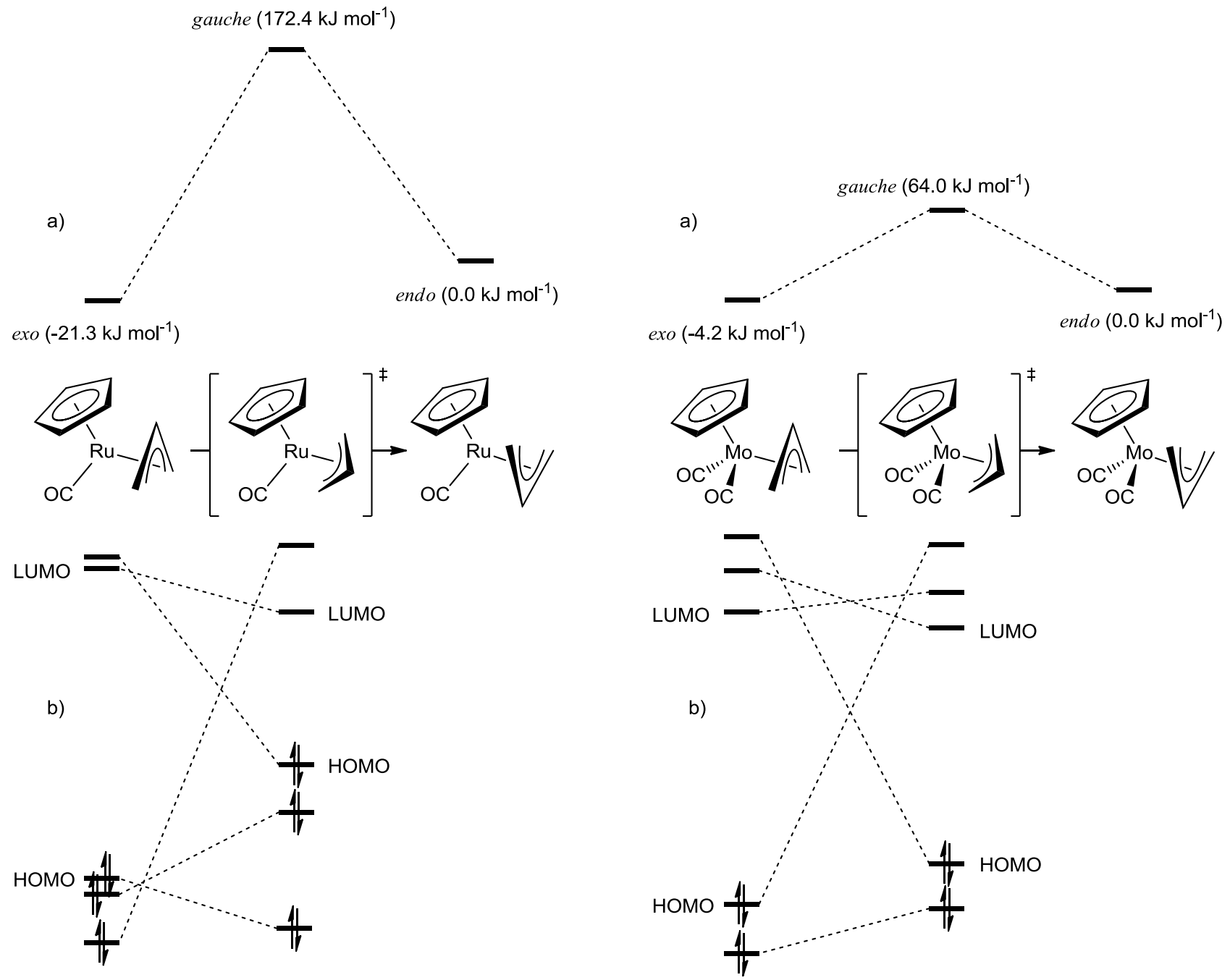

Figure 2. a) Energy profile and b) orbital correlation diagrams for the $\eta^{3}($ exo $) \rightarrow \eta^{3}$ (gauche) $\rightarrow \eta^{3}$ (endo) interconversions of complexes $\left[\mathrm{CpRu}(\mathrm{CO})\left(\eta^{3}-\mathrm{C}_{3} \mathrm{H}_{5}\right)\right]$ and $\left[\mathrm{CpMo}(\mathrm{CO})_{2}\left(\eta^{3}-\mathrm{C}_{3} \mathrm{H}_{5}\right)\right]$, adapted from [28]. The relative energies of the conformations, as afforded from the DFT calculations, are labelled on the energy profile diagrams. Illustrations of some of the representative orbitals are shown in Figure 3.

A discussion regarding the relative stabilities of the exo and endo conformers warrants both steric and electronic rationale. For complexes $\left[\mathrm{CpM}(\mathrm{CO})_{2}\left(\eta^{3}\right.\right.$-allyl $\left.)\right]\left(\mathrm{M}=\mathrm{Mo}, \mathrm{W}\right.$; allyl $=\mathrm{C}_{3} \mathrm{H}_{5}$, $\mathrm{C}_{3} \mathrm{H}_{4} \mathrm{Me}$ ), computational studies have evaluated the energies of the two rotamers from an electronic viewpoint. [29-31] There is a general consensus that the energies of the exo and endo conformers are very similar, and the stabilities of the rotamers are governed by many factors, e.g., ligand substitution patterns. For example, gaseous $\left[\mathrm{CpMo}(\mathrm{CO})_{2}\left(\eta^{3}-\mathrm{C}_{3} \mathrm{H}_{5}\right)\right]$ isolated in an argon matrix exhibits the two conformers, 3-A and 3-B, present in nearly equal quantities, [30] certainly pointing to a very small energetic difference between them, which is also supported by DFT calculations [28,30,31] (see also Figure 2). The relevant MOs for $\left[\mathrm{CpM}(\mathrm{CO})_{2}\left(\eta^{3}-\mathrm{C}_{3} \mathrm{H}_{5}\right)\right]$ are shown in Figure 3. The exo form of 
$\left[\mathrm{CpMo}(\mathrm{CO})_{2}\left(\eta^{3}-\mathrm{C}_{3} \mathrm{H}_{5}\right)\right](\mathbf{3 - A})$ has been reported to be of a slightly lower energy; this is attributed to the presence of the carbonyl ligands, since the complex $\left[\mathrm{CpMo}\left(\mathrm{PH}_{3}\right)_{2}\left(\eta^{3}-\mathrm{C}_{3} \mathrm{H}_{5}\right)\right]$ has been shown to favour the endo conformer. [31] With regards to the allyl ligand alone, the endo isomer is intrinsically preferred, since the principal metal-allyl bonding interaction (HOMO-2; Figure 3) constructed from the $\Psi_{2}$ non-bonding orbital of the allyl moiety and the $\mathrm{CpMoL}_{2}$ fragment orbital of appropriate symmetry (predominantly $4 \mathrm{~d}_{x y}$ in character) is weakened in the exo conformation. However, this penalty is more than compensated by the strengthened bonding interaction with the carbonyl ligands in the exo form on account of their $\pi$-accepting character; the strongly $\pi$-acidic nature of the carbonyl ligands also competes with the $\Psi_{3}$ orbital of the allyl ligand for electron density from the $4 \mathrm{~d}_{x^{2}-y^{2}}$ orbital in the HOMO-1, which destabilises the endo isomer. [31]

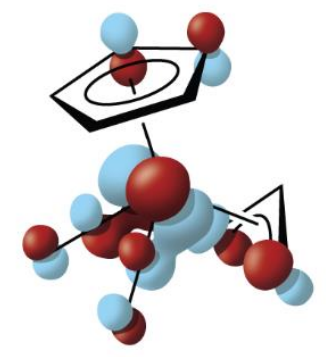

LUMO

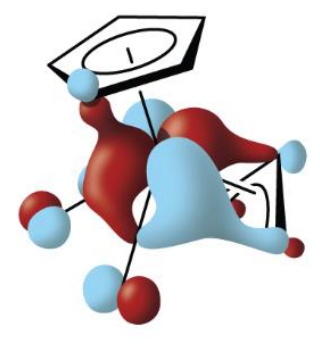

HOMO -1

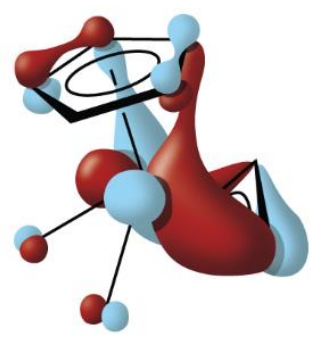

HOMO -2

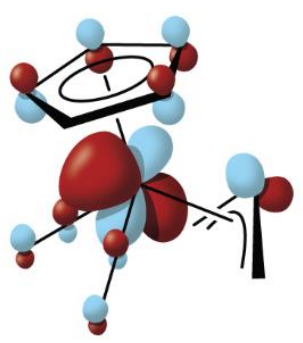

LUMO +1
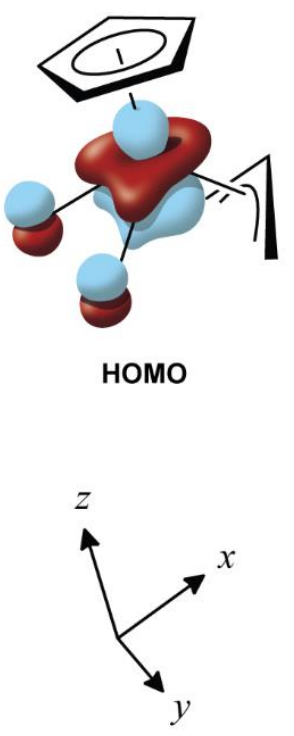
Figure 3. Illustrations of the pertinent molecular orbitals in $\left[\mathrm{CpM}(\mathrm{CO})_{2}\left(\eta^{3}-\mathrm{C}_{3} \mathrm{H}_{5}\right)\right]$, derived from refs $[28,32]$.

The energies of the exo and endo rotameric forms are also highly sensitive to solvent effects. More polar solvents promote the exo form as the prevailing conformer present in solution; exolendo ratios manifested by 3 in pentane, benzene and $\mathrm{CH}_{2} \mathrm{Cl}_{2}$ have been reported as 1.7:1, 3:1 and 4:1, respectively. [30,33] Subsequent DFT calculations confirmed that the stronger dipole moment of the exo form is responsible for this behaviour. [30] As one might expect, steric effects within the coordination sphere also have some bearing on the prevalence of each isomer; for example methylsubstitution of the allyl ligand at the meso carbon in the complex $\left[\mathrm{CpMo}(\mathrm{CO})_{2}\left(\eta^{3}-2-\mathrm{Me}\right.\right.$-allyl $\left.)\right]$ renders the endo rotameric form more stable than the exo conformer, [31,33] which is present in 11-fold excess in acetone. [34] This reversed isomeric preference is also followed by other complexes which bear substituents at the meso carbon of the allyl ligand [35-38] (vide infra), and presumably this arises as a result of the steric impedance between the 2-methylallyl and Cp ligands. Curiously, chromium congeners $\left[\mathrm{CpCr}(\mathrm{CO})_{2}\left(\eta^{3}\right.\right.$-allyl) $]$ 9a-e (Scheme 3) are reported to exist exclusively in the exo configuration, and the 2-methylallyl derivative $\left[\mathrm{CpCr}(\mathrm{CO})_{2}\left(\eta^{3}-2-\mathrm{Me}-\right.\right.$ allyl $\left.)\right]$ exhibits an approximately 1.9:1 endo/exo mixture. [8] The exo isomer can be selectively crystallised from pentane and thus separated from the endo isomer; supporting the conjecture that the exo conformation is more polar. In all reported cases, the chromium complexes are disposed more heavily towards the exo isomer, however the scarcity of information in the literature and the lack of clues in their X-ray crystallographic structures offer little satisfactory reasoning for this phenomenon.

\section{3. ${ }^{95}$ Mo and ${ }^{183}$ W NMR spectroscopy}

${ }^{95} \mathrm{Mo}$ NMR is useful for the identification of the exo and endo rotameric forms of $\left[\mathrm{CpMo}(\mathrm{CO})_{2}\left(\eta^{3}\right.\right.$-allyl) $](\mathbf{3 - A}$ and $\mathbf{3 - B}$; as well as derivatives thereof) from the preceding section, and ascertain their relative stabilities. The ${ }^{95}$ Mo nucleus $(I=5 / 2)$ features a non-trivial quadrupolar moment and thus broad lines are expected for low-symmetry complexes such as $\left[\mathrm{CpMo}(\mathrm{CO})_{2}\left(\eta^{3}-\mathrm{C}_{3} \mathrm{H}_{5}\right)\right]$. However, if the examination of the fine signal structure is not an objective, ${ }^{95}$ Mo NMR chemical shifts 
are highly sensitive to coordination environment, and hence useful for characterisation. They typically cover a broad chemical shift range of $c a .4000 \mathrm{ppm}$. [39,40] These chemical shifts of heavier nuclei, which are typically spread over a vast range, are often difficult to rationalise based on the electronic environment and inductive effects, as is readily achieved in ${ }^{1} \mathrm{H}$ NMR. This is due to a dominant contribution from the paramagnetic shielding term $\sigma_{\text {para }}$ to the total shielding tensor, and a generally negligible contribution from the diamagnetic term $\sigma_{\text {dia. }}$. The parameters of the component $\sigma_{\text {para }}$ are delineated by the Ramsey equation, [41] which has undergone numerous adaptations and simplifications to isolate the most pertinent variables; a heuristic form of the Ramsey equation $[42,43]$ is presented in Equation (1):

$$
\sigma_{\text {para }} \propto-\Delta E^{-1} \cdot\left\langle r^{-3}\right\rangle_{\mathrm{d}} D_{\mathrm{u}}
$$

A larger (negative) paramagnetic term deshields the nucleus, resulting in a downfield shift. $\Delta E$ generally refers to the HOMO-LUMO gap in the complex of interest, which has an inverse relationship with $\sigma_{\text {para }}$; a small energy gap between the HOMO and the LUMO will result in a stronger downfield shift. For ${ }^{95} \mathrm{Mo}$, the term $\left\langle r^{-3}\right\rangle_{\mathrm{d}}$ represents the $4 \mathrm{~d}$ orbital expansion term, which refers to the expectation value for the $4 \mathrm{~d}$ electrons, and $D_{\mathrm{u}}$ is the imbalance of electron population. The parameters contained within Equation (1) are difficult to evaluate individually, and, indeed, may not be entirely independent of one another; the often-antithetical chemical shift trends of heavier nuclei are hence more difficult to quantify and rationalise. However, empirical trends can be identified and often correlated with useful properties within a family of complexes; interpretations based on the nephelauxetic effect of ligands and the energy gap $\Delta E$ are readily ascribed. [44-48] For illustrative data for [CpMo(CO) $\left(\eta^{3}\right.$-allyl)] (3) and derivatives, see Table 1 . The ${ }^{95}$ Mo chemical shift range for the observed resonances is -1521 to 1833 ppm; [34] signals pertaining to the exo and endo conformations are adequately separated, with the endo form invariably appearing further downfield, allowing clear rotamer identification (Figure 4). The relative intensities of the two resonances can then be used to ascertain the prevailing isomer; assignment is aided by a comprehensive study using ${ }^{1} \mathrm{H}$ NMR methods. [49] The shifts shown in Table 1 reveal allyl-substitution patterns. As mention earlier, (Section 2.1), substitution at the meso carbon favours the endo rotameric form, as exemplified by the low percentage of the exo isomer present in solution for 
2-chloro-, 2-bromo- and 2-methyl- derivatives. The absence of a $\eta^{3} \rightarrow \eta^{1} \rightarrow \eta^{3}$ haptotropic shift of the allylic ligand in these complexes prohibits the interchange of syn and anti substituents on the terminal carbons. 1-Methyl- and 1,3-dimethyl- substitution almost exclusively adopts syn and syn,syn motifs, respectively, (as determined via ${ }^{3} J_{\mathrm{HH}}$ coupling constants in the allyl ligand), [49] and the excess of the exo conformer present for these complexes in solution is very similar to that of the unsubstituted allyl compound. When an anti methyl substituent is introduced, a very strong preference for the exo isomer is shown, which clearly surpasses the endo preference induced by meso substitution, as demonstrated by the $95 \%$ exo composition of the 1,1,2-trimethyl-allyl complex. This arises from steric hindrance between anti allyl-substituents, and the cyclopentadienyl group of the endo-isomer. Generally, there is a downfield shift of the exo isomer resonance on increased substitution of the allylic ligand. The decreasing shielding of the ${ }^{95}$ Mo nucleus is shown in Table 1 as allyl $>1$-methyl $>1,3$-dimethyl $>1,1$ dimethyl > 1,1,2-trimethyl. This tendency for more highly substituted allylic ligands to deshield the metal nucleus is also seen for cationic complexes derived from $\left[\mathrm{Fe}(\mathrm{CO})_{4}\left(\eta^{3} \text {-allyl }\right)\right]^{+}$subject to ${ }^{57} \mathrm{Fe}$ NMR studies (Figure 5). [50,51] Curiously, this pattern is not realised amongst the endo chemical shifts. However, it appears that a greater preference for the exo conformation amongst the aforementioned allylic ligands correlates somewhat with a stronger downfield shift of the endo resonance, indicating that perhaps the molecular structure undergoes other subtle steric adjustments that are amplified with increasing predisposition for the exo arrangement.

Table 1. ${ }^{95} \mathrm{Mo}$ chemical shifts for complexes based on $\left[\mathrm{CpMo}(\mathrm{CO})_{2}\left(\eta^{3}\right.\right.$-allyl $\left.)\right]$ with varying allylic ligand substituents. [34]

\begin{tabular}{lccc}
\hline & & \multicolumn{2}{c}{$\delta / \mathrm{ppm}^{a}$} \\
\cline { 3 - 4 }$\eta^{3}$-Allylic ligand & $\%$ exo & exo & endo \\
\hline allyl & 80 & -1832 & -1658 \\
1-methylallyl & 88 & -1789 & -1600 \\
1,3 -dimethylallyl & 80 & -1752 & -1709 \\
1,1-dimethylallyl & 100 & -1688 & - \\
1,1,2-trimethylallyl & 95 & -1657 & -1448 \\
\hline 2-chloroallyl & 6.3 & -1709 & -1521
\end{tabular}



2-bromoallyl

${ }^{a}$ Relative to the external standard of $\mathrm{Na}_{2}\left[\mathrm{MoO}_{4}\right]$; all samples recorded in acetone- $d_{6}$ at $303 \mathrm{~K}$ and $32.59 \mathrm{MHz}$.

${ }^{b}$ The percentage of the exo conformation in solution, calculated from the relative intensities of the exo and endo resonances in the ${ }^{95} \mathrm{Mo}$ NMR spectrum.

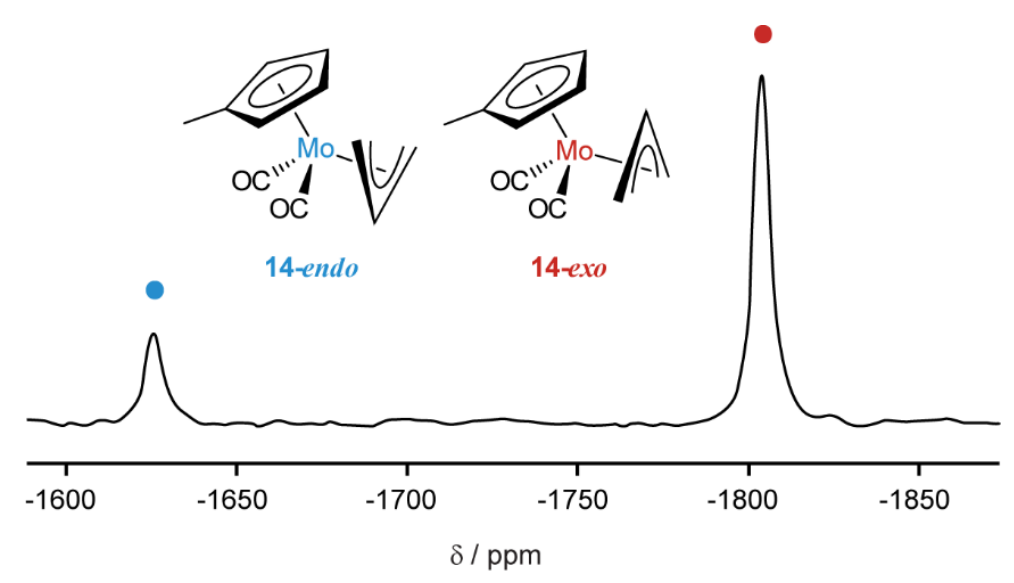

Figure 4. ${ }^{95} \mathrm{Mo} \mathrm{NMR}$ spectrum of $\left[(\mathrm{Me}-\mathrm{Cp}) \mathrm{Mo}(\mathrm{CO})_{2}\left(\eta^{3}-\mathrm{C}_{3} \mathrm{H}_{5}\right)\right]$ (14; see Chart 2) displaying well-resolved resonances belonging to exo and endo isomers; adapted from [32].
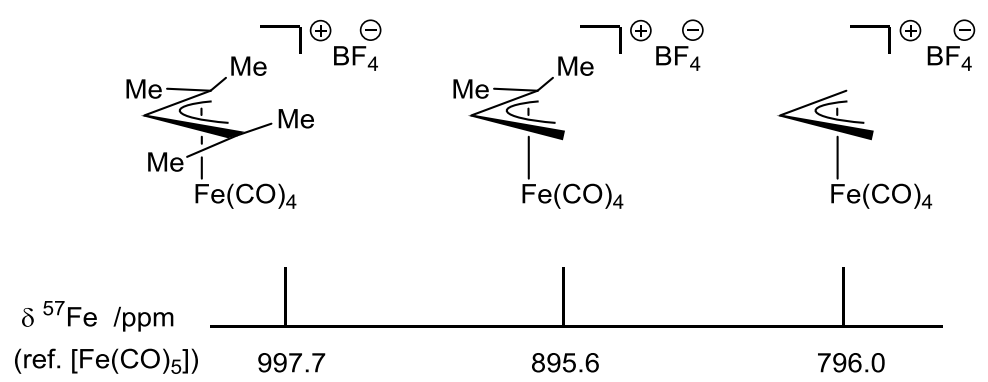

Figure 5. ${ }^{57} \mathrm{Fe}$ NMR chemical shifts for cationic allyl compounds of type $\left[\mathrm{Fe}(\mathrm{CO})_{4}\left(\eta^{3}\right.\right.$-allyl $\left.)\right][\mathrm{BF} 4] .[50]$

In Table 1, the meso substituted allylic ligands are separated on account of their inverse isomeric preference. The chemical shifts for both the exo and endo isomers correlate well with the prevalence of the former in solution. The contribution of the exo isomer rises as 2-chloro <2-bromo < 2-methyl, being accompanied by increased shielding at the ${ }^{95}$ Mo nucleus. An explanation for this is not obvious, but steric, electronic, and solvent effects may all contribute. Interestingly, preceding ${ }^{1} \mathrm{H}$ NMR studies of the same allylic ligands ascertained the order of increasing exo concentration to be 2- 
methyl < 2-chloro < 2-bromo, but the NMR experiments were performed in different solvents (Table 2), [49] which might alter the relative concentrations between the two isomeric forms (vide supra). Further complications may stem from the fact that the substitution at the allyl ligand with electronegative groups will necessarily adjust the polarity of the molecule. Here, the challenge of separating and quantifying the electronic and steric properties of a particular complex to rationalise the adopted exolendo isomeric preference. Similarly, isolating the contributions to the paramagnetic term (Equation 1) is difficult; although, several computational studies have been used to distinguish the contributions, [52-54] However, the aforementioned correspondence observed between the exolendo ratios and chemical shifts highlights the utility of NMR in establishing empirical correlations between chemical shifts of NMR-active transition metal nuclei, and the dynamic behaviour, chemical reactivity and even catalytic activity of their organometallic complexes. As a particularly interesting example, catalytic efficacy of complexes $\left[\left(\eta^{5}-\mathrm{R}-\mathrm{Cp}\right) \mathrm{Co}(\mathrm{COD})\right](\mathrm{COD}=1,6$-cyclooctadiene, $\mathrm{R}-\mathrm{Cp}=$ monosubstituted cyclopentadienyl) with regards to the cyclotrimerisation of acetylenes and nitriles has been shown to correlate with their respective ${ }^{59} \mathrm{Co}$ chemical shifts. $[51,55]{ }^{95} \mathrm{Mo}$ (and ${ }^{183} \mathrm{~W}$ ) NMR studies are promising for the characterisation of catalytic applications.

Table 2. Percentages of exo isomer presented for 2 -substituted allylic ligands $(\mathrm{L})$ in $\left[\mathrm{CpMo}(\mathrm{CO})_{2}\left(\eta^{3}-\mathrm{L}\right)\right]$ in different solvents, as ascertained by ${ }^{1} \mathrm{H}$ and ${ }^{95} \mathrm{Mo}$ NMR studies.

\begin{tabular}{lcccccccc}
\hline & \multicolumn{3}{c}{${ }^{1} \mathrm{H} \mathrm{NMR}^{a}$} & & \multicolumn{3}{c}{${ }^{95} \mathrm{Mo} \mathrm{NMR}^{b}$} \\
\cline { 2 - 4 } \cline { 6 - 8 } Allylic ligand & \% exo & Solvent & Temp. $^{c}$ & & \% exo & Solvent & Temp. \\
\hline 2-chloroallyl & 14 & $\mathrm{CDCl}_{3}$ & $5{ }^{\circ} \mathrm{C}$ & & 6.3 & acetone & $30{ }^{\circ} \mathrm{C}$ \\
2-bromoallyl & 17 & $\mathrm{C}_{6} \mathrm{H}_{6}$ & $0{ }^{\circ} \mathrm{C}$ & & 7.4 & acetone & $30{ }^{\circ} \mathrm{C}$ \\
2-methylallyl & 11 & $\mathrm{CDCl}_{3}$ & $0{ }^{\circ} \mathrm{C}$ & & 8.3 & acetone & $30{ }^{\circ} \mathrm{C}$ \\
\hline
\end{tabular}

${ }^{a}$ Percentage of the exo isomer present in the solution, as ascertained from the relative intensities of resonances belonging to the exo and endo isomers. [49]

${ }^{b}$ From [34], also listed in Table 1.

${ }^{c}$ Recorded at lower temperatures to avoid line broadening of the ${ }^{1} \mathrm{H}$ resonances caused by rapid interconversion between the two rotameric forms. It is worth noting that the exolendo isomerism is temperature-dependent. [32]

At present, ${ }^{95} \mathrm{Mo}$ NMR studies of allyl carbonyl complexes are relatively scarce in the literature. 
Recently, however, ${ }^{95} \mathrm{Mo}$ chemical shifts were collected for a number of allyl molybdenum complexes of the type $\left[\left(\eta^{5}-\mathrm{Cp}^{\prime}\right) \mathrm{Mo}(\mathrm{CO})_{2}\left(\eta^{3}-\mathrm{C}_{3} \mathrm{H}_{5}\right)\right]\left(\mathrm{Cp}^{\prime}=\mathrm{C}_{5} \mathrm{H}_{5}\right.$, substituted cyclopentadienyl, indenyl, fluorenyl; 13-19) (Chart 2), to study the effect of substitution at the $\eta^{5}$-cyclopentadienyl-type ligand. [32] Also communicated in this study are corresponding electroanalytical, photoelectron, IR, and ${ }^{13} \mathrm{C}$ NMR spectroscopic, and DFT computational investigations; a wide range of techniques for these complexes, , including the tungsten analogues of $\mathbf{1 3}, \mathbf{1 5}$ and $\mathbf{1 6} .{ }^{95} \mathrm{Mo}$ chemical shifts for the exo and endo isomers in this series of complexes are presented in Table 3, and clear trends may be observed amongst the different substitution patterns of the $\eta^{5}$-coordinated moieties. Increasing the substitution at the $\mathrm{Cp}^{\prime}$ ligand with inductively donating methyl substituents reliably deshields the ${ }^{95}$ Mo nucleus; an apparently counterintuitive phenomenon that exemplifies the negligible contribution from the diamagnetic shielding term $\sigma_{\text {dia }}$ in comparison to $\sigma_{\text {para }}$ in chemical shifts of nuclei other than ${ }^{1} \mathrm{H}$. [41] The decreased shielding of ${ }^{95} \mathrm{Mo}$ nucleus in the order $\mathrm{Cp}>\mathrm{Me}-\mathrm{Cp}>\mathrm{Me}_{5}-\mathrm{Cp}$ for cyclopentadienyl complexes and Ind $>\mathrm{Me}-\mathrm{Ind}>\mathrm{Me}_{2}-$ Ind for indenyl complexes finds a remarkable correlation with their calculated HOMO-LUMO energy differences $\Delta E$, as listed in Table 3. Figure 6 demonstrates an inverse linear relationship between the two variables, implying that the $\Delta E^{-1}$ component of the paramagnetic shielding term (Equation 1) is predominantly responsible for the observed deshielding of the ${ }^{95}$ Mo nucleus on increasing substitution of the $\mathrm{Cp}^{\prime}$ ligand.

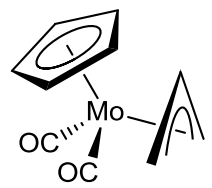

13

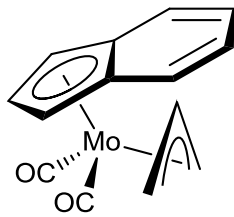

16

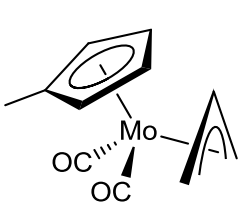

14

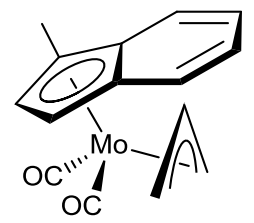

17

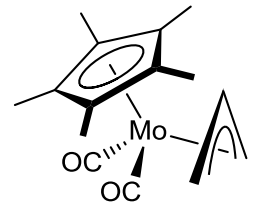

15

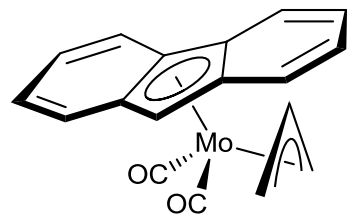

19

Chart 2. Complexes 13-19 of type $\left[\left(\eta^{5}-\mathrm{Cp}^{\prime}\right) \mathrm{Mo}(\mathrm{CO})_{2}\left(\eta^{3}-\mathrm{C}_{3} \mathrm{H}_{5}\right)\right]$, with varying $\eta^{5}$-coordinated moieties. 
Table 3. ${ }^{95} \mathrm{Mo}$ chemical shifts for compounds of type $\left[\left(\eta^{5}-\mathrm{Cp}^{\prime}\right) \mathrm{Mo}(\mathrm{CO})_{2}\left(\eta^{3}-\mathrm{C}_{3} \mathrm{H}_{5}\right)\right]$. [32]

\begin{tabular}{lcccc}
\hline & & \multicolumn{2}{c}{$\delta / \mathrm{ppm}^{b}$} \\
\cline { 3 - 4 } Compound $^{a}$ & & exo & endo & $\Delta E^{c}$ \\
\hline$\left[\mathrm{CpMo}(\mathrm{CO})_{2}\left(\eta^{3}-\mathrm{C}_{3} \mathrm{H}_{5}\right)\right]$ & $\mathbf{1 3}$ & -1822 & -1646 & 0.15943 \\
{$\left[(\mathrm{Me}-\mathrm{Cp}) \mathrm{Mo}(\mathrm{CO})_{2}\left(\eta^{3}-\mathrm{C}_{3} \mathrm{H}_{5}\right)\right]$} & $\mathbf{1 4}$ & -1804 & -1625 & 0.15926 \\
{$\left[\left(\mathrm{Me}_{5}-\mathrm{Cp}\right) \mathrm{Mo}(\mathrm{CO})_{2}\left(\eta^{3}-\mathrm{C}_{3} \mathrm{H}_{5}\right)\right]$} & $\mathbf{1 5}$ & -1699 & -1518 & 0.15754 \\
& & & & \\
{$\left[(\mathrm{Ind}) \mathrm{Mo}(\mathrm{CO})_{2}\left(\eta^{3}-\mathrm{C}_{3} \mathrm{H}_{5}\right)\right]$} & $\mathbf{1 6}$ & -1742 & -1556 & 0.14626 \\
{$\left[(\mathrm{Me}-\mathrm{Ind}) \mathrm{Mo}(\mathrm{CO})_{2}\left(\eta^{3}-\mathrm{C}_{3} \mathrm{H}_{5}\right)\right]$} & $\mathbf{1 7}$ & -1708 & -1518 & 0.14549 \\
{$\left[(\mathrm{Me}-\mathrm{Ind}) \mathrm{Mo}(\mathrm{CO})_{2}\left(\eta^{3}-\mathrm{C}_{3} \mathrm{H}_{5}\right)\right]$} & $\mathbf{1 8}$ & -1675 & -1485 & 0.14478 \\
& & & & \\
{$\left[(\mathrm{Flu}) \mathrm{Mo}(\mathrm{CO})_{2}\left(\eta^{3}-\mathrm{C}_{3} \mathrm{H}_{5}\right)\right]$} & $\mathbf{1 9}$ & -1543 & - & 0.14258 \\
\hline
\end{tabular}

${ }^{a}$ Abbreviations as follows: $\mathrm{Me}-\mathrm{Cp}=$ methylcyclopentadienyl; $\mathrm{Me}_{5}-\mathrm{Cp}=$ pentamethylcyclopentadienyl; Ind = indenyl; $\mathrm{Me}$-Ind = 1-methylindenyl; $\mathrm{Me}_{2}$-Ind = 1,3-dimethylindenyl; Flu = fluorenyl.

${ }^{b}$ Relative to the external standard of $\mathrm{Na}_{2}\left[\mathrm{MoO}_{4}\right]$; the solvent was $\mathrm{CHCl}_{3} / \mathrm{CDCl}_{3}$ [10:1] for all complexes apart from 13, which was measured in $\mathrm{CD}_{2} \mathrm{Cl}_{2}$ solution. Spectra were obtained on a Bruker ARX 400 at $26.08 \mathrm{MHz}$. ${ }^{c} \mathrm{HOMO}-\mathrm{LUMO}$ energy gap, as calculated with DFT, in arbitrary units (au).
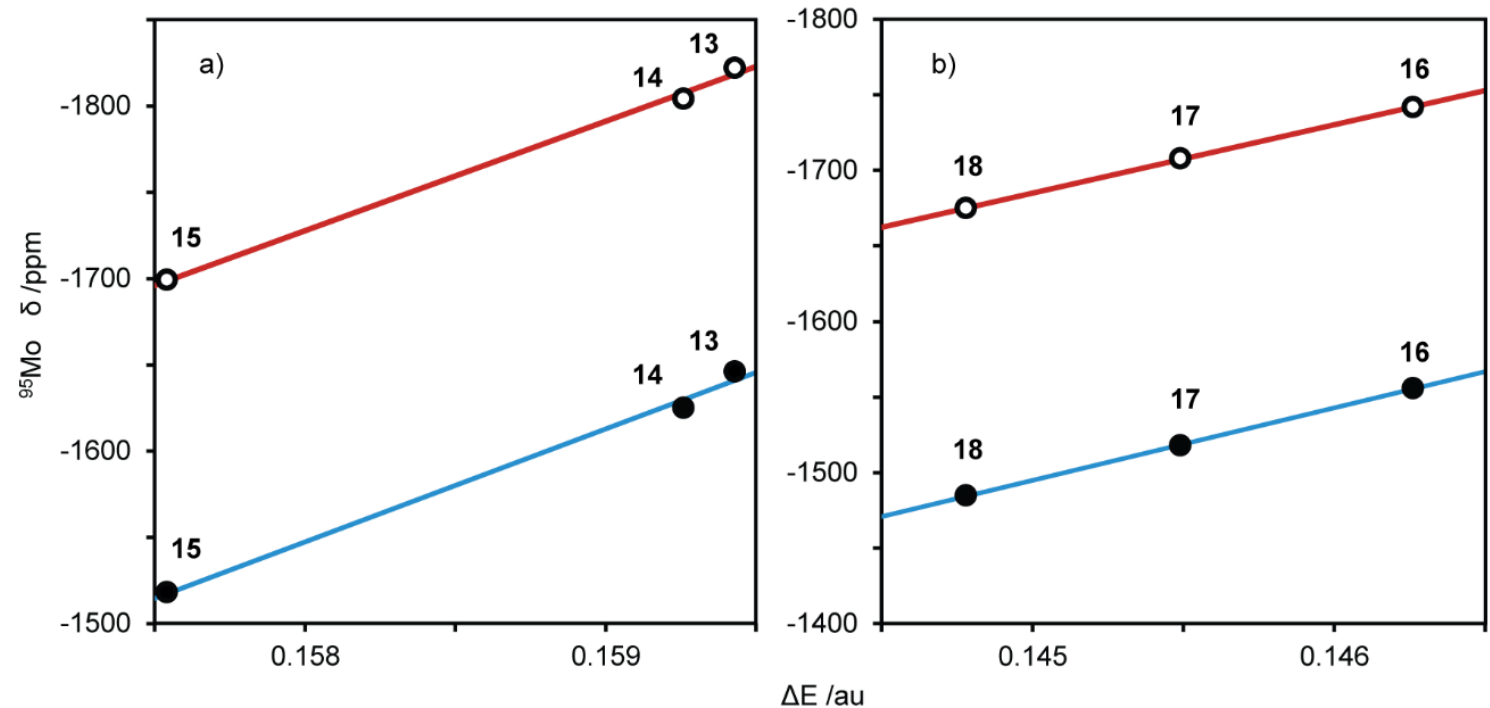

Figure 6. Plotted data [32] [demonstrating the correlation between the ${ }^{95}$ Mo chemical shifts and the increasing HOMO-LUMO energy gap of the substituted cyclopentadienyl complexes 13-15 (a) and indenyl complexes 1618 (b). The blue trend lines pertain to the endo isomers, and the red trend lines to the exo isomers.

The explanation put forward for the decreased HOMO-LUMO gap in more substituted 
complexes is that the more strongly donating substituted $\mathrm{Cp}^{\prime}$ ligands destabilise the HOMO more effectively than the LUMO, thus decreasing the energy gap between them. With regard to the metal-

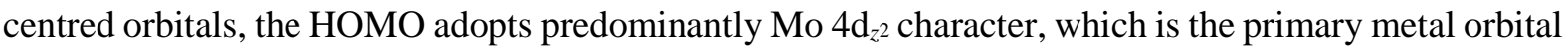
involved in the $\pi$-back-donation into carbonyl $\pi^{*}$ orbitals (Figure 3 ). Destabilisation of the HOMO hence markedly promotes $\pi$-back-bonding, and accordingly, decreasing carbonyl IR stretching frequencies which correlate well with the downfield ${ }^{95} \mathrm{Mo}$ chemical shifts. [32] The $\sigma$ interaction between the $\mathrm{Cp}^{\prime}$ ligand $a_{1}$ and metal $\mathrm{d}_{z^{2}}$ orbitals is known to be weak as they are far apart in energy (indeed as illustrated in Figure 3, the $\mathrm{Cp}^{\prime} a_{1}$ orbital does not evidently contribute to the HOMO); it might then be anticipated that the increased coefficient of the $a_{1}$ orbital, due to iterative methyl substitution, is therefore unlikely to perturb the HOMO significantly. The lowest energy virtual orbitals, of which there are three close in energy (Figure 2), are constructed from the $\pi$ interactions between $\mathrm{Cp}^{\prime}$ orbitals and the appropriate Mo 4d orbitals; Figure 3 illustrates the LUMO and LUMO +1 , involving mainly the $\mathrm{Cp} e_{2}$ degenerate pair (although mixing with $\mathrm{Cp} e_{1}$ orbitals is apparent), and Mo $4 \mathrm{~d}_{y z}$ and $4 \mathrm{~d}_{x z}$, respectively. With consideration of the more marked contribution of the Cp-based $\pi$ orbitals to the LUMO in contrast to the HOMO, it is perhaps then counterintuitive that iterative methylation of the $\mathrm{Cp}$ ring should serve to reduce the HOMO-LUMO gap in such a way. A parallel deshielding effect upon the increased substitution of a cyclic $\pi$-system is also observed amongst complexes $\left[\left(\eta^{6}-\right.\right.$ arene) $\left.\mathrm{Mo}(\mathrm{CO})_{3}\right],[56,57]$ and of particular note, the deshielding of the ${ }^{95}$ Mo nucleus upon advancing methylation of the allyl ligand (vide supra) is also in accordance with the above observations.

Photoelectron spectra collected for $\mathbf{1 3}$ and $\mathbf{1 5}$ provide some insight into the shift in energy of occupied orbitals upon permethylation of the Cp ligand (Figure 7). [32] Here, the HOMO is indeed raised in energy, though less than the HOMO-3 and HOMO-4 on account of their predominant $\mathrm{Cp} e_{1}$ orbital character. The occupied orbitals for the related $N-{ }^{t} \mathrm{Bu}$-azaallyl complex $\mathbf{2 0}$ also undergo a comparable shift to higher energies on permethylation to the $\mathrm{Me}_{5}-\mathrm{Cp}$ congener 21 (Figure 7); in particular, the observed increase in energy of the HOMO between $\mathbf{2 0}$ and $\mathbf{2 1}$ is very similar to that between 13 and $\mathbf{1 5}$. Note that the occupied orbital associated primarily with the nitrogen lone pair (labelled with an asterisk) does not undergo any appreciable shift in energy, suggesting that it interacts 
very little with the orbitals centred on the $\mathrm{Cp}^{\prime} \mathrm{Mo}(\mathrm{CO})_{2}$ fragment. Computational studies, however, have challenged this conjecture. [58] The difference in orbital energies concerning $\mathbf{1 3}$ and $\mathbf{2 0}$ (similarly $\mathbf{1 5}$ and 21) are presumably also influenced by a) the endo conformation exclusively adopted by $\eta^{3}$-azaallyl complexes of this type, [58-64] as opposed to the exo form of $\mathbf{1 3}$ and 15, b) the tert-butyl substituent on the azaallyl ligand, and c) the modified metal-ligand bonding properties as a consequence of the heteroatom incorporated within the allylic backbone. Thus direct comparison of the orbital for the $\eta^{3}-$ allyl and $\eta^{3}$-azallyl complexes is here not appropriate.

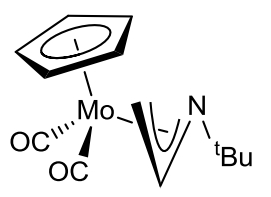

20

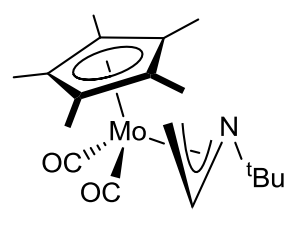

21
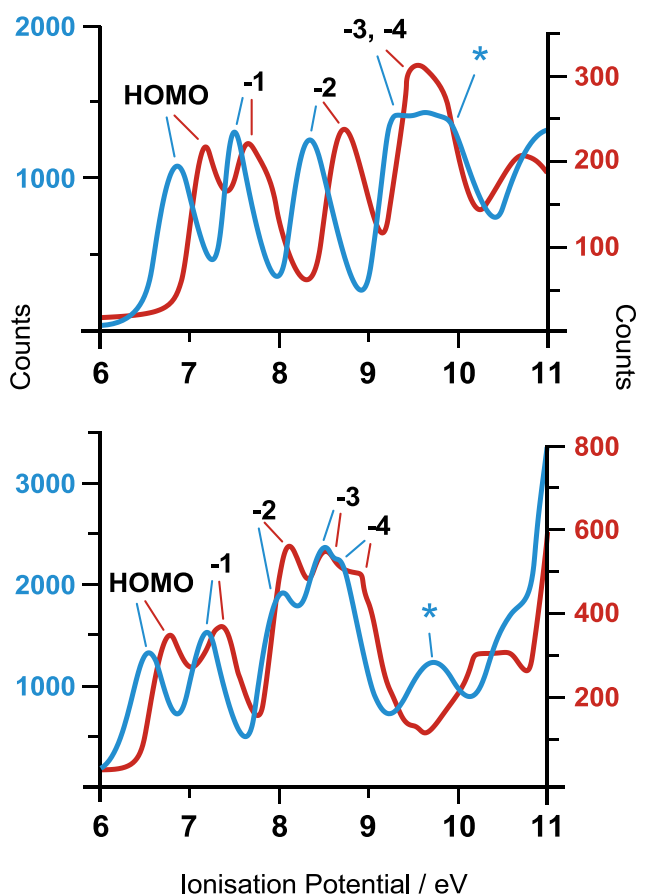

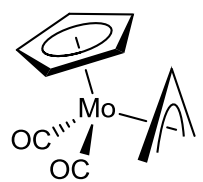

13

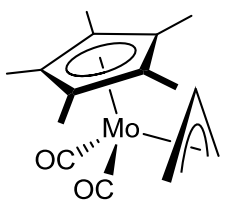

15

Figure 7. Photoelectron spectra plotted for $\mathrm{Cp}$ and $\mathrm{Me}_{5}-\mathrm{Cp} \eta^{3}$-allyl complexes 13 and 15 [32] (red), and the corresponding $\eta^{3}$-azaallyl complexes 20 and 21 [58] (blue), demonstrating the effect of permethylation of the $\mathrm{Cp}$ ring in each case. Assignments of the peaks belonging to the occupied orbitals from the HOMO to the HOMO-4 are shown, as well as the orbital primarily associated with the nitrogen lone pair in $\mathbf{2 0}$ and $\mathbf{2 1}$, marked with an asterisk.

Indenyl complexes 16-18 exhibit lower-field ${ }^{95} \mathrm{Mo}$ chemical shifts than cyclopentadienyl complexes 13-15, with fluorenyl complex 19 featuring the lowest $\delta$ at $-1543 \mathrm{ppm}$ for the exclusively observed exo isomer. This trend is readily ascribed to the lower energy gap $\Delta E$ between the HOMO and LUMO for the indenyl and fluorenyl complexes; their respective LUMOs will be stabilised by lowering 
the energy of the $\mathrm{Cp}^{\prime} \pi$-framework orbitals because of the extended delocalisation offered by the fused benzene ring(s). The $\mathrm{HOMO}$, as mentioned earlier, has a low contribution from the $\mathrm{Cp}^{\prime}$ ligand orbitals and, therefore, is not significantly altered in energy.

Whereas ${ }^{95} \mathrm{Mo}$ NMR spectroscopy is potentially useful here, the literature on ${ }^{53} \mathrm{Cr}$ NMR is very scarce, since the relatively large quadrupolar moment of ${ }^{53} \mathrm{Cr}$ and its low receptivity make it a particularly challenging nucleus to probe. $[45,56,57,65]$ However, the differences between the $\mathrm{Cr}$ and corresponding Mo and $\mathrm{W}$ complexes make ${ }^{53} \mathrm{Cr}$ NMR experiments potentially interesting.

${ }^{183} \mathrm{~W}$ is an $I=1 / 2$ nucleus that exhibits a number of measurement difficulties, on account of its low receptivity and long relaxation times. [45,56] Nonetheless, the sharp spectral lines allow for coupling to, e.g., ${ }^{1} \mathrm{H},{ }^{13} \mathrm{C}$ and ${ }^{31} \mathrm{P}$ to be observed. $[66,67]$ In addition, the chemical shift range for ${ }^{183} \mathrm{~W}$ signals exceeds $11,000 \mathrm{ppm}$. [39] A cursory ${ }^{183} \mathrm{~W}$ NMR study of related tungsten tris(pyrazolyl)borate complexes $\left[\mathrm{Tp}^{\prime} \mathrm{W}(\mathrm{CO})_{2}\left(1-\mathrm{R}-\eta^{3}\right.\right.$-allyl $\left.)\right]\left(\mathrm{Tp}^{\prime}=\right.$ hydrotris(3,5-dimethylpyrazolyl)borate; $\mathrm{R}=\mathrm{Ph}(\mathbf{2 2}), \mathrm{Me}$ (23)) (Chart 3) has been reported, [68] in which inverse 2D detection was employed. [69] The generally large hyperfine splitting exhibited by ${ }^{183} \mathrm{~W}$ in coupling with other nuclei allow the use of long-range coupling constants to $\mathrm{Tp}^{\prime}$ protons to detect the metal resonance, and coupling to the ${ }^{183} \mathrm{~W}$ nucleus is also exhibited by the allylic protons (Figure 8 ). The ${ }^{183} \mathrm{~W}$ chemical shifts for the similar compounds 22 and 23 are -460 and -838 ppm, respectively; showing the wide range for ${ }^{185} \mathrm{~W}$ chemical shifts.

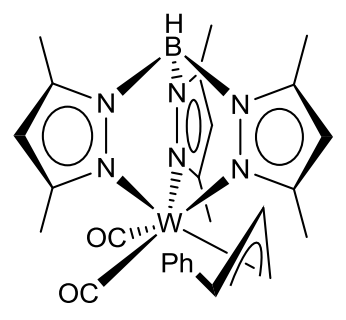

22

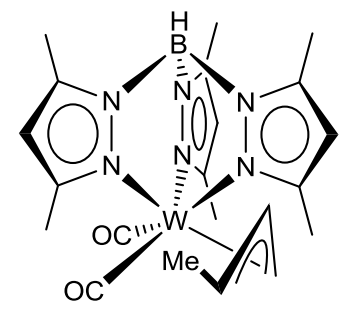

23

Chart 3. Complexes 22 and 23, which may be considered as being derived from $\left[\mathrm{CpW}(\mathrm{CO})_{2}\left(\eta^{3}\right.\right.$-allyl $\left.)\right](\mathbf{4})$, whereby the cyclopentadienyl ligand is replaced by a tris(pyrazolyl)borate derivative $\left(\mathrm{Tp}^{\prime}\right)$ ligand. [70,71] 


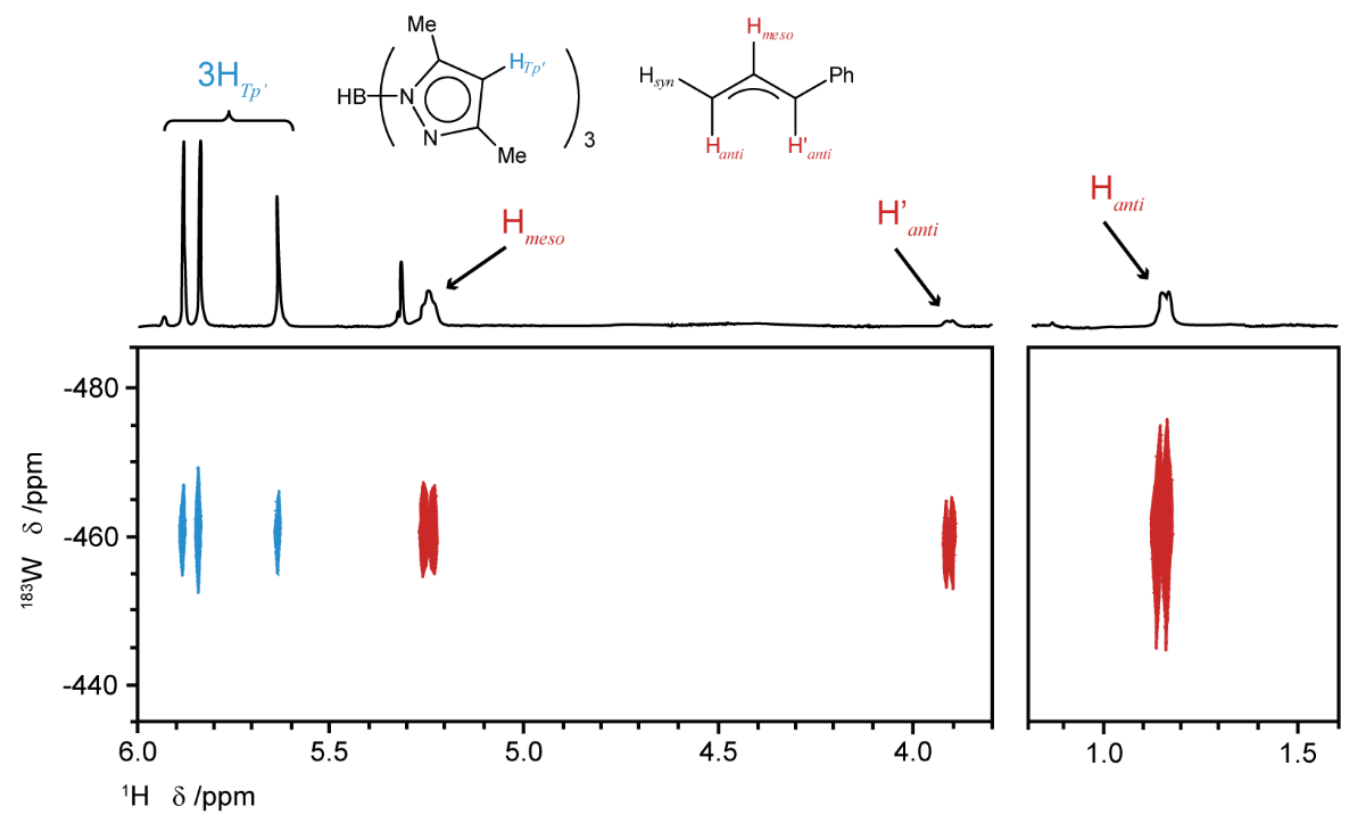

Figure 8. ${ }^{1} \mathrm{H}-{ }^{183} \mathrm{~W}$ correlation for complex 22. ${ }^{1} \mathrm{H}$ at $500 \mathrm{MHz} ;{ }^{183} \mathrm{~W}$ at $20.8 \mathrm{MHz} ; \mathrm{CD}_{2} \mathrm{Cl}_{2}$ solution. [68]

\subsection{Oxidized cationic complexes - reactivity, fluxionality, structural features}

The reactivity of complexes $\left[\mathrm{CpM}(\mathrm{CO})_{2}\left(\eta^{3}\right.\right.$-allyl $\left.)\right](\mathrm{M}=\mathrm{Cr}$, Mo, W) towards nitrosonium salts exemplifies the unique behaviour of the allylchromium complexes in comparison to molybdenum and tungsten congeners. The one-electron oxidation of $\left[\mathrm{CpCr}(\mathrm{CO})_{2}\left(\eta^{3}\right.\right.$-allyl) $]$ 9a,b,d (Scheme 3) with nitrosonium hexafluorophosphate produces the formally chromium(III) cationic complexes $\mathbf{2 4 a}, \mathbf{b}, \mathbf{d}$, without nitrosyl coordination (Scheme 5). To inhibit exposure of the oxidised 17 valence electron product to any donor solvent, the oxidation was performed in dimethoxyethane (DME), in which the $\mathrm{Cr}$ (III) complex is only sparingly soluble and rapidly precipitates pure, and in high yield. [72] Oxidation thus occurs without change in ligation, but with structural modification. Because of the strongly diminished $\pi$-back-donation from the $\mathrm{Cr}(\mathrm{III})$ centre to the $\pi^{*}(\mathrm{CO})$ orbitals, the oxidised congeners are readily characterised by significantly higher $\mathrm{CO}$-stretching frequencies in the infrared spectrum (Table 4). The metal to allylic-C distances are notably variable in $\mathrm{Cr}$ (III) allyls (Scheme 6), showing the electronic versatility of that ligand. Specifically, the oxidation of 9a is accompanied by modest contraction of the $\mathrm{Cr}-\mathrm{C}$ distances from the terminal allyl positions, viz. 2.231(5) and 2.239(5) $\AA$ in 9a, to 2.220 (3) $\AA$ in $\mathbf{2 4 a}$, and concomitant elongation of the bond to the meso carbon, viz. 2.108(4) $\AA$ in $\mathbf{9 a}$, 
to 2.151(4) $\AA$ in $\mathbf{2 4 a}$. This is presumably a manifestation of electronic effects; stabilisation of the relevant metal $\mathrm{d}$ orbitals reduces their interaction with the $\Psi_{3}$ LUMO on the allylic ligand, which possesses an appreciable coefficient at the meso carbon. The interaction with the $\Psi_{2}$ HOMO is instead strengthened, increasing its electron-donating character on account of the enhanced electrophilicity of the $\mathrm{Cr}$ (III) centre. The nodal plane of $\Psi_{2}$ at the central allylic position then accounts for the shorter metal-carbon distances at the termini. Additionally, the $\mathrm{CO}-\mathrm{Cr}-\mathrm{CO}$ plane rotates towards the $\mathrm{Cp}$ ligand by around $10 \mathrm{deg}$. (Scheme 6). This geometrical relaxation could be due to some electronic noninnocence of the $\mathrm{PF}_{6}-$ counterion that is seen in the crystal structure to reside in the cleft formed by the roughly square-pyramidal base of the complex. These changes may reflect, however, increased $\pi$-backdonation into the $\pi^{*}(\mathrm{CO})$ orbitals (which to some extent counters the aforementioned diminished retrodative bonding interaction from the oxidised $\mathrm{Cr}(\mathrm{III})$ centre). Whilst $\eta^{3}$-allyl and $\eta^{3}$-crotyl complexes $\mathbf{2 4 a}$ and $\mathbf{2 4 b}$, respectively, are green to yellow-green, the $\eta^{3}$-cyclohexenyl complex $20 \mathbf{d}$ are orange-red. This difference in the visible electronic absorption, along with the remarkably high conversion (96\%) to the $\mathrm{Cr}(\mathrm{III}) \eta^{3}$-cyclohexenyl complex, suggest the presence of a different electronic structure in $\mathbf{2 4 d}$. The possibility of an agostic interaction between the 17 valence electron chromium(III) centre and one of the hydrogens on the cyclohexenyl moiety was proposed. [72]

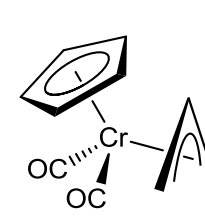

$9 \mathbf{a}$

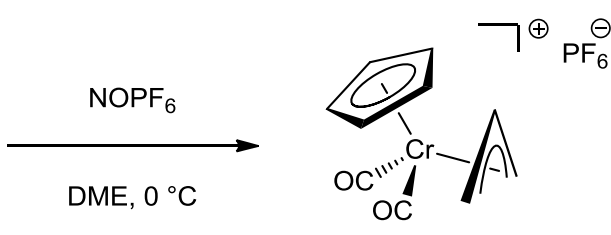

$24 a \quad 82 \%$

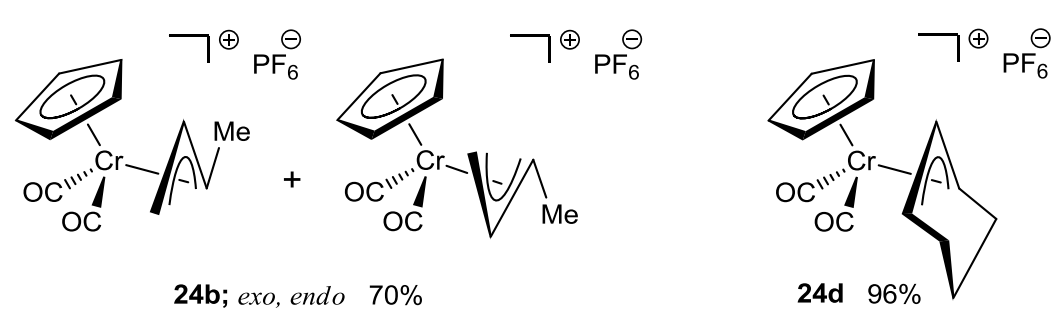

Scheme 5. Reaction of $9 \mathbf{a}$ with $\mathrm{NOPF}_{6}$ to form corresponding $\mathrm{Cr}(\mathrm{III})$ complex $\mathbf{2 4 a}$. The same reaction of allylmethylated analogues $\mathbf{9 b}$ and $\mathbf{9 d}$ yields $\mathbf{2 4 b}$ and $\mathbf{2 4 d}$, respectively.[72] 
Table 4. Infrared $v(\mathrm{CO})$ wavenumbers for the various neutral [8] and cationic [72] allylchromium complexes 9 and 24 (Schemes 3 and 5), respectively.

\begin{tabular}{clll}
\hline Complex $^{a}$ & $v(\mathrm{CO})^{c} / \mathrm{cm}^{-1}$ & Complex $^{b}$ & $v(\mathrm{CO})^{d} / \mathrm{cm}^{-1}$ \\
\hline 9a & 1939 & $\mathbf{2 4 a}$ & 2070 \\
& 1869 & 2032 \\
& & & 2065 \\
& & & 2040 \\
$9 \mathbf{9 b}$ & 1932 & $\mathbf{2 4 b}^{e}$ & 2031 \\
& 1863 & & 2022 \\
& & & 2039 \\
& & & 2002 \\
\hline
\end{tabular}

${ }^{a}$ Neutral chromium(II) complexes derived from $\left[\mathrm{CpCr}(\mathrm{CO})_{2}\left(\eta^{3}\right.\right.$-allyl $\left.)\right]$.

${ }^{b}$ Cationic chromium(III) complexes derived from $\left[\mathrm{CpCr}(\mathrm{CO})_{2}\left(\eta^{3}\right.\right.$-allyl $\left.)\right]\left[\mathrm{PF}_{6}\right]$.

${ }^{c}$ Recorded in THF.

${ }^{d}$ Recorded as a Nujol mull.

${ }^{e}$ Four IR $v(\mathrm{CO})$ absorptions have been reported for $\mathbf{2 4 b}$, implying a co-existence of exo and endo isomers.

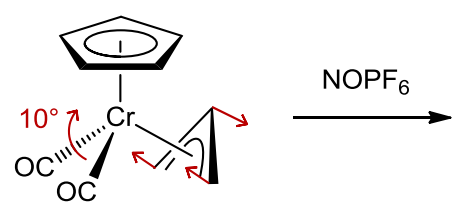

$9 a$

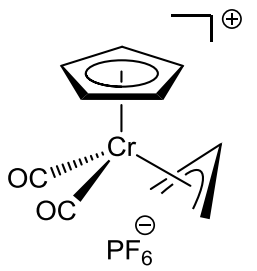

24a

Scheme 6. The structural adjustments observed on oxidation of $\mathrm{Cr}(\mathrm{II})$ complex 9a. The $\mathrm{Cr}(\mathrm{CO})_{2}$ plane is tilted toward the $\mathrm{Cp}$ ligand by $10 \mathrm{deg}$., and the allylic ligand alters its terminal and central $\mathrm{Cr}-\mathrm{C}$ distances. In the crystal structure of $\mathbf{2 4 a}$, the $\mathrm{PF}_{6}$ - counterion is seen to reside in the cleft below the relaxed square-pyramidal base of the complex, suggesting some interaction with the $\mathrm{Cr}$ (III) metal centre.[72]

The widely-accepted concept of agostic bonding regards it as a 2-electron donor interaction of the appropriate $\sigma(\mathrm{C}-\mathrm{H})$ orbital towards an empty metal-centred orbital, or, equivalently as a 3-centre, 2-electron $\mathrm{M}-\mathrm{H}-\mathrm{C}$ bonding interaction. For $\mathrm{d}^{n}(n>0)$ metal centres, modest back-bonding to the $\sigma^{*}(\mathbf{C}-$ H) orbital is also feasible, [73] and the agostic interaction is entirely analogous to an arrested state on 
the path to intramolecular $\mathrm{C}-\mathrm{H}$ bond activation. For more details see refs [73-75], and Chart 4 for a relevant example, viz. allylmolybdenum carbonyl complex 25. Notably, a handful of examples is known where 15 and 16 valence electron species exhibit clear agostic interactions to modify their valence shell, but their 17 valence electron congeners do not. [76,77] However, convincing examples of agostic interactions to formally 17 valence electron metal centres are known. Electrochemical studies on dialkyl complexes of the bent tungstenocene fragment $\left[\mathrm{Cp}_{2} \mathrm{WRR}^{\prime}\right][78]$ implied that peculiar trends in the oxidation potentials, which opposed the inductive effects of the alkyl ligands $\mathrm{R}$ and $\mathrm{R}^{\prime}$, result from $\alpha$ agostic interactions in the oxidised 17 valence electron cations $\left[\mathrm{Cp}_{2} \mathrm{WRR}^{\prime}\right]^{+}(\mathbf{2 6}$ in Chart 4 as the dimethyl example). It was thus speculated that a 3-centre, 3-electron $\mathrm{W}-\mathrm{H}-\mathrm{C}$ agostic construct would moderately stabilise the $\mathrm{d}^{1} \mathrm{~W}(\mathrm{~V})$ cationic species. The idea that agostic interactions are weaker for 17 than for 16 valence electron compounds is supported by an electrochemical study of $\left[\left(\mathrm{Ph}_{5}-\mathrm{Cp}\right) \mathrm{Rh}(1,3-\right.$ COD)] (27a) and [( $\left.\left.\mathrm{Ph}_{5}-\mathrm{Cp}\right) \mathrm{Rh}(1,5-\mathrm{COD})\right]$ (Chart 4). [79] The first and second oxidation potentials of 27a exhibit a marked negative shift relative to those of the corresponding 1,5-COD complex, which is surprising in view of the conjugation present in the 1,3-COD ligand. Furthermore, the negative shift of the second oxidation potential is larger than that of the first oxidation potential. The above observations are rationalised by an agostic interaction present only in the 1,3-COD isomer, which strengthens on further oxidation of monooxidized 17 valence electron species $\mathbf{2 7 \mathbf { b }}$ to the corresponding 16 valence electron dication. It may thus be expected that agostic interactions in the allylchromium cations $\mathbf{2 4}$ (Scheme 5), if present, are subtle in character. 


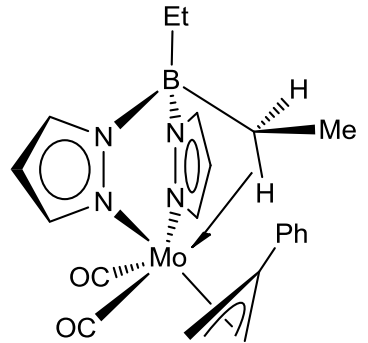

25

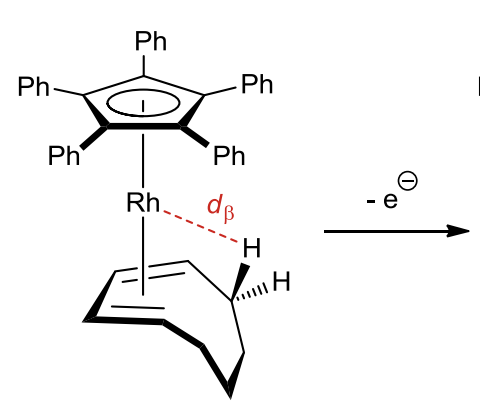

$27 a$

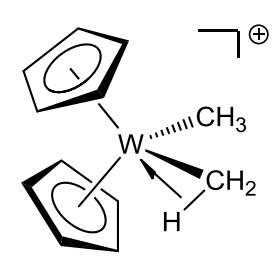

26

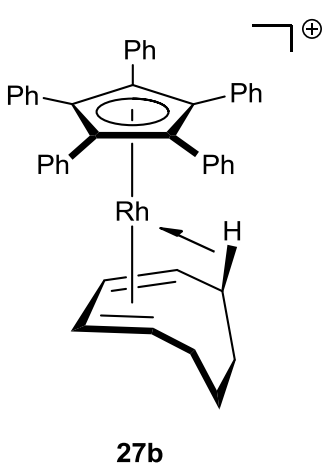

Chart 4. Some relevant examples, as referred to in the main text, of compounds featuring agostic interactions (illustrated with a half arrow): Molybdenum allyl carbonyl complex 25 is reminiscent of tris(pyrazolyl)borate tungsten complexes 22 and 23 (Chart 3); here the diethyl bis(pyrazolyl)borate ligand acts formally as a threeelectron donor, but a $\delta$-agostic interaction from one of the ethyl substituents supplements the otherwise 16 valence electron metal centre. [80,81] $\mathbf{2 6}$ and $\mathbf{2 7} \mathbf{b}$ demonstrate unusual 3-electron agostic interactions with the 17 valence electron metal centres; the $\beta$-agostic interaction in $\mathbf{2 7 b}$ is accomplished by electrochemical oxidation of $\mathbf{2 7 a}$, which shows a $\mathrm{Rh}-\mathrm{H}_{\beta}$ distance $d_{\beta}=2.53 \AA$.

Agostic interactions between the chromium centre and a number of the hydrogens at the $\eta^{3}$ cyclohexenyl ligand may be envisaged, as in $\mathbf{2 4} \mathbf{d}_{\boldsymbol{\alpha}}, \mathbf{2 4} \mathbf{d}_{\boldsymbol{\beta}}$ and $\mathbf{2 4} \mathbf{d}_{\gamma}$ shown in Chart 5 . Whilst the crystal structure of neutral congener 9d reveals that the $\alpha$-hydrogen is the most proximal, an optimum overlap with the appropriate metal orbital may favour interactions of the $\beta$ - or $\gamma$-hydrogens, with sufficient approach facilitated by a conformational distortion of the cyclohexenyl ring (Chart 5). The aptitude of the $\eta^{3}$-cyclohexenyl ligand to undergo fluxional agostic interactions at the $\beta$-hydrogens is already well proven with the complexes $\left[\mathrm{Mn}(\mathrm{CO})_{3}\left(\eta^{3}\right.\right.$-cyclohexenyl $\left.)\right](\mathbf{2 8})$ and $\left[\mathrm{OsH}_{2}\left(\mathrm{PPh}_{3}\right)_{2}\left(\eta^{3}\right.\right.$-cyclohexenyl $\left.)\right]$ (29), in which the conformation of the $\eta^{3}$-cyclohenenyl ligand distorts significantly from the paradigmatic 'chair' to bring the agostic $\beta$-hydrogens to within 1.860 and $1.913 \AA$, respectively, of the 16 valence electron metal centres (Chart 5). [17,82-86] The $\gamma$-agostic interaction is uncommon and, to our knowledge, not previously reported for the $\eta^{3}$-cyclohexenyl ligand. Indeed, some purported 
examples of $\gamma$-agostic $\mathrm{M}-\mathrm{H}-\mathrm{C}$ interactions have subsequently been shown to be due to other attractive interactions that bring the $\gamma$-hydrogen within the vicinity of the metal centre. [87]

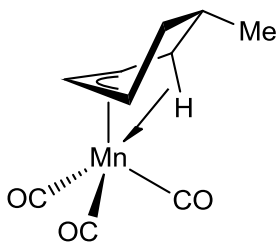

28

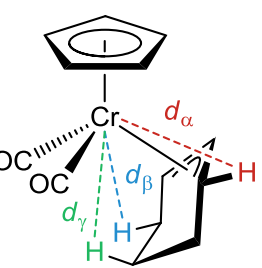

$9 d$

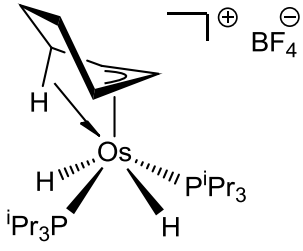

29

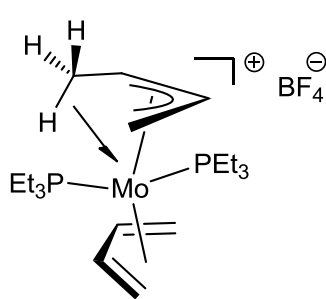

30

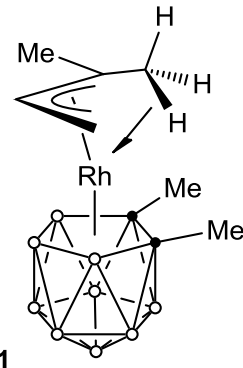

31

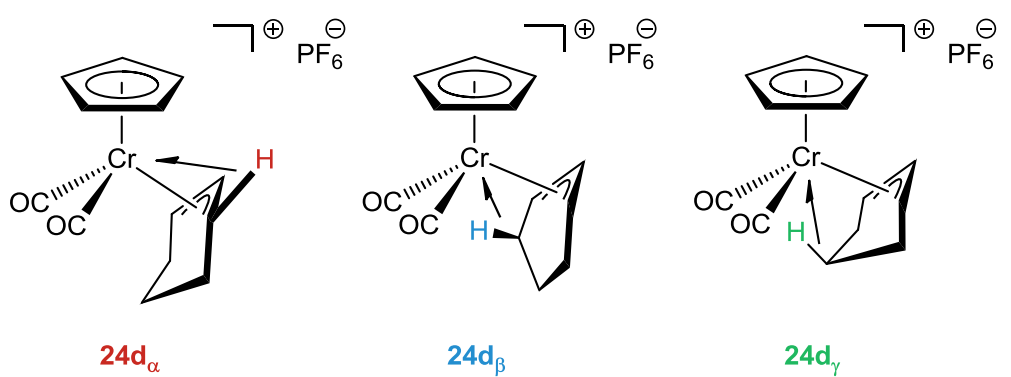

Chart 5. Selected literature examples demonstrating the aptitude of the cyclohexenyl and 1-methylallyl ligands towards agostic interactions. Complexes $\mathbf{2 8}$ and $\mathbf{2 9}$ are examples where the $\eta^{3}$-cyclohexenyl ligand contorts to establish an agostic interaction through its $\mathrm{H}_{\beta}$ substituents (the behaviour is fluxional). [82-85] Complexes 30 and 31 show the apparently preferred anti configuration of the 1-methyl substituent in a $\beta$-agostic interaction. Also illustrated here is neutral cyclohexenylchromium(II) complex 9d with metal-distal hydrogen distances $d_{\alpha}, d_{\beta}$ and $d_{\gamma}$, of $2.848,3.641$ and $3.217 \AA$, respectively. Structures $\mathbf{2 4} \mathbf{d}_{\alpha} \mathbf{2 4} \mathbf{d}_{\beta}$ and $\mathbf{2 4 d _ { \gamma }}$ demonstrate the potential agostic interactions with the $\mathrm{Cr}(\mathrm{III})$ centre in cationic 24d.

Agostic interactions may also be present in cationic allylchromium complexes $\mathbf{2 4 a}, \mathbf{b}, \mathbf{d}$.

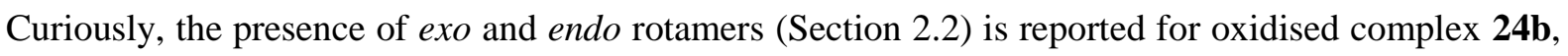
in contrast to the apparently exclusive exo composition of $\mathbf{9 b}$; a stabilisation of the endo isomer of $\mathbf{2 4 b}$ is thus assumed. The augmented electrophilicity of the $\mathrm{Cr}(\mathrm{III})$ centre here presumably prioritises the $4 \mathrm{~d}_{x y} \leftrightarrow \Psi_{2}$ interaction (Figure 3), which is stronger in the endo conformation (Section 2.2), [28] over back donation to the carbonyl $\pi^{*}$ orbitals. However, this bonding picture does not account for the single appearance of exo rotamer $\mathbf{2 4 a}$, which would be subject to very similar, if not the same electronic effects. Agostic interactions in 1-methylallyl complexes are demonstrated in Chart 5 by $\mathbf{3 0}$ and $\mathbf{3 1}$. $[88,89]$ Of particular interest is the apparent preference for agostic interactions through the anti methyl substituent, which is substantiated by the 1,1-dimethyl-allyl ligand in rhodacarborane complex 31 . In 
fact, the requirement for the agostic methyl substituent to be anti appears to be ubiquitous, [88-92] and cyclohexenyl complexes $\mathbf{2 8}$ and $\mathbf{2 9}$ are necessarily similar. As mentioned in Section 2.2, the syn/anti substitution pattern of the allyl ligand has a significant bearing on the stability of the exo and endo isomers of neutral complexes $\left[\mathrm{CpM}(\mathrm{CO})_{2}\left(\eta^{3}\right.\right.$-allyl $\left.)\right]$, but given the structural rearrangements apparent in the oxidised homologues (Scheme 6), the same reasoning may not apply. Nevertheless, it might be presumed that for an agostic interaction to exist in either the exo or endo isomer of $\mathbf{2 4 \mathbf { b }}$, an interconversion mechanism permitting a $s y n \rightleftharpoons$ anti exchange at the terminal allylic positions must be viable. Scheme 7 illustrates two previously described mechanisms that fulfil this requirement, [93] as well as the known exo $\rightleftharpoons$ endo interconversion effected by rotation about the metal-allyl vector (Section 2.2); the latter mechanism however does not engender syn $\rightleftharpoons$ anti exchange of the methyl substituent (Scheme 7c). Rearrangement via a $\pi \rightarrow \sigma \rightarrow \pi\left(\eta^{3} \rightarrow \eta^{1} \rightarrow \eta^{3}\right)$ haptotropic shift of the allyl moiety is a well-established mechanism amongst various $\eta^{3}$-allyl metal complexes that may proceed with interconversion of the syn and anti substituents via a $\mathrm{C}-\mathrm{C}$ rotation within the $\eta^{1}$-allyl intermediate (Scheme 7a). Van Staveren et al. demonstrated theoretically that an $\eta^{1}$-allyl intermediate of the related complex $\left[\mathrm{Mo}(\mathrm{CO})_{2}\left(\kappa^{3}-N, N, O\right.\right.$-L-his $)\left(\eta^{3}\right.$-allyl $\left.)\right]$ (his = histidine) was accompanied by an $\alpha$-agostic interaction; although, in this case the $\eta^{1}$-allyl intermediate was deemed to be too high in energy. [94]

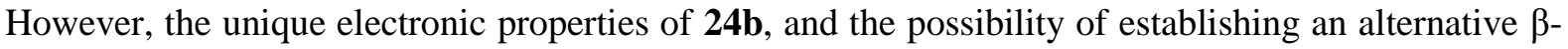
agostic interaction, may facilitate this pathway. It has been established that this haptotropic shift does not occur generally in the neutral species $\left[\mathrm{CpM}(\mathrm{CO})_{2}\left(\eta^{3}\right.\right.$-allyl $\left.)\right]$ (Section 2.2$)$, but very little is known about the electronic properties and behaviour of the oxidised homologues. Flipping of the allyl ligand through a $\kappa^{2}$-bound diyl intermediate, which is analogous to a metallacyclobutane moiety bearing a positive or negative charge at the meso carbon, is accompanied by a simultaneous $s y n \rightleftharpoons$ anti exchange at both termini of the allyl ligand (Scheme $7 b$ ). This mechanism has only been included as a theoretical contribution to the discussion of organometallic allyl fluxionality; its viability is contingent on a weak bonding interaction between the metal and the meso carbon, and presumably the capacity of the central carbon to accommodate an accumulated charge. The allylic fluxionality is generally not substantiated by spectroscopic data (vide infra). It may be disregarded in the case of annelated allylic ligands because 
of the inherent conformational obstruction to syn $\rightleftharpoons$ anti interconversion. This flip mechanism is discussed further in Section 3.2.

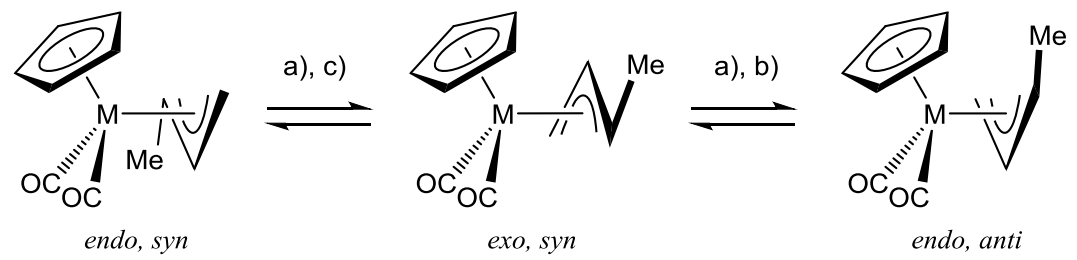

a)<smiles></smiles>

b)

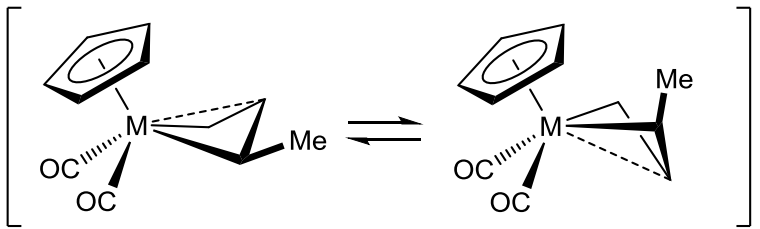

c)

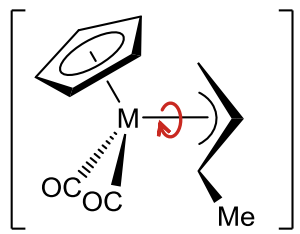

Scheme 7. General mechanisms concerning $\eta^{3}$-allyl ligand fluxionality, which stipulate the exo $\rightleftharpoons$ endo isomerism, as well as interconversion of syn and anti terminal allyl substituents. The three mechanisms are illustrated here with $\left[\mathrm{CpM}(\mathrm{CO})_{2}\left(\eta^{3}\right.\right.$-crotyl $\left.)\right](\mathrm{M}=\mathrm{Cr}$, Mo, W), but only rotation about the $\mathrm{M}$-allyl vector (shown in c)), which does not interconvert the syn/anti orientation of the methyl substituent, has thus far been considered viable for complexes of this type (Section 2.2). The remaining two mechanisms are delineated by a) $\pi \rightarrow \sigma \rightarrow \pi$ haptotropic shifts with bond rotation occurring in the $\eta^{1}$-bound intermediate, and b) 'ring-flip' through a metallacyclobutane intermediate. Here, syn $\leftrightarrow$ anti interconversion of the methyl substituent is possible (and in fact compulsory in b)). Note that in b), hypothetically either a partial positive or negative charge may accrue on the dissociated meso carbon. [93]

A characteristic feature of 1-methylallyl complexes 30, 31 exhibiting $\beta$-agostic interactions (Chart 5) is lengthening of the $\mathrm{M}-\mathrm{C}_{\text {meso }}$ distance. [88-92] This is paralleled by meso-C-amino substituted allyl complexes 32, which may be seen as adopting a significant metallacyclobutane character as a possible manifestation of resonance form 32' (Chart 6). [95,96] This also parallels the observed lengthening of the $\mathrm{M}-\mathrm{C}_{\text {meso }}$ distance in $\mathbf{2 4}$ with comparison to $\mathbf{9}$ (Scheme 6). It would be interesting to see if oxidised complexes structurally similar to $\mathbf{3 2}$ have clarifying structures, and less 
positive oxidation potentials because of the mesomeric influence exhibited by the meso- $\mathrm{NR}_{2}$ substituent. Also, with a sufficient contribution of resonance tautomer $\mathbf{3 2}^{\prime}$ to the bonding picture of a cationic species, one might anticipate its potential for a direct nucleophilic attack at the central carbon; a phenomenon not observed for complexes of this type (Section 2.5). Indeed, whereas the allylchromium cation $\mathbf{2 4 a}$ is reported to maintain the regioselectivity of nucleophilic attack at the terminal allylic positions, the reaction is markedly less efficient than the equivalent reaction of neutral congener 9a, [72] despite the positive charge borne by the formally $\mathrm{Cr}(\mathrm{III})$ complex. The structural rearrangements illustrated in Scheme 6 and the implicit contribution of the resonance tautomer $\mathbf{2 4 \mathbf { a } ^ { \prime }}$ (Chart 6) provide a tempting explanation for this loss of reactivity at the terminal positions of the allyl ligand; such a conjecture merits further investigation.

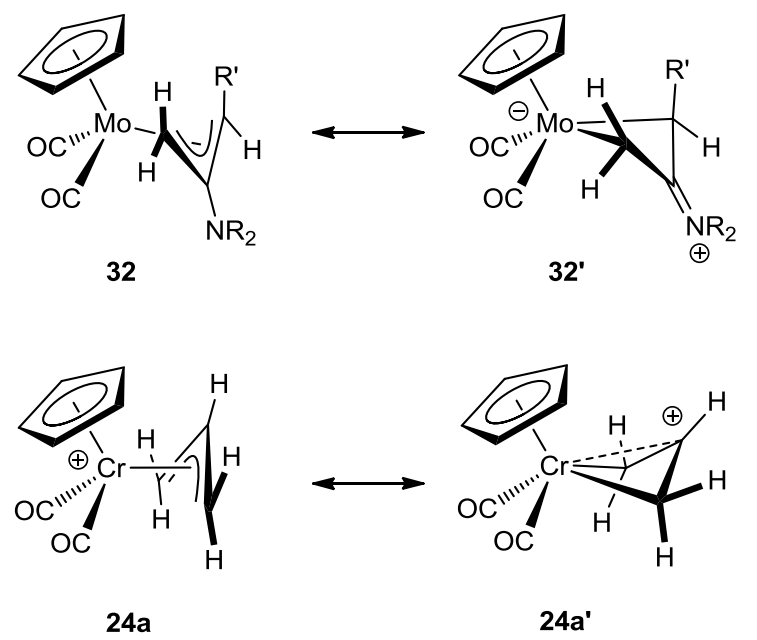

Chart 6. Mesomerically donating allyl meso-C substituents, as in complex 32 bearing an aminyl $\left(\mathrm{NR}_{2} ; \mathrm{R}=\mathrm{Et} ; \mathrm{R}^{\prime}\right.$ $=\mathrm{C}(\mathrm{O}) \mathrm{NEt}_{2}$ ) substituent, imply the involvement of a resonance tautomer, as illustrated by $\mathbf{3 2}^{\prime}$. Lengthening of the $\mathrm{M}-\mathrm{C}_{\text {meso }}$ bond in the crystal structures of such complexes substantiates this hypothesis. [95] Also illustrated is a proposed analogous tautomerism concerning $\mathbf{2 4 a}$, which suggests a possible means by which the positive charge borne by the formally $\mathrm{Cr}(\mathrm{III})$ centre may be delocalised.

It thus follows that substitution at meso carbon of the allylic ligand with a $\pi$-conjugated electron-withdrawing moiety implicates a contribution from a complementary zwitterionic tautomer, as illustrated by the acyl-substituted allyl tungsten complex $\mathbf{3 3} \leftrightarrow \mathbf{3 3}^{\prime}$ (Chart 7). Whilst in $\mathbf{3 2}^{\prime}$ and $\mathbf{2 4 a ^ { \prime }}$ the metal centre formally maintains its oxidation state and valence shell electron count, the tungsten centre 
in $\mathbf{3 3}^{\prime}$ is formally $\mathrm{W}(\mathrm{IV})$ and exhibits a 16 valence electron shell configuration. This offers a rationale for the apparently convincing evidence of an $\alpha$-agostic interaction between the W(IV) centre and the anti allylic hydrogen. The crystal structure of 33a shows the distance of $1.590 \AA$ A between the tungsten centre and the agostic hydrogen (Chart 7). [97] Other similar examples including 34b and 34c may be found in the CSD, [17] featuring unusually acute $\mathrm{W}-\mathrm{C}-\mathrm{H}$ bond angles at $\mathrm{C}_{1}$ or $\mathrm{C}_{3}$, and appropriate $\mathrm{W}-$ $\mathrm{H}$ distances, [73] though not as markedly as seen in 33. Presumably, there is a preference for the syn or anti hydrogens at either $\mathrm{C}_{1}$ or $\mathrm{C}_{3}$ in unsymmetrical allyl ligands, dictated largely by the substituent effects or conformational freedom in annelated allyl complexes. Crystallographic data for complexes 33-35 (Chart 8) show little evidence for either agostic interactions or a contribution from resonance form $\mathbf{3 3}^{\prime}$, and no spectroscopic support (by comparison with $\mathbf{3 6}$ and 37, see Chart 8). Reported infrared data (Table 5) reveal relatively low-frequency $v(\mathrm{C}=\mathrm{O})_{\mathrm{RCO}}$ absorption bands for meso-C-acyl complexes 33-35, which contrast with $\mathbf{3 7}$ where the ester carbonyl is not conjugated with the allylic moiety. Substituents $\mathrm{R}$ that tend to lower the energy of the $\pi^{*}(\mathrm{C}=\mathrm{O})_{\mathrm{RCO}}$ orbital appear to foster counterintuitively a lower $v(\mathrm{C}=\mathrm{O})_{\mathrm{RCO}}$ frequency, perhaps indicating that a reduced competition for the $\pi^{*}(\mathrm{C}=\mathrm{O})_{\mathrm{RCO}}$ orbital enhances the contribution from the resonance tautomer analogous to $\mathbf{3 3}^{\prime}$. $\mathrm{C}_{3}$-substitued acyl complexes 32 and $\mathbf{3 6}$ show that the low-frequency acyl stretch is not unique to the meso-C-substituted examples, although $\mathrm{C}_{2}$-carboxyl complex 31c exhibits $v(\mathrm{C}=\mathrm{O})$ some $100 \mathrm{~cm}^{-1}$ lower than $\mathrm{C}_{3}$-ethyl ester complex 36. NMR spectroscopic data, assembled in Table 6, appear to be less diagnostic, but of note is the unusually upfield shifted resonance of the terminal carbon $\mathrm{C}_{1}$ in complexes $\mathbf{3 5}$, accompanied by $\mathrm{H}_{\text {anti }}$ resonances of $c a .0 .7 \mathrm{ppm}$. However, this is not strongly indicative of an agostic interaction, which typically shifts ${ }^{1} \mathrm{H}$ and ${ }^{13} \mathrm{C}$ resonances noticeably upfield of TMS. [73] ${ }^{13} \mathrm{C}$ chemical shifts of allylic ligands in general are reported to occur between $c a .25$ and $140 \mathrm{ppm}$, [66] with terminal and central carbons for most complexes appearing in the range of 42-86 and 102-128 ppm, respectively; [98] for this discussion, the chemical shifts pertaining to $\mathbf{3 9}$ are used as a reference. [99] Hence, the upfield shifts, typically seen here for complexes of type $\left[\mathrm{CpM}(\mathrm{CO})_{2}\left(\eta^{3}\right.\right.$-allyl $\left.)\right]$, are presumably mostly due to magnetic anisotropy effects of the $\mathrm{Cp}$ ring. The lower frequency resonances of $\mathrm{C}_{1}$ and $\mathrm{C}_{3}$ in $\mathbf{3 2}, \mathbf{3 4}$ and $\mathbf{3 5}$ compared to $\mathbf{3 6}$ are perhaps a manifestation of augmented $\mathrm{sp}^{3}$ hybridisation at the allylic termini, as a result of contributing resonance forms $\mathbf{3 2}^{\prime}$ and $\mathbf{3 3}^{\prime}$. In support of an accumulated positive charge at $\mathrm{C}_{2}$ 
in $\mathbf{3 2}$, the meso carbon in $\mathbf{3 2}$ features a significantly downfield ${ }^{13} \mathrm{C}$ resonance. The broad proton resonances in complexes $\mathbf{3 5}$ are readily attributed to $e x o \rightleftharpoons$ endo isomerism; variable temperature NMR experiments on the meso-acylallyl complex $\left[\mathrm{CpW}(\mathrm{CO})_{2}(1,2,3-\eta)-2-(\right.$ methoxycarbonyl)-4-methyl-2,4pentadien-1-yl)] confirmed that this compound adheres to the expected rotation about the W-allyl vector (Scheme 7c) [100] (in accordance with the discussion in Section 2.2). Deserving a brief comment is related $\eta^{3}$-vinylcarbene complex 38 (Scheme 8). [99] The latter is readily converted into corresponding allyl complex 39 when treated with a hydride-donating nucleophile, suggesting the possibility that the $\eta^{3}$-vinylcarbene derived from $\mathbf{4 0}$ might be obtained from $\mathbf{3 3}$ with appropriate alkylsubstitution, or treatment with, e.g., $\mathrm{Ph}_{3} \mathrm{C}^{+}$(Scheme 8); indeed, it is intuitive to equate the observed agostic interaction (vide supra) in $\mathbf{3 3}$ as an arrested state on this hypothesised route to the respective $\eta^{3}$ vinylcarbene. Vinylcarbene complexes are also relevant as their existence has been suggested in terminal nucleophilic substitution coordinated allylic moieties bearing $\mathrm{C}_{1}$-alkoxy or arylsulfonyloxy substituents. Such complexes are based on the related $\operatorname{TpMo}(\mathrm{CO})_{2}\left(\mathrm{Tp}=\kappa^{3}\right.$-tris(pyrazolyl)borate) fragment. [101]

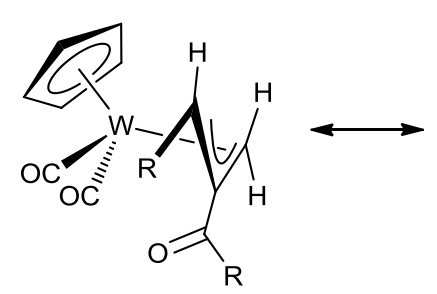

33

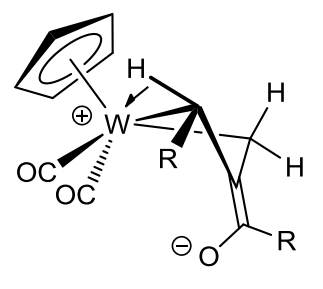

33'

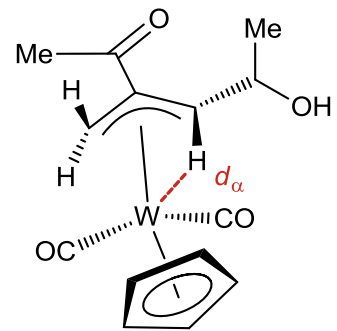

$33 \mathbf{a}$

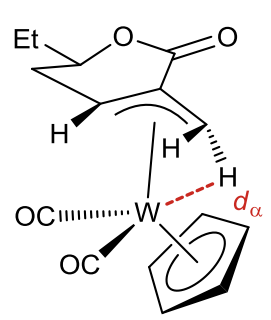

$34 b$

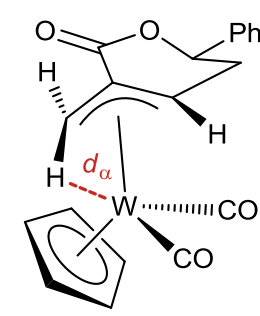

34c

Chart 7. Apparent agostic interactions in meso-C-acylallyl complexes 33a, 34b, 34c identified in corresponding crystal structures by unusually acute $\mathrm{W}-\mathrm{C}-\mathrm{H}$ bond angles and the close proximity of the agostic hydrogen. The crystal structure of 33a presents the most convincing case with a W-H distance $\left(d_{\alpha}\right)$ of just $1.590 \AA$. The W-H 
distances of 2.380 and $2.377 \AA$ for $\mathbf{3 4 b}$ and $\mathbf{3 4 c}$, respectively, are just within the typical region for agostic interactions. The agostic terminus in $\mathbf{3 4} \mathbf{c}$ exhibits a curious configuration whereby the syn hydrogen is almost entirely orthogonal to the plane of the allylic ligand. This is indeed reminiscent of the orientation of the corresponding phenyl substituent in the $\eta^{3}$-vinylcarbene complex 38 (Scheme 8). The postulated tautomerism shown for $\mathbf{3 3} \leftrightarrow \mathbf{3 3}^{\prime}$, complimentary to that shown in Chart 6 , provides an explanation for the observed agostic interaction.

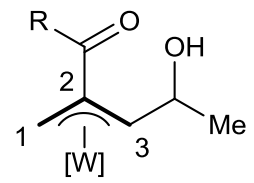

33

a $\mathrm{R}=\mathrm{Me}$

b $\mathrm{R}={ }^{\mathrm{n}} \mathrm{Bu}$

c $R=$ vinyl

d $\mathrm{R}=\mathrm{Ph}$

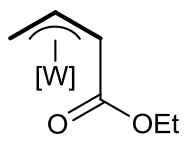

36<smiles>[R]C1CCC(C)(C)C(=O)OC1=O</smiles>

34

a $\mathrm{R}={ }^{\mathrm{i}} \mathrm{Pr}$

b $\mathrm{R}=\mathrm{Et}$

c $R=P h$

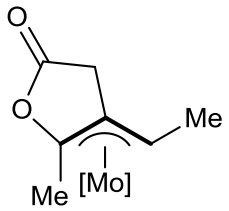

37<smiles>[R]C(=O)C(C)(C)C</smiles>

35

a $\mathrm{R}=\mathrm{Cl}$

b $\mathrm{R}=\mathrm{NHPh}$

c $\mathrm{R}=\mathrm{OH}$

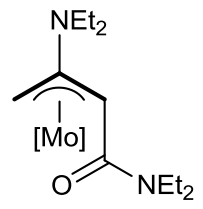

32

Chart 8. Complexes 32-35 bearing mesomerically influencing groups at $C_{2}$ (numbering for the allylic carbons, as referred to in the tabulated data and the main text, are labelled on $\mathbf{3 3}$ ), as well as $\mathrm{C}_{3}$ substituted 1-ethylacetylallyl complex 36, and $\beta$-acyl complex 37, selected for comparison of spectroscopic data presented in Tables 5 and 6. $[\mathrm{M}]=\mathrm{CpM}(\mathrm{CO})_{2}$.

Table 5.

\begin{tabular}{clll}
\hline Complex & $v(\mathrm{CO})_{\mathrm{MCO}} / \mathrm{cm}^{-1}$ & $v(\mathrm{CO})_{\mathrm{RCO}} / \mathrm{cm}^{-1}$ & Ref. \\
\hline 32 & 1931,1843 & 1601 & {$[95]$} \\
33a & 1969,1897 & 1661 & {$[97]$} \\
33b & 1967,1899 & 1659 & {$[97]$} \\
33c & 1968,1898 & 1658 & {$[97]$} \\
33d & 1964,1895 & 1620 & {$[97]$} \\
34a & 1949,1874 & 1705 & {$[102]$} \\
34b & 1946,1868 & 1703 & {$[102]$} \\
34c & 1944,1872 & 1695 & {$[102]$} \\
35a & $1997,1981,1939,1903^{a}$ & $1741,1727 \mathrm{sh}$ & {$[103]$} \\
35b & $1962,1942,1892,1864^{a}$ & 1699 & {$[103]$} \\
35c & $1979,1956 \mathrm{sh}, 1909,1874 \mathrm{sh}^{a}$ & 1601 & {$[103]$} \\
\hline
\end{tabular}




\begin{tabular}{rrrr}
\hline $\mathbf{3 6}$ & 1955,1869 & 1697 & {$[104]$} \\
$\mathbf{3 7}$ & 1946,1866 & 1776 & {$[105]$} \\
\hline
\end{tabular}

${ }^{a}$ Four $v(\mathrm{CO})$ bands observed are presumably due to the co-existence of two exo / endo isomers; in other examples two reported absorptions do not necessarily preclude the existence of both exo and endo isomers if their $v(\mathrm{CO})$ bands are overlapping.

Table 6.

\begin{tabular}{|c|c|c|c|c|c|c|c|}
\hline \multirow[b]{2}{*}{ Complex } & \multicolumn{3}{|c|}{$\delta^{13} \mathrm{C} / \mathrm{ppm}^{a}$} & \multicolumn{2}{|c|}{$\delta{ }^{1} \mathrm{H} / \mathrm{ppm}$} & \multirow[b]{2}{*}{ Solvent ${ }^{1} \mathrm{H} /{ }^{13} \mathrm{C}$} & \multirow[b]{2}{*}{ Ref. } \\
\hline & $\mathrm{C}_{1}$ & $\mathrm{C}_{2}$ & $\mathrm{C}_{3}$ & $\mathrm{H}_{s y n}$ & $\mathrm{H}_{\text {anti }}$ & & \\
\hline 32 & 23.4 & 140.9 & 37.7 & $3.50\left(\mathrm{C}_{1}\right), 4.09\left(\mathrm{C}_{3}\right)$ & 2.99 & $\mathrm{CDCl}_{3}$ & [95] \\
\hline $34 a$ & 19.4 & 61.9 & 81.5 & $2.69\left(\mathrm{C}_{1}\right), 2.02\left(\mathrm{C}_{3}\right)$ & 0.68 & $\mathrm{C}_{6} \mathrm{D}_{6}$ & [102] \\
\hline 34b & 19.6 & 61.7 & 78.0 & $2.70\left(\mathrm{C}_{1}\right), 1.96\left(\mathrm{C}_{3}\right)$ & 0.66 & $\mathrm{C}_{6} \mathrm{D}_{6}$ & [102] \\
\hline $34 c$ & 19.1 & 60.8 & 78.8 & $2.73\left(\mathrm{C}_{1}\right), 1.93\left(\mathrm{C}_{3}\right)$ & 0.72 & $\mathrm{C}_{6} \mathrm{D}_{6} / \mathrm{CDCl}_{3}$ & [102] \\
\hline $35 \mathbf{a}$ & 27.2 & 62.0 & 27.2 & $3.01 \mathrm{br}$ & $1.12 \mathrm{br}$ & $\mathrm{C}_{6} \mathrm{D}_{6}$ & [103] \\
\hline $35 b$ & 24.7 & $-^{b}$ & 24.7 & $3.34 \mathrm{br}$ & $1.75 \mathrm{br}$ & $\mathrm{C}_{6} \mathrm{D}_{6}$ & [103] \\
\hline $35 c$ & 26.1 & $-^{b}$ & 26.1 & $3.00 \mathrm{br}$ & $1.65 \mathrm{br}$ & $\mathrm{CD}_{3} \mathrm{CN} /$ acetone & [103] \\
\hline 36 & 38.9 & 64.5 & 37.6 & $3.22\left(\mathrm{C}_{1}\right), 3.74\left(\mathrm{C}_{3}\right)$ & 2.75 & $\mathrm{CD}_{3} \mathrm{CN} / \mathrm{C}_{6} \mathrm{D}_{6}$ & [104] \\
\hline $39^{c}$ & 47.1 & 103.2 & 47.6 & $3.80,3.84$ & - & $\mathrm{CD}_{3} \mathrm{CN} / \mathrm{CDCl}_{3}$ & [99] \\
\hline
\end{tabular}

${ }^{a}$ Refer to Chart 8 for the numbering system.

${ }^{b}$ Not reported in the literature source.

${ }^{c}$ Refer to Scheme 8; provided as an example for an allyl tungsten complex bearing no strongly influencing heteroatomic functional groups, in the absence of applicable data for the unfurnished compound $\left[\mathrm{CpW}(\mathrm{CO})_{2}\left(\eta^{3}-\right.\right.$ $\left.\left.\mathrm{C}_{3} \mathrm{H}_{5}\right)\right](4)$.

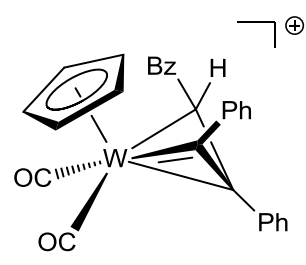

38

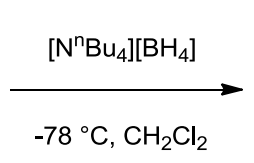

$-78{ }^{\circ} \mathrm{C}, \mathrm{CH}_{2} \mathrm{Cl}_{2}$

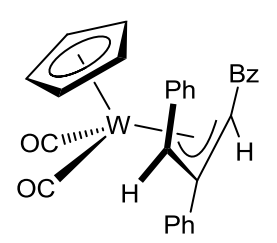

39

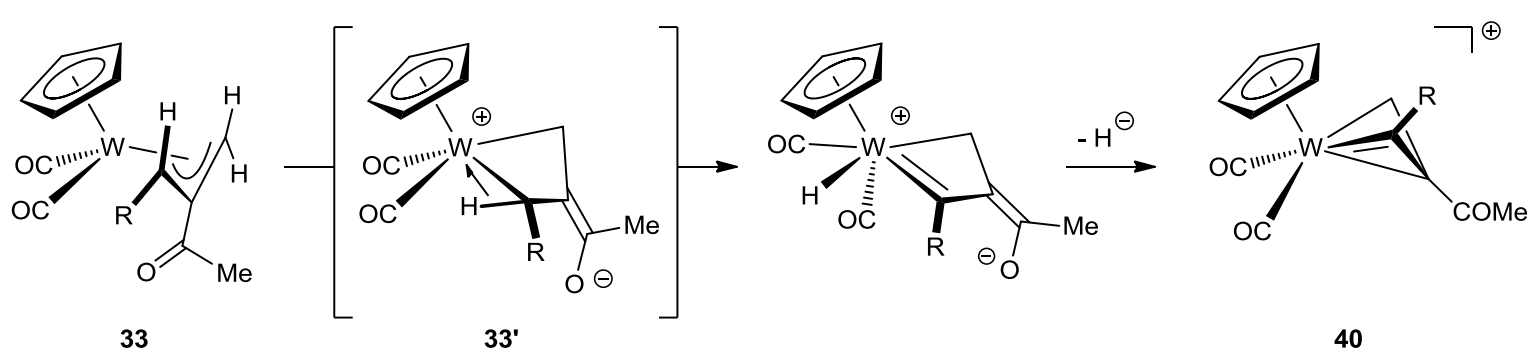

Scheme 8. The reaction of $\eta^{3}$-vinylcarbene complex 38 with a hydride nucleophile resulting in $\eta^{3}$-allyl product 39. Tentatively, resonance tautomer $\mathbf{3 3}^{\prime}$ may be represented as an arrested state to $\mathrm{C}-\mathrm{H}$ activation along a route to corresponding $\eta^{3}$-vinylcarbene complex 40. It is postulated that alteration of the allylic substituents, or additional reagents, may promote this reaction. [99] 
Characterisation of the postulated fluxionality, agostic interactions and reactivity in these complexes may be achieved with various analytical techniques. X-ray crystallography is particularly informative,, although electrochemical methods, such as those employed in the characterisation of $\mathbf{2 6}$, 27 and their derivatives [78,79], are also useful in the absence of structural data. Spectroelectrochemistry is powerful for identifying intermediates, tautomers and isomers by monitoring carbonyl infrared absorptions. NMR techniques, especially heteronuclear couplings such as ${ }^{1} \mathrm{H}-{ }^{13} \mathrm{C}$ and ${ }^{13} \mathrm{C}_{-}{ }^{183} \mathrm{~W}$, are also proven valuable for identifying and characterising agostic interactions, [73] although not in paramagnetic species. On the possible existence of comparably stable molybdenum and tungsten analogues of cationic allylchromium complexes $\mathbf{2 4}$, no example has yet been isolated. However, cyclic voltammetric studies have revealed almost entirely reversible anodic behaviour of complexes 13-15, the same being true for their tungsten congeners. [32,106] It is also worth noting here that the electrochemical oxidation was performed in acetonitrile, a relatively strong donor solvent, but to suggest that the oxidised species is stable in the presence of $\mathrm{MeCN}$ is not necessarily authoritative, given the short timescale of the conventional cyclic voltammetric experiment. Indeed, the cationic chromium complexes $\mathbf{2 4}$ are sensitive to donor solvents (see above). A disproportionation reaction occurs on introduction of $\mathrm{MeCN}$ to $\mathbf{2 4 a}$, affording neutral complex 9a and dicationic tris(acetonitrile) complex 41a in roughly equal quantities (Scheme 9). [72] It would be interesting to see whether 9a is converted entirely into 41a and hexa-1,5-diene on electrochemical oxidation in $\mathrm{MeCN}$, since 9a regenerated from the dispropotionation reaction of $\mathrm{MeCN}$ with $\mathbf{2 4 a}$ will be oxidised again under the positive electrode potential conditions.

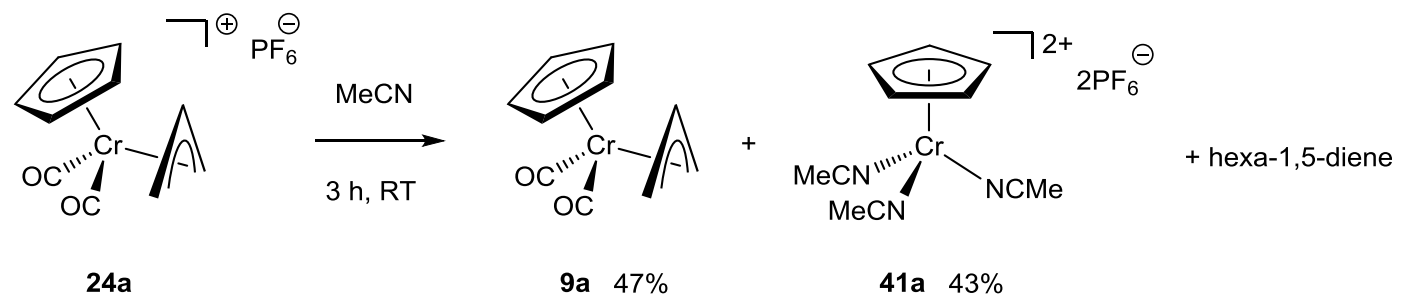

Scheme 9. The disproportionation reaction of cation 24a with acetonitrile, demonstrating the sensitivity of this family of 17 valence electron complexes to donor solvents. Gas chromatography has also confirmed the formation of hexa-1,5-diene, likely because of homolytic dissociation of allyl ligands from $\eta^{1}$-bound intermediates, and subsequent dimerisation. [72] 


\subsection{Mixed nitrosyl carbonyl complexes $\left[\mathrm{CpM}(\mathrm{CO})(\mathrm{NO})\left(\eta^{3}-\text { allyl }\right)\right]^{+}(\mathrm{M}=\mathrm{Mo}, \mathrm{W})$}

The reaction of $\left[\mathrm{CpM}(\mathrm{CO})_{2}\left(\eta^{3}\right.\right.$-allyl $\left.)\right](\mathrm{M}=\mathrm{Mo}(\mathbf{3}), \mathrm{W}(\mathbf{4}))$ with nitrosonium salts does not lead to simple oxidation to yield cationic compounds with coordination sphere unperturbed. [72] Instead, one of the carbonyl ligands is exchanged for a nitrosyl ligand, affording the corresponding cationic complexes $\left[\mathrm{CpM}(\mathrm{CO})(\mathrm{NO})\left(\eta^{3} \text {-allyl }\right)\right]^{+}(\mathrm{M}=\mathrm{Mo}(\mathbf{4 2}), \mathrm{W})$ Scheme 10). This reaction is inhibited for the corresponding allylchromium complexes 9 (Section 2.4), a fact that may be ascribed to a smaller radius of the metal centre and hence more crowded coordination sphere (Section 2.4). [72,107,108] The replacement of one $\mathrm{CO}$ ligand with $\mathrm{NO}^{+}$, and the resulting overall positive charge, augments the susceptibility of the substituted complex to nucleophilic attack at the allylic ligand. Furthermore, the complex is chiral, and the indirect electronic asymmetry exerted on the allylic ligand directs addition of a number of nucleophiles with remarkable stereo- and regioselectivity. [29,109-111] This is also manifested in the slight rotation of the allyl ligand about the Mo-allyl vector towards the carbonyl ligand in the allylmolybdenum nitrosyl complexes (illustrated in Schemes 10 and 11). As interpreted by the Davies-Green-Mingos (DGM) rules, [112] related cationic complexes derived from $\left[\mathrm{Cp}_{2} \mathrm{M}\left(\eta^{3}-\right.\right.$ allyl $)]^{+}(\mathrm{M}=\mathrm{Mo}, \mathrm{W})$ are well known [113] to direct nucleophilic attack at the allylic ligand to the meso carbon, mediated by the relatively electron rich $\mathrm{Cp}_{2} \mathrm{M}$ fragment. [114] In contrast, the more electrophilic fragment $\mathrm{CpMo}(\mathrm{CO})(\mathrm{NO})$ directs a nucleophilic attack to the termini of the allylic ligand, affording stable $\pi$-olefin complex $\mathbf{4 3}$. Due to the asymmetry in $\eta^{3}$-allyl complexes 42 , a nucleophilic attack cis or trans to the nitrosyl ligand yields two diastereomeric $\pi$-olefin complexes; the presence of exo and endo isomers (Section 2.2) further complicates the situation. Scheme 11 illustrates these features for unsubstituted allylmolybdenum cation $\mathbf{4 2}$, but the diagram is also largely applicable to substituted, nonprochiral (vide infra) analogues. Despite the apparently complex regiochemistry of the nucleophilic attack at these complexes, a remarkably high selectivity for the $\mathbf{4 3 a} \rightleftharpoons \mathbf{4 3 b}$ rotameric pair is reported in the case of $\mathbf{4 2}$ and a number of substituted allyl derivatives. [109-111] This is understood to be a consequence of the relative rates of endo-exo isomerisation and the nucleophilic additions at the allylic termini cis or trans to the $\mathrm{NO}^{+}$ligand. [115] Computational studies show that in the exo isomer the allylic carbon cis to $\mathrm{NO}^{+}$is appreciably more susceptible to a nucleophilic attack than the trans terminal 
carbon. Hence, nucleophilic addition occurs exclusively cis to $\mathrm{NO}^{+}$in the exo conformation, and $k_{1}{ }^{\prime \prime}[\mathrm{Nu}]$ is negligible. In the endo isomer, a very little difference in the charge and orbital coefficients between the two terminal carbons of the allyl ligand has been calculated for $\mathbf{4 2}$, with in fact a marginally more positive charge trans to $\mathrm{NO}^{+}$. $[29,116]$ However, the reaction rates of nucleophilic addition to the endo isomer $\left(k_{2}{ }^{\prime}[\mathrm{Nu}], k_{2}{ }^{\prime \prime}[\mathrm{Nu}]\right)$ are reported to be much smaller compared to those for the exo isomer $\left(k_{1}{ }^{\prime}[\mathrm{Nu}]\right)$, and indeed smaller than the rate of the endo $\rightarrow$ exo interconversion $\left(k_{-3}\right)$. Importantly, it is also understood that addition of the nucleophile catalyses the endo $\rightleftharpoons$ exo isomerism, further increasing $k_{-3}$. Hence, $\pi$-olefin species $\mathbf{4 3 a} \rightleftharpoons \mathbf{4 3 b}$ is formed almost exclusively from the exo conformation with explicit regioselectivity, the endo isomer being consumed by the rapid interconversion to the exo isomer. The latter transformation surpasses its own, less selective nucleophilic addition pathways. It therefore holds that $k_{1}{ }^{\prime}[\mathrm{Nu}]>k_{-3}>k_{3}>k_{2}{ }^{\prime}[\mathrm{Nu}]>k_{2}{ }^{\prime \prime}[\mathrm{Nu}]$. Some substituted allyls are observed to significantly inhibit the exo-endo equilibration, and in this case the selectivity depends on the isomer present. Whilst the exo isomer still directs the nucleophile cis to $\mathrm{NO}^{+}$and maintains the selectivity for $\pi$-olefin species $\mathbf{4 3 a} \rightleftharpoons \mathbf{4 3 b}$, the presence of the endo isomer will yield at least some of complementary diastereomer $\mathbf{4 3 c} \rightleftharpoons \mathbf{4 3 d}$, since $k_{-3}$ is now much smaller than $k_{2}{ }^{\prime}[\mathrm{Nu}]$. In this system, the relative rates go as $k_{1}{ }^{\prime}[\mathrm{Nu}]>k_{2}{ }^{\prime}[\mathrm{Nu}]>k_{2}{ }^{\prime \prime}[\mathrm{Nu}]>>k_{-3}>k_{3}$. [115]

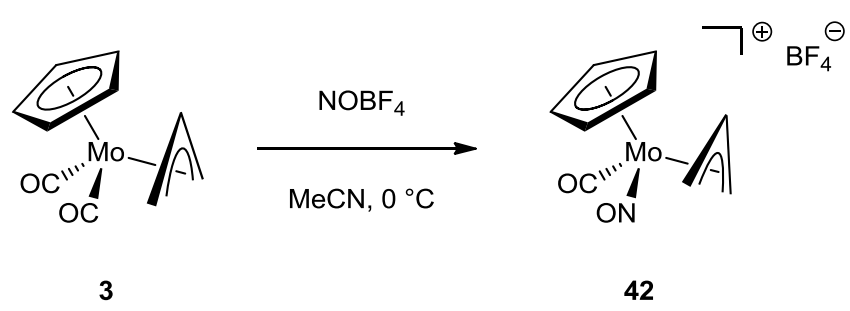

Scheme 10. Reaction of $\mathbf{3}$ with nitrosonium tetrafluoroborate to afford nitrosyl-substituted cationic complex $\mathbf{4 2}$. The reaction is applicable to different complexes bearing a wide range of substituted or cyclic allyl ligands. Alternative nitrosonium salts (e.g., $\left.\mathrm{NOPF}_{6}\right)$ have also been employed successfully. [72] 


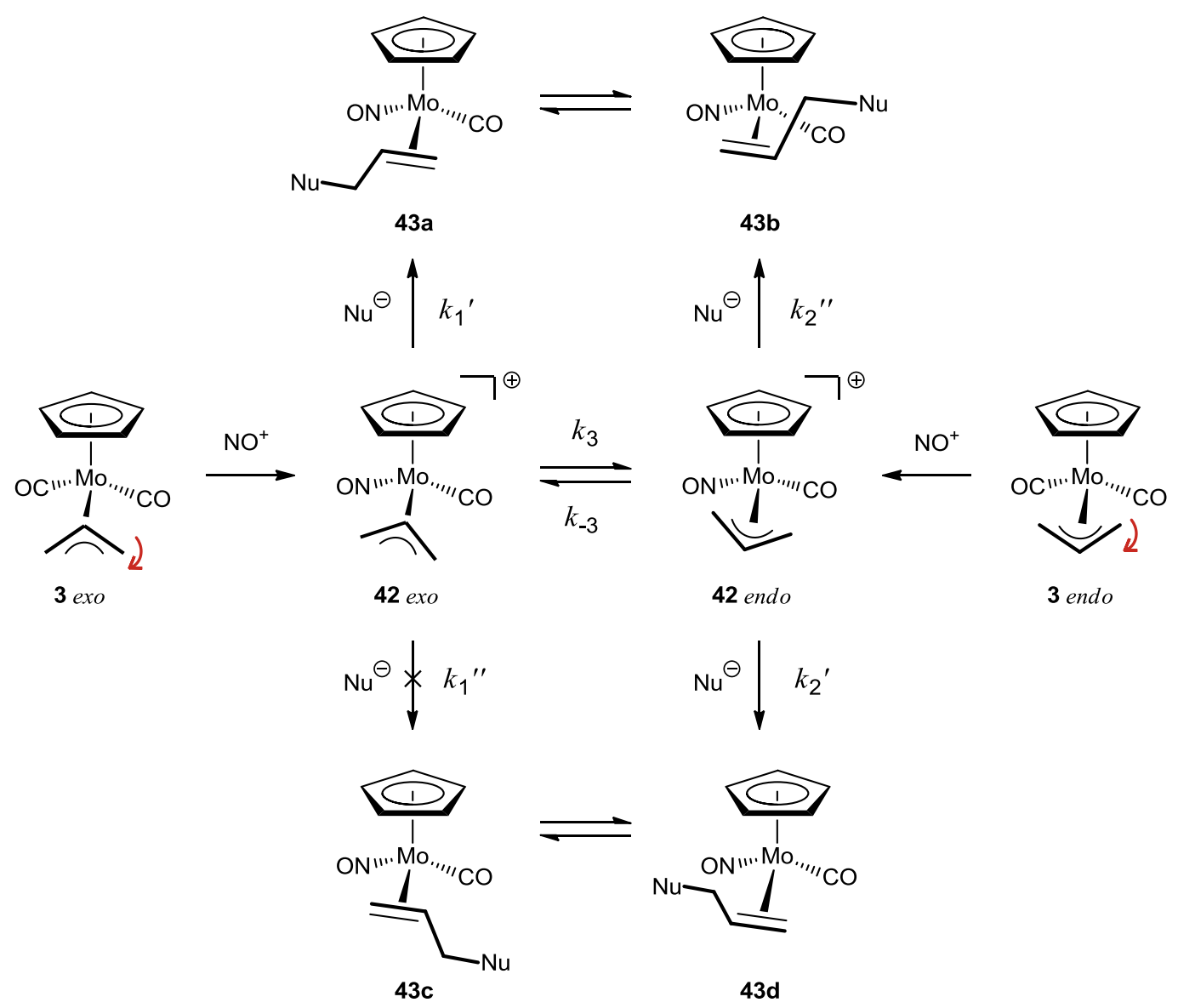

Scheme 11. The features of nucleophilic addition applicable to complexes derived from $\left[\mathrm{CpMo}(\mathrm{CO})(\mathrm{NO})\left(\eta^{3}-\right.\right.$ allyl) $]^{+}$. The reaction of dicarbonyl parent compound $\mathbf{3}$ with $\mathrm{NO}^{+}$is accompanied by rotation of the allyl ligand about the Mo-allyl vector towards the carbonyl ligand (shown by the red arrow); this rotation is also preserved in the $\pi$-olefin-bound species 43 (confirmed via X-ray crystallographic analysis). [109] Nucleophilic addition cis to the nitrosyl group in the exo conformer $\left(k_{1}{ }^{\prime}\right)$ and trans to $\mathrm{NO}^{+}$in the endo conformer $\left(k_{2}{ }^{\prime \prime}\right)$ affords the rotameric pair $43 \mathrm{a} \rightleftharpoons \mathbf{4 3 b}$, whilst the trans addition to the exo conformer $\left(k_{1}{ }^{\prime \prime}\right)$ and the cis addition to the endo conformer $\left(k_{2}{ }^{\prime}\right)$ afford the rotameric pair $\mathbf{4 3 c} \rightleftharpoons \mathbf{4 3 d}$, which are diastereomers to $\mathbf{4 3 a} \rightleftharpoons \mathbf{4 3 b}$. [115] It is worth noting that the trans addition to the exo isomer $\left(k_{1}{ }^{\prime \prime}\right)$ was not observed.

These processes (Scheme 11) thus provide a convenient means with which to prepare selectively, exo or endo isomers of substituted allyl derivatives of $\mathbf{4 2}$ that exhibit very slow rates of interconversion $\left(k_{3}, k_{-3}\right)$. For example, treatment of $\left[\mathrm{CpMo}(\mathrm{CO})_{2}\left(\eta^{3}\right.\right.$-cinnamyl)] (44) with $\mathrm{NO}^{+}$yields exclusively $\mathbf{4 5}$ endo-cis, and rotation of the allylic moiety to the accompanying exo-trans rotamer is extremely slow (Scheme 12a). [111] Instead, the regioselectivity illustrated in Scheme 11 may be exploited to obtain the exo-cis isomer of $\mathbf{4 5}$ via nucleophilic attack of the appropriate Grignard reagent on 42 to afford the desired $\pi$-olefin complex (46), followed by hydride extraction with trityl tetrafluoroborate (Scheme 12b). The hydride abstraction proceeds with remarkable selectivity for the 
exo-cis isomer of $\mathbf{4 5}$, whilst also maintaining the syn arrangement of the phenyl substituent.

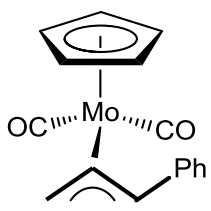

44

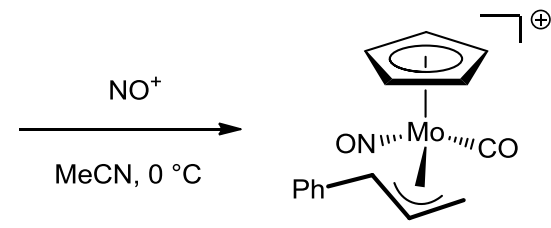

45 endo-cis

b)

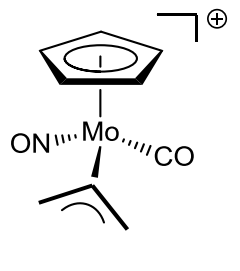

42

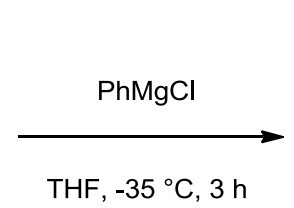

THF, $-35^{\circ} \mathrm{C}, 3 \mathrm{~h}$
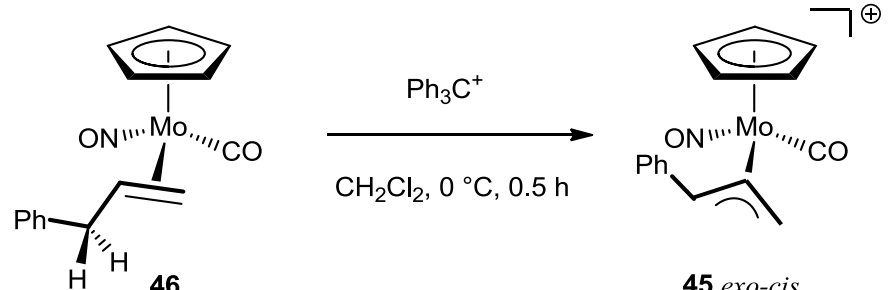

45 exo-cis

Scheme 12. Synthetic routes to a) the endo-cis isomer, as afforded via the conventional synthesis shown in Scheme 10 , and b) the exo-cis isomer. [111]

A consideration of stereochemistry, both intrinsic to these nitrosyl complexes and as a result of the nucleophilic addition, further adds to the complexity of the discussion. The isolation of $\mathbf{4 5}$ exo-cis in Scheme 12b provides a substrate to which a nucleophile may be directed reliably to the phenylsubstituted carbon of the allyl ligand (a testament to the strong directing power of the nitrosyl ligand). The nucleophilic attack results in the formation of a new chiral centre, which is preserved in the decomplexed olefin; its absolute configuration depends on the endo/exo conformation of the substrate and, in appropriately substituted allyls with two pro-chiral centres, the regioselectivity of addition. Scheme 13 illustrates this approach for syn,syn-1,3-dimethylallyl complex 47. Hence, the stereochemical outcome of the nucleophilic attack is governed by the same relative rates as delineated above (Scheme 11), and a single isomer $\mathbf{4 8}$ is afforded in the nucleophilic addition to $\mathbf{4 7}$ as a result of facile endo $\rightleftharpoons$ exo interconversion. The nitrosyl complexes $\left[\mathrm{CpM}(\mathrm{CO})(\mathrm{NO})\left(\eta^{3} \text {-allyl }\right)\right]^{+}$themselves are chiral at the molybdenum centre, giving rise to enantiomers $((R, R)-\mathbf{4 8} ;(S, S)-48)$ as a result of the potent cis-directing influence of the $\mathrm{NO}^{+}$ligand in the exo isomer (Scheme 13). [115] With the stereo- and regiochemical parameters in mind, it is particularly impressive that these transformations proceed with 
such excellent selectivity to yield a single product. Above are just a few examples from many possible transformations of Group-6 cyclopentadienylnitrosyl complexes, but see also [117].

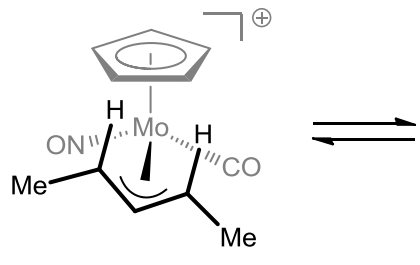

(R)-47 endo

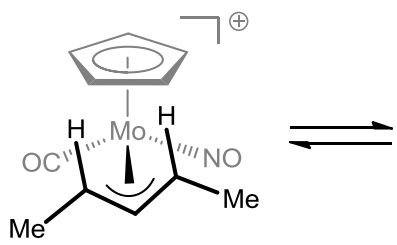

(S)-47 endo

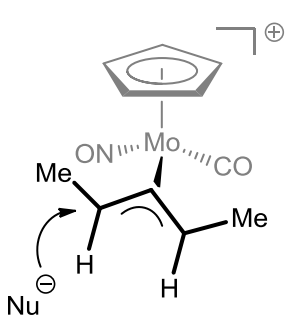

(R)-47 exo

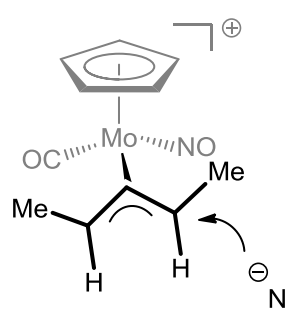

(S)-47 exo

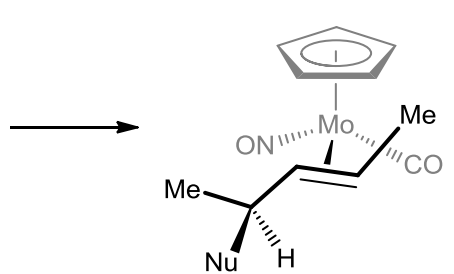

$(R, R)-48$

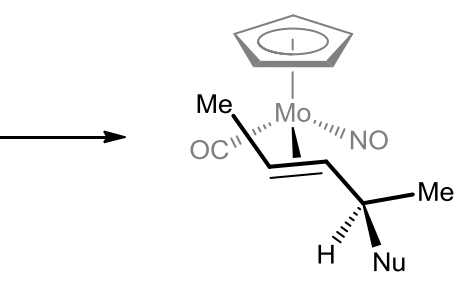

$(S, S)-48$

Scheme 13. Stereochemical consequences of nucleophilic addition to pro-chiral allylic substrates. Here, syn,syn1,3-dimethylallyl complex $\mathbf{4 7}$ is used as an example, but one may envisage more complex outcomes and product mixtures with asymmetrical allyls or nitrosyl complexes that exhibit slow endo $\rightleftharpoons$ exo interconversion. The fast endo $\rightleftharpoons$ exo isomerisation of $\mathbf{4 7}$ ensures that nucleophilic attack occurs almost exclusively on the exo conformation, which directs addition cis to $\mathrm{NO}^{+}$to yield a single enantiomer of product 48, assuming parent compound $\mathbf{4 7}$ is optically pure. It is the absolute configuration around the molybdenum centre that dictates which enantiomer of $\mathbf{4 8}$ forms as a result of the aforementioned regioselectivity. Note that in some cases the $R$ or $S$ labelling may be subject to change for different nucleophiles, depending on their Cahn-Ingold-Prelog priority, as well as on decomplexation from the metal centre. [115]

\section{Complexes $\left[\mathrm{M}(\mathrm{CO})_{2}\left(\eta^{3}\right.\right.$-allyl $)(\alpha$-diimine $\left.) \mathrm{X}\right](\mathrm{X}=$ anionic monodentate ligand $)$ and related}

\section{compounds}

$\alpha$-Diimines, 2,2'-bipyridine (bpy) being typical, have long been used as $N, N^{\prime}$-chelating fourelectron donor ligands. [118] Chart 8 presents selected $\alpha$-diimines with the abbreviations employed. Accompanied by an anionic two-electron donor $\mathrm{X}$ (e.g., halide, pseudohalide), an $\mathrm{L}_{2} \mathrm{X}$ framework is constructed as a substitute for the six-electron donor $\eta^{5}$-Cp ligand in the complexes described in Section 2. A number of complexes with related mono- and bidentate ligands are also added to the discussion, including cationic analogues $\left[\mathrm{M}(\mathrm{CO})_{2}\left(\eta^{3} \text {-allyl }\right)(\alpha \text {-diimine }) \mathrm{L}^{\prime}\right]^{+}$, other complexes bearing bidentate 
$\left(\mathrm{L}^{\frown} \mathrm{L}\right)$ donor ligands, and tricarbonyl complexes $\left[\mathrm{M}(\mathrm{CO})_{3}\left(\eta^{3} \text {-allyl }\right)(\alpha \text {-diimine })\right]^{+}$.
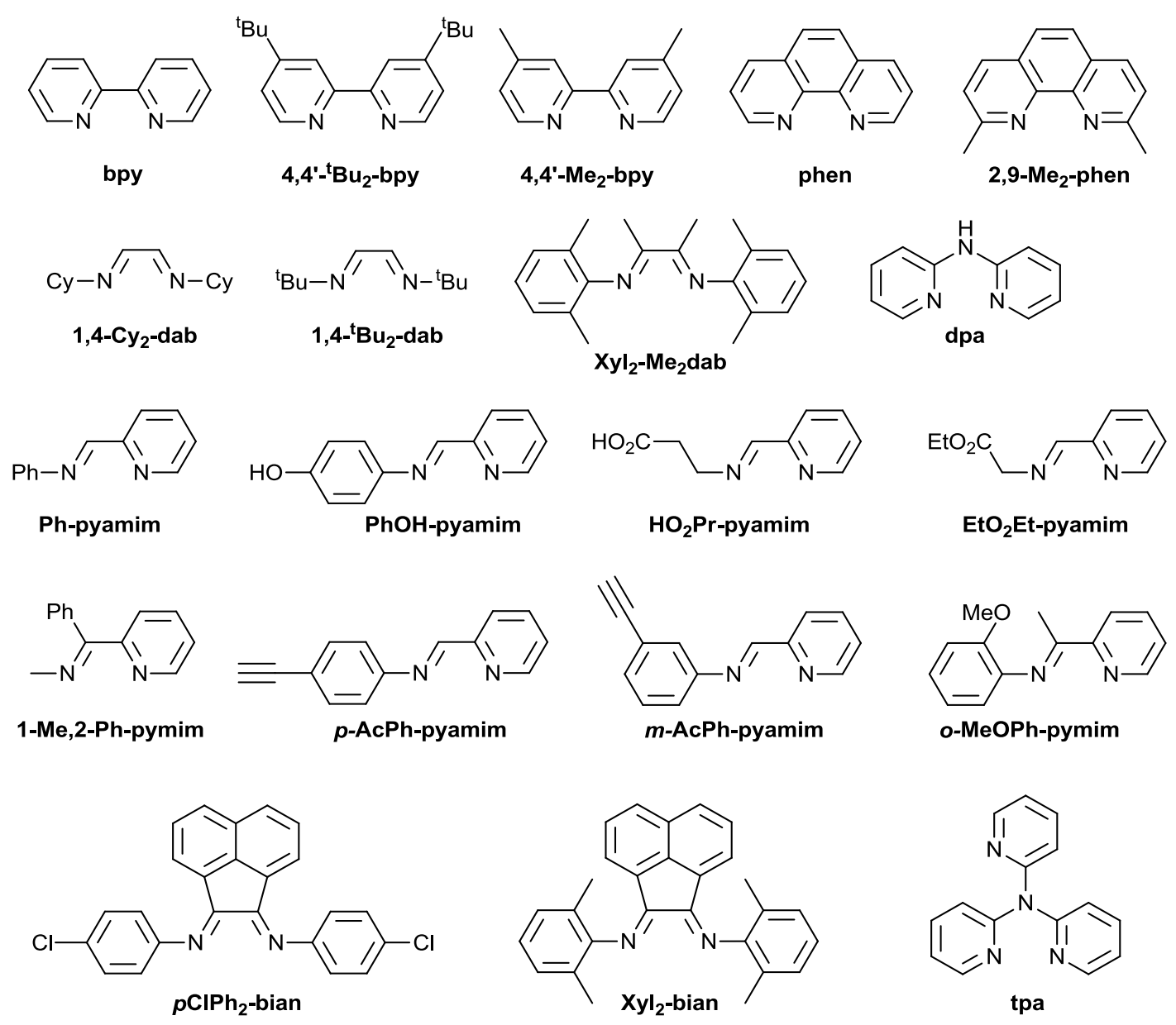<smiles>c1c[nH]c(-c2ncc[nH]2)n1</smiles>

biim<smiles>c1ccc(-c2cc[nH]n2)nc1</smiles>

pyim<smiles>c1ccc(-c2nc3ccccc3[nH]2)nc1</smiles>

pybzim

$$
\sum_{H N} N
$$

2-Me-imamim

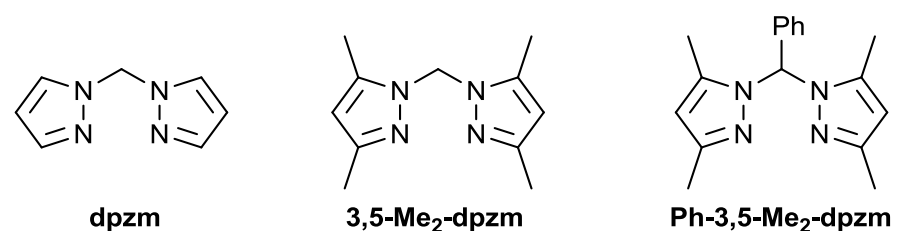

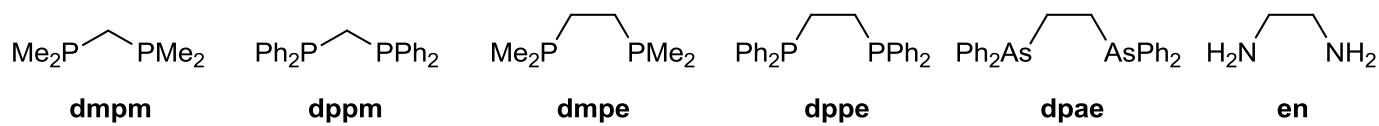$$
\mathrm{Ph}{ }_{\mathrm{N}}=\mathrm{H}_{\mathrm{H}^{-}} \mathrm{Ph}
$$$$
\begin{array}{llll}
\mathrm{Ph}_{2} \text {-imidam } & \text { py } & \mathrm{N} \text {-Me-im }
\end{array}
$$ 
Chart 8. Representatives of a wide range of $\alpha$-diimine ligands and their abbreviations as referred to in the main text. Related bi- and monodentate ligands presented in the main text are also depicted.

\subsection{Synthetic strategies}

The first synthesis of complexes $\left[\mathrm{M}(\mathrm{CO})_{2}\left(\eta^{3}\right.\right.$-allyl $)(\alpha$-diimine $\left.) \mathrm{X}\right]$ was reported in 1966 [119], shortly after that of the cyclopentadienyl analogues described in Section 2. The previously isolated tris(halido)-bridged dinuclear complexes $\left[\mathrm{Et}_{4} \mathrm{~N}\right]\left[\mathrm{M}_{2}(\mu-\mathrm{X})_{3}(\mathrm{CO})_{4}\left(\eta^{3} \text {-allyl }\right)_{2}\right](\mathrm{M}=\mathrm{Mo}, \mathrm{W} ; \mathrm{X}=\mathrm{Cl}, \mathrm{Br})$ (49) [120] undergo a bridge-cleavage thermal reaction with 2,2'-bipyridine to afford $\left[\mathrm{M}(\mathrm{CO})_{2}\left(\eta^{3}\right.\right.$ allyl)(bpy)X] (50) (Scheme 14). Since then, numerous improved syntheses have followed and proved general for a wide range of $\alpha$-diimines and anionic ligands X. Hull and Stiddard have presented a synthetic strategy starting with zerovalent metal precursors $\left[\mathrm{M}(\mathrm{CO})_{4}(\alpha\right.$-diimine $\left.)\right](\mathbf{5 1})$ or $\left[\mathrm{M}(\mathrm{CO})_{3}(\alpha-\right.$ diimine $)($ py)] $($ py = pyridine) $(\mathbf{5 2}),[121]$ readily obtained from the corresponding hexacarbonyls. [122124] Subsquent oxidative addition by allyl-X ( $\mathrm{X}=$ halide or pseudohalide) in refluxing THF affords respective Mo(II) or W(II) product 53 (Scheme 15). Tom Dieck and Friedel subsequently reported a synthetic route (Scheme 16) [125] that involves direct addition of allyl-X to $\left[\mathrm{M}(\mathrm{CO})_{6}\right]$ in acetonitrile to give the versatile precursor $\left[\mathrm{M}(\mathrm{CO})_{2}(\mathrm{MeCN})_{2}\left(\eta^{3}\right.\right.$-allyl $\left.) \mathrm{X}\right](\mathbf{5 4})$, presumably in an analogous manner to Scheme 15 via the intermediate $f a c-\left[\mathrm{M}(\mathrm{CO})_{3}(\mathrm{MeCN})_{3}\right]$. Bis(acetonitrile) complex $\mathbf{5 4}$ is then treated with the desired $\alpha$-diimine ligand, [106] a selection of which are listed in Chart 8 . The latter synthesis is presumably derived from the stepwise procedure that involves preparation of the versatile intermediate $\left[\mathrm{M}(\mathrm{CO})_{3}(\mathrm{MeCN})_{3}\right]$ [126-129] from molybdenum or tungsten hexacarbonyl in refluxing acetonitrile (the tungsten here requires very long reaction times), followed by oxidative addition of allyl-X.

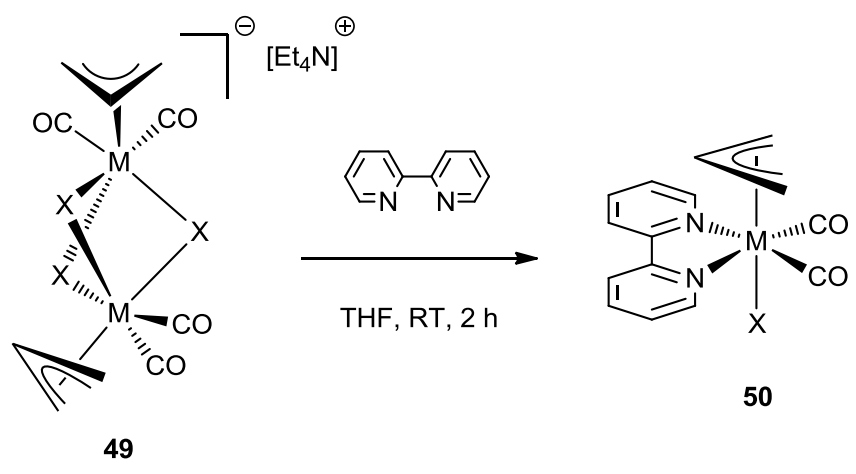


Scheme 14. Thermal reaction of $\left[\mathrm{Et}_{4} \mathrm{~N}\right]\left[\mathrm{M}_{2}(\mu-\mathrm{X})_{3}(\mathrm{CO})_{4}\left(\eta^{3} \text {-allyl }\right)_{2}\right](\mathrm{M}=\mathrm{Mo}, \mathrm{W} ; \mathrm{X}=\mathrm{Cl}, \mathrm{Br})(49)$ with 2,2'bipyridine. [120]<smiles></smiles>

51

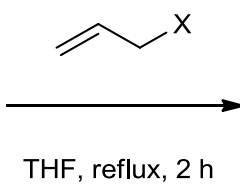

THF, reflux, $2 \mathrm{~h}$

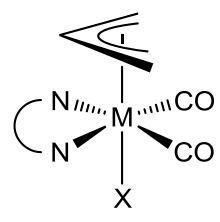

53

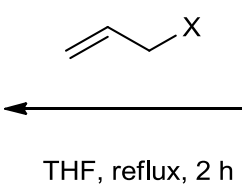

THF, reflux, $2 \mathrm{~h}$

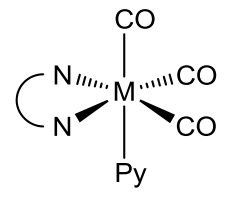

52

Scheme 15. $\mathrm{M}=\mathrm{Mo}, \mathrm{W} ; \mathrm{N}^{\urcorner} \mathrm{N}=\alpha$-diimine. [121]<smiles></smiles>

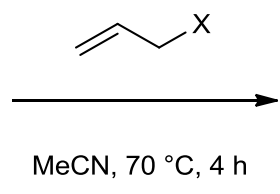

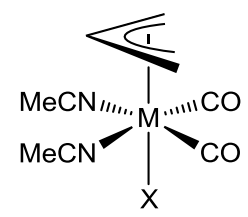

54

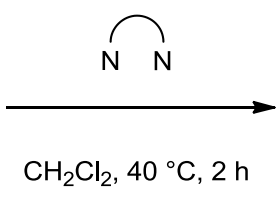

$\mathrm{CH}_{2} \mathrm{Cl}_{2}, 40^{\circ} \mathrm{C}, 2 \mathrm{~h}$

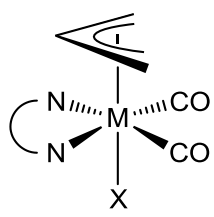

53

Scheme 16. $M=M o, W ; N^{\urcorner} N=\alpha$-diimine; this synthesis is suitable for a wide range of $\alpha$-diimine ligands.[125] An analogous route to tungsten congeners stipulates the prior synthesis of the intermediate fac$\left[\mathrm{W}(\mathrm{CO})_{3}(\mathrm{MeCN})_{3}\right]$, followed by the oxidative addition of allyl-X to yield the tungsten derivative of $\mathbf{5 4}$. [130]

An alternative photolytic route to allyl tungsten analogues has been described, [131] whereby tungsten hexacarbonyl absorbs UV light in the presence of allyl-X to form $\mathbf{5 5}$, followed by facile substitution of two CO ligands by chelating $\alpha$-diimines (Scheme 17). A more recent example in the literature alternatively employs anionic intermediate $\mathbf{5 6}$ to induce the oxidative addition step and produce $\alpha$-diimine complexes $\mathbf{5 3}$ in high yields. [132] Tetraethylammonium salts [ $\left.\mathrm{Et}_{4} \mathrm{~N}\right] \mathrm{X}$ react with tetracarbonyl precursor 51 binding the desired $\alpha$-diimine. The resulting anion, $f a c-\left[\mathrm{M}(\mathrm{CO})_{3}(\alpha-\right.$ diimine) $\mathrm{X}]^{-}(\mathbf{5 6})$, is sufficiently nucleophilic to complete the oxidative addition step rapidly at room temperature and with high conversion (Scheme 18). This route provides a more efficient access to tungsten congeners of 53; slower kinetics and more accessible decomposition pathways typically make their syntheses more challenging compared to the molybdenum derivatives. The route via an anionic intermediate is more convenient than that in Scheme 17, which requires long reaction times. Several 
complexes analogous to $\mathbf{5 3}$, bearing substituted allylic ligands, have also been prepared by this method. Noteworthy is the complex $\left[\mathrm{Mo}(\mathrm{CO})_{2}\left(\eta^{3}\right.\right.$-cyclohexenyl $\left.)(\mathrm{bpy}) \mathrm{Br}\right](\mathbf{5 8})$ that was successfully prepared from anionic tricarbonyl intermediate 57, albeit in modest yield (Scheme 19). [132] However, the 1,10phenanthroline (phen) congener $\left[\mathrm{Mo}(\mathrm{CO})_{2}\left(\eta^{3}\right.\right.$-cyclohexenyl $\left.)(\mathrm{phen}) \mathrm{Br}\right]$ was found to be particularly sensitive to oxidation and its isolation failed.<smiles></smiles>

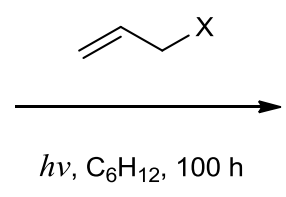

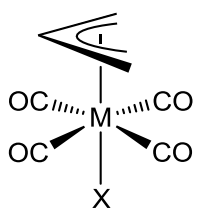

55
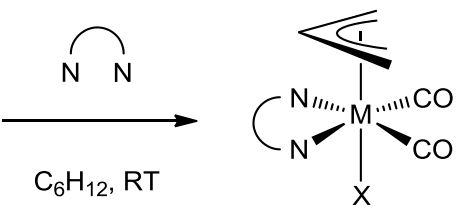

53

Scheme 17. $\mathrm{M}=\mathrm{W} ; \mathrm{N}^{\urcorner} \mathrm{N}=\alpha$-diimine. [131]<smiles>O=C[N+](O)(C=O)N1CCNC1</smiles>

51

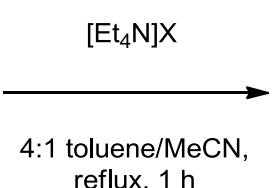

reflux, $1 \mathrm{~h}$

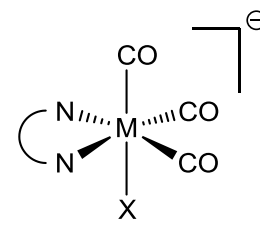

56

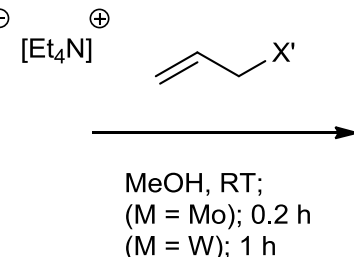

$(\mathrm{M}=\mathrm{W}) ; 1 \mathrm{~h}$

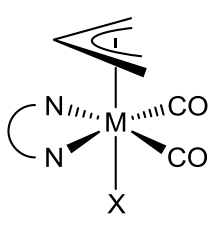

53

Scheme 18. In this synthesis, the retention of anionic ligand in intermediate $\mathbf{5 6}$ (as well as $\mathbf{5 9}$ in Scheme 20, and presumably $\mathbf{5 7}$ in Scheme 19) is noteworthy; although, in some cases exchange of this ligand was observed in solution upon standing. [132]

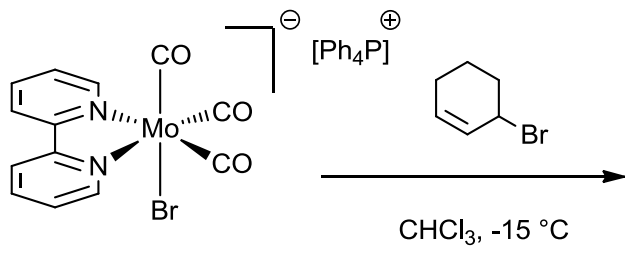

57

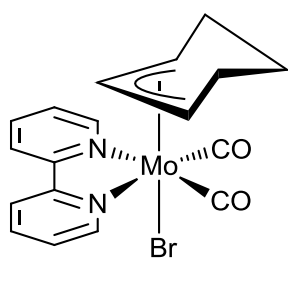

58

Scheme 19. Preparation of complex $\left[\mathrm{Mo}(\mathrm{CO})_{2}\left(\eta^{3}\right.\right.$-cyclohexenyl $\left.)(\mathrm{bpy}) \mathrm{Br}\right](\mathbf{5 8})$. [132] 
As mentioned in Section 2.1, organochromium complexes are typically more difficult to isolate than their molybdenum and tungsten congeners, and the $\alpha$-diimine complexes represent no exception. The above synthetic methods are not applicable to complexes of chromium. However, in 1974 Brisdon and Griffith prepared $\mathbf{5 3}(\mathrm{M}=\mathrm{Cr})$, also useful for the molybdenum and tungsten congeners. [133] The milder conditions of this reaction again involve preparation of an anionic intermediate, most conveniently achieved by the reaction of $\mathbf{5 1}$ with sodium iodide. The anionic intermediate (59) subsequently reacts with allyl-X to furnish M(II) iodo product 53-I (Scheme 20).

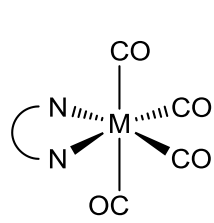

51

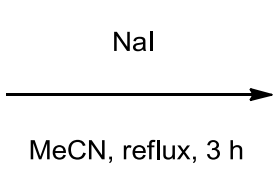

$\mathrm{MeCN}$, reflux, $3 \mathrm{~h}$

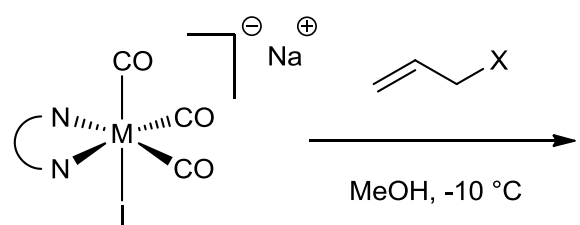

59

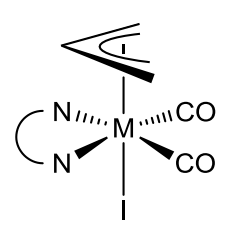

53-1

Scheme 20. $\mathrm{M}=\mathrm{Cr}, \mathrm{Mo}, \mathrm{W} ; \mathrm{N}^{\urcorner} \mathrm{N}=\alpha$-diimine; although for the chromium complexes, this reaction does not typically proceed for bidentate ligands other than 2,2'-bipyiridine. [130]

An interesting route to cationic molybdenum tricarbonyl complex $\mathbf{6 2}$ proceeds via displacement of the $\eta^{6}$-bound $p$-xylene ligand in $\mathbf{6 0}$ (Scheme 21). The resulting tris(tetrahydrofuran) adduct undergoes oxidative addition of an allyloxyphosphonium salt to furnish bis(tetrahydrofuran) allylmolybdenum complex 61. Use of an allyloxyphosphonium reagent inhibits coordination of a counterion, retaining the three carbonyl ligands, and the weakly coordinated THF moieties are then readily displaced by the desired $\alpha$-diimine ligand. [134] This route uses mild conditions, and thus may be suited for preparing chromium complexes; (arene)chromium tricarbonyl complexes are well known, [135] so the precursor is readily obtained. Amongst the aforementioned preparative routes, it is yet to be proven whether all are general to the full complement of $\alpha$-diimine ligands shown in Chart 8 , in particular the 1,4diazabutadiene (dab) ligands bearing sterically demanding $N$-substituents that are more difficult to install. 


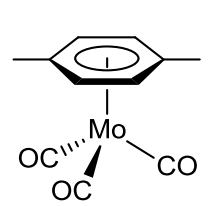

60

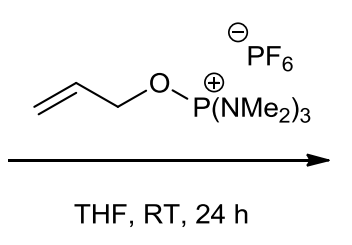

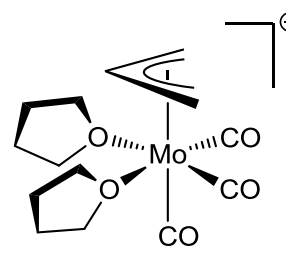

61

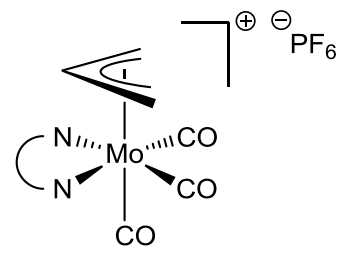

62

Scheme 21. Preparation of cationic allylmolybdenum $\alpha$-diimine tricarbonyl complex 62. [134]

\subsection{Mechanistic features, structural aspects, and dynamic behaviour}

The mechanistic details pertaining to the oxidative addition of allyl-X substrates to zerovalent Group 6 metal complexes, as described in Section 3.1, are not yet well understood and warrant some further discussion. There are clues amongst the distinct synthetic transformations described in Sections 2.1 and 3.1, suggesting that the oxidative additions, conducted with the various synthetic intermediates, are not necessarily subject to the same mechanism. Brisdon and co-workers proposed two candidates for the mechanism by which complexation of the allyl ligand proceeds. [132] A pathway involving loss of $\mathrm{CO}$ and subsequent pre-coordination of the (localised) olefinic part of the allylic substrate, followed by rapid displacement of the leaving group $\mathrm{X}^{\prime}$ from the $\alpha$-carbon (Scheme 22), has also been postulated for the transformations $\left[\operatorname{Ir}(\mathrm{CO}) \mathrm{L}_{2} \mathrm{X}\right] \rightarrow\left[\operatorname{Ir}(\mathrm{CO})\left(\eta^{1}\right.\right.$-allyl $\left.) \mathrm{L}_{2} \mathrm{X}\right]$. [136] The expected inertness of the carbonyl ligands, the retention of the initially bound anionic ligand $\mathrm{X}$, and the reported ingress of ligated $\mathrm{X}^{\prime}$ only after standing for some time, preclude a similar mechanism involving dissociation of $\mathrm{X}$ to form a coordinatively unsaturated species $\left[\mathrm{M}(\mathrm{CO})_{3}\left(\mathrm{~N}^{\urcorner} \mathrm{N}\right)\right](\mathrm{M}=\mathrm{Mo}, \mathrm{W})$, which then undergoes the oxidative addition step. Labelling studies with ${ }^{13} \mathrm{CO}$ have demonstrated the lability of $\mathrm{CO}$ in similar complexes; [137-139] although dissociation of $\mathrm{MeCN}$ in some precursors and even ring opening of the chelate may form the highly fluxional, [137] 5-coordinate intermediate. The ensuing substitution by the olefinic moiety would therefore be expected to proceed via a dissociative mechanism. [140-142] A proclivity to $\mathrm{M}-\mathrm{CO}$ bond fission in the apical position was observed for $\left[\mathrm{Mo}(\mathrm{CO})_{4}(\mathrm{dppe})\right],[139]$ and in the case of 56, the presence of the anionic ligand in the coordination sphere, as well as the nature of the bidentate 
ligand, could either enhance or inhibit this selectivity. Although the anionic $\pi$-olefin transient $\left[\mathrm{M}(\mathrm{CO})_{2}\left(\mathrm{~N}^{\urcorner} \mathrm{N}\right)\left(\eta^{2} \text {-olefin }\right) \mathrm{X}\right]^{-}$(63) has so far eluded isolation, analogous neutral complexes $\left[\mathrm{M}(\mathrm{CO})_{3}(\mathrm{R}-\mathrm{dab})\left(\eta^{2}\right.\right.$-olefin $\left.)\right](\mathrm{R}-$ dab $=$ substituted 1,4-diazabutadiene ligands; see Chart 8$)$, prepared from $\left[\mathrm{M}(\mathrm{CO})_{4}(\mathrm{R}-\mathrm{dab})\right]$, have been characterised by X-ray crystallographic studies, [143] showing the propensity of $\mathbf{6 3}$ to undergo the intramolecular attack at the $\mathrm{C}-\mathrm{X} \sigma^{*}$ orbital, on account of the formal negative charge of the complex, and the proximity of the $\mathrm{C}-\mathrm{X}$ bond. This provides compelling evidence that Scheme 22 applies as the prevailing mechanism for the synthetic routes in Schemes 2, 15 and 16; the latter presumably proceeding via dissociation of $\mathrm{CO}$ and/or $\mathrm{MeCN}$ from $f a c-\left[\mathrm{M}(\mathrm{CO})_{3}(\mathrm{MeCN})_{3}\right]$ as in Scheme 3, or from cis-[M(CO) $\left.)_{4}(\mathrm{MeCN})_{2}\right]$. Further evidence comes from studies investigating the propensity for some molybdenum-based systems to effect oxidative addition to allylic acetates with retention of stereochemistry. [144-153] Of particular relevance is the oxidative addition to $\left[\mathrm{Mo}(\mathrm{CO})_{3}(\mathrm{MeCN})_{3}\right]$ by chiral allylic substrate $\mathbf{6 4}$, which is reported to proceed with retention to yield allylmolybdenum complex 66a [144] via chelating olefinic intermediate 65a (Scheme 23a). [153,154] Lower selectivity is observed under different conditions; the pathway in Scheme 23b is competitive when there is a high concentration of the molybdenum precatalyst species $\mathrm{ML}_{6}$ present, [153] but $\pi$ olefin species are implicit in both routes. Scheme 23 also pictures the two generalised transition states $\mathbf{T S}_{1}$ and $\mathbf{T S}_{2}$ that are applicable to a concerted mechanism with retention, and an intramolecular $\mathrm{S}_{\mathrm{N}} 2-$ type mechanism with inversion, respectively. [155] It is evident that the chelation of the acetate moiety leads to a concerted oxidative addition similar to $\mathbf{T S}_{\mathbf{1}}$, but this is unlikely to apply to $\mathbf{6 3}$, since the necessity of concomitant coordination of the leaving group $\mathrm{X}^{\prime}$ does not follow the observation that the initially coordinated anionic ligand $X$ is persistent in product 53. However, this does not preclude a concerted pathway via $\mathbf{T S}_{1}$, see Sections 2.1 and 3.1. Further work is needed to explain the low yields for many complexes with cyclic allylic ligands, $[8,132,156]$ and afford some insight on the potential of these complexes to effect various $\mathrm{C}-\mathrm{X}, \mathrm{C}-\mathrm{H}$ or $\mathrm{C}-\mathrm{C}$ bond activations, which delineate a duality with the concerted mechanism of oxidative addition. 


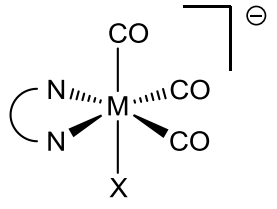

56

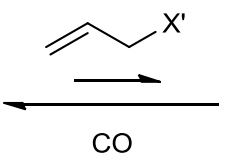

$\mathrm{CO}$

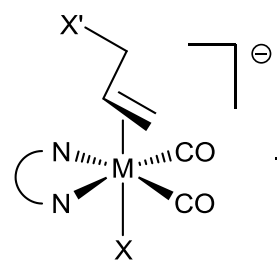

63
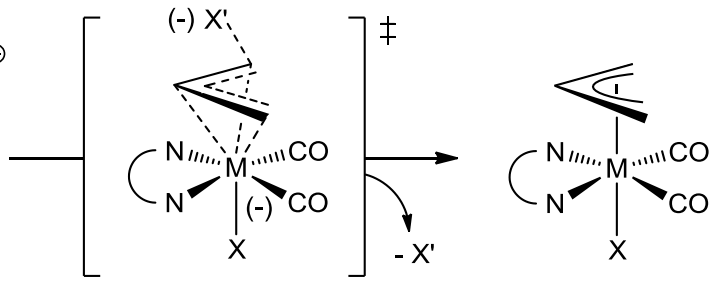

53

Scheme 22. A proposed mechanism pertaining to oxidative addition to the allyl- $X^{\prime}$ moiety, via initial dissociation of a CO ligand and subsequent pre-coordination of the olefin part of allyl- $\mathrm{X}^{\prime}$. [132]

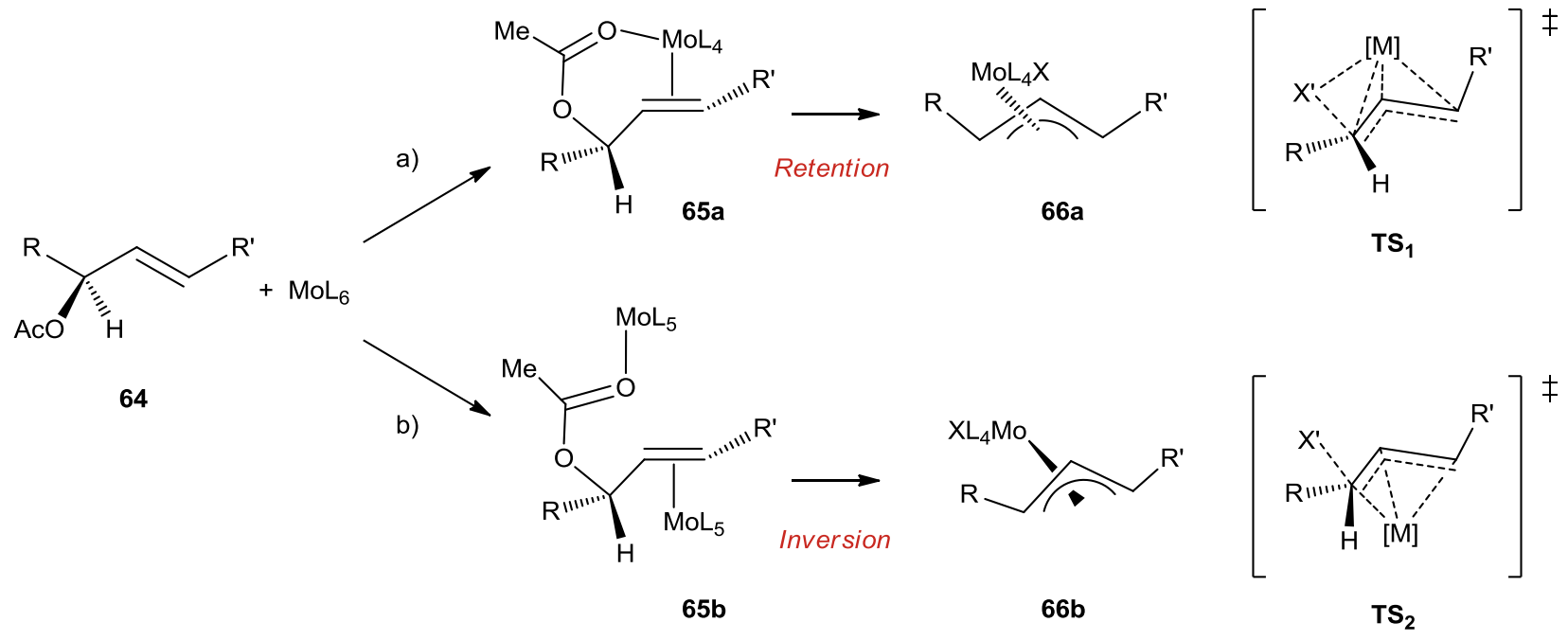

Scheme 23. Oxidative addition by zerovalent molybdenum precursors $\left[\mathrm{MoL}_{6}\right]\left(\mathrm{L}_{6}\right.$ may refer to the hexacarbonyl complex, or various tetracarbonyl, tricarbonyl or dicarbonyl species bearing other L-type ligands; e.g., MeCN) to allyl-acetates, which may proceed with a) retention, in the case of low concentrations of the precursor; or b) inversion, where high concentrations of $\mathrm{ML}_{6}$ are present. The transition states $\mathbf{T S}_{\mathbf{1}}$ and $\mathbf{T S}_{\mathbf{2}}$ are general for oxidative additions to allyl-X that may proceed with retention or inversion, respectively. [153, 154]

The alternative mechanism proposed by Brisdon et al. [132] involves a direct $\mathrm{S}_{\mathrm{N}} 2$ expulsion of the allylic leaving group $X^{\prime}$ by 56 to yield 7-coordinate $\sigma$-allyl intermediate $\mathbf{6 7}$ (Scheme 24), followed by dissociation of CO to furnish $\eta^{3}$-allyl complex $\mathbf{5 3}$. It is not clear whether $\mathrm{S}_{\mathrm{N}} 2\left(\mathbf{T S}_{3}\right)$ or $\mathrm{S}_{\mathrm{N}} 2^{\prime}\left(\mathbf{T S}_{4}\right)$ mechanisms are applicable in this case; whereas $\mathrm{S}_{\mathrm{N}} 2^{\prime}$ reactions are less common, it has been alluded to in allylic substitutions involving rhodium(III) complexes $\left[\mathrm{RhCl}(\mathrm{PPh})_{3}\left(\eta^{3}\right.\right.$-allyl)X] on account of increased substitution of the alkene significantly increasing reaction times. [157] Interestingly, compounds 53, having terminal alkene substitution on the allyl ligand, are obtained without longer reaction times or loss in yield. Increased substitution at the alkene terminus of the allylic substrate is conducive neither to diminished yields, nor longer reaction times. Instead, it appears that substitution at the $\alpha$-carbon bearing the leaving group has this effect, as is the case for $\eta^{3}$-cyclohexenyl derivatives; 
$[8,132]$ although, there are not enough examples to confirm this rationale. In support of a mechanism proceeding via a $\eta^{1}$-allyl intermediate is the mixture of $s y n$ and anti isomers observed on oxidative addition to $(Z)$ substituted allylic substrates in some examples. [158] This is despite the reported lack of the $\eta^{3} \rightleftharpoons \eta^{1} \rightleftharpoons \eta^{3}$ isomerism for $\alpha$-diimine complexes $\mathbf{5 3}$ (vide infra). It is thus proposed that this isomerism leading to the more stable syn isomer is inherent to the oxidative addition step. The $\mathrm{S}_{\mathrm{N}} 2^{\prime}$ mechanism via $\mathbf{T S}_{4}$ could potentially be conducive to this by allowing rotation of the bonds in $\eta^{1}$-allyl intermediate $\mathbf{6 7}$ before coordination of the localised olefinic component, and concomitant or preceding expulsion of a carbonyl ligand. Regarding the feasibility of intermediate 67, 7-coordinate complexes of Group 6 metals are well known (Chart 9). [159-169] Relevant to this discussion is the structural characterisation of some complexes of the type $\left[\mathrm{M}(\mathrm{CO})_{3}\left(\mathrm{~N}^{\urcorner} \mathrm{N}\right) \mathrm{X}_{2}\right]$, such as $\mathbf{6 8}$, and of some orthometalated analogues such as 69.. These complexes are formed because of an intramolecular activation of an aryl $\mathrm{C}-\mathrm{X}$ bond, raising the question as to whether this may be applied to the intermolecular, concerted oxidative addition of allyl- $\mathrm{X}^{\prime}\left(\mathbf{T S}_{\mathbf{5}}\right)$ to the compounds of interest herein. Naturally, this involves coordination of the leaving group $\mathrm{X}^{\prime}$, so this pathway is unlikely for $\mathbf{5 6}$. Furthermore, 70 (Chart 9), where the allyl group is chelated to the nitrogen donor group in an analogous manner to 69, was not prepared by intramolecular oxidative addition by the allyl group, [170] thus raising the question as to whether allylations may proceed intramolecularly to yield unusual chelate motifs.

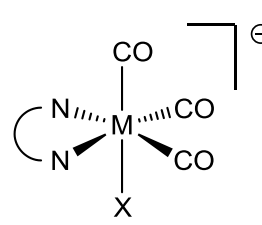

56

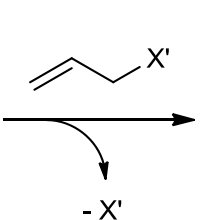

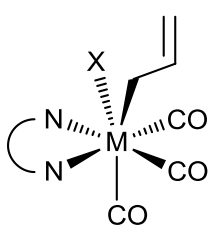

67

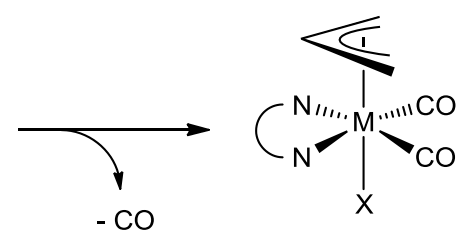

53

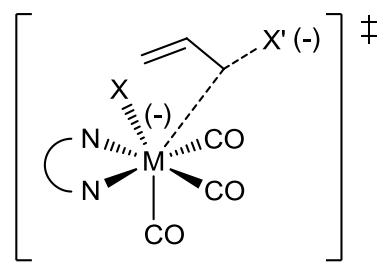

$\mathrm{TS}_{3}$

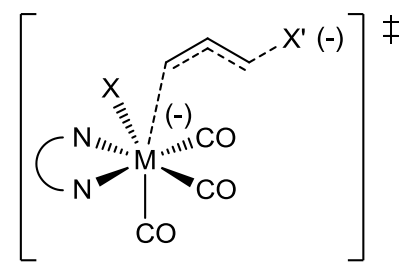

$\mathrm{TS}_{4}$

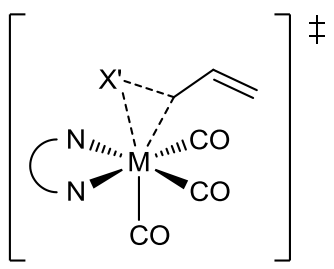

$\mathrm{TS}_{5}$ 
Scheme 24. An alternative mechanism proposed by Brisdon et al. [132] in accompaniment to that delineated in Scheme 22. In this example, 56 undergoes oxidative addition of allyl- $X^{\prime}$ to afford 7-coordinate complex 67. Rapid dissociation of $\mathrm{CO}$ then furnishes $\eta^{3}$-allyl product 53. The various possible transition states $\mathbf{T S}_{\mathbf{3 - 5}}$ regarding the oxidative addition step, as discussed in the main text, are also illustrated.

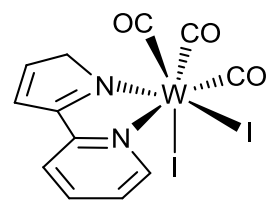

68

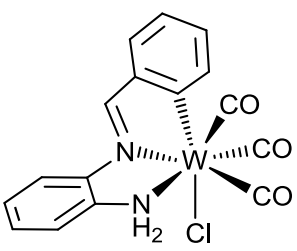

69

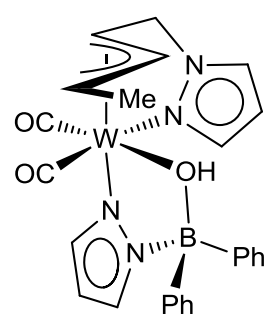

70

Chart 9. 7-Coordinate complexes, such as $\mathbf{6 8}$ and 69, are well known for Group 6 metals, hence supporting the feasibility of $\mathbf{6 7}$ in the mechanism illustrated in Scheme 24. Complex $\mathbf{7 0}$ is an example of a relevant structure, distinguished by an unusual chelate motif, whereby the allylic ligand is joined to one of the $N$-donor ligands via a methylene bridge.

Discussion surrounding the structural features belonging to complexes $\left[\mathrm{M}(\mathrm{CO})_{2}\left(\eta^{3}-\right.\right.$ allyl $\left.)\left(\mathrm{L}^{\frown} \mathrm{L}\right) \mathrm{X}\right]$ and their cationic analogues $\left[\mathrm{M}(\mathrm{CO})_{2}\left(\eta^{3} \text {-allyl }\right)\left(\mathrm{L}^{\frown} \mathrm{L}\right) \mathrm{L}^{\prime}\right]^{+}$imbues the literature, and the corresponding dynamic behaviour in solution is also frequently visited. An analogous exo $\rightleftharpoons$ endo rotamerism pertaining to the allyl ligand, is not generally observed in the neutral complexes $\left[\mathrm{M}(\mathrm{CO})_{2}\left(\eta^{3}\right.\right.$-allyl $\left.)\left(\mathrm{L}^{\frown} \mathrm{L}\right) \mathrm{X}\right]$ (in contrast to the cyclopentadienyl complexes described in Section 2.2), and in the solid state, the open face of the allylic ligand is almost invariably orientated over the carbonyl ligands as in structure $\mathbf{C}$ and $\mathbf{D}$ (Chart 10). From computational studies [114] it is understood that the alignment of the allyl ligand in $\mathbf{C}$ and $\mathbf{D}$ represents the lowest-energy orientation by $c a .40-60 \mathrm{~kJ} \mathrm{~mol}^{-1}$, whereas that with the allyl ligand rotated by $180^{\circ}$ in $\mathbf{C}^{\prime}$ and $\mathbf{D}^{\prime}$ does not represent a potential energy minimum; hence, the latter is the only observed rotamer in variable-temperature NMR studies of disphosphine complexes (vide infra). [171] Detailed studies [114] suggest that the $\pi$-orbitals $\Psi_{1,2,3}$ of the allyl ligand maintain a more efficient overlap with the metal-centred orbitals in $\mathbf{C}$, as opposed to the respective rotamer $\mathbf{C}^{\prime}$. Amongst the remaining three sites of the roughly octahedral coordination sphere, which are occupied by the $\mathrm{L}^{\frown} \mathrm{L}$ and $\mathrm{X}$ ligands, there is a further opportunity for isomerism illustrated by $\mathbf{C}$ and $\mathbf{D}$. The bidentate ligand may occupy the equatorial plane together with the carbonyl ligands 
as in the symmetrical stereoisomer $\mathbf{C}$, or assume an axial arrangement as in the asymmetric stereoisomer $\mathbf{D}$, which is characterised by a pair of enantiomers ( $\mathbf{D}_{\mathbf{1}}$ and $\mathbf{D}_{2}$; Scheme 25). Crystallographic studies show that both structures are common: for examples see Table 7, and accompanying references. Furthermore, there are a few reported examples of a mutually trans-carbonyl stereoisomer $\mathbf{E}$, but this case is rare and apparently only adopted by dmpm (Chart 8) complexes (Table 7; entries 67, 68).

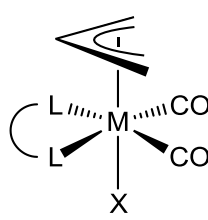

C

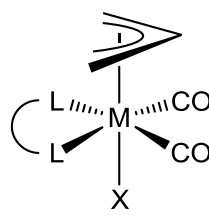

$C^{\prime}$

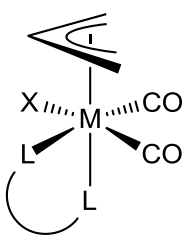

D

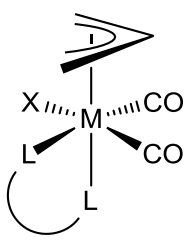

$D^{\prime}$

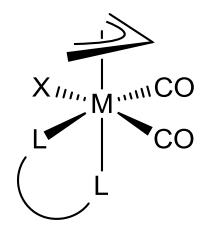

D"

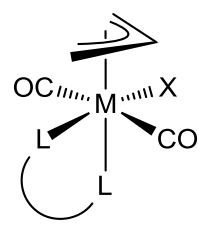

$\mathbf{E}$

Chart 10. Stereoisomers adopted by the various complexes listed in Table 7. $\mathbf{C}$ and $\mathbf{D}$ are the isomers most ubiquitous amongst the solid state structures of complexes explored in Sections 3 and 4 . The $180^{\circ}$ rotamer, $\mathbf{C}^{\prime}$, is not observed, but rotamer $\mathbf{D}^{\prime \prime}$ is adopted by a few isolated examples of dmpm (abbreviations refer to Chart 8) complexes; here the allyl ligand is rotated $c a .135^{\circ}$ from $\mathbf{D}$, such that the open face eclipses the anionic ligand $\mathrm{X}$. Stereoisomer $\mathbf{E}$ is rare, exhibited by some dmpm complexes; the allyl ligand is orientated over one of the mutually trans carbonyl ligands. For cationic complexes, $\mathrm{X}$ is replaced by a neutral two-electron donor $\mathrm{L}$.

Table 7. Group 6 metal allyl carbonyl complexes bearing a variety of mono- and bidentate $N$ - and $P$-donor ligands, with their structural forms as elucidated by their solid state structures.

\begin{tabular}{llll}
\hline Entry & Complex $^{a}$ & Stereoisomer $^{b}$ & Ref. \\
\hline $2,2^{\prime}$-Bipyridine Complexes & & \\
1 & {$\left[\mathrm{Mo}(\mathrm{CO})_{2}\left(\eta^{3}\right.\right.$-allyl $\left.)(\mathrm{bpy}) \mathrm{Br}\right]$} & $\mathrm{C}$ & {$[172]$} \\
2 & {$\left[\mathrm{Mo}(\mathrm{CO})_{2}\left(\eta^{3}\right.\right.$-1-MeO${ }_{2} \mathrm{C}$-allyl $\left.)(\mathrm{bpy}) \mathrm{Br}\right]$} & $\mathrm{C}$ & {$[173]$} \\
3 & {$\left[\mathrm{Mo}(\mathrm{CO})_{2}\left(\eta^{3}\right.\right.$-allyl $\left.)(\mathrm{bpy})(\mathrm{NCS})\right]$} & $\mathrm{C}$ & {$[174]$} \\
4 & {$\left[\mathrm{Mo}(\mathrm{CO})_{2}\left(\eta^{3}\right.\right.$-allyl $\left.)(\mathrm{bpy})\left(\mathrm{CH}_{3}\right)\right]$} & $\mathrm{C}$ & {$[175]$} \\
5 & {$\left[\mathrm{Mo}(\mathrm{CO})_{2}\left(\eta^{3}\right.\right.$-allyl $\left.)(\mathrm{bpy})\left(\mathrm{NCBH}_{3}\right)\right]$} & $\mathrm{C}$ & {$[176]$} \\
6 & {$\left[\mathrm{~W}(\mathrm{CO})_{2}\left(\eta^{3}\right.\right.$-allyl $\left.)(\mathrm{bpy})(\mathrm{NCBH})\right]$} & $\mathrm{C}$ & {$[176]$} \\
7 & {$\left[\mathrm{Mo}(\mathrm{CO})_{2}\left(\eta^{3}\right.\right.$-allyl $\left.)(\mathrm{bpy})(\mathrm{C} \equiv \mathrm{CPh})\right]$} & $\mathrm{C}$ & {$[177]$}
\end{tabular}




\begin{tabular}{|c|c|c|c|}
\hline 8 & {$\left[\mathrm{Mo}(\mathrm{CO})_{2}\left(\eta^{3}\right.\right.$-allyl $\left.)(\mathrm{bpy})\left(\mathrm{CF}_{3} \mathrm{SO}_{3}\right)\right]$} & $\mathrm{D}$ & [178] \\
\hline 9 & {$\left[\mathrm{Mo}(\mathrm{CO})_{2}\left(\eta^{3}\right.\right.$-allyl $\left.)\left(4,4^{\prime}-{ }^{-} \mathrm{Bu}_{2}-\mathrm{bpy}\right) \mathrm{Cl}\right]$} & $\mathrm{C}$ & [179] \\
\hline 10 & {$\left[\mathrm{Mo}(\mathrm{CO})_{2}\left(\eta^{3}\right.\right.$-allyl $)\left(4,4^{\prime}-\mathrm{Me}_{2}\right.$-bpy $\left.) \mathrm{Br}\right]$} & $\mathrm{C}$ & [180] \\
\hline \multicolumn{4}{|c|}{ 1,10-Phenanthroline Complexes } \\
\hline 11 & {$\left[\mathrm{Mo}(\mathrm{CO})_{2}\left(\eta^{3}\right.\right.$-allyl $)($ phen $\left.) \mathrm{F}\right]$} & $\mathrm{C}$ & [181] \\
\hline 12 & {$\left[\mathrm{Mo}(\mathrm{CO})_{2}\left(\eta^{3}\right.\right.$-allyl $)($ phen $\left.) \mathrm{Cl}\right]$} & $\mathrm{C}$ & [175] \\
\hline 13 & {$\left[\mathrm{Mo}(\mathrm{CO})_{2}\left(\eta^{3}\right.\right.$-allyl $)($ phen $\left.) \mathrm{Br}\right]$} & $\mathrm{C}$ & [172] \\
\hline 14 & {$\left[\mathrm{Mo}(\mathrm{CO})_{2}\left(\eta^{3}-1-\mathrm{MeO}_{2} \mathrm{C}\right.\right.$-allyl $)($ phen $\left.) \mathrm{Br}\right]$} & $\mathrm{C}$ & [173] \\
\hline 15 & {$\left[\mathrm{Mo}(\mathrm{CO})_{2}\left(\eta^{3}-1-\mathrm{Ph}\right.\right.$-allyl $)($ phen $\left.)(\mathrm{NCS})\right]$} & $\mathrm{C}$ & [182] \\
\hline 16 & {$\left[\mathrm{Mo}(\mathrm{CO})_{2}\left(\eta^{3}-2-\mathrm{Me}-\right.\right.$ allyl $)($ phen $\left.)(\mathrm{NCS})\right]$} & $\mathrm{C}$ & [183] \\
\hline 17 & {$\left[\mathrm{Mo}(\mathrm{CO})_{2}\left(\eta^{3}-2-\mathrm{Me}\right.\right.$-allyl $)($ phen $\left.)\left(\mathrm{CH}_{3}\right)\right]$} & $\mathrm{C}$ & [177] \\
\hline 18 & {$\left[\mathrm{Mo}(\mathrm{CO})_{2}\left(\eta^{3}\right.\right.$-allyl $)($ phen $\left.)(\mathrm{C} \equiv \mathrm{CPh})\right]$} & $\mathrm{C}$ & [184] \\
\hline 19 & {$\left[\mathrm{Mo}(\mathrm{CO})_{2}\left(\eta^{3}\right.\right.$-allyl $)($ phen $\left.)\left(\mathrm{CF}_{3} \mathrm{SO}_{3}\right)\right]$} & $\mathrm{D}$ & [178] \\
\hline 20 & {$\left[\mathrm{Mo}(\mathrm{CO})_{2}\left(\eta^{3}-2-\mathrm{Me}-\right.\right.$ allyl $)($ phen $\left.)\left(\mathrm{CF}_{3} \mathrm{SO}_{3}\right)\right]$} & $\mathrm{C}$ & [181] \\
\hline 21 & {$\left[\mathrm{Mo}(\mathrm{CO})_{2}\left(\eta^{3}\right.\right.$-allyl $)($ phen $\left.)\left(\mathrm{CF}_{3} \mathrm{CO}_{2}\right)\right]$} & $\mathrm{D}$ & [185] \\
\hline 22 & {$\left[\mathrm{Mo}(\mathrm{CO})_{2}\left(\eta^{3}-1-\mathrm{Me}\right.\right.$-allyl $)($ phen $\left.)\left(\mathrm{CF}_{3} \mathrm{CO}_{2}\right)\right]$} & $\mathrm{D}$ & [185] \\
\hline 23 & {$\left[\mathrm{~W}(\mathrm{CO})_{2}\left(\eta^{3}\right.\right.$-allyl $)($ phen $\left.)(\mathrm{OMe})\right]$} & $\mathrm{C}$ & [186] \\
\hline 24 & {$\left[\mathrm{Mo}(\mathrm{CO})_{2}\left(\eta^{3}-2-\mathrm{Me}-\right.\right.$ allyl $)($ phen $\left.)(\mathrm{OH})\right]$} & $\mathrm{C}$ & [187] \\
\hline 25 & {$\left[\mathrm{Mo}(\mathrm{CO})_{2}\left(\eta^{3}-2-\mathrm{Me}-\right.\right.$ allyl $)($ phen $\left.)(\mathrm{SH})\right]$} & $\mathrm{C}$ & [188] \\
\hline 26 & {$\left[\mathrm{Mo}(\mathrm{CO})_{2}\left(\eta^{3}\right.\right.$-allyl $)($ phen $\left.) \mathrm{NCCH}_{2}\right]$} & $\mathrm{C}$ & [189] \\
\hline 27 & {$\left[\mathrm{Mo}(\mathrm{CO})_{2}\left(\eta^{3}-2-\mathrm{Me}\right.\right.$-allyl $)(\mathrm{phen})(p$ Tol-NH $\left.)\right]$} & $\mathrm{C}$ & [190] \\
\hline 28 & {$\left[\mathrm{Mo}(\mathrm{CO})_{2}\left(\eta^{3}-2-\mathrm{Me}-\right.\right.$ allyl $\left.)(\mathrm{phen})\left(p \mathrm{Tol}_{2}-\mathrm{N}\right)\right]$} & $\mathrm{C}$ & [191] \\
\hline 29 & {$\left[\mathrm{Mo}(\mathrm{CO})_{2}\left(\eta^{3}\right.\right.$-allyl $)($ phen $\left.)(\mathrm{CN})\right]$} & $\mathrm{C}$ & [192] \\
\hline 30 & {$\left[\mathrm{Mo}(\mathrm{CO})_{2}\left(\eta^{3}\right.\right.$-allyl $)\left(2,9-\mathrm{Me}_{2}\right.$-phen $\left.) \mathrm{Cl}\right]$} & $\mathrm{C}$ & [193] \\
\hline
\end{tabular}

Other $\alpha$-Diimine Complexes

$31 \quad\left[\mathrm{Mo}(\mathrm{CO})_{2}\left(\eta^{3}\right.\right.$-allyl $)\left(\mathrm{Xyl}_{2}-\right.$-bian $\left.)(\mathrm{NCS})\right] \quad \mathrm{D}$

$32 \quad\left[\mathrm{Mo}(\mathrm{CO})_{2}\left(\eta^{3}\right.\right.$-allyl $)\left(p \mathrm{ClPh}_{2}\right.$-bian $\left.) \mathrm{Br}\right]$

D 


\begin{tabular}{|c|c|c|c|}
\hline 33 & {$\left[\mathrm{Mo}(\mathrm{CO})_{2}\left(\eta^{3}\right.\right.$-allyl $\left.)\left(1,4-\mathrm{Cy}_{2}-\mathrm{dab}\right) \mathrm{Br}\right]$} & $\mathrm{C}$ & [196] \\
\hline 34 & {$\left[\mathrm{Mo}(\mathrm{CO})_{2}\left(\eta^{3}-2-\mathrm{Me}-\mathrm{allyl}\right)\left(1,4-\mathrm{Cy}_{2}-\mathrm{dab}\right) \mathrm{Cl}\right]$} & $\mathrm{C}$ & [197] \\
\hline 35 & {$\left[\mathrm{Mo}(\mathrm{CO})_{2}\left(\eta^{3}\right.\right.$-allyl $\left.)\left(1,4-\mathrm{Bu}_{2}-\mathrm{dab}\right) \mathrm{Br}\right]$} & $\mathrm{C}$ & [198] \\
\hline 36 & {$\left[\mathrm{Mo}(\mathrm{CO})_{2}\left(\eta^{3}\right.\right.$-allyl $\left.)(\mathrm{dpa}) \mathrm{Br}\right]$} & $\mathrm{C}$ & [199] \\
\hline 37 & {$\left[\mathrm{Mo}(\mathrm{CO})_{2}\left(\eta^{3}-2-\mathrm{Me}-\right.\right.$ allyl $\left.)\left(\kappa^{2}-\mathrm{tpa}\right) \mathrm{Br}\right]$} & $\mathrm{D}$ & {$[200]$} \\
\hline 38 & {$\left[\mathrm{Mo}(\mathrm{CO})_{2}\left(\eta^{3}-2-\mathrm{Me}\right.\right.$-allyl $\left.)\left(\kappa^{2}-\mathrm{tpa}\right)\left(\mathrm{CH}_{3} \mathrm{SO}_{3}\right)\right]$} & $\mathrm{D}$ & {$[200]$} \\
\hline 39 & {$\left[\mathrm{Mo}(\mathrm{CO})_{2}\left(\eta^{3}\right.\right.$-allyl $\left.)(\mathrm{dpzm}) \mathrm{Cl}\right]$} & $\mathrm{C}$ & [201] \\
\hline 40 & {$\left[\mathrm{~W}(\mathrm{CO})_{2}\left(\eta^{3}\right.\right.$-allyl $)\left(3,5-\mathrm{Me}_{2}\right.$-dpzm $\left.) \mathrm{Cl}\right]$} & $\mathrm{C}$ & [201] \\
\hline 41 & {$\left[\mathrm{Mo}(\mathrm{CO})_{2}\left(\eta^{3}\right.\right.$-allyl $\left.)\left(\mathrm{Ph}-3,5-\mathrm{Me}_{2}-\mathrm{dpzm}\right) \mathrm{Br}\right]$} & $\mathrm{C}$ & {$[202]$} \\
\hline 42 & {$\left[\mathrm{Mo}(\mathrm{CO})_{2}\left(\eta^{3}\right.\right.$-allyl $)(2-\mathrm{Me}$-imamim $\left.) \mathrm{Br}\right]$} & $\mathrm{D}$ & [203] \\
\hline 43 & {$\left[\mathrm{Mo}(\mathrm{CO})_{2}\left(\eta^{3}\right.\right.$-allyl $)($ pyim $\left.) \mathrm{Br}\right]$} & $\mathrm{C}$ & {$[159]$} \\
\hline 44 & {$\left[\mathrm{Mo}(\mathrm{CO})_{2}\left(\eta^{3}-2-\mathrm{Me}\right.\right.$-allyl $)($ pyim $\left.) \mathrm{Cl}\right]$} & $\mathrm{C}$ & {$[159]$} \\
\hline 45 & {$\left[\mathrm{Mo}(\mathrm{CO})_{2}\left(\eta^{3}\right.\right.$-allyl $)($ pyim $\left.) \mathrm{CF}_{3} \mathrm{SO}_{3}\right]$} & $\mathrm{D}$ & [204] \\
\hline 46 & {$\left[\mathrm{Mo}(\mathrm{CO})_{2}\left(\eta^{3}-2-\mathrm{Me}\right.\right.$-allyl $\left.)(\mathrm{biim}) \mathrm{Br}\right]$} & $\mathrm{C}$ & {$[205]$} \\
\hline 47 & {$\left[\mathrm{Mo}(\mathrm{CO})_{2}\left(\eta^{3}\right.\right.$-allyl $)(1-\mathrm{Ph}$-pyamim $\left.) \mathrm{Cl}\right]$} & $\mathrm{C}$ & [193] \\
\hline 48 & {$\left[\mathrm{Mo}(\mathrm{CO})_{2}\left(\eta^{3}\right.\right.$-allyl $\left.)(1-\mathrm{Me}, 2-\mathrm{Ph}-\mathrm{pymim}) \mathrm{Cl}\right]$} & $\mathrm{C}$ & [206] \\
\hline 49 & {$\left[\mathrm{Mo}(\mathrm{CO})_{2}\left(\eta^{3}-2-\mathrm{Me}\right.\right.$-allyl $)(1-m \mathrm{AcPh}$-pyamim $\left.) \mathrm{Cl}\right]$} & $\mathrm{C}$ & {$[207]$} \\
\hline 50 & {$\left[\mathrm{Mo}(\mathrm{CO})_{2}\left(\eta^{3}-2-\mathrm{Me}-\right.\right.$ allyl $)(1-p \mathrm{AcPh}-$ pyamim $\left.) \mathrm{Cl}\right]$} & $\mathrm{C}$ & {$[207]$} \\
\hline 51 & {$\left[\mathrm{Mo}(\mathrm{CO})_{2}\left(\eta^{3}\right.\right.$-allyl $)(1-\mathrm{PhOH}$-pyamim $\left.) \mathrm{Cl}\right]$} & $\mathrm{C}$ & {$[208]$} \\
\hline 52 & {$\left[\mathrm{Mo}(\mathrm{CO})_{2}\left(\eta^{3}-2-\mathrm{Me}-\right.\right.$ allyl $\left.)(1-\mathrm{PhOH}-\mathrm{pyamim}) \mathrm{Cl}\right]$} & $\mathrm{C}$ & {$[208]$} \\
\hline 53 & {$\left[\mathrm{Mo}(\mathrm{CO})_{2}\left(\eta^{3}-2-\mathrm{Me}\right.\right.$-allyl $)\left(1-\mathrm{EtO}_{2}\right.$ Et-pyamim $\left.) \mathrm{Cl}\right]$} & $\mathrm{C}$ & [209] \\
\hline 54 & {$\left[\mathrm{Mo}(\mathrm{CO})_{2}\left(\eta^{3}-2-\mathrm{Me}\right.\right.$-allyl $)\left(1-\mathrm{HO}_{2} \mathrm{Pr}-\right.$ pyamim $\left.) \mathrm{Cl}\right]$} & $\mathrm{C}$ & {$[210]$} \\
\hline 55 & {$\left[\mathrm{Mo}(\mathrm{CO})_{2}\left(\eta^{3}\right.\right.$-allyl $)(1-o \mathrm{MeOPh}$-pymim $\left.) \mathrm{Cl}\right]$} & $\mathrm{C}$ & [206] \\
\hline
\end{tabular}

Bidentate Aliphatic Donor Ligand Complexes

$56 \quad\left[\mathrm{Mo}(\mathrm{CO})_{2}\left(\eta^{3}\right.\right.$-allyl $\left.)(\mathrm{en}) \mathrm{Br}\right] \quad \mathrm{D}$

$57 \quad\left[\mathrm{~W}(\mathrm{CO})_{2}\left(\eta^{3}\right.\right.$-allyl $\left.)(\mathrm{en}) \mathrm{Br}\right] \quad \mathrm{D}$

$58 \quad\left[\mathrm{Mo}(\mathrm{CO})_{2}\left(\eta^{3}\right.\right.$-allyl $\left.)(\mathrm{en}) \mathrm{N}_{3}\right]$

D 


\begin{tabular}{|c|c|c|c|}
\hline 59 & {$\left[\mathrm{~W}(\mathrm{CO})_{2}\left(\eta^{3}\right.\right.$-allyl $\left.)(\mathrm{en}) \mathrm{N}_{3}\right]$} & $\mathrm{D}$ & [211] \\
\hline 60 & {$\left[\mathrm{Mo}(\mathrm{CO})_{2}\left(\eta^{3}\right.\right.$-allyl $\left.)(\mathrm{en})\left(\mathrm{NCBH}_{3}\right)\right]$} & $\mathrm{D}$ & {$[176]$} \\
\hline 61 & {$\left[\mathrm{~W}(\mathrm{CO})_{2}\left(\eta^{3}\right.\right.$-allyl $\left.)(\mathrm{en})\left(\mathrm{NCBH}_{3}\right)\right]$} & $\mathrm{D}$ & {$[176]$} \\
\hline 62 & {$\left[\mathrm{~W}(\mathrm{CO})_{2}\left(\eta^{3}\right.\right.$-allyl $\left.)(\mathrm{en})(\mathrm{NCS})\right]$} & $\mathrm{D}$ & {$[212]$} \\
\hline 63 & {$\left[\mathrm{Mo}(\mathrm{CO})_{2}\left(\eta^{3}\right.\right.$-allyl $\left.)(\mathrm{en})(\mathrm{CN})\right]$} & $\mathrm{C}$ & [211] \\
\hline 64 & {$\left[\mathrm{~W}(\mathrm{CO})_{2}\left(\eta^{3}\right.\right.$-allyl $\left.)(\mathrm{en})(\mathrm{CN})\right]$} & $\mathrm{C}$ & [211] \\
\hline 65 & {$\left[\mathrm{Mo}(\mathrm{CO})_{2}\left(\eta^{3}\right.\right.$-allyl $\left.)(\mathrm{dppm}) \mathrm{Cl}\right]$} & $\mathrm{D}$ & {$[213]$} \\
\hline 66 & {$\left[\mathrm{Mo}(\mathrm{CO})_{2}\left(\eta^{3}\right.\right.$-allyl $\left.)(\mathrm{dmpm}) \mathrm{N}_{3}\right]$} & $\mathrm{D}^{\prime \prime}$ & {$[214]$} \\
\hline 67 & {$\left[\mathrm{Mo}(\mathrm{CO})_{2}\left(\eta^{3}\right.\right.$-allyl $\left.)(\mathrm{dmpm})(\mathrm{CN})\right]$} & $\mathrm{E}$ & {$[214]$} \\
\hline 68 & {$\left[\mathrm{~W}(\mathrm{CO})_{2}\left(\eta^{3}\right.\right.$-allyl $\left.)(\mathrm{dmpm})(\mathrm{C} \equiv \mathrm{CPh})\right]$} & $\mathrm{E}$ & {$[214]$} \\
\hline 69 & {$\left[\mathrm{~W}(\mathrm{CO})_{2}\left(\eta^{3}\right.\right.$-1-vinyl-allyl $\left.)(\mathrm{dmpe}) \mathrm{Br}\right]$} & $\mathrm{D}$ & {$[215]$} \\
\hline 70 & {$\left[\mathrm{Mo}(\mathrm{CO})_{2}\left(\eta^{3}\right.\right.$-allyl $\left.)(\mathrm{dppe}) \mathrm{Cl}\right]$} & $\mathrm{D}$ & {$[171]$} \\
\hline 71 & {$\left[\mathrm{Mo}(\mathrm{CO})_{2}\left(\eta^{3}-1-\mathrm{Me}-\mathrm{allyl}\right)(\mathrm{dppe}) \mathrm{Cl}\right]$} & $\mathrm{D}$ & [171] \\
\hline 72 & {$\left[\mathrm{~W}(\mathrm{CO})_{2}\left(\eta^{3}-1-\mathrm{Me}-\right.\right.$ allyl $\left.)(\mathrm{dppe}) \mathrm{Cl}\right]$} & $\mathrm{D}$ & [216] \\
\hline 73 & {$\left[\mathrm{Mo}(\mathrm{CO})_{2}\left(\eta^{3}\right.\right.$-allyl $\left.)(\mathrm{dppe}) \mathrm{N}_{3}\right]$} & $\mathrm{D}$ & {$[217]$} \\
\hline 74 & {$\left[\mathrm{~W}(\mathrm{CO})_{2}\left(\eta^{3}\right.\right.$-allyl $\left.)(\mathrm{dppe})\left(\mathrm{NCBH}_{3}\right)\right]$} & $\mathrm{D}$ & [176] \\
\hline 75 & {$\left[\mathrm{Mo}(\mathrm{CO})_{2}\left(\eta^{3}\right.\right.$-allyl $\left.)(\mathrm{dppe})(\mathrm{NCS})\right]$} & D & [212] \\
\hline
\end{tabular}

Bis(monodentate) Ligand Complexes

$76 \quad\left[\mathrm{Mo}(\mathrm{CO})_{2}\left(\eta^{3}\right.\right.$-allyl $\left.)(\mathrm{MeCN})_{2} \mathrm{Br}\right] \quad \mathrm{C}$

$77 \quad\left[\mathrm{Mo}(\mathrm{CO})_{2}\left(\eta^{3}\right.\right.$-allyl $\left.)(\mathrm{MeCN})_{2} N C S\right] \quad \mathrm{C}$

$78 \quad\left[\mathrm{Mo}(\mathrm{CO})_{2}\left(\eta^{3}\right.\right.$-allyl $\left.)(\mathrm{MeCN})_{2}\left(\mathrm{NCBH}_{3}\right)\right] \quad \mathrm{C}$

$79 \quad\left[\mathrm{Mo}(\mathrm{CO})_{2}\left(\eta^{3}-2-\mathrm{Me}-\right.\right.$ allyl $\left.)(\mathrm{MeCN})_{2} \mathrm{Cl}\right] \quad \mathrm{C}$

$80 \quad\left[\mathrm{Mo}(\mathrm{CO})_{2}\left(\eta^{3}\right.\right.$-allyl $\left.)(\mathrm{py})_{2}\left(\mathrm{PhCO}_{2}\right)\right] \quad \mathrm{D}$

$81 \quad\left[\mathrm{Mo}(\mathrm{CO})_{2}\left(\eta^{3}\right.\right.$-allyl $\left.)(\mathrm{pz})_{2} \mathrm{Br}\right] \quad \mathrm{D}$

$82 \quad\left[\mathrm{Mo}(\mathrm{CO})_{2}\left(\eta^{3}-2-\mathrm{Me}-\mathrm{allyl}\right)(\mathrm{pz})_{2} \mathrm{Cl}\right] \quad \mathrm{D}$

$83 \quad\left[\mathrm{Mo}(\mathrm{CO})_{2}\left(\eta^{3}\right.\right.$-allyl $\left.)\left(\mathrm{Ph}_{2} \text {-imidam }\right)_{2} \mathrm{Cl}\right]$

$\mathrm{D}$

Cationic Complexes 


\begin{tabular}{|c|c|c|c|}
\hline 84 & {$\left[\mathrm{Mo}(\mathrm{CO})_{2}\left(\eta^{3} \text {-allyl }\right)(\mathrm{bpy})(\mathrm{MeCN})\right]^{+}$} & $\mathrm{D}$ & [172] \\
\hline 85 & {$\left[\mathrm{Mo}(\mathrm{CO})_{2}\left(\eta^{3}-1 \text {-vinyl-allyl }\right)(\mathrm{bpy})(\mathrm{MeCN})\right]^{+}$} & $\mathrm{D}$ & [170] \\
\hline 86 & {$\left[\mathrm{Mo}(\mathrm{CO})_{2}\left(\eta^{3} \text {-allyl }\right)(\mathrm{bpy})(\mathrm{py})\right]^{+}$} & $\mathrm{C}$ & [225] \\
\hline 87 & {$\left[\mathrm{Mo}(\mathrm{CO})_{2}\left(\eta^{3} \text {-allyl }\right)(\mathrm{bpy})(4-\mathrm{CN}-\mathrm{py})\right]^{+}$} & $\mathrm{C}$ & [180] \\
\hline 88 & {$\left[\mathrm{Mo}(\mathrm{CO})_{2}\left(\eta^{3} \text {-allyl }\right)(\mathrm{bpy})(4-\mathrm{Me}-\mathrm{py})\right]^{+}$} & $\mathrm{C}$ & [180] \\
\hline 89 & {$\left[\mathrm{Mo}(\mathrm{CO})_{2}\left(\eta^{3} \text {-allyl }\right)\left(4,4^{\prime}-\mathrm{Me}_{2}-\mathrm{bpy}\right)(\mathrm{MeCN})\right]^{+}$} & $\mathrm{D}$ & [180] \\
\hline 90 & {$\left[\mathrm{Mo}(\mathrm{CO})_{2}\left(\eta^{3} \text {-allyl }\right)\left(4,4^{\prime}-{ }^{t} \mathrm{Bu}_{2}-\text { bpy }\right)\left(\mathrm{H}_{2} \mathrm{O}\right)\right]^{+}$} & $\mathrm{D}$ & [179] \\
\hline 91 & {$\left[\mathrm{Mo}(\mathrm{CO})_{2}\left(\eta^{3}-2-\mathrm{Me}-\text { allyl }\right)(\text { phen })\left(\mathrm{H}_{2} \mathrm{O}\right)\right]^{+}$} & $\mathrm{C}$ & [187] \\
\hline 92 & {$\left[\mathrm{Mo}(\mathrm{CO})_{2}\left(\eta^{3}-2-\mathrm{Me} \text {-allyl }\right)(\mathrm{phen})\left(p \mathrm{Tol}-\mathrm{NH}_{2}\right)\right]^{+}$} & $\mathrm{C}$ & [188] \\
\hline 93 & {$\left[\mathrm{Mo}(\mathrm{CO})_{2}\left(\eta^{3} \text {-allyl }\right)(\mathrm{dpa})(\mathrm{MeCN})\right]^{+}$} & $\mathrm{D}$ & [226] \\
\hline 94 & {$\left[\mathrm{Mo}(\mathrm{CO})_{2}\left(\eta^{3}-2-\mathrm{Me}-\text { allyl }\right)(\mathrm{biim})\left({ }^{t} \mathrm{BuNC}\right)\right]^{+c}$} & $\mathrm{C}$ & [205] \\
\hline 95 & {$\left[\mathrm{Mo}(\mathrm{CO})_{2}\left(\eta^{3} \text {-allyl }\right)(\mathrm{dmpm})(\mathrm{MeCN})\right]^{+}$} & $\mathrm{D}^{\prime \prime}$ & [213] \\
\hline 96 & {$\left[\mathrm{Mo}(\mathrm{CO})_{2}\left(\eta^{3} \text {-allyl }\right)(\mathrm{dppe})(\mathrm{MeCN})\right]^{+}$} & $\mathrm{D}$ & [172] \\
\hline
\end{tabular}

Tricarbonyl Complexes

97

$$
\left[\mathrm{Mo}(\mathrm{CO})_{3}\left(\eta^{3}-2-\mathrm{Me}-\mathrm{allyl}\right)\left(\mathrm{Xyl}_{2}-\mathrm{Me}_{2} \mathrm{dab}\right)\right]^{+} \quad \mathrm{D}
$$

\footnotetext{
${ }^{a}$ Refers to Chart 8 for ligand abbreviations.

${ }^{b}$ Illustrated in Chart 10; in the solid state.

${ }^{c}$ The ${ }^{t} \mathrm{BuNC}$ ligand is bound through the carbon atom.
}

Table 7 reveals few clear trends regarding the stereoisomerism of the listed allyl carbonyl complexes. It appears that the adopted stereoisomer is subject to subtle electronic and steric effects from all the ligand types. For example, most $\alpha$-diimine ligands and other unsaturated $N, N^{\prime}$-bidentate donor ligands favour structure $\mathbf{C}$, but some ligands such as bian and tpa (Chart 8) are strongly inclined to $\mathbf{D}$. Strong-field, soft anionic ligands appear to particularly favour isomer $\mathbf{C}$, with $\mathrm{CN}^{-}$even negating the tendency for complexes bearing aliphatic-backbone $N$ - or $P$-donor ligands to adopt the form of stereoisomer $\mathbf{D}$ (entries 63, 64). Conversely, weakly donating anionic ligands such as $\mathrm{CF}_{3} \mathrm{SO}_{3}{ }^{-}$promote structure $\mathbf{D}$, most notably amongst complexes of phen and bpy. Cationic complexes exhibit an apparent proclivity to adopt stereoisomer $\mathbf{D}$, along with heterocyclic monodentate ligand complexes. Acetonitrile complexes of type $\left[\mathrm{M}(\mathrm{CO})_{2}\left(\eta^{3}\right.\right.$-allyl $\left.)(\mathrm{MeCN})_{2} \mathrm{X}\right]$ instead favour $\mathbf{C}$, perhaps reflecting the lower bulk of 
the linear $\mathrm{MeCN}$ ligands. The nature of the allylic ligand appears to have less effect on the stereochemistry of the complex, except for 2-methylallyl complexes exhibiting a decided predisposition for $\mathbf{C}$. This isomerism is further complicated by a dynamic behaviour in solution. Variable-temperature NMR experiments offer the best insight into the interconversion mechanisms and observed isomeric preferences. Such studies are readily found in the literature for diphosphine complexes $\left[\mathrm{M}(\mathrm{CO})_{2}\left(\eta^{3}-\right.\right.$ allyl $\left.\left(\mathrm{P}^{\frown} \mathrm{P}\right) \mathrm{X}\right]$, [171] which are characterised by the existence of a rapid exchange process interconverting three isomeric forms $\mathbf{C}, \mathbf{D}_{\mathbf{1}}$ and $\mathbf{D}_{2}$, the latter two delineating a pair of enantiomers (Scheme 25). This interconversion is achieved by a 'trigonal twist', whereby the $\mathrm{L}_{2} \mathrm{X}$ component of the complex rotates relative to the other trigonal pyramidal motif constructed from the allyl and two carbonyl ligands, through a trigonal prismatic transition state. $[158,171,172,176]$ Such a transformation is reminiscent of the free rotation manifested by the Cp ligand in complexes discussed in Section 2. In the latter case this rotation is largely inconsequential given the symmetry of the ligated Cp moiety, but it is to be expected that the energy barriers to interconversion of $\mathbf{C}, \mathbf{D}_{\mathbf{1}}$ and $\mathbf{D}_{2}$, and their stabilities, will vary with the ligand combinations $\mathrm{L}_{2} \mathrm{X}$. In the ambient-temperature ${ }^{31} \mathrm{P}$ NMR spectrum measured for $\left[\mathrm{Mo}(\mathrm{CO})_{2}\left(\eta^{3}\right.\right.$-allyl $\left.)(\mathrm{dppe})\left(\mathrm{NCBH}_{3}\right)\right](\mathbf{7 1})$, the observed sharp singlet at $52.2 \mathrm{ppm}$ is consistent with an averaged signal from the two phosphorus atoms undergoing the rapid trigonal twist mechanism, which broadens upon cooling to $-90{ }^{\circ} \mathrm{C}$ and eventually becomes resolved into two singlets of equal intensities at 48.0 and $47.1 \mathrm{ppm}$. [176] The non-equivalence of the two phosphorus atoms in 71, manifested in the limiting low-temperature spectrum, is due to the slowing of the rapid trigonal twist mechanism interconverting $\mathbf{D}_{\mathbf{1}}$ and $\mathbf{D}_{\mathbf{2}}$. Since $\mathbf{D}_{\mathbf{1}}$ and $\mathbf{D}_{\mathbf{2}}$ are effectively enantiomers in this circumstance (the interconversion of $\delta$ and $\lambda$ conformations of the diphosphine backbone is rapid in comparison; vide infra), no more resonances are expected; however, in this low-temperature spectrum a broader resonance materialises at $65.9 \mathrm{ppm}$. The latter signal is most likely attributed to a more short-lived occupancy of the symmetric $\mathbf{C}$ isomer on the trigonal twist coordinate, which presumably represents a higher-energy minimum for diphosphine complexes (i.e., $k_{-4}, k_{-6}>k_{4}, k_{6}$; Scheme 25 ), attesting to the marked preference amongst these complexes for structure $\mathbf{D}$ in the solid state (Table 7; entries 65-75). 


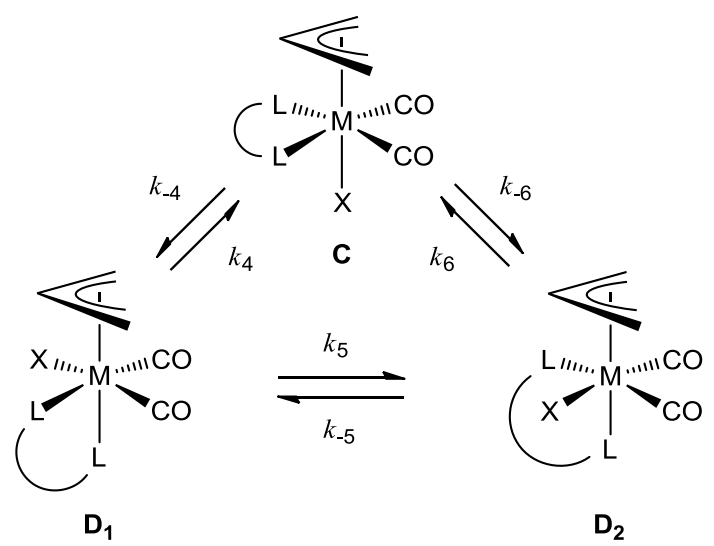

Scheme 25. Rotation of the $\mathrm{L}_{2} \mathrm{X}$ component in complexes $\left[\mathrm{Mo}(\mathrm{CO})_{2}\left(\eta^{3}\right.\right.$-allyl $\left.)\left(\mathrm{L}^{\frown} \mathrm{L}\right) \mathrm{X}\right]$ (and similarly the various other complexes discussed in this section, including cationic $\left[\mathrm{Mo}(\mathrm{CO})_{2}\left(\eta^{3} \text {-allyl }\right)\left(\mathrm{L}^{\frown} \mathrm{L}\right) \mathrm{L}^{\prime}\right]^{+}$complexes and those featuring various chelation motifs), engendered by a trigonal twist relative to the $\left[\mathrm{M}(\mathrm{CO})_{2}\left(\eta^{3}\right.\right.$-allyl $\left.)\right]$ component. The various rate constants $k_{4,5,6}$ and corresponding reverse rate constants illustrate that interconversions between the structures $\mathbf{C}, \mathbf{D}_{\mathbf{1}}$ and $\mathbf{D}_{\mathbf{2}}$ are not necessarily equivalent.

For complexes of type $\left[\mathrm{M}(\mathrm{CO})_{2}\left(\eta^{3}\right.\right.$-allyl $)(\alpha$-diimine $\left.) \mathrm{X}\right]$, fluxional behaviour in solution, as ascertained by variable temperature ${ }^{1} \mathrm{H}$ NMR, contrasts with that of the aforementioned diphosphine complexes. Low solubility precluded studies of the dynamic behaviour of many such compounds,

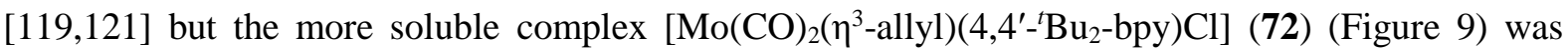
examined spectroscopically. [179] The room-temperature ${ }^{1} \mathrm{H}$ NMR spectrum contains two separate sets of resonances (pertaining to two sets of resonances belonging to $4,4^{\prime}{ }^{t}{ }^{-} \mathrm{Bu}_{2}-\mathrm{bpy}$ ligands and two $\mathrm{A}_{2} \mathrm{M}_{2} \mathrm{X}$ patterns of symmetrical allyl ligands) that ostensibly indicate the presence of two symmetrical isomers. However, this room temperature spectrum is also consistent with the presence of isomer $\mathbf{C}$ and a rapidly interconverting $\mathbf{D}_{1} \rightleftharpoons \mathbf{D}_{2}$ pair. Upon cooling to $-65^{\circ} \mathrm{C}$, the latter set of resonances broaden and diverge, revealing an asymmetric signal pattern which exhibits non-equivalence of the bpy ligand protons, characteristic of the now only slowly interconverting $\mathbf{D}_{\mathbf{1}} / \mathbf{D}_{\mathbf{2}}$ enantiomeric pair $\left(k_{5}, k_{-5}\right)$. This assignment is supported by a) a larger chemical shift divergence of the now inequivalent ortho-protons $\left(\mathrm{H}_{6}\right)$ in comparison to bpy proton resonances more distant from the coordination sphere; b) more pronounced difference in chemical shift between the two allylic $\mathrm{H}_{s y n}$ protons (with accompanying coalescence at higher temperatures) than the $\mathrm{H}_{\text {anti }}$ protons in the low temperature limiting spectrum; and c) NOEs between the ortho-protons and $\mathrm{H}_{\text {syn }} / \mathrm{H}_{\text {meso }}$ in related examples (vide infra). [158,199] In the low temperature spectra, the resonances belonging to structure $\mathbf{C}$ remain sharp and unperturbed. However, 
when the temperature is increased to $55^{\circ} \mathrm{C}$, the two sets of resonances in the room temperature spectrum broaden, thus implying a concomitant slower $\mathbf{C} \rightleftharpoons \mathbf{D}$ interconversion $\left(k_{4}, k_{-4}, k_{6}, k_{-6}\right)$. Most interestingly, the ratios of $\mathbf{C}$ and $\mathbf{D}$ vary between the $\mathrm{CDCl}_{3}$ and $\mathrm{CD}_{2} \mathrm{Cl}_{2}$ solvents; the ratios 1:1 and 2:1, respectively, support the idea that the two isomers are very close in energy, and one might suggest that structure $\mathbf{D}$ is more polar. The foregoing discussion highlights the principal differences in isomerism between diphosphine and $\alpha$-diimine complexes, represented by $\mathbf{7 1}$ and $\mathbf{7 2}$, respectively. For the latter the relative stabilities of the symmetric $(\mathbf{C})$ and asymmetric $(\mathbf{D})$ isomers are similar, but the kinetic barriers to $\mathbf{C} \rightleftharpoons$ $\mathbf{D}$ and $\mathbf{D}_{1} \rightleftharpoons \mathbf{D}_{\mathbf{2}}$ interconversions are markedly different. Indeed, ab initio DFT calculations on the model complex $\left[\mathrm{Mo}(\mathrm{CO})_{2}\left(\eta^{3} \text {-allyl }\right)(\mathrm{bpy})(\mathrm{NCH})\right]^{+}$have demonstrated that structure $\mathbf{D}$ is more stable than $\mathbf{C}$ by just $2 \mathrm{~kJ} \mathrm{~mol}^{-1}$. [172] VT NMR spectra for 71 show, however, that although the interconversion barriers between the 3 isomers on the trigonal twist coordinate (Scheme 25) are relatively low, isomer $\mathbf{C}$ has significantly lower stability than the $\mathbf{D}_{\mathbf{1}} / \mathbf{D}_{\mathbf{2}}$ enantiomeric pair. For further examples see below. Complex 72 was used as a precursor to the cationic complex $\left[\mathrm{Mo}(\mathrm{CO})_{2}\left(\eta^{3} \text {-allyl }\right)\left(4,4^{\prime}-{ }^{t} \mathrm{Bu}_{2}-\mathrm{bpy}\right)\left(\mathrm{H}_{2} \mathrm{O}\right)\right]^{+}(\mathbf{7 3})$ that serves as a particularly intriguing example of an aquo-ligated organometallic compound. Conversely, 73 adopts stereochemistry $\mathbf{D}$ in the solid state. [179] 


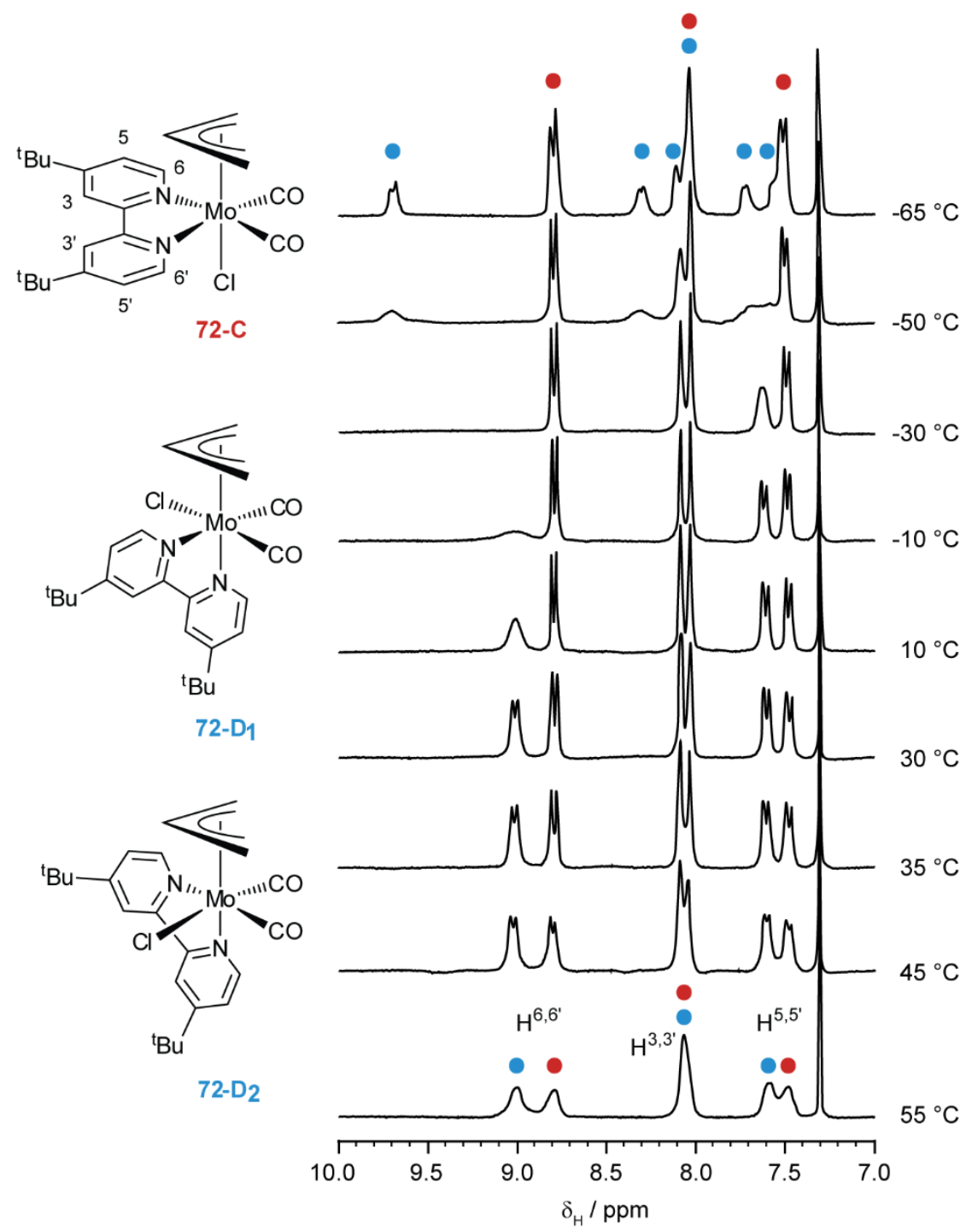

Figure 9. ${ }^{1} \mathrm{H}$ NMR spectra of 72 recorded in $\mathrm{CDCl}_{3}$ over the temperature range $-65{ }^{\circ} \mathrm{C}$ to $55{ }^{\circ} \mathrm{C}$. [179] Shown here are the signals in the region of the $4,4^{\prime}-{ }^{t} \mathrm{Bu}_{2}$-bpy proton signals only; the allylic resonances are overlapping and hence less diagnostic.

A dynamic behaviour in agreement with the aforementioned $\alpha$-diimine complex $\mathbf{7 2}$ is observed in variable-temperature ${ }^{1} \mathrm{H}$ NMR spectra of complexes $\left[\mathrm{Mo}(\mathrm{CO})_{2}\left(\eta^{3} \text {-allyl }\right)(\mathrm{dpa})(\mathrm{MeCN})\right]^{+}(\mathbf{7 4}),[226]$ and $\left[\mathrm{Mo}(\mathrm{CO})_{2}\left(\eta^{3}\right.\right.$-allyl $\left.)(\mathrm{dpa}) \mathrm{Br}\right](\mathbf{7 5})$ [199] (Chart 11), amongst other related complexes based on the $\mathrm{M}(\mathrm{CO})_{2}\left(\eta^{3}\right.$-allyl) fragment (see also Section 4.1). [227] An unusual phenomenon is engendered by the $N$-substitution of the dpa-derivative ligand at the non-coordinated nitrogen, exemplified by the complexes $\left[\mathrm{Mo}(\mathrm{CO})_{2}\left(\eta^{3}\right.\right.$-allyl $\left.)(\mathrm{dpa}) \mathrm{Br}\right](\mathbf{7 5}),\left[\mathrm{Mo}(\mathrm{CO})_{2}\left(\eta^{3}\right.\right.$-allyl $\left.)(\mathrm{dpaCOFc}) \mathrm{Br}\right](\mathbf{7 6})$, and $\left[\mathrm{Mo}(\mathrm{CO})_{2}\left(\eta^{3}-\right.\right.$ allyl)( $\kappa^{2}$-tpa)Br] (77) (Chart 11). Whereas unsubstituted dpa complex $\mathbf{7 5}$ favours structure $\mathbf{C}$ in both the 
solid state and solution, [199] variable temperature ${ }^{1} \mathrm{H}$ NMR studies on $\mathbf{7 7}$ (which adopts structure $\mathbf{D}$ in the solid state) reveal the total absence of $\mathbf{C}$ in solution. At room temperature, $\mathbf{7 7}$ exhibits one set of averaged resonances in $\mathrm{CD}_{2} \mathrm{Cl}_{2}$ that collapse to the asymmetric $\mathbf{D}_{\mathbf{1}} / \mathbf{D}_{2}$ pair. [200] Note that here one pyridine remains uncoordinated while in related complexes intraligand pyridyl exchange occurs. $[227,228]$ It is not clear why such a disparity arises, based on such a remote substituent on the dpaderivative ligand. It may be a consequence of the non-planar 'boat-like' conformation of the sixmembered metallacycle constructed from the $\kappa^{2}$-dpa ligand, and the subsequent steric obtrusions within the coordination sphere and the ligand itself. Conversely, the ${ }^{1} \mathrm{H}$ NMR spectra recorded for the corresponding unsubstituted $\kappa^{2}$-dpa complex (75) between $-40{ }^{\circ} \mathrm{C}$ and room temperature are in fact consistent with three distinguishable isomers present in the ratio 1:0.3:0.1. The two dominant isomers follow a trend over the examined temperature range in accordance with the above discussion for $\mathbf{7 2}$ (Figure 9). The major isomer is assigned to structure $\mathbf{C}$, as found in the solid state of $\mathbf{7 5}$. The subordinate set of resonances due to the second isomer collapses at low temperature, in accordance with a slowly interconverting enantiomeric pair $\mathbf{D}_{\mathbf{1}} / \mathbf{D}_{\mathbf{2}}$. Finally, the minor species (ratio 0.1) corresponds to a set of resonances belonging to a symmetrical structure, which remain intact on cooling. Given the apparent presence of water impurity ( $c a .3 .9 \mathrm{ppm}$ in DMF- $d_{7}$; the downfield shift on lowering the temperature indicates a hydrogen-bonded proton), the minor species may in fact be a cationic $\mathrm{H}_{2} \mathrm{O}$ adduct of the parent compound (vide supra). Indeed, this third species is absent in the corresponding spectrum of $\mathbf{7 4}$, which also appears to exhibit parallel dynamic behaviour to $\mathbf{7 2}$. However, the spectrum indicates that in comparison the $\mathbf{C} \rightleftharpoons \mathbf{D}$ interconversion is faster and the $\mathbf{D}_{\mathbf{1}} \rightleftharpoons \mathbf{D}_{\mathbf{2}}$ interconversion slower for $\mathbf{7 4}$. [226] Upon warming $\mathbf{7 4}$ to room temperature, the inconspicuous advent of a duplicate set of $\mathrm{N}-\mathrm{H}$ signals accompanies the broadening resonances of the two major species, as the $\mathbf{C} \rightleftharpoons \mathbf{D}$ interconversion rate becomes rapid relative to the timescale of the NMR experiment (Figure 10). These emerging signals have been discussed as corresponding to isomers $\mathbf{C}^{\prime}$ and $\mathbf{D}^{\prime}$; the former has been identified, by use of theoretical calculations, to be a local potential energy minimum for the model complex $\left[\mathrm{Mo}(\mathrm{CO})_{2}\left(\eta^{3}-\right.\right.$ allyl)(bpy)(NCH)$]^{+}$, while isomer $\mathbf{D}^{\prime}$ in this case was found to be unstable. [172] The increasing intensity of these peaks with temperature, however, does not logically match this description. An alternative possibility is dissociation of $\mathrm{MeCN}$ from cationic complex 74, and coordination of the 
triflate counterion to form the neutral complex $\left[\mathrm{Mo}(\mathrm{CO})_{2}\left(\eta^{3}\right.\right.$-allyl $\left.)(\mathrm{dpa})(\mathrm{OTf})\right](\mathbf{7 8})$. The OTf $^{-}$ counterion associated with cationic complex $\mathbf{7 4}$ presumably interacts with the $\mathrm{N}-\mathrm{H}$ proton through a hydrogen bond, a similar motif to that reported for the related complex $\left[\mathrm{Mo}(\mathrm{CO})_{2}\left(\eta^{3}-2-\mathrm{Me}-\right.\right.$ allyl $)\left(\kappa^{3}-\right.$ tpa)][OTf]. [200] This association is then largely maintained throughout the temperature range, as demonstrated by the lacking upfield shift of the $\mathrm{N}-\mathrm{H}$ proton resonances belonging to $\mathbf{7 4}$ (isomers $\mathbf{C}$ and D) upon warming to room temperature. However, the pronounced upfield shift of the emerging $\mathrm{N}-\mathrm{H}$ resonances tentatively assigned to $\mathbf{7 8}$ is likely due to an analogous, weaker hydrogen bonding interaction, either with a coordinated OTf ligand in another molecule of $\mathbf{7 8}$, or the OTf-counterion associated with an adjacent molecule of $\mathbf{7 4}$. The former is entirely analogous to the hydrogen bond established between the $\mathrm{N}-\mathrm{H}$ hydrogen and the bromide ligand in the solid state structure of $\mathbf{7 5}$, which also manifests an upfield shift of such proton resonances in the variable temperature ${ }^{1} \mathrm{H}$ NMR spectra, as the interaction is compromised on warming. [199] Logically, the two weak resonances may belong to isomers $\mathbf{C}$ and $\mathbf{D}$ of $\mathbf{7 8}$, the latter presumably being capable of rapid interconversion of the two associated enantiomers $\mathbf{D}_{\mathbf{1}} \rightleftharpoons \mathbf{D}_{\mathbf{2}}$. The concurrence of the coalescence concerning the two major sets of resonances (belonging to $\mathbf{7 4} ; \mathbf{C}$ and the $\mathbf{D}_{\mathbf{1}} / \mathbf{D}_{\mathbf{2}}$ pair) with the hypothesised emergence of $\mathbf{7 8}$, presumably formed via dissociation of $\mathrm{MeCN}$ at higher temperatures, is perhaps no coincidence, and in fact it may be an intermediate through which the $\mathbf{C} \rightleftharpoons \mathbf{D}$ interconversion of $\mathbf{7 4}$ is executed. The accompanying signal of free $\mathrm{MeCN}$ is not observed in the ${ }^{1} \mathrm{H}$ NMR spectrum, but it may be concealed by peak overlap. A mechanism involving dissociation of a neutral ligand $\mathrm{L}$ to form a five-coordinate species has been suggested by Brisdon and Woolf in the case of acetylacetonate (acac) complexes $\left[\mathrm{Mo}(\mathrm{CO})_{2}\left(\eta^{3}-\right.\right.$ allyl)(acac)(L)] (L = py); [229] however, this was unsubstantiated based on NMR spectra at room temperature. For further discussion on the lability of coordinated MeCN see Section 4. 


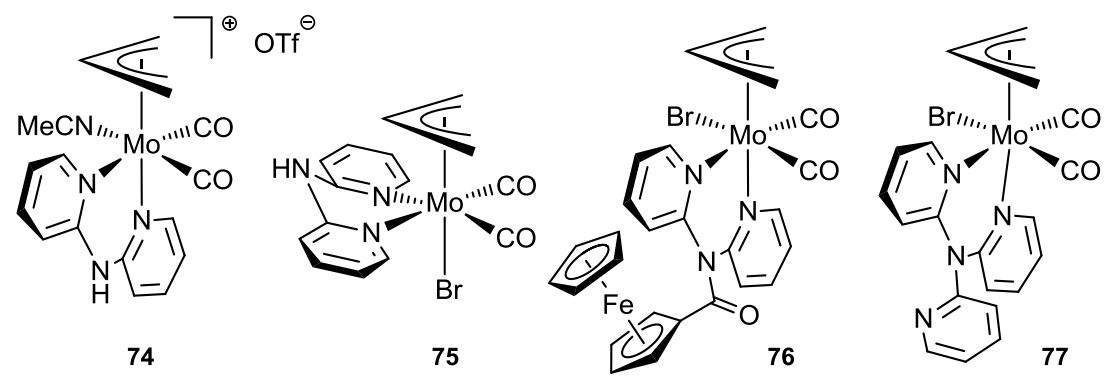

\section{Chart 11.}

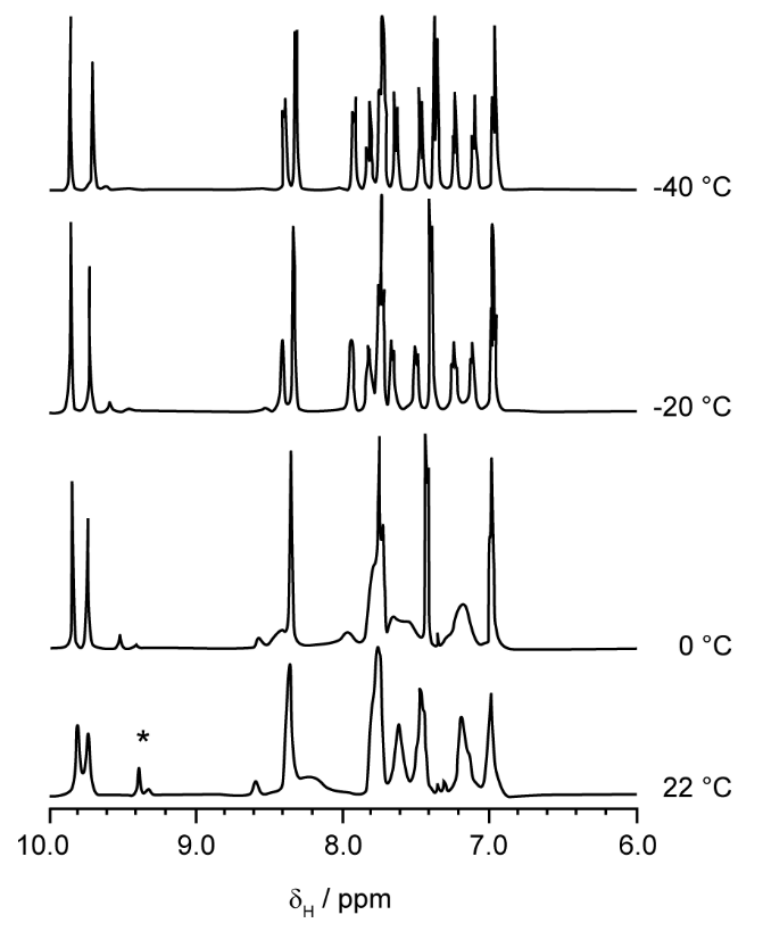

Figure 10. ${ }^{1} \mathrm{H}$ NMR spectra of $\mathbf{7 4}$ in $\mathrm{CD}_{2} \mathrm{Cl}_{2}$, showing the aromatic region. [226] The $\mathrm{N}-\mathrm{H}$ proton resonances that grow as the solution is warmed to room temperature are marked with an asterisk. Some corresponding signals are just observable in the pyridyl proton region, but line broadening and overlap render their identification difficult.

The separation of the two interconversions $\mathbf{C} \rightleftharpoons \mathbf{D}$ and $\mathbf{D}_{\mathbf{1}} \rightleftharpoons \mathbf{D}_{\mathbf{2}}$ in the case of $\mathbf{7 2}$ contrasts to that of $\mathbf{7 1}$ where the dppe ligand appears to rotate more freely. The higher barrier to the trigonal twist interconverting $\mathbf{C}$ and $\mathbf{D}$ in the case of $\alpha$-diimine complexes, is readily attributed to a steric incursion between the rotating $\mathrm{L}_{2} \mathrm{X}$ component and the meso substituent of the allyl group, in the trigonal prismatic intermediate on the trigonal twist coordinate. This may be due to proximity to the allyl ligand 
of a) a bulky anionic ligand, or b) substituents on the $\alpha$-diimine ligand (e.g., the ortho protons of bpy $\left(\mathrm{H}_{6}\right)$ or phen $\left(\mathrm{H}_{2}, \mathrm{H}_{9}\right)$, or various bulky $N$-substituents on 1,4-diazabutadiene (dab) ligands). Presumably, in the case of $\mathbf{7 1}$ and the related chlorido complex $\left[\mathrm{Mo}(\mathrm{CO})_{2}\left(\eta^{3}\right.\right.$-allyl)(dppe)Cl], neither of these factors apply, since the $P$-substituents of the diphosphine ligand are swept back away from the coordination sphere, and the $\mathrm{M}-\mathrm{P}$ bond is longer ( $c a .0 .3 \AA$ longer than $d(\mathrm{M}-\mathrm{N})$ for closely related allyl molybdenum complexes $[175,230]$ ). The trigonal twist mechanism is therefore rapid (indeed, the ${ }^{1} \mathrm{H}$ NMR spectrum of 71 exhibits broad signals even at $-90{ }^{\circ} \mathrm{C}$ [176]), and largely indiscriminate with regards to the $\mathbf{C} \rightleftharpoons \mathbf{D}$ and $\mathbf{D}_{\mathbf{1}} \rightleftharpoons \mathbf{D}_{\mathbf{2}}$ interconversions. The steric incursion between freely rotating $N$ substituents and the meso hydrogen of the allyl ligand is also minimised in the case of $\mathrm{Xyl}_{2}$-bian and $p \mathrm{ClPh}_{2}$-bian, whereby such aryl substituents are planar. Hence, these complexes adopt structure $\mathbf{D}$ in the solid state (Table 7; entries 31,32), in contrast to those with bulkier $N$-substituents (e.g., butyl or cyclohexyl) (entries 33-35). It is evident that the barrier to the interconversion $\mathbf{C} \rightleftharpoons \mathbf{D}$ is increased by substitution at the meso carbon of the allylic ligand, which, to some extent, might explain the marked stereochemical preference for equatorial isomer $\mathbf{C}$ exhibited by $\eta^{3}$-2-Me-allyl complexes in the solid state. Substitution at the termini of the allyl ligand has a noteworthy effect on the solution dynamic behaviour of some complexes, exemplified by that of $\left[\mathrm{Mo}(\mathrm{CO})_{2}\left(\eta^{3}\right.\right.$-crotyl $\left.)(\mathrm{phen})\left(\mathrm{CF}_{3} \mathrm{CO}_{2}\right)\right](\mathbf{7 9})$ and $\left[\mathrm{Mo}(\mathrm{CO})_{2}\left(\eta^{3}\right.\right.$-crotyl $)\left(2,9-\mathrm{Me}_{2}\right.$-phen $\left.)\left(\mathrm{CF}_{3} \mathrm{CO}_{2}\right)\right](\mathbf{8 0})$. [158] Owing to the additional chirality element at the substituted allylic terminus of the $\eta^{3}$-crotyl ligand, the $\mathbf{D}_{1} / \mathbf{D}_{2}$ pair is now diastereotopic in nature, and may be distinguished in the ${ }^{1} \mathrm{H}$ NMR spectra. Subsequently, it has been reported that $\mathbf{7 9}$ manifests

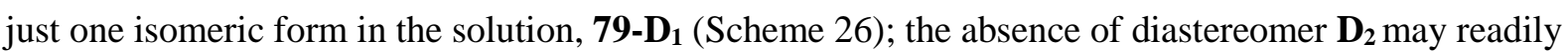
be attributed to the steric hindrance between the ortho- $\mathrm{H}$ of the equatorial pyridyl moiety and the methyl substituent on the allylic ligand. Supporting evidence came from NOEs observed between only one of the ortho protons of the phen ligand, and $\mathrm{H}_{\text {meso }}(16 \%)$ and $\mathrm{H}_{\text {syn }}(11 \%)$ of the allyl ligand (Scheme 26). An analogous steric phenomenon is likely the cause of the contrasting solution ${ }^{1} \mathrm{H}$ NMR spectra recorded for $\mathbf{8 0}$, in which only isomer $\mathbf{C}$ was present over the investigated temperature, substantiated by a small NOE (2\%) observed between one of the methyl substituents on the 2,9-Me - -phen ligand, and $\mathbf{H}_{s y n}$ of the $\eta^{3}$-crotyl ligand (Scheme 26). The destabilisation of both $\mathbf{D}$ diastereomers in this case, as a result of the steric interference between the 2,9-Me $-\mathrm{Me}_{2}$-phen ligand and the syn substituents of the allylic 
ligand, is supported by the equivalent ${ }^{1} \mathrm{H}$ NMR spectrum of the complex $\left[\mathrm{Mo}(\mathrm{CO})_{2}\left(\eta^{3}\right.\right.$-allyl $)\left(2,9-\mathrm{Me}_{2}\right.$-phen $\left.)\left(\mathrm{CF}_{3} \mathrm{CO}_{2}\right)\right]$ bearing the unadorned allyl ligand. Here again, the only observed structure in the solution is equatorial isomer $\mathbf{C}$. The stereochemically rigid solution structures observed by ${ }^{1} \mathrm{H}$ NMR for $\mathbf{7 9}$ and $\mathbf{8 0}$ are consistent with their crystal structures. However, the solution dynamics present in the unsubstituted phen complex $\left[\mathrm{Mo}(\mathrm{CO})_{2}\left(\eta^{3}\right.\right.$-allyl $\left.)(\mathrm{phen})\left(\mathrm{CF}_{3} \mathrm{CO}_{2}\right)\right](\mathbf{8 1})$ mimics that previously discussed for $4,4^{\prime}{ }^{t}{ }^{t} \mathrm{Bu}_{2}$-bpy complex 72 (vide supra), albeit with a reversal in the prevailing isomer (the $\mathbf{C}: \mathbf{D}$ ratio of 1:2 in deuterated tetrachloroethane has been reported for 81). [158]

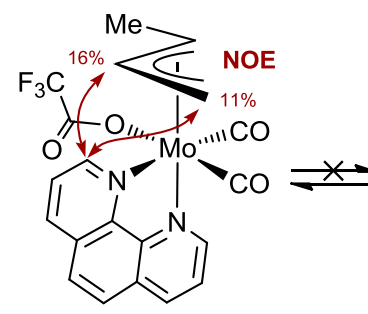

79-D 1

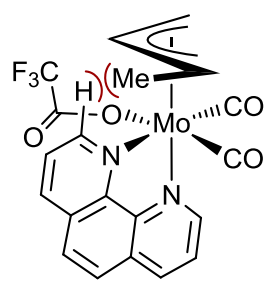

79-D 2

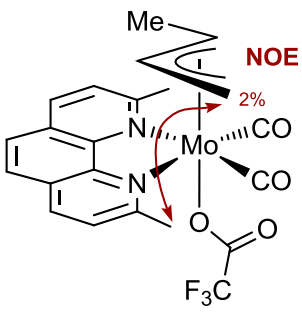

80

Scheme 26.

The fluxionality of these $\alpha$-diimine complexes is elaborate and appears to depend on the exact nature of the $\alpha$-diimine, monodentate $\mathrm{X}$ and allylic ligands. For further discussion in the context of the related amidinato complexes, see Section 4. In parallel to the cyclopentadienyl complexes in Section 2, no evidence for the operant $\eta^{3} \rightleftharpoons \eta^{1} \rightleftharpoons \eta^{3}$ isomerism (Scheme 7a) in $\alpha$-diimine compounds has yet been reported. However, for the related tris(pyrazolyl)borate (Tp) complexes (see Chart 3), the $\pi \rightleftharpoons \sigma \rightleftharpoons \pi$ interconversion of the allyl moiety is well known, [70,231] raising the question as to whether complexes containing dpzm ligands (seen as bearing a resemblance to Tp), also exhibit this behaviour. Regarding the prototypical exo $\rightleftharpoons$ endo isomerism of the Cp complexes (Section 2.2), an analogous rotamerism has been suggested in some cases to account for dynamic processes apparent in variable-temperature ${ }^{1} \mathrm{H}$ NMR spectra of the types of complexes $\left[\mathrm{M}(\mathrm{CO})_{2}\left(\eta^{3}\right.\right.$-allyl $\left.)\left(\mathrm{L}^{\frown} \mathrm{L}\right) \mathrm{X}\right]$ and $\left[\mathrm{M}(\mathrm{CO})_{2}\left(\eta^{3} \text {-allyl }\right)\left(\mathrm{L}^{\frown} \mathrm{L}\right) \mathrm{L}^{\prime}\right]^{+}$. Whilst it appears that none of these complexes adopts structure $\mathbf{C}^{\prime}$ in the solid state, another possibility 
is that in some cases, the $180^{\circ}$ rotamer equilibrates with $\mathbf{C}$ (in solution), which is also consistent with the $\mathbf{C} \rightleftharpoons \mathbf{D}$ and $\mathbf{D}_{\mathbf{1}} \rightleftharpoons \mathbf{D}_{\mathbf{2}}$ isomerism presented above. However, the extent to which $\mathbf{C}^{\prime}$ is apparently present depends largely on the nature of the complex, and is not easy to predict. An analogous equilibration between $\mathbf{D}$ and the respective $180^{\circ}$ rotamer, $\mathbf{D}^{\prime}$, is also reported for some complexes that typically adopt this structure in the solid state: As mentioned previously, this is not the case for diphosphine complexes, [171] but ethylenediamine complexes have been reported to manifest this behaviour, identified by two separate sets of $\mathrm{ABCDX}$ resonance patterns in the low temperature ${ }^{1} \mathrm{H}$ NMR spectra of $\left[\mathrm{M}(\mathrm{CO})_{2}\left(\eta^{3}\right.\right.$-allyl $\left.)(\mathrm{en}) \mathrm{X}\right]\left(\mathrm{M}=\mathrm{Mo}, \mathrm{W} ; \mathrm{X}=\mathrm{Br}, \mathrm{N}_{3}\right)$. [211] The relative concentrations of each rotamer vary amongst the different complexes, most significantly with the anionic ligand, but the major isomer has invariably been established as the lower energy rotamer, D. [114]

Complexes containing bidentate ligands bound via two $P$-donor atoms have received some attention pertaining to their unique dynamic processes and chirality. [171,216,230,232,233] The trigonal twist mechanism (vide supra), which is rapid at room temperature $\left(\Delta G^{\star} \approx 30-45 \mathrm{~kJ} \mathrm{~mol}^{-1}\right)$, has been well described for complexes $\left[\mathrm{M}(\mathrm{CO})_{2}\left(\eta^{3}\right.\right.$-allyl $\left.)\left(\mathrm{P}^{\frown} \mathrm{P}\right) \mathrm{X}\right]\left(\mathrm{P}^{\frown} \mathrm{P}=\mathrm{dmpm}\right.$, dmpe, dppm, dppe; see Chart 8) adopting solid-state stereochemistry $\mathbf{D}$, consistent with the VT NMR features.. At room temperature, the ${ }^{31} \mathrm{P}\left\{{ }^{1} \mathrm{H}\right\}$ NMR spectra exhibit one resonance pertaining to the two ${ }^{31} \mathrm{P}$ nuclei that are magnetically equivalent by virtue of the rapid trigonal twist interconverting the two enantiomers (Scheme 27a). At sufficiently low temperature, the instantaneous structure manifests two separate resonances of equal intensity from each of the now non-equivalent ${ }^{31} \mathrm{P}$ nuclei. This is paralleled by the magnetic non-equivalence of the allylic termini at low temperature, as elucidated by the respective ${ }^{1} \mathrm{H}$ and ${ }^{13} \mathrm{C}$ resonance patterns. [171] The above is applicable to diphosphine complexes, whereby only the chirality at the pseudo-octahedral metal centre is of consequence. The inherent chirality of the diphosphine backbone (Scheme 27d) does not perturb the simplicity of the NMR spectra, unless a chiral diphosphine is used, such that the conformation of the backbone is constrained, and interconversion between $\delta$ and $\lambda$ epimers is arrested. [234] Additional chirality elements may be introduced with asymmetrical Group-16 donor ligands (e.g., $\left.\mathrm{R}_{2} \mathrm{P}^{\frown} \mathrm{AsR}_{2}\right)$, [171] or by substitution at one terminus of the allylic ligand. The latter gives rise to a room temperature ${ }^{31} \mathrm{P}$ spectrum consistent with the non- 
equivalence of the two phosphorus atoms of the diphosphine ligand because of the now diastereotopic nature of the trigonal twist (Scheme 27b). Interestingly, the low temperature spectrum at $-85^{\circ} \mathrm{C}$ reveals the presence of just one diastereomer pertaining to the trigonal twist, presumably due to the reduced steric hindrance with the asymmetric allylic ligand in the preferred isomer (an analogous phenomenon to that observed in 79; Scheme 26). [216] Electronic circular dichroism measurements on the $\eta^{3}$-crotyl complex $\left[\mathrm{Mo}(\mathrm{CO})_{2}\left(\eta^{3}-1-\mathrm{Me}-\right.\right.$ allyl $\left.)(\mathrm{dppe}) \mathrm{Cl}\right]$ (Table 7; entry 71$)$ have revealed that inversion at the stereogenic centre of the methyl-substituted allyl ligand also occurs (Scheme 27c), albeit much more slowly than the trigonal twist fluxionality. [230] Thus, the $(R) \rightleftharpoons(S)$ interconversion of the $\eta^{3}$-crotyl ligand is not manifested in the respective variable temperature NMR spectra, since the two $(R)$ and $(S)$ epimers are effectively enantiomeric. The mechanism by which the stereochemistry of the $\eta^{3}$-crotyl ligand is inverted, is not known. However, rotation about the M-allyl vector and the 'flip' mechanism may be discounted, since the latter is necessarily accompanied by a syn-anti interconversion of the terminal substituents, and neither result in a change of absolute configuration about the stereogenic allylic termini. Hence, the haptotropic $\pi \rightleftharpoons \sigma \rightleftharpoons \pi$ mechanism (Scheme 7a) was proposed as a feasible pathway to the observed slow interconversion. [230] Studies of complexes bearing allylic ligands with different substitution motifs, as well as alternative ancillary ligands, may provide some support for this hypothesis. Indeed, it is already well understood that variation of the anionic and diphosphine ligands (in particular the bite angle of the latter) alters the rate at which the trigonal twist fluxionality occurs. [171] In addition, the choice of anionic ligand has a bearing on the syn/anti isomerism of the substituted allylic ligand. [216] 
a)

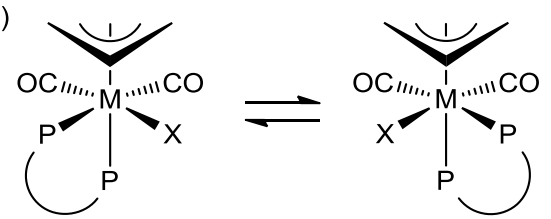

b)
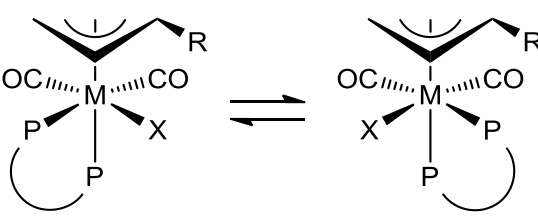

c)
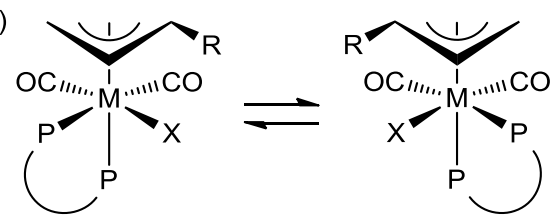

d)
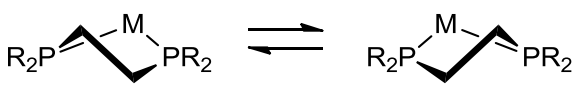

$\lambda$

Scheme 27. Dynamic processes as described for complexes $\left[\mathrm{M}(\mathrm{CO})_{2}\left(\eta^{3}\right.\right.$-allyl $\left.)(\mathrm{P} \cap \mathrm{P}) \mathrm{X}\right]$. The trigonal twist mechanism (also referred to as a turnstile rotation in some literature) delineated in (a), induces an epimerisation that may be approximated to an interconversion between pseudo-enantiomers if the absolute configuration of the pseudo-octahedral metal centre is the only pertinent element of chirality. An additional chiral component may be introduced by substitution of the allyl ligand (b); the stereogenic centre may also undergo an interconversion as shown in (c). The $\delta \rightleftharpoons \lambda$ chirality of the diphosphine ligand shown in (d) is only encountered for chiral phosphines where the backbone is conformationally constrained.

Interestingly, complexes bearing the dmpm ligand exhibit unique features amongst the collated Group 6 metal allyl carbonyls in Table 7. $\left[\mathrm{M}(\mathrm{CO})_{2}\left(\eta^{3}\right.\right.$-allyl $\left.)(\mathrm{dmpm}) \mathrm{Cl}\right]$ (entry 65) adopts the form of stereoisomer $\mathbf{D}$ in the solid state, as is characteristic of the other diphosphine complexes, but the corresponding azido and cationic acetonitrile complexes (Entries 66, 95) are characterised by an orientation of the allyl group over the monodentate ligand, as in D" (Chart 10). The cyanide and alkynyl $(-\mathrm{C} \equiv \mathrm{CR})$ ligands are electronically different from other listed anionic ligands, being $\sigma$-donors but $\pi$ acceptors. Whilst the $\pi$-acidic character of the cyanide ligand is well known, alkynyl ligands are typically stronger $\sigma$-donors and their tendency to undergo $\pi$-back-donation depends on the substituent R. $[235,236]$ Nevertheless, the two similar ligands typically yield complexes with comparable physical properties. [235,237] The examples in Table 7 demonstrate a decided influence on the stereochemical outcome for complexes bearing $\mathrm{N}^{\urcorner} \mathrm{N}$ donor ligands (entries 7, 18, 29, 63, 64, all adopting the form of 
isomer $\mathbf{C}$ ). In the case of the dmpm complexes bearing cyanide and phenylethynyl ligands (entries 67, 68), novel trans isomer $\mathbf{E}$ is the favoured stereochemistry (Figure 11). DFT calculations have shown isomer $\mathbf{E}$ to be more stable for $\left[\mathrm{Mo}(\mathrm{CO})_{2}\left(\eta^{3}\right.\right.$-allyl $\left.)(\mathrm{dmpm})(\mathrm{CN})\right](\mathbf{8 2})$ than cis isomer $\mathbf{D}^{\prime \prime}$ by $12.6 \mathrm{~kJ}$ $\mathrm{mol}^{-1}$. Unlike the aforementioned, highly fluxional diphosphine complex $\mathbf{8 2}$ is reported to be stereochemically rigid in solution at room temperature (Figure 11a). [214] However, a curious feature in the crystal structure of $\left[\mathrm{W}(\mathrm{CO})_{2}\left(\eta^{3}\right.\right.$-allyl $\left.)(\mathrm{dmpm})(\mathrm{C} \equiv \mathrm{CPh})\right]$ (83) (entry 68) challenges this assignment for the tungsten phenylethynyl complex (Figure 11b). The geometry of the allyl ligand in this case appears to parallel that of a tungstenacyclobutane moiety, with all four atoms $\mathrm{C}_{1}, \mathrm{C}_{2}, \mathrm{C}_{3}$ and $\mathrm{W}$ being co-planar and the orientation of the $\alpha$-hydrogens suggesting $\mathrm{sp}^{3}$ hybridisation at the allylic termini. Also noteworthy is the strongly distorted thermal ellipsoid of the meso carbon (Figure 11b). We thus describe a flipping mechanism for pseudo-enantiomer interconversions involving a metallocyclobutane intermediate (Scheme 7b). This invites some investigation of the orbital interactions in the proposed metallacyclobutane intermediate, as well as the roles of the ancillary ligands and the metal centre in stabilising it. Some interesting bonding interactions have previously been described for metallacyclobutane complexes, [238] including a particularly intriguing $\alpha-\beta-(\mathrm{C}-\mathrm{C}-\mathrm{C})$ 'agostic' bond (here, 'agostic' is used loosely, normally being reserved for three-centre two-electron $\mathrm{M}-\mathrm{H}-\mathrm{C}$ interactions [73]). [239] The NMR spectroscopic data in this case are not symptomatic on because of the enantiomerisation which the interconversion may be approximated to. If this proposed dynamic process is either sufficiently slow or fast on the NMR timescale, well resolved ${ }^{1} \mathrm{H}$ and ${ }^{13} \mathrm{C}$ resonance patterns will be ostensibly consistent with just one isomer present.

An interesting feature of the tungsten dmpm complexes is that wide range of NMR active nuclei may be probed conveniently. For example, the proton decoupled ${ }^{31} \mathrm{P}$ NMR spectrum of $\mathbf{8 3}$ yields an $\mathrm{AB}$ quartet pattern consistent with the two expectedly non-equivalent phosphorus donor atoms $\left(\delta{ }^{31} \mathrm{P}\right.$ $\left.=-40.67,-48.35 \mathrm{ppm} ;{ }^{2} J\left({ }^{31} \mathrm{P},{ }^{31} \mathrm{P}\right)=52 \mathrm{~Hz}\right)$. [240] In comparison, 82 exhibits a similar spectrum with chemical shifts $\delta^{31} \mathrm{P}=-11.4,-21.4 \mathrm{ppm} ;{ }^{2} J\left({ }^{31} \mathrm{P},{ }^{31} \mathrm{P}\right)=85.4 \mathrm{~Hz}$ [183]. It is difficult to make any reasoned interpretation regarding the ${ }^{31} \mathrm{P}$ chemical shifts in this case, given the dominance of the paramagnetic term within the shielding tensor of the ${ }^{31} \mathrm{P}$ nucleus (Section 2.3). [241] In addition, the larger coupling 
constant ${ }^{2} J\left({ }^{31} \mathrm{P},{ }^{31} \mathrm{P}\right)$ observed in $\mathbf{8 2}$ is not necessarily indicative of an increased bond strength, since this parameter varies significantly amongst different metals; molybdenum complexes reliably yield larger ${ }^{2} J\left({ }^{31} \mathrm{P},{ }^{31} \mathrm{P}\right)$ values then their tungsten congeners. [242] Indeed, comparison of the two crystal structures (Figure 11) reveals that in fact the shorter $\mathrm{M}-\mathrm{P}$ bonds are found in tungsten complex 83. In addition, spin-spin coupling between the tungsten and phosphorus atoms in 83 is observed; ${ }^{1} J\left({ }^{183} \mathrm{~W},{ }^{31} \mathrm{P}\right)=191.2$ Hz. Despite the apparent tungstenacyclobutanoid structure present in $\mathbf{8 3}$, the disordered structure is also entirely consistent with the presence of the two $180^{\circ}$ rotamers with respect to the allyl ligand, which interconvert via a simple rotation. In support of this, similarly disordered structures have been reported in related complexes. $[23,243,244]$ The crystal structure of the cationic analogue $\left[\mathrm{Mo}(\mathrm{CO})_{2}\left(\eta^{3}-\right.\right.$ allyl $(\mathrm{dmpm})(\mathrm{MeCN})]^{+}$reveals a most unusual bent carbonyl ligand. [213] A non-innocent behaviour involving electron transfer from the counterion, which takes the form of complex $\mathbf{4 9}$, or dinucleation through a $\mu_{2}$-carbonyl, could be the cause for this appearance. The carbonyl ligand hence assumes a bent geometry, avoiding a 19 valence electron metal centre. However, this phenomenon remains to be substantiated, and whilst not entirely unprecedented, [245] previously reported bent carbonyl ligands in crystal structures [246] have often been shown to be due to erroneous measurements. [247]
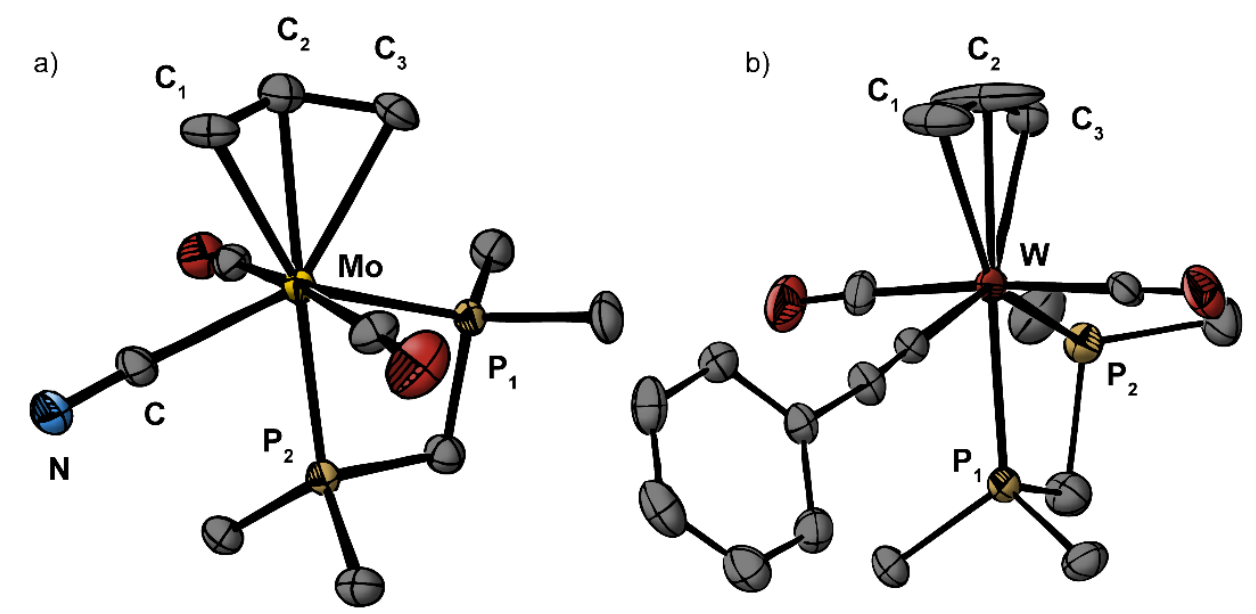

Figure 11. a) Crystal structure of $\left[\mathrm{Mo}(\mathrm{CO})_{2}\left(\eta^{3}\right.\right.$-allyl $\left.)(\mathrm{dmpm})(\mathrm{CN})\right](\mathbf{8 2})$ (Table 7, entry 67); thermal ellipsoids are drawn at $30 \%$ probability. Selected bond lengths $(\AA) ; \mathrm{C}_{1}-\mathrm{Mo} 2.393, \mathrm{C}_{2}-\mathrm{Mo} 2.386, \mathrm{C}_{3}-\mathrm{Mo} 2.459, \mathrm{P}_{1}-\mathrm{Mo}$ 2.501, $\mathrm{P}_{2}-\mathrm{Mo}$ 2.504; and angles (deg.); $\leq \mathrm{C}_{1}-\mathrm{C}_{2}-\mathrm{C}_{3}$ 122.62, $\leq \mathrm{P}_{1}-\mathrm{Mo}-\mathrm{P}_{2}$ 68.16. [214] b) Crystal structure of $\left[\mathrm{W}(\mathrm{CO})_{2}\left(\eta^{3}\right.\right.$-allyl $\left.)(\mathrm{dmpm})(\mathrm{C} \equiv \mathrm{CPh})\right](\mathbf{8 3})($ Table 7 , entry 68); thermal ellipsoids are drawn at $30 \%$ probability. Selected bond lengths $(\AA) ; \mathrm{C}_{1}-\mathrm{W} \quad 2.393, \mathrm{C}_{2}-\mathrm{W} \quad 2.304, \mathrm{C}_{3}-\mathrm{W} \quad 2.338, \mathrm{P}_{1}-\mathrm{W} \quad 2.450, \mathrm{P}_{2}-\mathrm{W} \quad 2.462$; and angles (deg.); $\leq \mathrm{C}_{1}-\mathrm{C}_{2}-\mathrm{C}_{3}$ 153.42, $\leq \mathrm{P}_{1}-\mathrm{W}-\mathrm{P}_{2}$ 67.20. (Redrawn from ref. [239]). 
3.3. Monodentate ligands bound to $\mathrm{M}(\mathrm{CO})_{2}\left(\eta^{3}\right.$-allyl $)(L \mathcal{L})$ : Reactivity and intermediacy in allylic alkylations

Despite their implicit role as intermediates and transient species in catalytic processes, [248,249] as well as their pertinence in biological contexts, [250] relatively few hydroxido (OH), alkoxido (OR) and amido $\left(\mathrm{NR}_{2}\right)$ organometallic complexes of low-valent transition metals have been isolated, in contrast to those based on early transition metals in high oxidation states. [251-255] Facile decomposition pathways are pervasive in these complexes containing non-dative heteroatomic ligands, and their syntheses are typically challenging and not general. [256] Nevertheless, it is this reactivity which makes them interesting. The allyl molybdenum dicarbonyl fragment provides a robust scaffold to which a number of non-dative heteroatomic ligands can be introduced, affording the respective monomeric complex of the type $\left[\mathrm{Mo}(\mathrm{CO})_{2}\left(\eta^{3}\right.\right.$-allyl $)(\alpha$-diimine $\left.) \mathrm{X}\right]\left(\mathrm{X}=\mathrm{OR}, \mathrm{SR}, \mathrm{NR}_{2}, \mathrm{NCCR}_{2}\right.$, etc. $)$. Their synthesis is straightforward in this instance, involving metathesis of parent chlorido complex 84 and $\mathrm{MX}(\mathrm{M}=\mathrm{Na}, \mathrm{K})$, as delineated in Scheme 28 for a number of examples.

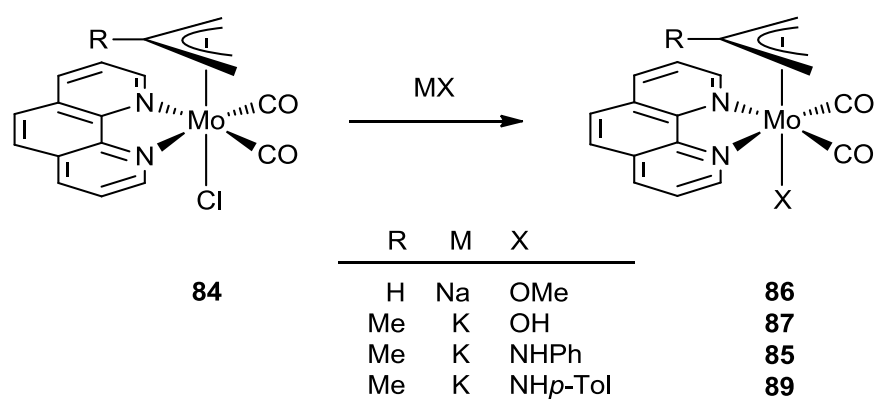

Scheme 28. A substitution reaction installing various non-dative heteroatomic anionic ligands $\mathrm{X}$ via metathesis of parent chloride complex $\mathbf{8 4}$ with the sodium or potassium salts, MX. [187, 190.191, 257]

Amide and alkoxide ligands bound to highly oxidised early transition metals attain appreciable $\pi$-donation into vacant metal d-orbitals, and the nucleophilic character of the heteroatom is thus curtailed. In contrast, their coordination to low-valent metal centres are best described in terms of a strongly polarised single $\mathrm{M}-\mathrm{X}$ bond, where the heteroatom maintains or exhibits enhanced nucleophilicity and the metal is rendered more electrophilic in character. The conflict between 
populated metal $\mathrm{d}_{\pi}$ orbitals and the $\pi$-donor character of the non-dative heteroatomic ligand (the source of reactivity), is exacerbated by donating ancillary ligands which serve to increase the electron density on the metal. The ambi-electronic nature of these complexes is apparent in their reactivity, and characterised by insertion of electrophilic substrates into the $\mathrm{M}-\mathrm{X}$ bond. The reaction of $\mathbf{8 5}$ with carbon disulfide (Scheme 29a) proceeds this way via the intermediate shown in Scheme 29d. [190] The analogous reaction of $\mathbf{8 6}$ with $\mathrm{CS}_{2}$ afforded a new cis-dicarbonyl compound which has thus far eluded characterisation, due to its lacking solubility. [186] The latter reaction proceeds faster, presumably on account of the difficulty encountered with nucleophilic attack by the sterically hindered NHPh group. [190] There is an apparent divergence in reactivity exhibited by corresponding hydroxide complex $\mathbf{8 7}$, which proceeds further to afford hydrosulfide complex $\mathbf{8 8}$, with concomitant loss of carbonyl sulfide (Scheme 30) [188]. Tetracyanoethylene (TCNE) has been shown to react with transition metal alkyl complexes to form keteniminates as the insertion product, [258] and an analogous reaction is identified for amido complex 89 (Scheme 29b). [191] Here, it is suggested that nucleophilic addition to the electron-deficient alkene, with subsequent loss of $\mathrm{HCN}$ (presumably via an $\mathrm{E} 1_{\mathrm{cB}}$ mechanism), precedes a rearrangement as shown in Scheme 29e. Resultant keteniminate complex 90 is not an isolated example, since reaction of $\mathbf{8 4}$ with $\mathrm{K}\left(\mathrm{CH}_{2} \mathrm{CN}\right)$ also yields the respective keteniminate complex with $\mathrm{N}=\mathrm{C}=\mathrm{CH}_{2}$ as the anionic ligand $\mathrm{X},[189]$ in accordance with the metathesis reactions described in Scheme 28. It is quite apparent from the aforementioned reactions that the molybdenum centre in complexes of this type is somewhat 'Lewis-hard' in character, which perhaps makes the reaction of $\mathbf{8 6}$ with dimethylacetylene dicarboxylate (DMAD) quite surprising (Scheme 29c). The rearrangement following the initial nucleophilic attack on the DMAD substrate (Scheme 29f), affixes the carbanion of the enolate to the metal centre, [257] which is associated with its softer character in comparison with the oxygen. It is not apparent whether this is due a suitability in terms of orbital overlap with the metal centre and steric restrictions, or indeed impaired resonance because of the allenolate nature of the carbanion. Alternatively, it may be envisaged that a stabilising effect is present in the $C$-coordinated structure, involving back donation to the electron poor vinyl moiety and an implicit contribution from a carbenoid resonance form. Further reaction of 91 with triflic acid (HOTf) demetallates the vinyl moiety to afford the $(Z)$-alkene and $\left[\mathrm{Mo}(\mathrm{CO})_{2}\left(\eta^{3}\right.\right.$-allyl)(bpy)(OTf)] (92), cf. the hard Lewis acid nature 
of the metal. In addition, a reaction of molybdenum and tungsten congeners of $\mathbf{8 4}$ with the potassium enolate of acetophenone results in preferred $O$-coordination of the enolate in complexes $\mathbf{9 3}$ (Scheme 31). [189] This is in contrast with the coordination of enolate anions at the $\mathrm{CpM}(\mathrm{CO})_{3}(\mathrm{M}=\mathrm{Mo}, \mathrm{W})$ fragment, which are instead bound through the carbon atom. [259,260] It is thus apparent that the acceptor properties of the molybdenum or tungsten centres regarding the preference for hard or soft Lewis base donors are sensitive to the ancillary ligands constituting the coordination sphere. It is perhaps also necessary to consider the steric penalty associated with the $C$-coordination of enolates (or related heteroatom-conjugated carbanions), particularly those that are additionally substituted at the coordinated carbon atom.

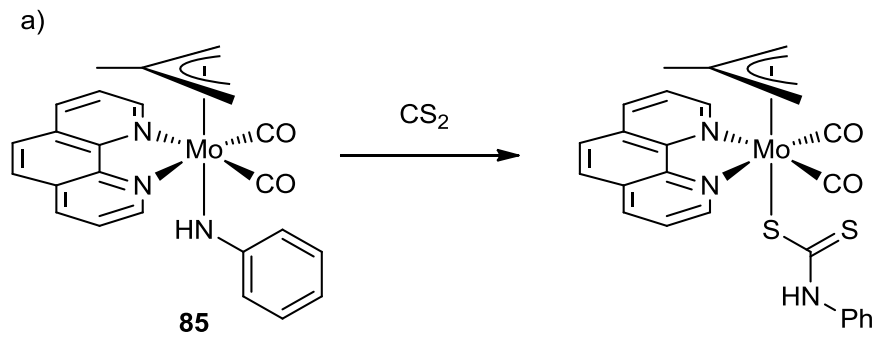

d)

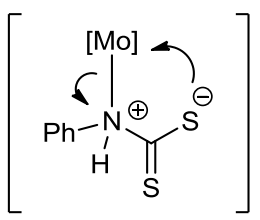

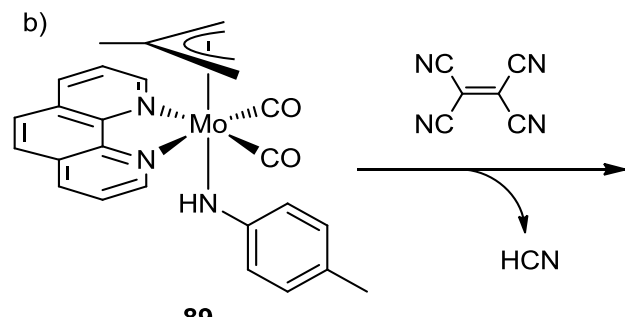

89

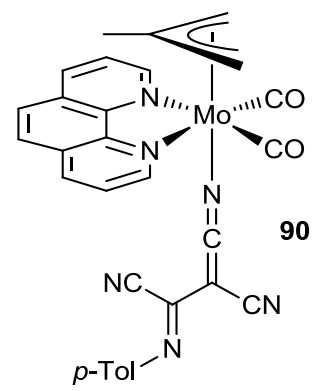

e)

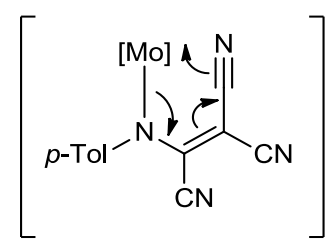

c)

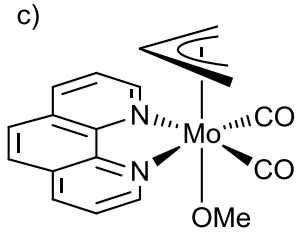<smiles>COCC(=O)OC</smiles>

86

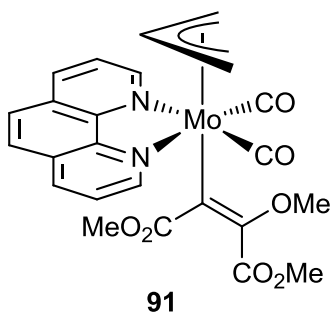

f)<smiles>CCO/C(C(=O)OC)=C(/COC)OC</smiles>

Scheme 29. a) The corresponding reaction of amido complex 85 with carbon disulfide (cf. Scheme 30); an 
insertion reaction proceeds, via the rearrangement shown in d) as the key step. A similar insertion is illustrated in b) with the electron-poor tetracyanoethylene; the rearrangement shown in e) furnishes keteniminate complex $\mathbf{9 0 .}$ The analogous insertion reaction of dimethyl acetylenedicarboxylate with the alkoxide complex $\mathbf{8 6}$ yields vinyl complex 91.

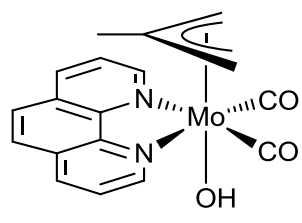

87

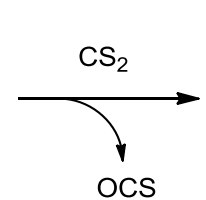

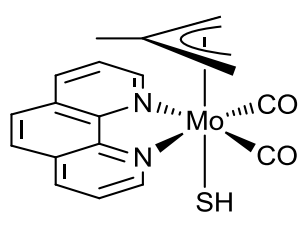

88

Scheme 30. Reaction of hydroxide complex 87 with carbon disulfide to afford corresponding hydrosulfide complex 88. [188]

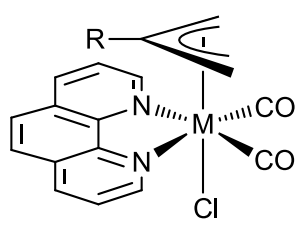

84

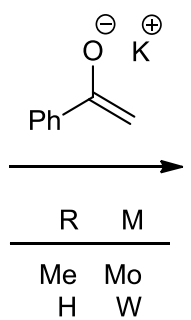

$\mathrm{H} \quad \mathrm{W}$

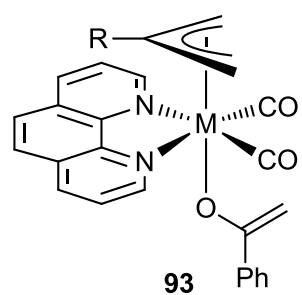

Scheme 31. Reaction of 84 with the potassium enolate of acetophenone. [189]

It is appropriate to mention here the early advances in ascertaining the receptivity of these complexes towards a nucleophilic attack at the allyl ligand. The contemporary molybdenum-based catalyst system for allylic alkylation is now a well-established synthetic tool, achieving high regio- and enantioselectivity with a variety of allylic substrates and stabilised carbon nucleophiles. Some indications of the mechanism of Mo-catalysed allylic alkylation have emerged, but the details remain to be elucidated. Currently used Mo-based catalysts are derived from the original $\alpha$-diimine or diphosphine compounds on which our discussion will focus, together with studies on alkylations using non-stabilised carbanions. For further details see references [144, 145], and [261-265]. The discussion regarding allylic alkylations mediated by the complexes $\left[\mathrm{CpM}(\mathrm{CO})(\mathrm{NO})\left(\eta^{3} \text {-allyl }\right)\right]^{+}$provides some context here (Section 2.5), but there are important mechanistic distinctions to be made concerning the 
trajectory of the nucleophile. The attack by the nucleophile on the external $\pi$-face of the coordinated allyl moiety observed in the cyclopentadienyl complexes $[109,115]$ is likely due to the shielding effect of the Cp ligand, discouraging pre-coordination at the metal centre. [266]

Stoichiometric reactions of the molybdenum complexes $\left[\mathrm{Mo}(\mathrm{CO})_{2}\left(\eta^{3}\right.\right.$-allyl $\left.)\left(\mathrm{L}^{\frown} \mathrm{L}\right) \mathrm{X}\right]\left(\mathrm{L}^{\frown} \mathrm{L}=\right.$ bpy, dppe) with stabilised carbanion nucleophiles to afford olefins was first reported by Trost and Lautens in 1982, [266,267] which was soon developed into a catalytic process employing allylic acetates and zerovalent molybdenum precatalysts of the type $\left[\mathrm{Mo}(\mathrm{CO})_{4}\left(\mathrm{~L}^{\frown} \mathrm{L}\right)\right]\left(\mathrm{L}^{\frown} \mathrm{L}=\right.$ various $\alpha-$ diimine and diphosphine bidentate ligands; the hexacarbonyl was also employed as a catalyst precursor). [152,266-268] Mo-catalysed allylic alkylation in this iteration generally proceeds with overall retention of stereochemistry, like that of the analogous Pd-catalysed reaction. [269,270] However, whilst the latter reaction has been shown to operate via a double-inversion mechanism, the Mo-catalysed reaction is instead understood to achieve net stereochemical outcome via a doubleretention mechanism. [144-146,148-153,271] Some discussion regarding the retentive oxidative addition step to allylic acetates may be found in Section 3.2. The nature of the step involving nucleophilic attack on the coordinated allyl moiety, which has also been shown to proceed with retention of stereochemistry [271] (though this probably depends on the nature of the nucleophile), implies coordination of the nucleophile to the metal centre preceding the formation of an olefinic species. Naturally, the necessity of a cis arrangement of the two reacting ligands within the coordination sphere is expected, being reminiscent of a rudimentary reductive elimination; this stereochemical requirement is delineated by structure $\mathbf{D}$ (Chart 10). Indeed, this conjecture is substantiated by the reactions of unadorned, non-stabilised carbanions with complexes of the type $\left[\mathrm{M}(\mathrm{CO})_{2}\left(\eta^{3}-\right.\right.$ allyl $\left.\left(\mathrm{L}^{\frown} \mathrm{L}\right) \mathrm{Cl}\right]\left(\mathrm{M}=\mathrm{Mo}, \mathrm{W} ; \mathrm{L}^{\frown} \mathrm{L}=\right.$ bpy, phen, dppe), where a clear divergence in reactivity is encountered. The reaction of $\left[\mathrm{M}(\mathrm{CO})_{2}\left(\eta^{3}\right.\right.$-allyl $\left.)\left(\mathrm{N}^{\frown} \mathrm{N}\right) \mathrm{Cl}\right]\left(\mathrm{M}=\mathrm{Mo}, \mathrm{W} ; \mathrm{N}^{\urcorner} \mathrm{N}=\right.$ bpy, phen $)$ with alkyl reagents simply affords the respective metathesis product $\left[\mathrm{M}(\mathrm{CO})_{2}\left(\eta^{3}\right.\right.$-allyl) $\left.\left(\mathrm{N}^{\urcorner} \mathrm{N}\right) \mathrm{R}\right](\mathbf{9 4})(\mathrm{Scheme}$ 32a). [175,177] The strong preference for bpy or phen complexes of this type to adopt structure $\mathbf{C}$ in the solid state, is maintained with the respective alkyl compounds. However, low-temperature NMR spectra demonstrate the lack of an accessible pathway to isomerisation of these complexes from 
structure $\mathbf{C}$ to $\mathbf{D}$ in solution, [175] in contrast to halide congeners (Section 3.2). Thus, no alkylation of the coordinated allyl moiety is observed in this case. The corresponding diphosphine complexes $\left[\mathrm{M}(\mathrm{CO})_{2}\left(\eta^{3}\right.\right.$-allyl $\left.)\left(\mathrm{P}^{\frown} \mathrm{P}\right) \mathrm{Cl}\right](\mathbf{9 5})$ instead customarily adopt stereochemistry $\mathbf{D}$, and stereospecific substitution of the chloride ligand yields the respective alkyl complex, 96, which initially retains the native D stereochemistry of the coordination sphere (Scheme 32b). [240] However, this relatively shortlived intermediate rapidly isomerises to 96-E, in which the carbonyl ligands are in mutually trans positions (Chart 10). [214] It is from here that a slow intramolecular migration of the ligand $\mathrm{R}$ effects the allylic alkylation. It is worth noting that the above observations are applicable to complexes with the dmpm ligand. Complexes bearing dppm and dppe ligands were not directly studied because of their sensitivity and difficulties in obtaining pure samples for characterisation, especially for strongly donating organometallic compounds. Thus, it remains unknown whether they have a propensity to rearrange to structure $\mathbf{E}$ in such a circumstance. [240] It is also not clear whether isomerisation to $\mathbf{E}$ is a requirement for the intramolecular migration of the $C$-bound anionic ligand, since in both $\mathbf{D}$ and $\mathbf{E}$ the ligated carbon nucleophile and the allyl ligand are mutually cis; it may simply be that isomerisation to the, in this case, more stable $\mathbf{E}$ isomer [214] is fast compared to the slow reductive elimination of the olefinic product. 
a)

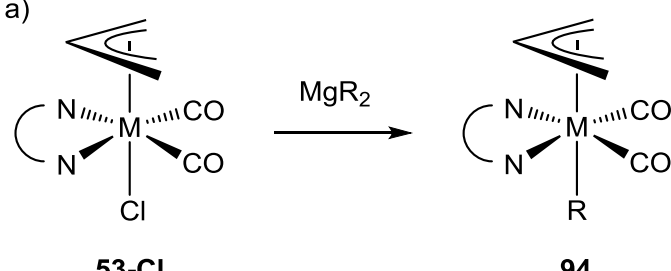

b)

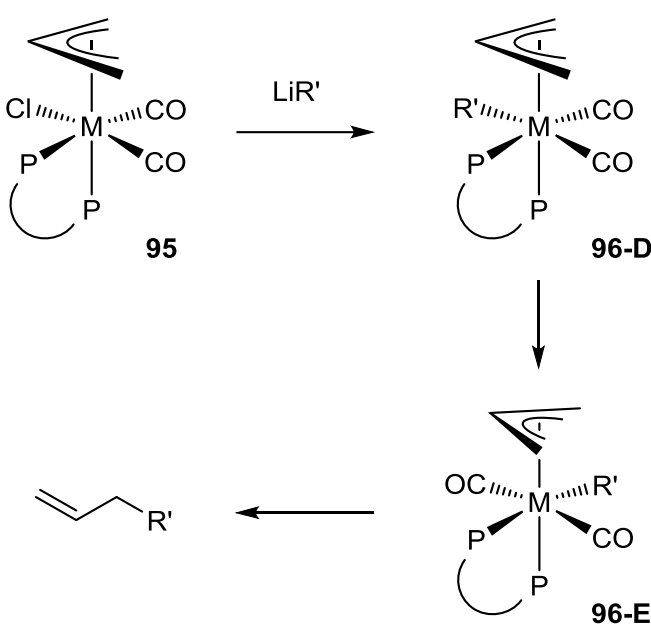

Scheme 32. Comparison between the reactions of non-stabilised carbanions ( $R=$ methyl, ethyl, benzyl) with $\alpha$ diimine complexes $94\left(\mathrm{M}=\mathrm{Mo}, \mathrm{W} ; \mathrm{N}^{\frown} \mathrm{N}=\mathrm{bpy}\right.$, phen), and that of the molybdenum and tungsten dmpm congeners $95\left(\mathrm{R}^{\prime}=\mathrm{Ph},-\mathrm{C} \equiv \mathrm{CPh}, 2\right.$-furyl, 2-thienyl). $\mathrm{C}-\mathrm{C}$ coupling via an intramolecular migration is only observed for the latter, while $\mathbf{9 4}$ is not able to isomerise such that the coordinated carbanion becomes cis to the allyl ligand. [240]

In the case of $\alpha$-diimine complexes $\left[\mathrm{Mo}(\mathrm{CO})_{2}\left(\eta^{3}\right.\right.$-allyl $\left.)\left(\mathrm{N}^{\urcorner} \mathrm{N}\right) \mathrm{X}\right](\mathbf{5 3})$, retentive allylic alkylation is achieved with select nucleophiles. Stabilised carbanions such as those derived from malonic esters make suitable candidates, although less reactive examples thereof, such as $\beta$-ketoester and $\beta$-diketone derived anions, exhibit limited efficacy. [261] It appears that the nature of the nucleophile is a key controlling the stereochemical outcome. The apparent oxophilicity of the molybdenum centre in these complexes mandates the $O$-coordination of the nucleophile. This presumption gets support from the preference for the $O$-coordination demonstrated by the enolate anion of acetophenone in complexes 93 (Scheme 31). This behaviour raises the question as to whether the carbon atom, through which the nucleophile reacts, is able to approach the metal centre cis to the appropriate allylic terminus, to effect the migration as apparently observed in the aforementioned dmpm complexes (vide supra). Alternatively, retentive $\mathrm{C}-\mathrm{C}$ coupling may occur within the coordination sphere away from the metal centre. The preferred structure $\mathbf{C}$, whereby the anionic ligand (in this case, 
the nucleophile) and the coordinated allyl moiety are positioned mutually trans, is not conducive to the intramolecular migration required to effect the retentive alkylation. In view of the aforementioned, it appears that $\alpha$-diimine complexes with bulky anionic ligands maintain this structure without appreciable isomerisation to $\mathbf{D}$. [175] The observation made in Section 3.2 that $\alpha$-diimine complexes of this type bearing anionic ligands such as $\mathrm{CF}_{3} \mathrm{CO}_{2}{ }^{-}$and $\mathrm{CF}_{3} \mathrm{SO}_{3}{ }^{-}$tend to adopt structure $\mathbf{D}$ in the solid state (Table 7), and have also been shown to undergo $\mathbf{C} \rightleftharpoons \mathbf{D}$ interconversion in solution (Section 3.2), [158] is particularly enlightening in this context. A common feature amongst these $O$-coordinated anionic ligands is the availability of more than one donor oxygen for coordination to the metal centre. Indeed, the aforementioned suitable nucleophiles (e.g., $\beta$-diketonates) are no exception. This property suggests that $\mathbf{C} \rightleftharpoons \mathbf{D}$ isomerisation occurs via chelation of the anionic ligand through both oxygen atoms, which circumvents, in this case, the sterically hindered trigonal twist mechanism. This $\kappa^{2}-O, O$ chelate in the intermediate may be accommodated by either haptotropic $\eta^{3} \rightleftharpoons \eta^{1}$ shift of the allyl ligand, or dissociation of one $N$-donor of the $\alpha$-diimine ligand. Though not unknown, (particularly for more flexible ligands such as bpy and some dab derivatives [272]) such dissociation is uncommon; here it may be favoured by the oxophilicity of the Mo centre and the neutralisation of the chelate effect. Salient evidence for the lability of the $\alpha$-diimine ligand with respect to a $\beta$-diketonate moiety comes from the observation that the bpy ligand in $\left[\mathrm{Mo}(\mathrm{CO})_{2}\left(\eta^{3}\right.\right.$-allyl $\left.)(\mathrm{bpy}) \mathrm{Cl}\right](\mathbf{9 8})$ is displaced entirely by sodium acetylacetonate $(\mathbf{9 9})$ in the presence of pyridine, to furnish the complex $\left[\mathrm{Mo}(\mathrm{CO})_{2}\left(\eta^{3}\right.\right.$-allyl)(acac)(py)] (100) (Scheme 33). [273] The crystal structure of $\mathbf{1 0 0}$ [229], has revealed stereochemistry D. (Note that the descriptors $\mathbf{C}$ and $\mathbf{D}$ relate to the symmetric and asymmetric isomers, respectively, and not strictly to the anionic component $\mathrm{X}$ that represents in this case a part of the chelating ligand.)

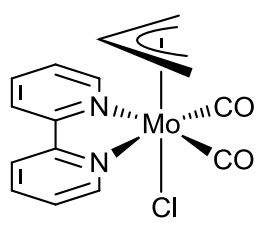

98

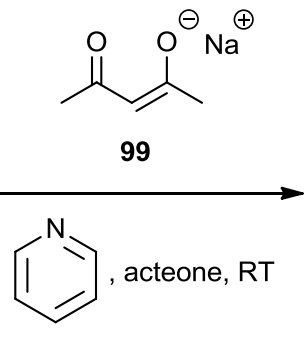

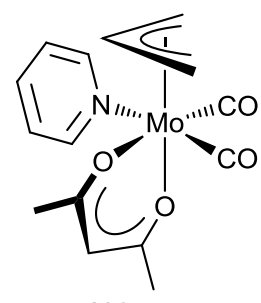

100

Scheme 33. Reaction of $\mathbf{9 8}$ with sodium acetylacetonate (99) in the presence of pyridine, affording complex $\mathbf{1 0 0}$ 
with the chelating bpy ligand entirely substituted by the $\beta$-diketonate moiety. [273]

The complete dissociation of the bpy ligand in $\mathbf{9 8}$ to form $\mathbf{1 0 0}$ raises the question as to whether a species containing a monodentate coordinated nucleophile, or that featuring the $\kappa^{2}-O, O$ coordinated enolate, could be the reactive species. The latter presumably requires a significant puckering of the otherwise almost planar moiety, to allow sufficient approach of the reactive carbon to the molybdenum centre. This phenomenon is exhibited by one of the $\beta$-diketiminate ligands in $\left[\mathrm{Cr}\left(\mathrm{Ph}_{2} \text {-nacnac }\right)_{2} \mathrm{Ph}\right](\mathbf{1 0 1})$ (Figure 12a). [274] Here, the $\alpha$-carbon of the $\mathrm{Ph}_{2}$-nacnac ligand distorts out of the plane to approach the vacant coordination site at the chromium centre, though a formal $\mathrm{Cr}-\mathrm{C}$ bond is not necessarily implied. Note that in this circumstance, the coordination mode adopted by $\mathrm{Ph}_{2}$-nacnac is best described as tridentate $\kappa^{3}-N, C, N$, as opposed to a $\eta^{5}$ motif analogous to a pentadienyl moiety. This unusual out-ofplane bonding presumably results from interactions between the metal and orthogonal ligand $\pi$-orbitals (Figure 12b). [275] The more frequently encountered $\kappa^{2}-N, N$ coordination motif exhibited by ligands of this type is best described by $\sigma$-donation through the in-plane, heteroatom-centred $6 a_{1}$ and $5 b_{2}$ orbitals. A supplementary bonding interaction with the out-of-plane $2 b_{1}$ orbital, which features a significant coefficient at the $\alpha$-carbon, is accomplished by a puckering of the ligand backbone, at little cost to the principal $6 a_{1}$ and $5 b_{2} \sigma$-interactions. [276] Formally, the ligand becomes a six-electron donor, which in the case of $\left[\mathrm{Cr}\left(\mathrm{Ph}_{2} \text {-nacnac }\right)_{2} \mathrm{Ph}\right](\mathbf{1 0 1})$, seems to somewhat quench the apical vacancy left by the square-pyramidal geometry about the chromium centre. 
a)<smiles></smiles>
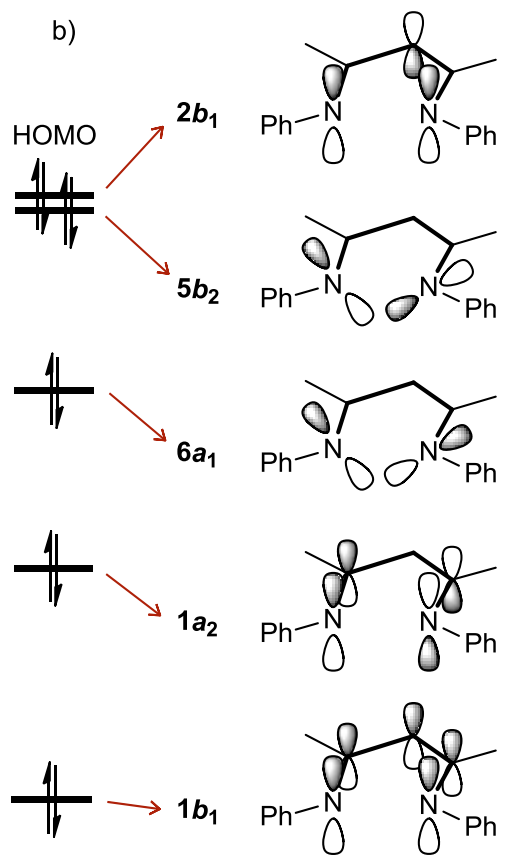

Figure 12. The unusual geometry of the complex $\left[\mathrm{Cr}\left(\mathrm{Ph}_{2} \text {-nacnac }\right)_{2} \mathrm{Ph}\right](\mathbf{1 0 1})$, [274] where one of the $\mathrm{Ph}_{2}$-nacnac ligands is significantly distorted, allowing the $\alpha$-carbon to approach the metal centre within $2.561 \AA$. This phenomenon is attributed to the supplementary donor interaction to stabilise the coordinatively unsaturated, formally $\mathrm{Cr}(\mathrm{III})$ centre, by the HOMO of the nacnac ligand $\left(2 b_{1}\right)$ that features a marked coefficient centred at the $\alpha$-carbon. In this bonding character, the distorted nacnac ligand may be a six-electron donor, as opposed to the usual four electron donation, primarily through $6 a_{1}$ and $5 b_{2}$, exhibited by the planar nacnac ligand.

Rhodium(I) complex 102 gives some insight into the $\mathrm{C}-\mathrm{C}$ coupling induced by the $\alpha$-carbon of the chelated acac ligand (Scheme 34). [277] The carbometalation of the perfluorinated cycloocta-1,5diene $\left(1,5-\mathrm{COD}-\mathrm{F}_{12}\right)$ ligand necessarily proceeds on the same face of the trans olefin, as dictated by the conformational and steric restraint imposed by the ring. This process demonstrates the feasibility of retentive $\mathrm{C}-\mathrm{C}$ coupling at the $\alpha$-carbon of the coordinated enolate nucleophile. Presumably, this reaction proceeds from the precursor $\left[\mathrm{Rh}(\mathrm{CO})_{2}(\mathrm{acac})\right](\mathbf{1 0 3})$, via substitution of a carbonyl ligand with $\eta^{2}-1,5-$ COD-F $\mathrm{F}_{12}$, followed by concerted 1,4-addition of the bound olefin carbons across the rhodacyclic moiety constructed from the acac ligand $\left(\mathbf{T S}_{\mathbf{6}}\right)$. This purported cycloaddition of fluorinated $\mathrm{C}=\mathrm{C}$ bonds to $\beta$ diketonatometallacycles has also been observed in other systems. [278] The acac distortion mentioned 
above is required for effective orbital overlap, and the proximity of the $\alpha$-carbon may allow the metal to directly mediate the $\mathrm{C}-\mathrm{C}$ coupling. The latter suggestion is consistent with the fact that the relatively electron deficient and strained olefin is presumably strongly bound to the metal centre (rhodacyclopropane), which is then likely involved in $\mathrm{C}-\mathrm{C}$ coupling. A pericyclic construct could also describe the mechanism by which allylation of the diketonate moiety occurs in the allylmolybdenum systems. However, in this case, the $\mathrm{C}-\mathrm{C}$ bond formation could conceivably occur remotely from the metal centre, being reminiscent of a [3,4]-sigmatropic rearrangement (Scheme 35). Some evidence for this conjecture comes from computational studies that focused on the coupling of two allyl moieties about a palladium(II) centre, where it was ascertained that $\mathrm{C}-\mathrm{C}$ coupling through the non-coordinated allylic termini in a bis $\left(\eta^{1}\right.$-allyl $)$ species represented the lowest energy pathway. [279] Whereas allylic alkylation was reported to eventually proceed for 100, [266] the suggested mechanism illustrated in Scheme 35 indicates that 104-D is unreactive. Complex 100 has been shown to exhibit a relatively slow equilibrium between two isomers assigned as $\mathbf{D}$ (major) and $\mathbf{C}$ (minor); [273] this $\mathbf{C} \rightleftharpoons \mathbf{D}$ isomerism has been thoroughly discussed in Section 3.2. This phenomenon was also observed in complexes $\left[\mathrm{Mo}(\mathrm{CO})_{2}\left(\eta^{3}\right.\right.$-allyl)(acac)L] (104) and attributed to the trigonal twist mechanism (Scheme 25). [279] In accordance with this presumption, the analogous complex 105 (Scheme 36), whereby the ligand $(\mathrm{L}=$ $\mathrm{NMe}_{2}$ ) is tethered to the allylic moiety, apparently does not undergo allylation of the coordinated acac moiety. No reaction is observed even in the presence of the more reactive diethyl malonate. [280] This observation is readily explained by the lack of feasible pathway from adopted structure $\mathbf{D}$ to $\mathbf{C}$, enforced by the allylic tether. Instead, complexes of this type have displayed some preliminary utility in stereoand regioselective reactions with aldehydes to form homoallylic alcohols. [281]

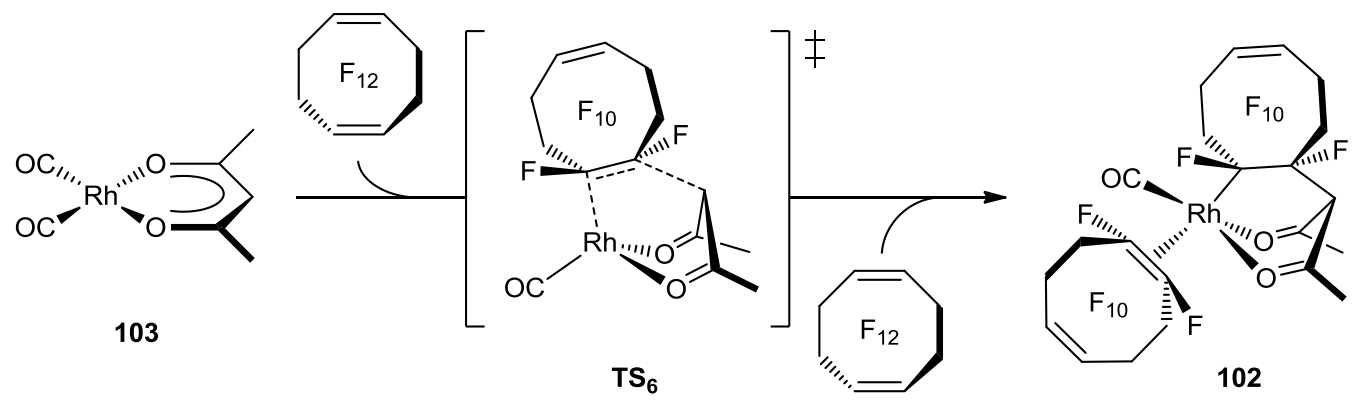


Scheme 34. The reaction of rhodium(I)-acac complex 103 with two equivalents of perfluorinated cycloocta-1,5diene. The isolated product (102) apparently reveals the $\eta^{2}$-coordination of one molecule of 1,5-COD-F 12 , while the other undergoes 1,4-insertion via TS6 into the rhodacycle constructed from the chelating acac moiety. The trans stereochemistry of the fluorine substituents is preserved during the apparent $\left[\pi^{2}+\left(\sigma^{2}+\pi^{2}\right)\right]$ cycloaddition. [277]
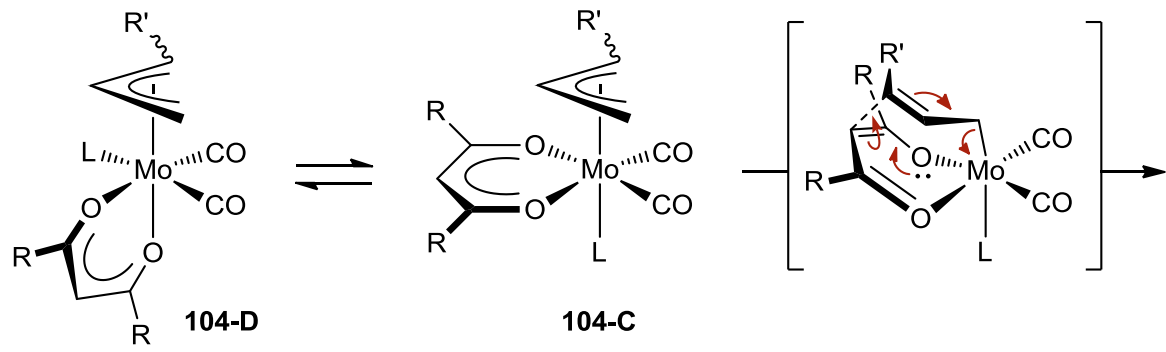<smiles>[R]C(=O)C(C([R])=O)C([R])C=C</smiles>

Scheme 35. A plausible mechanistic rationale involving a chelating nucleophile that undergoes stoichiometric allylic alkylation reactions. This suggested mechanism stipulates the isomersation of 104-D to 104-C, where 104D is the structure found in the solid state. The $\eta^{3} \rightarrow \eta^{1}$ isomerism of the allyl ligand then provides sufficient orbital overlap of the terminal allylic position with the nucleophilic $\alpha$-carbon of the $\beta$-diketonate moiety. Several arrangements that acquire this overlap may be envisaged, resulting in the various observed organic products encompassing diverse stereo- and regiochemistry.

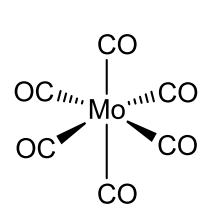<smiles>[R]C(/C=C/CCI)OC(C)=O</smiles>

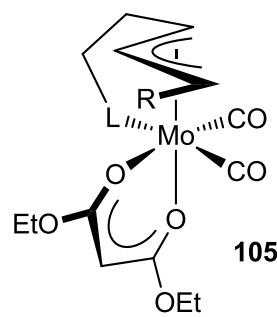

105

Scheme 36. Under conditions that usually permit allylic alkylation, use of allylic acetates bearing tethered functional groups (e.g., $\mathrm{L}=\mathrm{NMe}_{2}$ ) capable of binding to the metal centre, yields complex 105 from parent molybdenum hexacarbonyl. The product is reported to be stable towards alkylation of the allylic substrate (prolonged heating at $150{ }^{\circ} \mathrm{C}$ did not result in any decomposition of 105), even in the presence of the more reactive diethyl malonate. For $\mathrm{L}=\mathrm{SMe}$ the product is unstable but the nature of the thermal decomposition has not been reported. [280]

Alternatively, a similar mechanism to allylic alkylation can be envisaged, involving $\mathrm{C}-\mathrm{C}$ coupling between the dissociated terminus of the $\eta^{1}$-allylic substrate and the nucleophile bound in a monodentate fashion (Scheme 37). In this case the chelation of the nucleophile (vide supra) may instead simply constitute an intermediate through which $\mathbf{C} \rightleftharpoons \mathbf{D}$ isomerism is executed, in order to place the nucleophile cis to the allylic termini. Essentially, there is a requirement for the nucleophile to be coordinated cis to the allylic group, and this monodentate arrangement may indeed be achieved from 
either 104-C or 104-D (Scheme 35). It is reasonable to assume that this pathway is more applicable to diphosphine (e.g., dppe, dppm) coordinated precursors, since stereochemistry $\mathbf{D}$ is highly favoured in this case. In stoichiometric reactions involving, for example, $\left[\mathrm{Mo}(\mathrm{CO})_{2}\left(\eta^{3}-\mathrm{R}\right.\right.$-allyl $\left.)(\mathrm{dppe}) \mathrm{Cl}\right]$, metathesis with the sodium enolate should lead directly to $\mathbf{1 0 6}-\mathbf{D}_{\mathbf{1}}$ or $\mathbf{1 0 6}-\mathbf{D}_{2}$, depending on the stereochemistry of the starting material. The conformational freedom of the $\beta$-diketonate moiety in the monodentate coordination mode seemingly lends itself to more efficient $\mathrm{C}-\mathrm{C}$ coupling, since a significant rotation of the allyl ligand from its favoured conformation eclipsing the carbonyl ligands (Section 3.2), is not required to accompany the $\eta^{3} \rightarrow \eta^{1}$ haptotropic shift in the migration towards the $\alpha$-carbon of the nucleophile. Scheme 38 illustrates the difference in stoichiometric allylic alkylations mediated by bpy and dppe complexes $\left[\mathrm{Mo}(\mathrm{CO})_{2}\left(\eta^{3}\right.\right.$-crotyl $\left.)\left(\mathrm{L}^{\frown} \mathrm{L}\right) \mathrm{Cl}\right](\mathbf{1 0 7}$ and $\mathbf{1 0 8}$, respectively) with regard to the regioselectivity of the reactions, when the sodium salt of 2-carbomethoxycyclopentanone is used as a nucleophile. [267] These stoichiometric reactions are markedly improved on addition of triphenylphosphine, an observation previously attributed to the displacement of the chloride ligand by $\mathrm{PPh}_{3}$ to furnish a cationic adduct [266] that is then more susceptible to an attack by the nucleophile at the metal centre. In light of this, the added pyridine in the reaction delineated by Scheme 33 assumes a similar role. An additional role of $\mathrm{PPh}_{3}$ in the reaction might be its ability to stabilise the molybdenum( 0$)$ fragment as a leaving group, on account of its modest $\pi$-acceptor properties; this is consistent with the reportedly slow progress of the $\mathrm{C}-\mathrm{C}$ coupling in $\mathbf{1 0 0}$ (in the absence of $\mathrm{PPh}_{3}$ ). Perhaps related is the requirement of a source of $\mathrm{CO}$ in the synchronous Mo-catalysed allylic alkylation reaction; the isolated $\eta^{3}$-allyl intermediate does not react with nucleophiles without the presence of $\left[\mathrm{Mo}(\mathrm{CO})_{6}\right]$ or under a $\mathrm{CO}$ pressure. [262] Here, some attention must be drawn to the discussion in Section 3.2 surrounding the mechanism of oxidative addition to allylic substrates. Scheme 24 illustrates a proposed mechanistic pathway involving a 7-coordinate, $\eta^{1}$-allyl tricarbonyl intermediate; with consideration of the principle of microscopic reversibility, perhaps this intermediate could play a role in the latter elementary steps of alkylation. 
<smiles>[R]C=CCC(C([R])=O)C([R])=O</smiles>

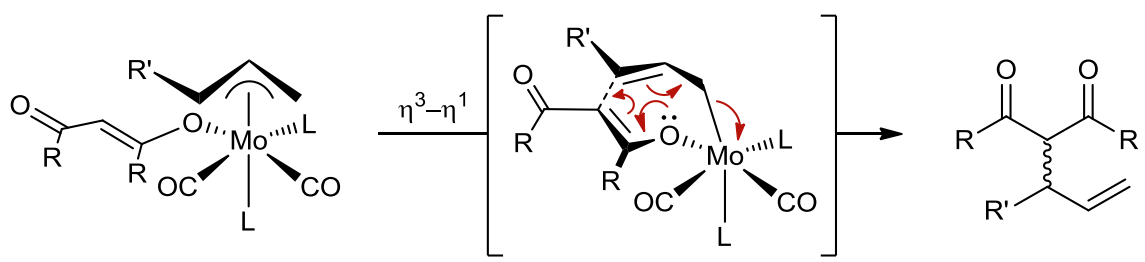

$106-D_{2}$

Scheme 37. Illustration of the complimentary mechanistic discussion to that presented in Scheme 35, whereby the possibility of a reactive species involving monodentate $O$-coordination of the nucleophile is explored. Steric impedance between the allylic substituent $\left(\mathrm{R}^{\prime}\right)$ and the cis positioned donor L (such as a pyridyl moiety; see Section 4.1), or between the $\alpha$-substituent on the nucleophile ( $\left.\mathrm{R}^{\prime \prime}\right)$ and $\mathrm{R}^{\prime}$ could perhaps be the provenance of the remarkable regioselectivity often observed with some catalytic systems, which tellingly varies significantly with the nature of the nucleophile, the allylic substrate, and the ligands constituting the coordination sphere of the reactive species. [266]

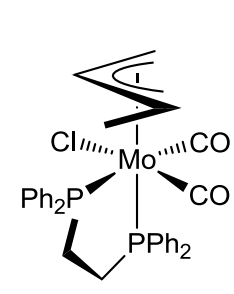

107

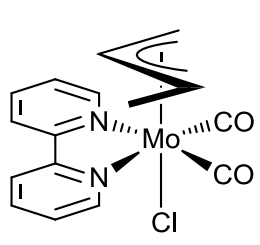

108
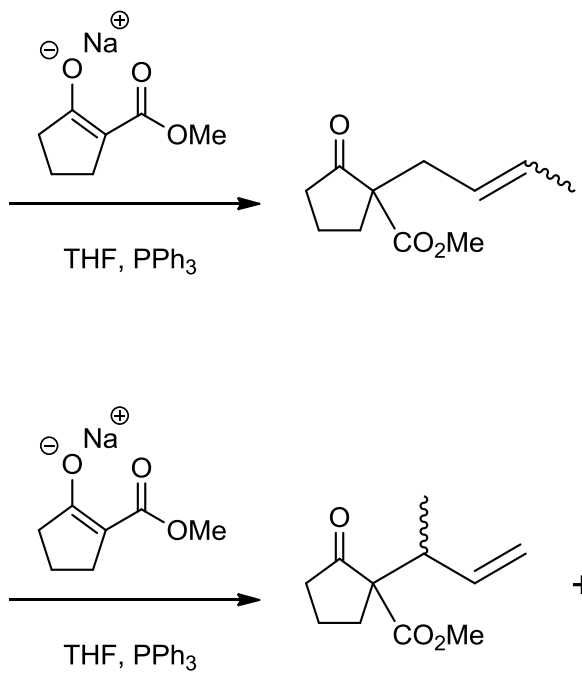<smiles>C=C[C@@H](C)C1(C(=O)[O-])CCCC1=O</smiles><smiles>CC=CCC1(C(C)=O)CCCC1=O</smiles>

Scheme 38. The nature of the bidentate ligand in stoichiometric allylic alkylations has a marked bearing on the regiochemical outcome of the reaction. Whilst dppe complex 107 mediates the alkylation exclusively at the primary carbon of the $\eta^{3}$-crotyl ligand, the corresponding bpy complex (108) enforces very little regioselectivity, with all conceivable organic alkylation products observed. [267]

The aforementioned mechanistic discussion stipulates the change in hapticity of the allyl ligand from $\eta^{3}$ to $\eta^{1}$, which has not been reported for $\alpha$-diimine complexes and only inferred from the slow $(R)$ 
$\rightleftharpoons(S)$ interconversion observed in dppe complexes of the type $\left[\mathrm{Mo}(\mathrm{CO})_{2}\left(\eta^{3}\right.\right.$-crotyl $\left.)(\mathrm{dppe}) \mathrm{Cl}\right](\mathrm{Scheme}$ 27). [230] Indeed, evidence precluding the $\eta^{3} \rightleftharpoons \eta^{1} \rightleftharpoons \eta^{3}$ isomerism in complexes of this type comes largely from variable-temperature NMR studies, for which it is possible that high enough temperatures cannot be achieved to view this haptotropic shift on the NMR timescale. The high temperatures and long reaction times required for the allylic alkylation in these complexes may thus be attributed to this factor. Interestingly, heating the pure syn and anti isomers with respect to the $\eta^{3}$-crotyl ligand in complexes 79 and $\mathbf{8 0}$ (Scheme 26) in refluxing benzene (24 h) did not result in any observed isomerism, [158] but the non-coordinating nature of the solvent is also significant. As was mentioned earlier, the only other group of compounds exhibiting the $\pi \rightleftharpoons \sigma \rightleftharpoons \pi$ isomerism, are $\left[\mathrm{TpM}(\mathrm{CO})_{2}\left(\eta^{3}\right.\right.$-allyl $\left.)\right](\mathrm{Tp}=$ tris(pyrazolyl)borate and derivatives, $\mathrm{M}=\mathrm{Mo}, \mathrm{W}$ ). [70,231,282] Given the similarity of these complexes to the cyclopentadienyl congeners (Section 2), which do not undergo this hapticity change, it is very difficult to rationalise this observation. However, it has been reported that the methylated analogues $\left[\mathrm{Tp} \mathrm{p}^{\prime} \mathrm{M}(\mathrm{CO})_{2}\left(\eta^{3}\right.\right.$-allyl) $)\left(\mathrm{Tp}^{\prime}=\right.$ hydrotris(3,5-dimethylpyrazolyl)borate) (Chart 3) exhibit a lower energy barrier for interconversion than the unsubstituted congeners. [283] In light of this apparent steric influence, the added $\mathrm{PPh}_{3}$ may play a role in promoting the $\eta^{3} \rightarrow \eta^{1}$ haptotropic shift, since the postulated $\eta^{1}$-allyl intermediate is a 16 valence electron complex, and the aptitude for complexes of Group 6 metals to form sterically crowded, 7-coordinate species is well proven (Section 3.2), including those containing $\mathrm{PPh}_{3}$ as a ligand. [284,285]

\subsection{Redox Properties and Electrocatalysis}

Potential use as molecular electrocatalysts has provoked fresh interest in the redox chemistry of $\left[\mathrm{M}(\mathrm{CO})_{2}\left(\eta^{3}\right.\right.$-allyl $)(\alpha$-diimine $\left.) \mathrm{X}\right]$ species. The stability of the cyclopentadienyl complexes towards electrochemical and chemical oxidation has already been mentioned (Section 2.4), and largely reversible anodic behaviour is also reported for many complexes with chelating donor nitrogen ligands, viz. $\left[\mathrm{M}(\mathrm{CO})_{2}\left(\eta^{3}\right.\right.$-allyl $\left.)\left(\mathrm{N}^{\urcorner} \mathrm{N}\right) \mathrm{X}\right]\left(\mathrm{M}=\mathrm{Mo}, \mathrm{W} ; \mathrm{N}^{\urcorner} \mathrm{N}=\right.$ bpy, phen, dpa, $1,4-{ }^{t} \mathrm{Bu}_{2}-\mathrm{dab} ; \mathrm{X}=\mathrm{Cl}, \mathrm{Br}$, OTf; abbreviations refer to Chart 8). [286,287] The stability of the cationic species $\left[\mathrm{Mo}(\mathrm{CO})_{2}\left(\eta^{3} \text {-allyl }\right)\left(\mathrm{L}^{\frown} \mathrm{L}\right) \mathrm{Cl}\right]^{+}$bearing withdrawing diphenyldiphosphine ligands $\left(\mathrm{L}^{\frown} \mathrm{L}=\mathrm{dppm}\right.$, dppe) 
is limited; rapid decomposition of the formally $\mathrm{M}$ (III) cations to $\mathrm{M}(\mathrm{II})$ tricarbonyl complexes and other highly oxidised products has been reported. [286] However, the $\alpha$-diimine complexes discussed here are typified by low-lying LUMOs (SALCs of metal $d$-, and $\alpha$-diimine $\pi^{*}$-orbitals), which introduces low cathodic potentials and relatively thermally stable reduction products. The bonding motif encompassing an $\alpha$-diimine moiety coordinated to a transition metal centre, is also a characteristic feature of complexes $f a c-\left[\mathrm{M}(\mathrm{CO})_{3}(\alpha\right.$-diimine $\left.) \mathrm{X}\right](\mathrm{M}=\mathrm{Mn}, \mathrm{Re} ; \mathrm{X}=$ various halides or pseudohalides $)$, which have been recognised as active electrocatalysts for the reduction of $\mathrm{CO}_{2}$ to $\mathrm{CO}$. [288-294] The recent advances made with regard to the Group-7 ( $\mathrm{Mn}, \mathrm{Re}$ ) complexes have led to the parallel exploration of the electrocatalytic activity exhibited by analogous Group-6 compounds, initially encountered for zerovalent Group-6 tetracarbonyl complexes, [M(CO)4 $(\alpha$-diimine $)]$. [295-298]

The exploration of catalyst systems that permit a relatively low energy and highly selective pathway to the conversion of $\mathrm{CO}_{2}$ to more useful carbon-based species, for use either as fuels (e.g., in fuel cells), or as feedstocks for further synthetic transformations, represents one of the most topical and challenging pursuits of contemporary chemistry. To this end, homogeneous electrocatalysts based on transition metal complexes have much to offer. [299-301] Indeed, a particular advantage in the utility of such molecular catalysts lies in the ability to 'tune' their performance by appropriate substitution of the organometallic scaffold. Expanding the compound range from the $\mathrm{M}(0)\left[\mathrm{M}(\mathrm{CO})_{4}(\alpha\right.$-diimine $\left.)\right]$ species to include the $\mathrm{M}(\mathrm{II})\left[\mathrm{M}(\mathrm{CO})_{2}\left(\eta^{3}\right.\right.$-allyl $)(\alpha$-diimine $\left.) \mathrm{X}\right]$ analogues provides further tuning possibilities by variation of the allyl substituents, through both steric and electronic factors. Naturally, since the coordinated $\alpha$-diimine is the most electrochemically active part of these complexes, its substitution effects the most marked modification to their redox behaviour. [302] Substitution of such carbon-based ligand backbones also presents an opportunity for immobilisation of the molecular species, [303] or might enable their operation in aqueous media by installation of appropriately hydrophilic functional groups. [304] Exploration of the two-electron reduction of $\mathrm{CO}_{2}$ catalysed by Group-6 allyl carbonyl complexes is still very much in its infancy, and our discussion is focused on tetracarbonyl complexes and Group 7 analogues. Emphasis is placed on analytical methods and mechanistic detail. 
IR carbonyl- and $\mathrm{C} \equiv \mathrm{N}$ stretching frequencies are mechanistically particularly informative. The aforementioned anodic behaviour of complexes $\left[\mathrm{M}(\mathrm{CO})_{2}\left(\eta^{3}\right.\right.$-allyl $\left.)\left(\mathrm{L}^{\frown} \mathrm{L}\right) \mathrm{X}\right]$ was monitored by $\mathrm{IR}$ spectroelectrochemistry, [286] which revealed a marked hypsochromic shift of the two $v(\mathrm{CO})$ bands, consistent with a large metal contribution to the HOMO. [194] Reversible oxidation occurs for $\left[\mathrm{Mo}(\mathrm{CO})_{2}\left(\eta^{3}\right.\right.$-allyl $\left.)(\mathrm{bpy})(\mathrm{NCS})\right](\mathbf{1 0 9})$ at $0.20 \mathrm{~V}$ vs. the ferrocene/ferrocenium redox couple $\left(\mathrm{Fc} / \mathrm{Fc}^{+}\right)$in weakly coordinating THF already at ambient temperature, and the cationic product is readily detectable by IR spectroscopy (Scheme 39). [194] The cathodic behaviour of 109 is irreversible for the first, $1 \mathrm{e}^{-}$ reduction at $-1.99 \mathrm{~V}(\mathbf{R 1})$. The rapid dissociation of $\mathrm{NCS}^{-}$from the transient radical anion, [109] ${ }^{-}$, affords the likewise transient, neutral radical species $[\mathbf{1 1 0}]^{\circ}$ that directly reduces at $E\left(\mathbf{R} 1^{\prime}\right)$ to fivecoordinate $[\mathbf{1 1 0}]^{-}$. The anodic counter wave $\mathbf{0 1}$ ' corresponds to the reverse one-electron oxidation of $[110]^{-}$. Anion $[\mathbf{1 1 0}]^{-}$reacts further with 109 to yield dimer 111, which converts again to $[110]^{-}$by reduction at -2.52 V ( $(\mathbf{R}(\mathbf{D}))$. This comproportionation ECEC mechanism at the charged cathode is more likely than direct dimerisation of $[110]^{\circ}$. [305] It should be noted that this may not apply to first row transition metals [306] (i.e., Cr), which have lower energy d-orbitals, and the ancillary ligands (i.e., substitution at the $\eta^{3}$-allylic moiety) should also have some significant impact in this context. The cyclic voltammogram of $\mathbf{1 0 9}$ exhibits an additional cathodic wave $\mathbf{R 2}^{\prime}$ at $-2.82 \mathrm{~V}$, attributed to the largely Mocentred one-electron reduction of $[\mathbf{1 1 0}]^{-}$to the corresponding dianion. 


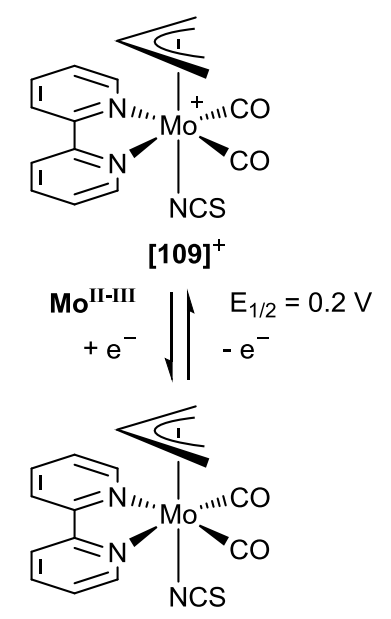

109

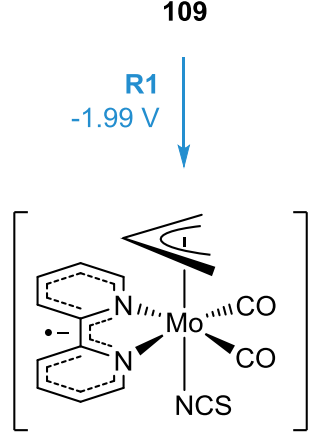

$[109]^{\bullet-}$

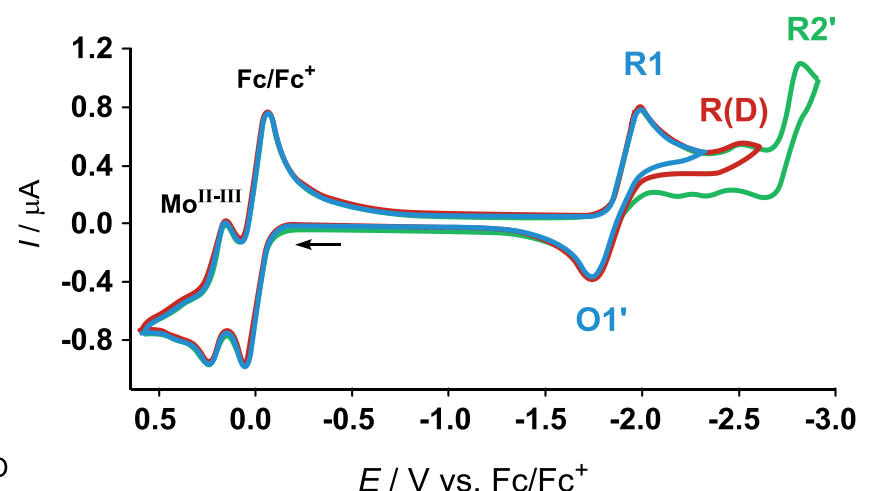

$E / \mathrm{V}$ vs. $\mathrm{Fc} / \mathrm{Fc}^{+}$

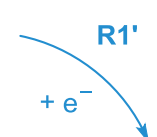

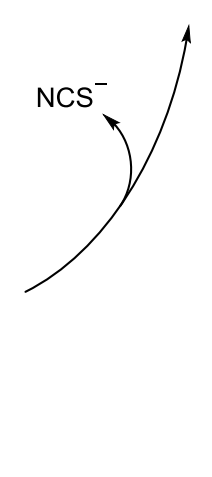

$[110]^{\circ}$
$\overbrace{1=N \ldots+\ldots}^{T}$
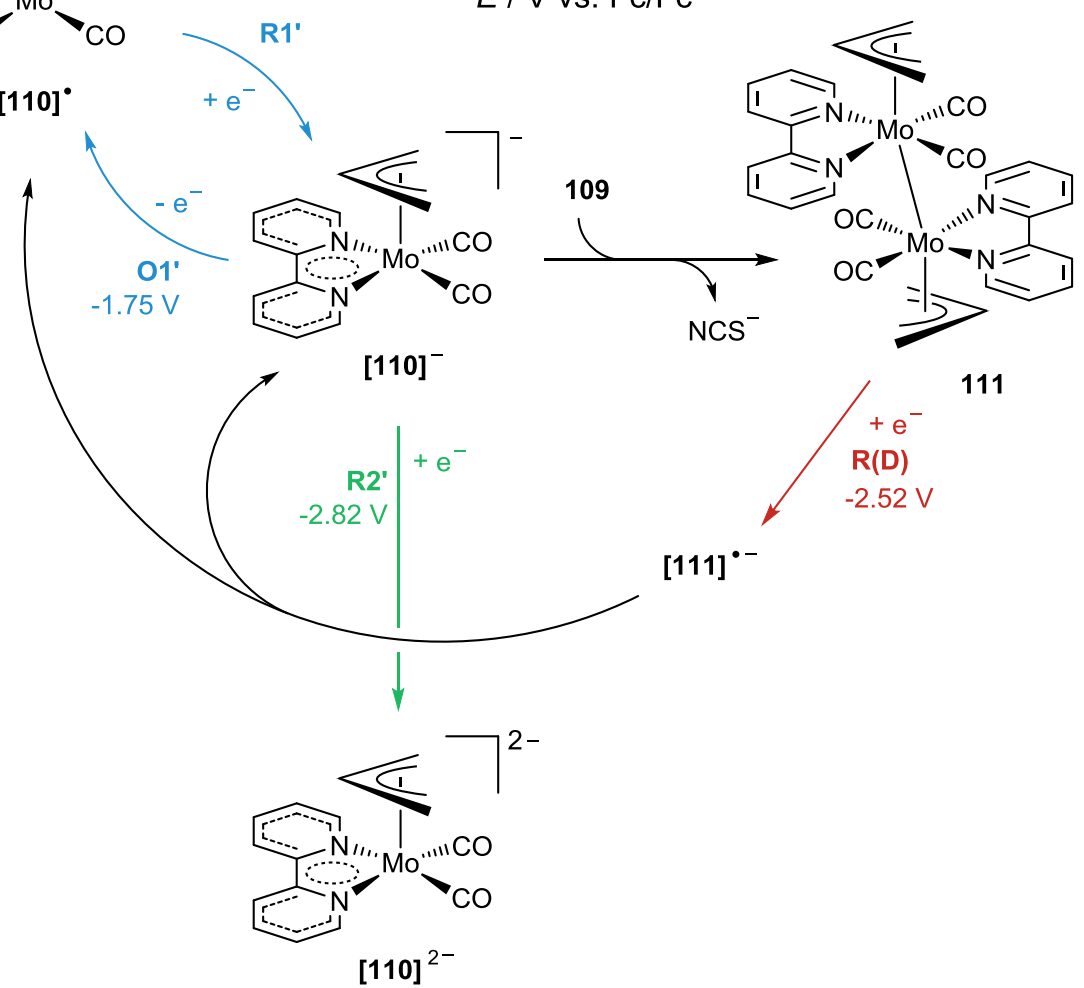

$[110]^{2-}$

Scheme 39. Cathodic path of $\left[\mathrm{Mo}(\mathrm{CO})_{2}\left(\eta^{3}\right.\right.$-allyl)(bpy)(NCS)] (109) $\left(\mathrm{THF} / \mathrm{Bu}_{4} \mathrm{NPF}_{6}\right.$, room temperature). [194]

The cathodic behaviour of $\mathbf{1 0 9}$ is distinctly similar to that of $\left[\mathrm{Mn}(\mathrm{CO})_{3}(\mathrm{bpy}) \mathrm{Cl}\right]$, which in particular, also features rapid dissociation of the chloride ligand induced by one-electron reduction of the bpy ligand [263-265]. [305,306] Dimerisation by the zero-electron comproportionation reaction of two-electron-reduced $\left[\mathrm{Mn}(\mathrm{CO})_{3}(\mathrm{bpy})\right]^{-}$, (analogous to $[\mathbf{1 1 0}]^{-}$) with the parent compound $\left[\mathrm{Mn}(\mathrm{CO})_{3}(\mathrm{bpy}) \mathrm{Cl}\right]$ was also observed by IR spectroelectrochemistry, $[305,306]$ mimicking the ECEC formation of 111 triggered by the one-electron reduction of 109. [194] $\left[\mathrm{Mn}(\mathrm{CO})_{3}(\mathrm{bpy})\right]_{2}(\mathbf{1 1 2})$ has also been chemically generated and structurally characterised by X-ray crystallographic analysis (Scheme 40a). [306] In addition, iterative chemical reductions of $\left[\mathrm{Re}(\mathrm{CO})_{3}(\mathrm{bpy}) \mathrm{Cl}\right]$ have also been reported, leading to the isolation and characterisation of $\left[\operatorname{Re}(\mathrm{CO})_{3}(\mathrm{bpy})\right]_{2}(\mathbf{1 1 3}),\left[\operatorname{Re}(\mathrm{CO})_{3}(\mathrm{bpy})\right]_{2}^{-}(\mathbf{1 1 4})$, and 
$\left[\operatorname{Re}(\mathrm{CO})_{3}(\mathrm{bpy})\right]^{-}(\mathbf{1 1 5})$; i.e., species analogous to 111, $[\mathbf{1 1 1}]^{--}$and $[\mathbf{1 1 0}]^{-}$, respectively (Scheme $\left.40 \mathrm{c}\right)$. [307] The eclipsing conformation of the two bpy ligands in $\mathbf{1 1 4}$ is attributed to a $\pi$ - $\pi$ stacking interaction. [307] Interestingly, the chemically induced dimerisation of $\left[\mathrm{Mo}(\mathrm{CO})_{4}\left(1,4-{ }^{\mathrm{i}} \mathrm{Pr}_{2}\right.\right.$-dab)] leads to $\mathrm{C}-\mathrm{C}$ coupling between the two dab moieties, with two of the nitrogen atoms bridging the molybdenum centres in $\left[\mathrm{Mo}(\mathrm{CO})_{3}\left(1,4-{ }^{\mathrm{i}} \mathrm{Pr}_{2}-\mathrm{dab}\right)\right]_{2}$ (116) (Scheme 40b). [308] As an aside, bimetallic allylmolybdenum complexes lacking a formal metal-metal bond have been isolated via the deprotonation of coordinated pyim (refer to Chart 8) ligands. [159]

a)

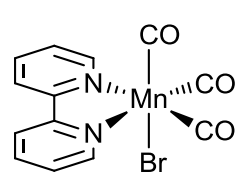

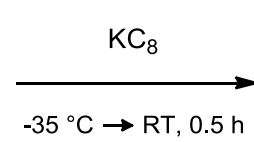

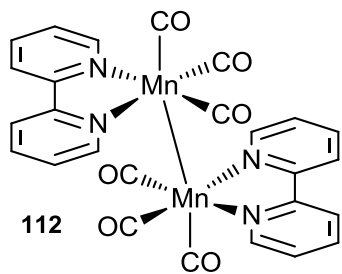

b)<smiles></smiles>

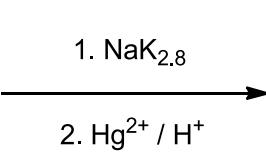

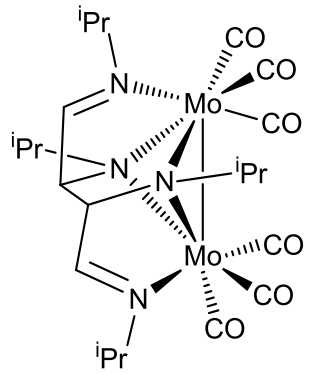
116

c)

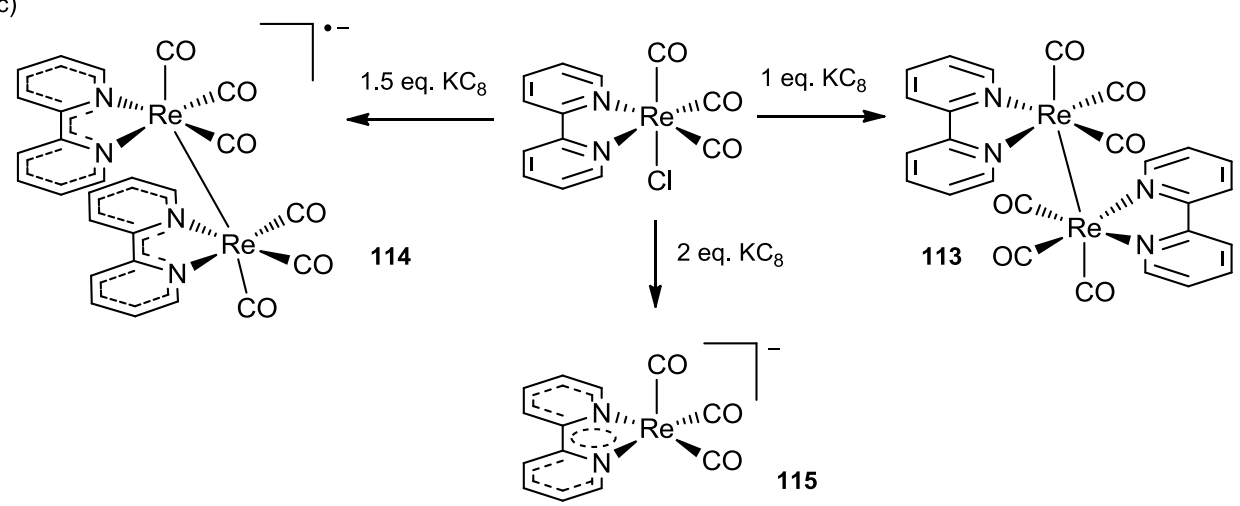

Scheme 40. Chemical reduction and subsequent dimerisation of a) $\left[\mathrm{Mn}(\mathrm{CO})_{3}(\mathrm{bpy}) \mathrm{Br}\right]$, b) $\left[\mathrm{Mo}(\mathrm{CO})_{4}\left(1,4-{ }^{\mathrm{i}} \mathrm{Pr}_{2}-\right.\right.$ dab)], and c) $\left[\operatorname{Re}(\mathrm{CO})_{3}(\mathrm{bpy}) \mathrm{Cl}\right] .[306-308]$

This divergence in reactivity, apparently between the bpy and non-aromatic dab ligands, is not 
entirely unexpected. An interesting example is provided by the complexes $\left[\mathrm{Mo}(\mathrm{CO})_{2}\left(\eta^{3}\right.\right.$-allyl $)(\mathrm{R}-$ pyamim) $(N$-R-im)] (117) $(\mathrm{R}$-pyamim $=N$-substituted 2-pyridylaldimine; $N$-R-im $=N$-substituted imidazole; refer to Chart 8) (Scheme 41a), [309] and the bpy congener (118) (Scheme 41b), [310] when treated with a strong base. Complex 118 is deprotonated by $\mathrm{K}\left[\mathrm{N}\left(\mathrm{SiMe}_{3}\right)_{2}\right]$ to afford neutral 119; DFT studies have suggested that the rearrangement of the $N$-metallated imidazole complex 118 to the $C$ metallated imidazolate complex 119 is mediated by the carbonyl ligands. [310] Following alkylation with an alkyl triflate, the cationic $N$-heterocyclic carbene complex (120) is furnished, with the bpy ligand left unperturbed. The same treatment of the Me-pyamim complex (117) affords the $\mathrm{C}-\mathrm{C}$ coupled product (121), whereby the deprotonated imidazolate moiety has attacked the imine carbon of the $N, N^{\prime}-$ chelating ligand. [309] The arrangement of the resulting tridentate ligand here is noteworthy; the pyridyl moiety occupies the position trans to the allyl ligand, an arrangement presumably effected by a subsequent trigonal twist operation (Section 3.2). Protonation of $\mathbf{1 2 1}$ occurs at the amide nitrogen to afford the cationic complex $\mathbf{1 2 2}$. Whereas a reaction entirely analogous to that of $\mathbf{1 1 8}$ is also reported for the manganese complex $\left[\mathrm{Mn}(\mathrm{CO})_{3}(\mathrm{bpy})(\mathrm{N}\right.$-R-im) $]$, [311] the rhenium congener $\left[\operatorname{Re}(\mathrm{CO})_{3}(\mathrm{bpy})(\mathrm{N}-\right.$ R-im)] (123) yields the $\mathrm{C}-\mathrm{C}$ coupling product (124) upon treatment with a strong base (Scheme 41c). [312] However, the $\mathrm{C}-\mathrm{C}$ coupling in this case contrasts with that shown in Scheme 41a, in that it occurs at the ortho $\left(\mathrm{C}_{6}\right)$ position of the 2,2'-bipyridine moiety. Further reaction of $\mathbf{1 2 4}$ with one equivalent of methyl triflate methylates the nitrogen donor $\alpha$ to the new $\mathrm{C}-\mathrm{C}$ bond. The phen analogue of $\mathbf{1 2 3}$ also undergoes this initial step, but the bpy complex adds a second equivalent of MeOTf inducing a ringopening rearrangement within the tridentate ligand, affording complex 125. Computational studies have demonstrated that an analogous $\mathrm{C}-\mathrm{C}$ bond formation in the allylmolybdenum bpy complex (118) is a marginally less favourable pathway to the observed rearrangement of the imidazole ligand by $c a$. 14.6 $\mathrm{kJ} \mathrm{mol}^{-1}$. [310] 

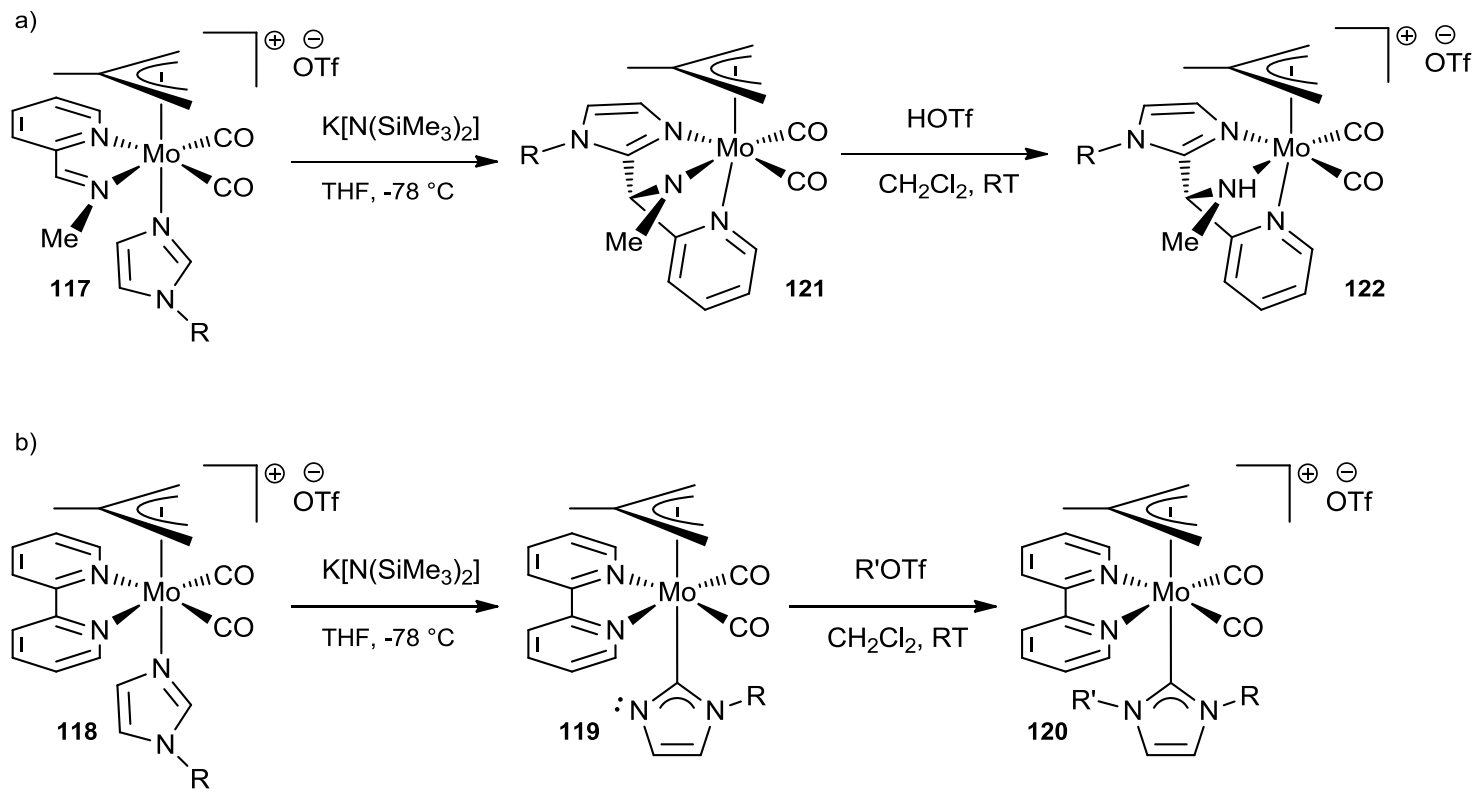

c)

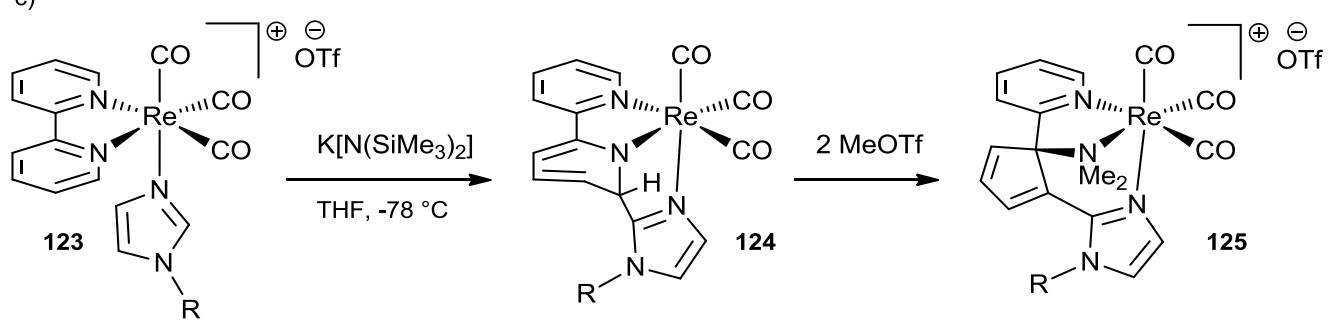

Scheme 41. Divergent behaviour upon treatment of $\alpha$-diimine complexes 117, 118 and 123 with a strong base, followed by protonation/alkylation. $\mathrm{R}=\mathrm{Me}$, Mes; $\mathrm{R}^{\prime}=\mathrm{H}, \mathrm{Me}$, Et. [309, 311, 312]

In the two-electron reduction of $\mathrm{CO}_{2}$ to $\mathrm{CO}$, catalysed by allylmolybdenum complexes of this type, it is presumed that $[\mathbf{1 1 0}]^{-}$is the active species, coinciding with that of the corresponding rhenium and manganese catalyst systems. [3,306] This is consistent with the prominent catalytic current seen at $\mathbf{R}(\mathbf{D})$ (-2.52 V; refer to Scheme 35) in the cyclic voltammogram of $\mathbf{1 0 9}$, recorded in THF saturated with $\mathrm{CO}_{2}$. [194] It follows that the formation of dimer 111, which requires more negative potentials to cleave the Mo-Mo bond and regenerate [110] $]^{-}$, is therefore an undesired side reaction. [312] This dimerisation is apparently impeded when $\mathbf{1 0 9}$ undergoes reduction in $\mathrm{PrCN}$, as revealed by the almost complete disappearance of the cathodic wave $\mathbf{R}(\mathbf{D})$; this observation is attributed to stronger coordinating nature of $\mathrm{PrCN}$ in comparison to THF. [194] Additionally, the examination of the cathodic behaviour of 109 in $\operatorname{PrCN}$ at low temperatures $(200 \mathrm{~K})$, or at higher scan rates $\left(2 \mathrm{~V} \mathrm{~s}^{-1}\right)$ also permits the tentative 
observation of $[\mathbf{1 0 9}]^{--}$, as well as the doubly reduced species, $[\mathbf{1 0 9}]^{2-}\left(E_{\mathrm{p}, \mathrm{c}}=-2.54 \mathrm{~V}\right)$, which promptly dissociates $\mathrm{NCS}^{-}$to form $[\mathbf{1 1 0}]^{-}$. There is mounting evidence that the binding of $\mathrm{CO}_{2}$ by the active species $[\mathbf{1 1 0}]^{-}$is different from that of the equivalent active species in the Group 7 metal catalytic systems. The latter are understood to bind $\mathrm{CO}_{2}$ as the $C$-bound hydroxycarbonyl ligand, [306,313-315] protonated in the presence of a Brønsted acid; the observed selectivity over the competitive proton reduction is rationalised in terms of a $\pi$-interaction with the reduced $\mathrm{CO}_{2}^{-}$ligand in accompaniment to the metal-ligand $\sigma$ interaction; [290] for details see reference [313]. However, recent studies on tetracarbonyl complexes of Group 6 metals have demonstrated the involvement of the diimine ligand in the activation of $\mathrm{CO}_{2}$. [296] Treatment of $\left[\mathrm{Mo}(\mathrm{CO})_{4}\left({ }^{i} \mathrm{Pr}_{2} \mathrm{Ph}\right.\right.$-pymim) $]$ (126) (Scheme 42) with excess $\mathrm{KC}_{8}$ yields the dianionic complex $\left[\mathrm{Mo}(\mathrm{CO})_{3}\left({ }^{i} \mathrm{Pr}_{2} \mathrm{Ph}-\text { pymim }\right)\right]^{2-}(\mathbf{1 2 7})$. Subsequent reaction with carbon dioxide affords the $\mathrm{CO}_{2}$ adduct $\mathbf{1 2 8}$, for which an X-ray structure has been obtained, as well as NMR spectroscopic data. The regiochemistry of the $\mathrm{C}-\mathrm{C}$ bond formation, as shown in Scheme 42, is noteworthy in this case; the reactivity of the imine carbon described in Schemes $40 \mathrm{~b}$ and $41 \mathrm{a}$ is enlightening in this context, and DFT studies have demonstrated the predominant coefficient at the imine carbon in the HOMO of doubly reduced $\mathbf{1 2 7}$ (which naturally is analogous to the LUMO of 126). [296] In light of this, and by comparison to Scheme 41c, one might assume that the regiochemistry of $\mathrm{C}-\mathrm{C}$ bond formation may be different for $2,2^{\prime}$-bipyridines, if this pathway is followed.

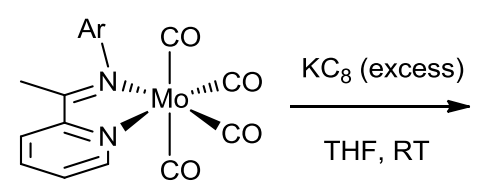

126<smiles>CCCc1cccc(C(C)C)c1N</smiles>

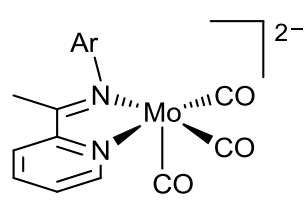

127

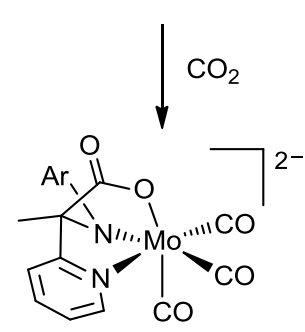

128

Scheme 42. The isolation and characterisation of $\mathbf{1 2 8}$, by reduction of the precursor $\mathbf{1 2 6}$ to the dianion $\mathbf{1 2 7}$, provides structural evidence for the mechanism by which $\mathrm{CO}_{2}$ is activated in molybdenum tetracarbonyl 
complexes. [296] Here, the binding of $\mathrm{CO}_{2}$ at the imine carbon is reminiscent of the regiochemistry of intramolecular migration shown in Scheme 41a.

It is quite possible that this mechanism by which $\mathrm{CO}_{2}$ is activated may be applicable to the $\mathrm{M}$ (II) allyl dicarbonyl complexes, and indeed the formation of the $\mathrm{CO}_{2}$ adduct may be favoured by the higher oxidation state metal centre. This is supported by the considerations in Section 3.3 concerning coordination by hard Lewis donors. Subsequently, an understanding of the bonding properties amongst such complexes of non-dative heteroatomic ligands may provide some valuable insight in this context. The allyl ligand, particularly because of its trans position to both the leaving ligand $\mathrm{X}$ in the neutral precursor complex, and the coordinated oxygen atom in the $\mathrm{CO}_{2}$ adduct, might offer a powerful means with which to promote the desired catalytic reaction by appropriate substitution (and indeed impede dimerisation; Scheme 39). The mechanism by which $\mathrm{CO}_{2}$ ligates is not clear: e.g., whether the $\mathrm{C}=\mathrm{O}$ bond is activated by $\mathrm{O}$-coordination prior to the $\mathrm{C}-\mathrm{C}$ bond formation (involving possibly the imino $\mathrm{C}$ ), or whether a nucleophilic attack at $\mathrm{CO}_{2}$ initiates carboxylate formation. Additionally, the influence of the complex isomerism (Section 3.2) has yet to be explored. Whereas the ease of the dissociation of the monodentate anionic ligand $\mathrm{X}$ upon electrochemical reduction is most likely governed by the aptitude of the $\alpha$-diimine ligand to bear the subsequent negative charge, the difference in steric and electronic environment between isomeric forms $\mathbf{C}$ and $\mathbf{D}$ (Chart 10) may also alter the dissociative nature of $\mathbf{X}$ (pertinently, the difference between coordinated pyridine ligands cis or trans to the allyl ligand is discussed in Section 4.1). In consideration of this, the complex $\left[\mathrm{Mo}(\mathrm{CO})_{2}\left(\eta^{3}\right.\right.$-allyl $)\left(\mathrm{Xyl}_{2}\right.$-bian $\left.)(\mathrm{NCS})\right]$ (129) provides a fitting comparison to bpy analogue 109, [194] for which the cathodic behaviour has already been thoroughly described (vide supra). Little is known regarding the dynamic behaviour in solution belonging to such bpy complexes, on account of their generally poor solubility, which impedes their characterisation by variable-temperature NMR experiments. $[119,121,189,316]$ (Although, the closely related complex $\left[\mathrm{Mo}(\mathrm{CO})_{2}\left(\eta^{3}-\mathrm{C}_{7} \mathrm{H}_{7}\right)(\mathrm{bpy})(\mathrm{NCO})\right]$ has been shown to exist exclusively as isomer C in solution, aside from a separate fluxionality pertaining to the $\mathrm{C}_{7} \mathrm{H}_{7}$ ring. [316]) The solid-state structures of 109 and 129, however, clearly show opposing isomeric forms $\mathbf{C}$ and $\mathbf{D}$, respectively. Moreover, the low-lying empty $\pi^{*}$ orbitals residing on the $\mathrm{Xyl}_{2}$-bian ligand, because of extended 
delocalisation over its $\pi$-framework, induce more positive reduction potentials and the added spin density localised dominantly on the ligand. As a result, the one-electron reduction $\left(\mathbf{R} 1\right.$ at $E_{1 / 2}=-1.16 \mathrm{~V}$ vs. $\mathrm{Fc} / \mathrm{Fc}^{+}$) to $[\mathbf{1 2 9}]^{-}$is both chemically and electrochemically reversible, and does not result in the loss of the monodentate anionic ligand X (Scheme 43). A second electrochemical reduction R2, at $-2.09 \mathrm{~V}$, affords five-coordinate anionic species $[\mathbf{1 3 0}]^{-}$, which then, as a further demonstration of the accepting power of the $\mathrm{Xyl}_{2}$-bian ligand, is even able to coordinate THF (analogous to the cathodic behaviour of 109 in PrCN; vide supra) to form $[\mathbf{1 3 1}]^{-}$. [194]
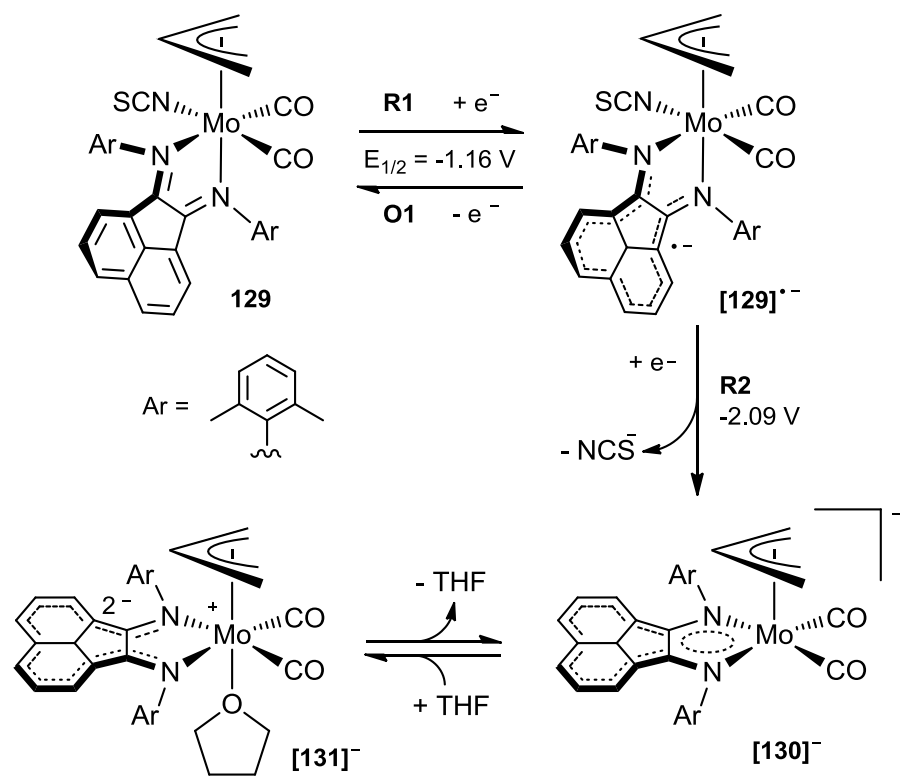

Scheme 43. Cathodic path of complex 129. [194]

\section{Amidinato and pyrazolato complexes related to $\left[\mathrm{M}(\mathrm{CO})_{2}\left(\eta^{3}\right.\right.$-allyl $)(\alpha$-diimine $\left.) \mathrm{X}\right]$}

We now turn from $\alpha$-diimine complexes with five-membered (e.g., bpy) or six-membered (e.g., dpa; see Chart 8) chelate rings to an anionic amidinate ligand forming a four-membered chelate ring. The amidinate ligand is best described as a $\kappa^{2}-N, N$-bound four-electron donor with primary metal-ligand interactions through nitrogen-centred orbitals. [317] Hence, appreciably different bonding properties prevail in comparison to $\pi$-allyl ligands, which may similarly be considered as four-electron donating 
anions with a bent triatomic ligand backbone. Notably, numerous examples of complexes $\left[\mathrm{CpM}(\mathrm{CO})_{2}\right.$ (amidinate)] have been reported [318-320] where the amidinate ligand directly replaces the allyl ligand in $\left[\mathrm{CpM}(\mathrm{CO})_{2}\left(\eta^{3}\right.\right.$-allyl)] (Section 2). In this section, we focus on the relatively new mixedligand complexes $\left[\mathrm{M}(\mathrm{CO})_{2}\left(\eta^{3}\right.\right.$-allyl $)($ amidinate $\left.) \mathrm{L}\right]$ for which the literature is thus far sparse. Whereas the amidinate ligand in this context shares much in common with the previously discussed $\alpha$-diimine ligands, pertaining to the isomerism and dynamic behaviour of such complexes, some interesting characteristic features of their reactivity have recently been identified, originating from the inherent lability of the neutral monodentate ligand L. Where appropriate, the discussion is expanded to some examples of related complexes with pyrazolate ligands, bound typically in a $\eta^{2}$-fashion to a $\mathrm{M}(\mathrm{CO})_{2}\left(\eta^{3}-\right.$ allyl) $\mathrm{L}^{+}$fragment through the adjacent nitrogen atoms. Hence, the pyrazolate ligand joins a family of anionic four-electron donor ligands bound through two donor heteroatoms, much like acac, nacnac (Section 3.3), and amidinate.

\subsection{Synthesis and dynamic behaviour}

The first preparation of an amidinato complex based on the $\mathrm{M}(\mathrm{CO})_{2}\left(\eta^{3}\right.$-allyl) fragment was reported in 2004 by Yamaguchi et al. (Scheme 44a). [224] The bis(amidine) (amidine $=N, N^{\prime}-$ diphenylformimidamide, $N, N^{\prime}$-di-p-tolylformimidamide) complexes $\mathbf{1 3 2}$ are deprotonated by a strong base to afford the respective complexes $\left[\mathrm{Mo}(\mathrm{CO})_{2}\left(\eta^{3}\right.\right.$-allyl)(formamidinate)(amidine)] (133). However, this reaction did not proceed for meso-substituted amidine ligands, as well as any tungsten congeners. In light of the poor scope concerning this preliminary synthetic route, a superior version was sought. The displacement reaction, readily applicable as a route to $\alpha$-diimine complexes from the bis(acetonitrile) precursor 54 (Scheme 16), was not consignable to the analogous reaction with $\mathrm{Li}$ amidinate salts. However, a slight modification involving bis(pyridine) complex 134 proved successful for various substituted amidinate ligands, as well as some congeners of tungsten, affording complexes $\left[\mathrm{M}(\mathrm{CO})_{2}\left(\eta^{3}\right.\right.$-allyl)(amidinate)(py)] (135) (Scheme 44b). [321,322] Bis(pyridine) complex 134 was hence also used as a precursor in the synthesis of the pyrazolato (pz) complexes $\left[\mathrm{M}(\mathrm{CO})_{2}\left(\eta^{3}\right.\right.$-allyl $\left.)\left(\eta^{x}-3,5-\mathrm{R}_{2}-\mathrm{pz}\right)(\mathrm{py})_{3-x}\right]\left(\mathrm{M}=\mathrm{Mo}, \mathrm{W} ; \mathrm{R}=\mathrm{CF}_{3}, x=1 \quad(\mathbf{1 3 6}) ; \mathrm{R}={ }^{t} \mathrm{Bu}, x=2(\mathbf{1 3 7})\right)$ 


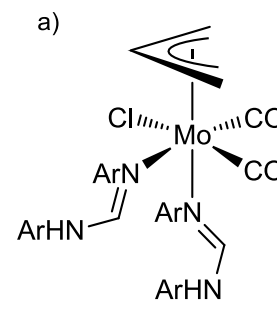

132

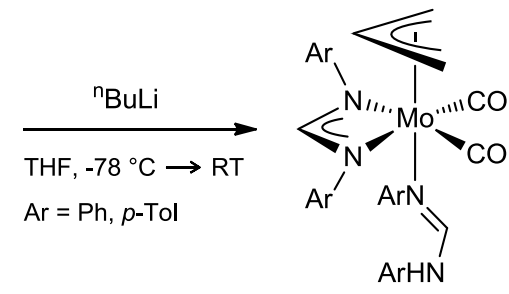

133

b)

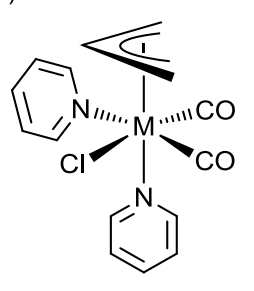

134

c)

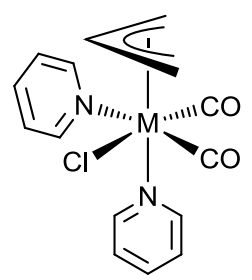

134

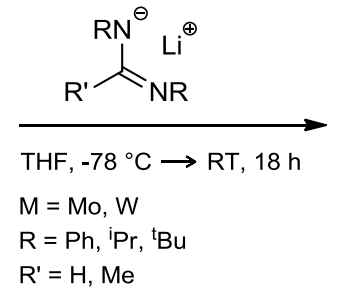

$\mathrm{R}^{\prime}=\mathrm{H}, \mathrm{Me}$

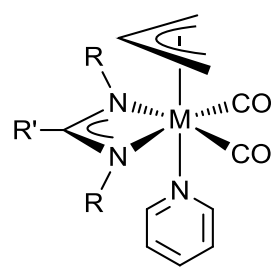

135

) and 127 [322].

The direct metathesis of chlorido precursor 134 with the potassium salt of 3,5-( $\left.\mathrm{CF}_{3}\right)_{2}-\mathrm{pz}$ affords bis(pyridine) monodentate pyrazolato complex 136, whereby the pyrazolate ligand is unable to displace one of the pyridine ligands. Conversely, for the ligand $3,5-{ }^{t} \mathrm{Bu}_{2}-\mathrm{pz}$, the presumably relatively weak $\eta^{2}$-coordination is observed. The crystal structure of molybdenum analogue $\mathbf{1 3 7}$ shows that the axial (trans to the allyl ligand) and equatorial $\mathrm{M}-\mathrm{N}$ bond lengths differ by $0.11 \AA$ (2.120 and $2.230 \AA$, respectively), and the plane of the pyrazolate ring is bent out of the plane of the metal-ligand bond axis. 
[322] These structural aberrations may however also be explained by steric effects. The apparently weak $\eta^{2}$-coordition may hence be exploited to facilitate coordination of a useful substrate upon the $\eta^{2} \rightarrow \eta^{1}$ shift of the pyrazolate ligand. The solid-state structure and dynamic behaviour in solution are comparable in both pyrazolato complexes. In $\mathbf{1 3 6}$ the monodentate pyrazolate ligand most likely occupies an equatorial position at the metal centre, consistent with isomer $\mathbf{D}$ (Chart 10). An X-ray study shows a similar structure for $\eta^{2}$ - pyrazolato complex $\mathbf{1 3 7}$. The ${ }^{1} \mathrm{H}$ NMR spectra of $\mathbf{1 3 7}$ recorded at variable temperature reveal fluxionality similar to that of $\kappa^{2}$-tpa complex 77 (Section 3.2). Thus, an averaged, ostensibly symmetrical resonance pattern at higher temperatures is consistent with the rapid interconversion $\mathbf{D}_{\mathbf{1}} \rightleftharpoons \mathbf{D}_{\mathbf{2}}$ (Scheme 25). Below $-60{ }^{\circ} \mathrm{C}$, an asymmetric resonance pattern is observed belonging to the $\mathbf{D}_{\mathbf{1}} / \mathbf{D}_{\mathbf{2}}$ enantiomeric pair slowly interconverting on the NMR timescale. No evidence was found for the existence of structure $\mathbf{C}$. The dynamic behaviour in solution exhibited by $\mathbf{1 3 6}$ is almost entirely equivalent to that of $\mathbf{1 3 7}$, with the exception that the barrier to $\mathbf{D}_{\mathbf{1}} \rightleftharpoons \mathbf{D}_{\mathbf{2}}$ interconversion is much higher, with sharp asymmetric resonances being observed at up to $-20{ }^{\circ} \mathrm{C}$. With regard to $\mathbf{1 3 6}$, the absence of structure $\mathbf{C}$ in solution highlights the suggestion that pyridine ligands typically prefer to occupy the axial site trans to the allyl ligand, as is also documented in Section 3. Table 7 shows a trend in which various pyridine complexes all exhibit an isomeric preference in the solid state that places as few pyridine ligands as possible in the equatorial plane. This is likely due to the steric presence of orthohydrogens $\left(\mathrm{H}_{2,6}\right)$ on the coordinated pyridine ring and the subsequent obtrusion with the syn-allylic hydrogens, which imposes some restriction to the rotation of the ring about the $\mathrm{M}-\mathrm{N}$ axis. This is particularly well demonstrated by the solution fluxionality of complexes $\left[\mathrm{Mo}(\mathrm{CO})_{2}\left(\eta^{3}-2-\mathrm{R}-\right.\right.$ allyl $\left.)\left(\mathrm{py}^{\prime}\right)_{2} \mathrm{X}\right](\mathrm{X}=\mathrm{Cl}, \mathrm{Br}, \mathrm{I} ; \mathrm{R}=\mathrm{H}, \mathrm{Me}$; py' stands for various substituted pyridine moieties), which mimics that of $\mathbf{7 7}$ and 137. [323] The rate of $\mathbf{D}_{\mathbf{1}} \rightleftharpoons \mathbf{D}_{\mathbf{2}}$ interconversion in these bis(pyridine) complexes depends on the anionic ligand in the order $\mathrm{Cl}>\mathrm{Br}>\mathrm{I}$, and it is further retarded by meso substitution of the allyl ligand as in the $\eta^{3}$-2-Me-allyl derivative. In addition, the structure of the latter complex also restricts the rotation of just one pyridine ligand at low temperatures; logically, the one bound cis to the allyl ligand. Such findings indicate that it is sterically less favourable to place a pyridine ligand cis to the allyl ligand. It is instructive to note that $\mathrm{M}-\mathrm{N}$ (cis-py) bonds are considerably longer in this case compared to M-N(trans-py); viz. 2.346 vs. $2.252 \AA$, respectively, in 136. [322] Furthermore, it follows 
that the interconversion of the $\mathbf{D}_{\mathbf{1}} \rightleftharpoons \mathbf{D}_{\mathbf{2}}$ enantiomeric pair via structure $\mathbf{C}$ is prohibited; instead, it is the less bulky halide ligand which eclipses the allyl ligand on the trigonal twist coordinate. On account of the rigidity imposed by the chelation in various related $2,2^{\prime}$-bipyridine complexes and derivatives thereof (Section 3), this hindrance with the syn-allyl substituents is alleviated in structure $\mathbf{C}$, but significant in structure $\mathbf{D}$, which to some extent explains the reverse isomeric preference, especially in the case of 2,9- $\mathrm{Me}_{2}$-phen complex 80 (Section 3.2). This is particularly well demonstrated by the solution fluxionality of $\left[\mathrm{Mo}(\mathrm{CO})_{2}\left(\eta^{3}-\right.\right.$ allyl $\left.)\left(\kappa^{2}-O, N-\mathrm{OPPy}{ }_{2} \mathrm{Ph}\right) \mathrm{Br}\right](\mathbf{1 3 8})(\mathrm{Scheme} 45)$. [228] It is then perhaps unusual that $\mathbf{1 3 7}$ elects to maintain the presumably more sterically unfavourable structure $\mathbf{D}$, with no evidence of isomer $\mathbf{C}$, even in solution. (Examples have been reported of mono(pyridine) complexes adopting the solid-state structure $\mathbf{D},[229,324]$ but equilibrating with $\mathbf{C}$ in solution [273]). The isomerism exhibited by $\mathbf{1 3 7}$ is thus likely, for a great deal, due to an electronic effect.
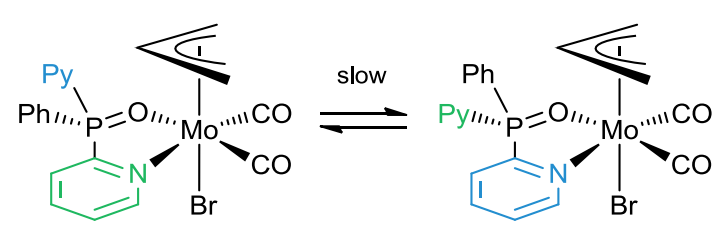

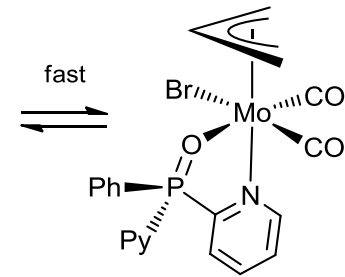

$138-D_{1}$

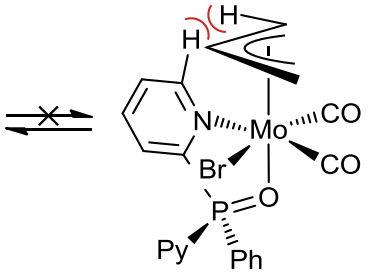

$138-D_{2}$

Scheme 45. The solution fluxionality of $\mathbf{1 3 8}$ elegantly demonstrates the disfavoured cis arrangement of a coordinated pyridyl moiety with respect to the allylic ligand. This is especially so if it is part of a chelate ligand structure (e.g., bpy, phen), and thus conformationally constrained to lie orthogonal to the plane delineated by the allyl ligand. The resultant steric hindrance between the pyridyl ortho-hydrogens $\left(\mathrm{H}_{2,6}\right)$ and the syn-allylic hydrogens hence precludes the existence of $\mathbf{1 3 8}-\mathbf{D}_{2}$ in solution. [228]

Amongst the amidinato complexes 139-141 (Chart 12), markedly different dynamic behaviour is observed in solution, despite their outward similarity; they differ only in the $\mathrm{N}, \mathrm{N}$ - and mesosubstitution of the amidinate moiety, but this seems to acutely change both the thermodynamic and kinetic parameters of their $\mathbf{C} \rightleftharpoons \mathbf{D}$ isomerism. Variable-temperature NMR spectra recorded for $N$-phenyl amidinato complex 139 are consistent with rapid $\mathbf{C} \rightleftharpoons \mathbf{D}$ interconversion at $60{ }^{\circ} \mathrm{C}$, resulting in sharp, symmetrical allyl proton signals. [321] On cooling, the signals broaden as the $\mathbf{C} \rightleftharpoons \mathbf{D}$ interconversion 
slows; this process is accompanied by concomitant splitting of the $\mathbf{D}$ isomer resonances to an asymmetric pattern that remains broad at $-60{ }^{\circ} \mathrm{C}$, implying that the kinetics associated with $\mathbf{C} \rightleftharpoons \mathbf{D}$ and $\mathbf{D}_{\mathbf{1}} \rightleftharpoons \mathbf{D}_{\mathbf{2}}$ isomerism are comparable (see Section 3.2 for this isomerism in the $\alpha$-diimine and diphosphine families of complexes). In addition, isomer $\mathbf{C}$ predominates over $\mathbf{D}$ (4:1) in solution, in line with the solid-state structure of $\mathbf{1 3 9}$, presumably owing to the bulk of the pyridine ligand. In contrast, isomer $\mathbf{C}$ is reported to be absent in solution for $\mathbf{1 4 0}$, which bears an $N$-isopropyl amidinato ligand methylated in the meso position. [322] In accordance with the solid-state structure $\mathbf{D}$ identified for this complex, the high temperature limiting spectrum shows only one set of ${ }^{1} \mathrm{H}$ allyl signals belonging to a rapid $\mathbf{D}_{\mathbf{1}} \rightleftharpoons \mathbf{D}_{\mathbf{2}}$ interconversion, with the asymmetric spectrum becoming resolved at $-40{ }^{\circ} \mathrm{C}$. Essentially, this observation demonstrates a slower $\mathbf{D}_{1} \rightleftharpoons \mathbf{D}_{\mathbf{2}}$ interconversion for $\mathbf{1 4 0}$ compared to $\mathbf{1 3 9}$; the latter, owing to the planarity of the aryl substituents, presumably permits a less sterically hindered trigonal twist of the $\mathrm{L}_{2} \mathrm{X}$ component. Most interesting is the consistency of the ${ }^{1} \mathrm{H}$ NMR spectra belonging to $N{ }^{-}$butylmeso-methyl amidinato complex 141 measured over the temperature range -80 to $80{ }^{\circ} \mathrm{C}$; the persistent resonance pattern is consistent with a symmetrical structure $\mathbf{C}$ that remains stereochemically rigid.

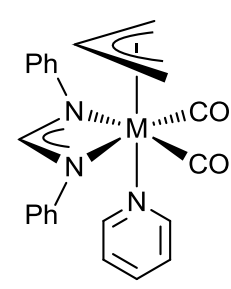

139

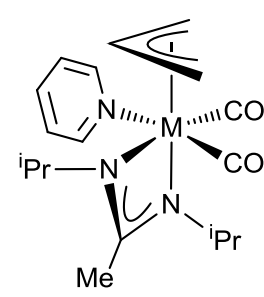

140

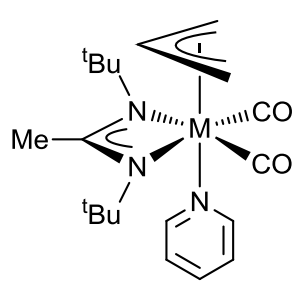

141

Chart 12. Complexes $\left[\mathrm{M}(\mathrm{CO})_{2}\left(\eta^{3}\right.\right.$-allyl)(amidinate)(py)], 139-141 (shown generally as $\mathbf{1 3 5}$ in Scheme 44), as they appear in their solid-state structures.

Such a contrast to the dynamic behaviour exhibited by $\mathbf{1 4 0}$ is surprising, given the outward similarity between the $N$-substituted ${ }^{i} \mathrm{Pr}$ and ${ }^{t} \mathrm{Bu}$ groups, especially with regards to the bonding properties of the respective amidinate ligands and, therefore, the electronic stability of the $\mathbf{C}$ and $\mathbf{D}$ isomers. A tentative rationale for the observed fluxionality (or lack thereof) and the isomerism amongst complexes 139-141 is based on the effect that the meso-substitution of the amidinate backbone has on 
the different $N$-substituents. The crystal structure of $\mathbf{1 4 0}$ shows that the conformation of the amidinate $N$-isopropyl substituents orientates the methine hydrogens syn to the meso-methyl group. The steric impedance to the free rotation of the isopropyl substituents, enforced by methylation of the amidinate backbone, is apparent in the low-temperature ${ }^{1} \mathrm{H}$ NMR spectra of 140, in which the two $\mathrm{CH}_{3}$ units manifest their non-equivalence. [322] As illustrated by 140-C in Chart 13, this orientation destabilises the equatorial structure $\mathbf{C}$ on account of the steric hindrance between the $\mathrm{CH}_{3}$ units with the syn allyl hydrogens. An analogous picture for 141 provides some explanation for the opposing isomeric preference; the solid state structures of the related five-coordinate complexes $\left[\mathrm{M}(\mathrm{CO})_{2}\left(\eta^{3}\right.\right.$-allyl $)\left(N, N^{\prime}-\right.$ di- ${ }^{t}$ butyl-3-methylamidinate)] ( $\left.\mathrm{M}=\mathrm{Mo}, \mathrm{W}\right) 142$ (Section 4.2; Scheme 47) reveals the gauche orientation of the butyl $\mathrm{CH}_{3}$ units, such that the steric interaction between the methylated backbone of the amidinate ligand and the syn allyl hydrogens is minimised. In structure $\mathbf{D}$, one must bear in mind a potential steric interaction in the equatorial plane between the pyridine ligand and the $N$-substituent of the respective amidinate ligand terminus. In $\mathbf{1 3 9}$, the absence of a methyl substituent on the amidinate backbone permits the coplanarity of the phenyl rings with the metal-amidinate metallacycle. Clearly this conformation is electronically beneficial, and indeed it may alter the metal-ligand bonding properties (and potentially, the relative stabilities of the $\mathbf{C}$ and $\mathbf{D}$ isomers). However, steric interactions with the allyl ligand are also minimised in structure $\mathbf{C}$. While $\mathrm{C}_{2}$-methylated $N, N^{\prime}$-diphenyl-3methylamidinate congener $\mathbf{1 4 3}$ has not yet been structurally characterised, or studied using variabletemperature NMR experiments, the room-temperature ${ }^{1} \mathrm{H}$ NMR spectra differs from $\mathbf{1 3 9}$ in that the resonance patterns are well resolved. [321] This suggests that $\mathbf{C} \rightleftharpoons \mathbf{D}$ isomerism, which tends to manifest itself as broad or averaged signals in the room temperature spectrum (cf. 139, and other examples in Section 3.2), is not operant in solution for 143. Whereas there are numerous examples of other meso-substituted $N, N$-di- ${ }^{t}$ butylamidinate complexes that demonstrate a parallel conformational preference in their solid state structures (as shown in Chart 13), [325-327] the aforementioned torsional orientations of $N$-substituents in $\mathbf{1 3 9}$ and $\mathbf{1 4 0}$ are less well enforced amongst analogous complexes in the literature, and the steric interaction between the meso substituent and the $N$-substituents appears to be generally weaker than that between the other coordinated ligands. [328-330] Furthermore, the ${ }^{1} \mathrm{H}$ NMR spectra recorded for $\mathbf{1 4 0}$ and $\mathbf{1 4 1}$ demonstrate the chemical equivalence of the $\mathrm{CH}_{3}$ units of the 
${ }^{i} \mathrm{Pr}$ and ${ }^{t} \mathrm{Bu}$ substitutents at room temperature ('frozen out' resonances are reported only for $\mathbf{1 4 0}$ at low temperatures), indicating that free rotation about the $\mathrm{N}-\mathrm{C}$ bond is relatively facile, and the aforementioned conformational preferences are chiefly solid-state phenomena. Another consideration is that structure $\mathbf{C}$ for $\mathbf{1 4 1}$ represents a kinetic product from its formation (stereospecific metathesis of the parent chloride complex $\mathbf{1 3 4}$ in a similar manner to examples discussed in Section 3.3, preceding chelation via displacement of the presumably more labile equatorial pyridine ligand (vide supra) would provide a kinetically favourable route to $\mathbf{C}$ ), which is unable to execute the required trigonal twist as a route to isomer $\mathbf{D}$; however, it is difficult to imagine that this should be the case at high temperature, given the existence of isomer $\mathbf{D}$ for $\mathbf{1 4 0}$. Alternatively, one final suggestion leads conveniently to the subject matter of Section 4.2. The $\mathbf{C} \rightleftharpoons \mathbf{D}$ isomerism may be a viable process for $\mathbf{1 4 1}$, with the absence of isomer $\mathbf{D}$ in the ${ }^{1} \mathrm{H}$ NMR spectra due to it being 'consumed'. Owing to the probable steric interaction of an equatorial pyridine (vide supra), it is conceivable that $\mathbf{C} \rightleftharpoons \mathbf{D}$ isomerism leads to dissociation of that ligand to form a five-coordinate, 16 valence electron species 142 (see Section 4.2) that also exhibits a symmetric geometry (Scheme 46). This may explain the reported broad peaks of the allyl protons and of the pyridine ortho- $\mathrm{H}\left(\mathrm{H}_{2,6}\right)$, suggesting exchange with free pyridine for 141 and 142 . (The $\mathrm{H}_{2,6}$ signal is presumably broadened because of the wider shift range in coordinated with respect to free pyridine; the reported chemical shifts of $\mathrm{H}_{3,5}$ and $\mathrm{H}_{4}$ match very closely that of free pyridine in toluene- $d_{8}$ [331]).

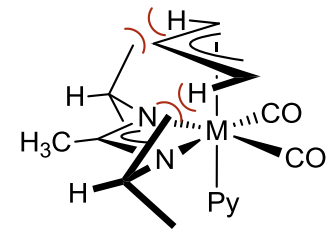

140-C

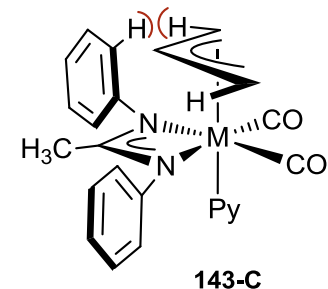

$143-\mathrm{C}$

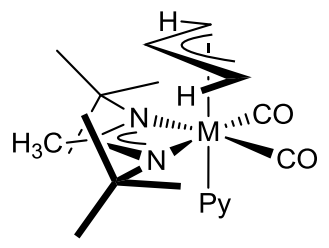

$141-\mathrm{C}$

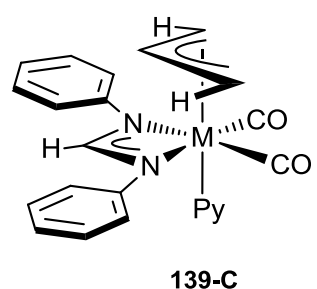

Chart 13. Purported elements of steric hindrance in selected amidinato complexes, with consideration of the 


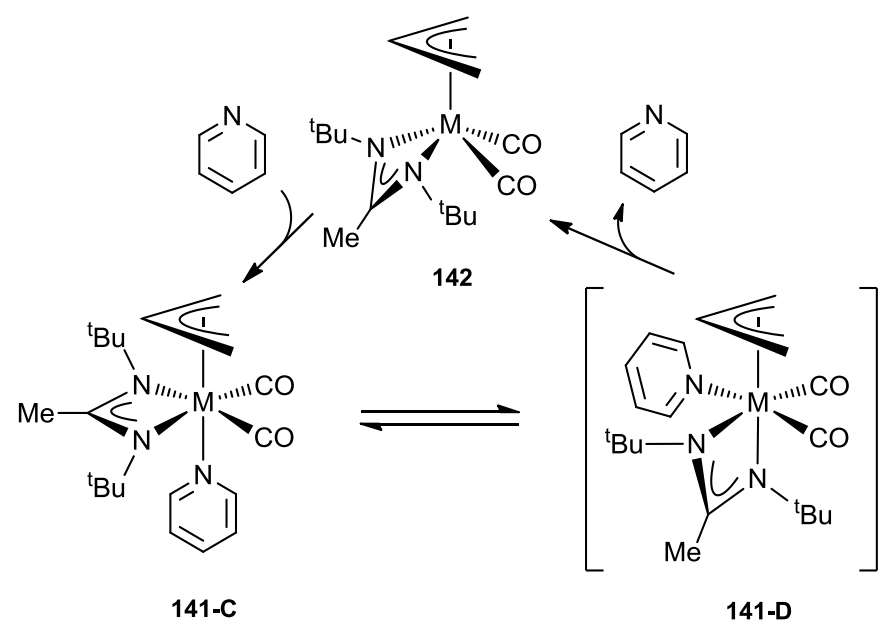

Scheme 46. Proposed rationale for the absence of 141-D in the variable-temperature ${ }^{1} \mathrm{H}$ NMR spectra of 141.

\subsection{Coordinatively unsaturated species and their reactivity}

Sublimation of 141 affords [M(CO $)_{2}\left(\eta^{3}\right.$-allyl $)\left(N, N^{\prime}\right.$-ditert-butyl-3-methylamidinate $\left.)\right]$ (142) in low yields as a general route for both molybdenum and tungsten (M) congeners (Scheme 47). [322] The formally 16 valence electron, 5-coordinate complex adopts a square pyramidal geometry about the metal centre, which, by examination of the crystal structure of 142 , is appreciably shielded by the steric presence of the $\mathrm{N}, \mathrm{N}^{\mathrm{t}}{ }^{\mathrm{b}}$ butyl groups. In addition, the amidinate ligand bends slightly, such that the mesocarbon approaches the metal centre. This might suggest that the amidinate ligand distorts to provide an additional (weak) bonding interaction, to somewhat alleviate the electronically unsaturated metal centre ( $c f$. the bonding interaction of the nacnac ligand in 101; Section 3.3). The isolation of $\mathbf{1 4 2}$ demonstrates clearly the lability of the pyridine ligand in these complexes, and so: a) the complexes 139-141 and 143, and other pyridine derivatives, are suitable precursors for pyridine displacement as a route to complexes with other monodentate ligands, and $\mathrm{b}$ ) the $\mathbf{C} \rightleftharpoons \mathbf{D}$ isomerism occurs via $\mathbf{1 4 2}$ (or the respective coordinatively unsaturated species corresponding to other complexes $\left[\mathrm{M}(\mathrm{CO})_{2}\left(\eta^{3}-\right.\right.$ allyl)(amidinate)(py)]) in a dissociative process, as opposed to the previously discussed trigonal twist mechanism, which is presumably sterically encumbered in this case. Given the prevalence of the 
trigonal twist for such organometallic compounds, this conjecture is unexpected. However, further investigation is required. Assuming the dissociative isomerism permits the intermolecular exchange of pyridine ligands, suitable NMR experiments have previously been reported that could elucidate such a mechanism. [332]

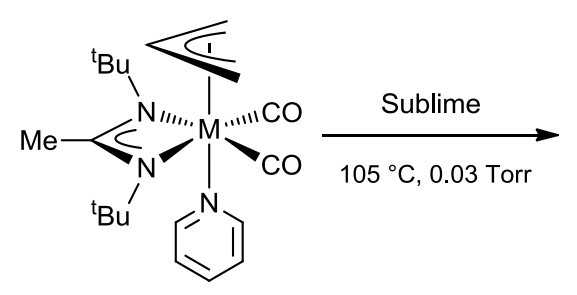

141

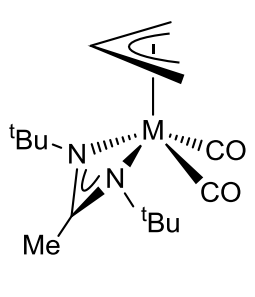

142

Scheme 47. Preparation of the complexes $\left[\mathrm{M}(\mathrm{CO})_{2}\left(\eta^{3}\right.\right.$-allyl $)\left(N, N^{\prime}\right.$-ditert-butyl-3-methylamidinate $\left.)\right](\mathrm{M}=\mathrm{Mo}, \mathrm{W})$ (142). [322]

IR and ${ }^{1} \mathrm{H}$ NMR spectra of $\mathbf{1 3 9}$ recorded in acetonitrile, both revealed the dissociation of pyridine from the parent compound. [321] Two additional IR $v(\mathrm{CO})$ absorption bands were identified, but their assignment was not aided by the ${ }^{1} \mathrm{H}$ NMR spectrum that exhibited aromatic resonances due to free pyridine and broad signals belonging to a metal complex. Since isolation of the new complex was unsuccessful, it remains unknown whether the acetonitrile complex $\left[\mathrm{M}(\mathrm{CO})_{2}\left(\eta^{3}\right.\right.$-allyl $)\left(N, N^{\prime}-\right.$ diphenylamidinate)(MeCN)] was formed, or a different species gives rise to the spectra. In either case, it is obvious why these amidinato complexes cannot be obtained from the bis(acetonitrile) precursor $\left[\mathrm{M}(\mathrm{CO})_{2}\left(\eta^{3}\right.\right.$-allyl $\left.)(\mathrm{MeCN})_{2} \mathrm{Cl}\right](\mathbf{1 4 4})$, in place of 134; [321] presumably, it is the instability of the product that precludes this synthetic route, rather than the lability of the precursor. However, the reaction of 144 with the potassium salt of 3,5-'butylpyrazolate affords the dimer 145 with bridging pyrazolate ligands (Scheme 48). [322] Variable-temperature ${ }^{1} \mathrm{H}$ NMR spectra of $\mathbf{1 4 5}$ recorded in toluene- $d_{8}$ reveal the presence of two isomers in the ratio $1: 4$, which remain separate over the temperature range of -80 to $80{ }^{\circ} \mathrm{C}$. The lability of acetonitrile in these complexes is well demonstrated here; presumably, the formation of an analogous dimeric complex is feasible in the case of amidinato 
complex 139, provided the steric bulk around the bridging nitrogen donor does not prohibit the dimerisation (presumably the case for $\mathbf{1 4 1}$ because of the isolated five-coordinate species, 142). Examples of dimeric complexes with bridging amidinato ligands are readily found in the literature.
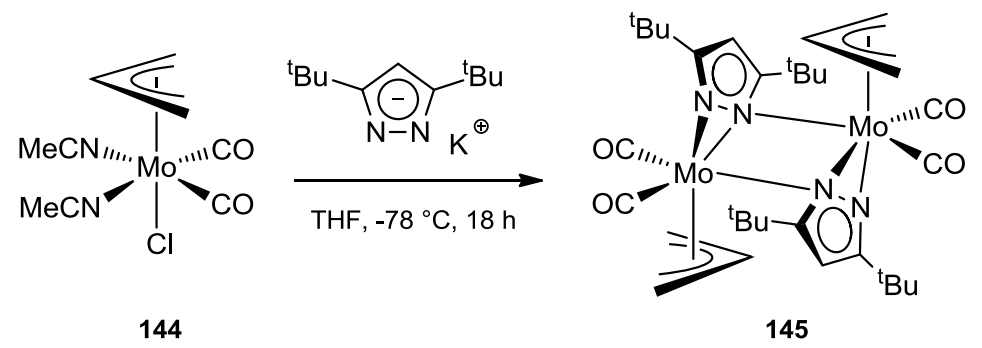

Scheme 48. Reaction of complex 144 with the potassium salt of 3,5-'butylpyrazolate. [322]

Pyridine substitution in these amidinato complexes can lead to stable products. Reaction of $\mathbf{1 3 9}$ with triethylphosphine readily affords $\left[\mathrm{M}(\mathrm{CO})_{2}\left(\eta^{3}\right.\right.$-allyl $)\left(N, N^{\prime}\right.$-diphenylamidinate $\left.)\left(\mathrm{PEt}_{3}\right)\right] \quad$ (146) (Scheme 49a). [321] The formation of $\mathbf{1 4 6}$ in this case is confirmed by X-ray crystallography, as well as various NMR techniques (the tungsten analogue manifests ${ }^{1} J_{\mathrm{P}, \mathrm{W}}=223.3 \mathrm{~Hz}$ in the ${ }^{31} \mathrm{P} \mathrm{NMR}$ spectrum). It is noteworthy that there is no monodentate phosphine counterpart in the $\alpha$ diimine/diphosphine family of complexes (Section 3); attempts to prepare $\mathrm{PR}_{3}$ complexes of this type typically result in decomposition [337] (the only pertinent example that has been structurally characterised is the cationic complex $\left[\mathrm{Mo}(\mathrm{CO})_{2}\left(\eta^{3}-2-\mathrm{Me}-\mathrm{allyl}\right)(\mathrm{pica})\left(\mathrm{PPh}_{3}\right)\right]\left[\mathrm{BAr}_{4}^{\prime}\right]$ (pica = picolinaldehyde; $\mathrm{BAr}_{4}{ }_{4}=$ tetrakis(3,5-bis(trifluoromethyl)phenyl)borate) [209]). Whereas the reaction of 139 with trimethylphosphite afforded the stable product $\left[\mathrm{M}(\mathrm{CO})_{2}\left(\eta^{3}\right.\right.$-allyl $)\left(N, N^{\prime}-\right.$ diphenylamidinate) $\left.\left\{\mathrm{P}(\mathrm{OMe})_{3}\right\}\right]$ (147) (Scheme 49b) in the case of the tungsten complex, the molybdenum congener decomposed, although its spectroscopic characterisation could be accomplished. [321] Some insight into the accelerating effect of added triphenylphosphine on the Mo-catalysed allylic alkylation reaction (discussed in Section 3.3) may be obtained from the behaviour of 146, 147, and their derivatives. It is instructive to note that the decomposition products isolated from the reaction of $\mathbf{1 4 4}$ 
with monodentate phosphines include zerovalent molybdenum species and allylphosphonium chloride salts. [337] A similar reaction of $\mathbf{1 3 9}$ with the triethylborane adducts of various $N$-heterocyclic carbenes provides a route to the $\mathrm{NHC}$ complexes $\left[\mathrm{M}(\mathrm{CO})_{2}\left(\eta^{3}\right.\right.$-allyl $)\left(N, N^{\prime}\right.$-diphenylamidinate $\left.)(\mathrm{NHC})\right](\mathrm{M}=\mathrm{Mo}$, $\left.\mathrm{W} ; \mathrm{NHC}=\mathrm{IMes}(\mathbf{1 4 8}), \mathrm{I}^{i} \operatorname{Pr}(\mathbf{1 4 9})\right)($ Scheme 50). [336] $N$-heterocyclic carbenes as ligands are often considered to be close neighbours to phosphine ligands in the context of organometallic chemistry and catalysis; [338] however, their bonding properties are generally characterised by stronger donation, which is here substantiated by the lower-frequency $v(\mathrm{CO})$ bands exhibited by 148 , compared to 146 (1906, 1811 vs. $1921,1836 \mathrm{~cm}^{-1}$, respectively). In line with the solid state structure of $\mathbf{1 4 8}$ and $\mathbf{1 4 9}$, the ${ }^{1} \mathrm{H}$ NMR spectra recorded over the temperature range of -60 to $80{ }^{\circ} \mathrm{C}$ feature a resonance pattern consistent with symmetrical isomer $\mathbf{C}$ (Chart 10). [336] In the solid-state structures of $\mathbf{1 4 8}$ and $\mathbf{1 4 9}$, the orientation of the NHC ligands relative to the metal fragment is invariably such that the plane of the imidazole ring lies perpendicular to the molecule's plane of symmetry. In the limiting low temperature ${ }^{1} \mathrm{H}$ NMR spectrum of $\mathbf{1 4 9}$, the non-equivalent isopropyl methyl protons are observable at 0.33 and 1.40 ppm. The appreciable upfield shift of one set of $\mathrm{CH}_{3}$ resonances is presumably due to the influence of magnetic anisotropy induced by ring currents about the $N$-phenyl substituents of the amidinate ligand, which is in concurrence to the solid-state structure. At room temperature, the separate ${ }^{i} \mathrm{Pr}^{-} \mathrm{CH}_{3}$ signals have coalesced, but remain broad, and in the limiting high temperature spectrum, a single doublet is observed. Since the room-temperature ${ }^{1} \mathrm{H}$ NMR spectrum of $\mathbf{1 4 8}$ manifests sharper averaged signals belonging to the 2,6-methyl substituents of the mesityl moieties, the dynamic process responsible for these spectroscopic features is most likely a rotation about the $\mathrm{M}-\mathrm{NHC}$ bond rather than the N-Pr or $\mathrm{N}-\mathrm{Mes}$ bonds, since the latter would be more sterically encumbered for $\mathbf{1 4 8}$.

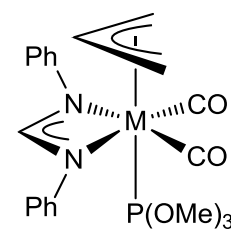

147
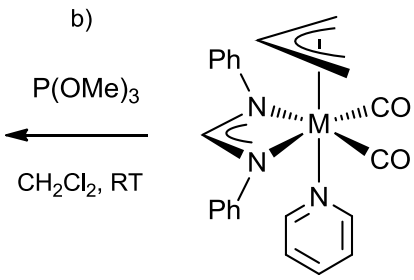

139
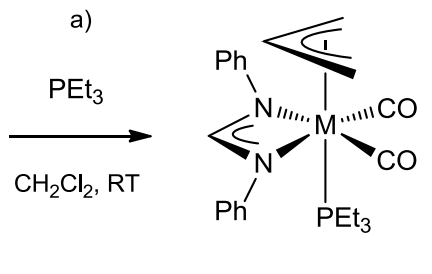

146 
Scheme 49. Pyridine-substitution reactions of amidinato complexes 139 with a/ $\mathrm{PEt}_{3}(\mathrm{M}=\mathrm{Mo}, \mathrm{W})$, and $\mathrm{b} /$ $\mathrm{P}(\mathrm{OMe})_{3}(\mathrm{M}=\mathrm{Mo}) .[321]$

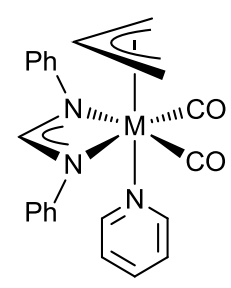

139

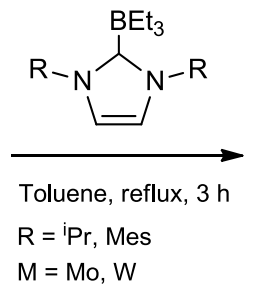

$M=M o, W$

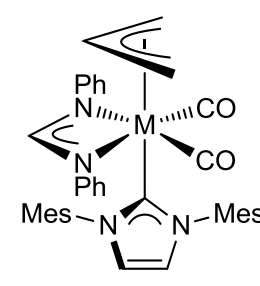

148

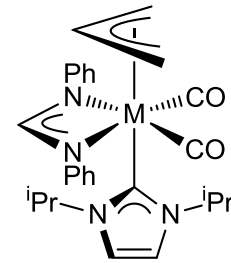

149

Scheme 50. Pyridine-substitution reactions of amidinato complexes $139(\mathrm{M}=\mathrm{Mo}, \mathrm{W})$ with triethylborane adducts of various $N$-heterocyclic carbenes. [336]

In accordance with the installation of the monodentate ligands (vide supra), the pyridine ligand in $\mathbf{1 3 9}$ is also readily displaced by bidentate ligands, presumably through a coordinatively unsaturated intermediate close to 142 (Scheme 42). Reaction of 139 with strongly chelating 1,10-phenanthroline (phen) affords the monodentate-amidinato complex $\left[\mathrm{M}(\mathrm{CO})_{2}\left(\eta^{3}\right.\right.$-allyl $)($ phen $)\left(\kappa^{1}-N, N\right.$-diphenylamidinate)] $(\mathrm{M}=\mathrm{Mo}, \mathrm{W})$ (150) (Scheme 51). [244] The $\kappa^{2}$-coordination mode of the phen ligand is endorsed by the rigidity of the ligand backbone, and accommodated by a change in denticity of the amidinate ligand, which in its $\kappa^{1}$-coordination motif occupies the position trans to the allyl ligand in the sold state, as in structure $\mathbf{C}$. The low temperature ${ }^{1} \mathrm{H}$ NMR spectrum recorded for $\mathbf{1 5 0}$ at $-40{ }^{\circ} \mathrm{C}$ in $\mathrm{CD}_{2} \mathrm{Cl}_{2}$ displays a well-resolved signal pattern consistent with the solid-state structure. Higher temperature spectra, measured in DMSO- $d_{6}$, exhibited broad peaks from room temperature to $c a .70$ ${ }^{\circ} \mathrm{C}$, where upon the advent of a new set of sharp signals indicated the formation of $N, N^{\prime}-$ diphenylallylamidine, as a result of a coupling reaction between the termini of the allyl and amidinate ligands. As discussed in Section 3.3, this coupling reaction necessitates the cis relationship between the two reacting ligands, and hence the existence of isomer D (Scheme 51). Interestingly, the coupling reaction does not proceed for the tungsten congener, and whilst the allylmolybdenum-2,2'-bipyridine analogue to $\mathbf{1 5 0}$ was also prepared in the same manner, its subsequent reactivity and fluxionality were 
not reported. In the case of the reaction of $\mathbf{1 3 9}$ with dppe under identical ambient experimental conditions, dppe-bridged dinuclear complex 151 was isolated (Scheme 52a). [244] Such an observation demonstrates the chelating power of the rigid, convergent $N$-lone pair structures of phen and, to some extent, bpy. Under more forcing conditions, the dppe ligand achieves a bidentate coordination mode at the expense of a carbonyl ligand in the mononuclear complex $\left[\mathrm{M}(\mathrm{CO})\left(\eta^{3}\right.\right.$-allyl $)\left(N, N^{\prime}-\right.$ diphenylamidinate)(dppe)] $(\mathrm{M}=\mathrm{Mo}, \mathrm{W})$ (152) (Scheme 52b). Clearly, 152 does not have the stereochemical constraints associated with the orientation of the allyl ligand in the dicarbonyl complexes explored in Sections 3 and 4 (refer to Section 3.2 for additional discussion). Convincing evidence for the existence of two isomers $\mathbf{F}$ and $\mathbf{F}^{\prime}$ (Scheme 52), distinguished by a $180^{\circ}$ rotation of the allyl ligand (note that the descriptors $\mathbf{C}$ and $\mathbf{D}$ for symmetric and asymmetric structures, respectively, (Chart 10) are not applicable here), is provided by the X-ray structure of 152. In the crystal structure the allyl group is disordered, with the meso-carbon appearing in two sites. Such an observation is consistent with the two rotamers $\mathbf{F}$ and $\mathbf{F}^{\prime}$, whereby the former predominates (3:1 for $\mathbf{M}=\mathrm{Mo} ; 2: 1$ for $\mathrm{M}=\mathrm{W}$ ), which is in agreement with a similar isomerism reported for related monocarbonyl allyl molybdenum complexes bearing $\kappa^{2}-\left(\mathrm{X}^{\urcorner} \mathrm{X}\right)(\mathrm{X}=\mathrm{S}, \mathrm{N} ;$ e.g., dithiocarbamate, dithiophosphate, pyridine2-thionate) ligands with allylic backbones; these complexes are beyond of the scope of this review, but their resemblance to the amidinato complexes provides some useful insight into the reactivity and fluxionality discussed herein. [243,339-342]

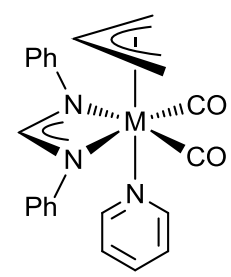

139
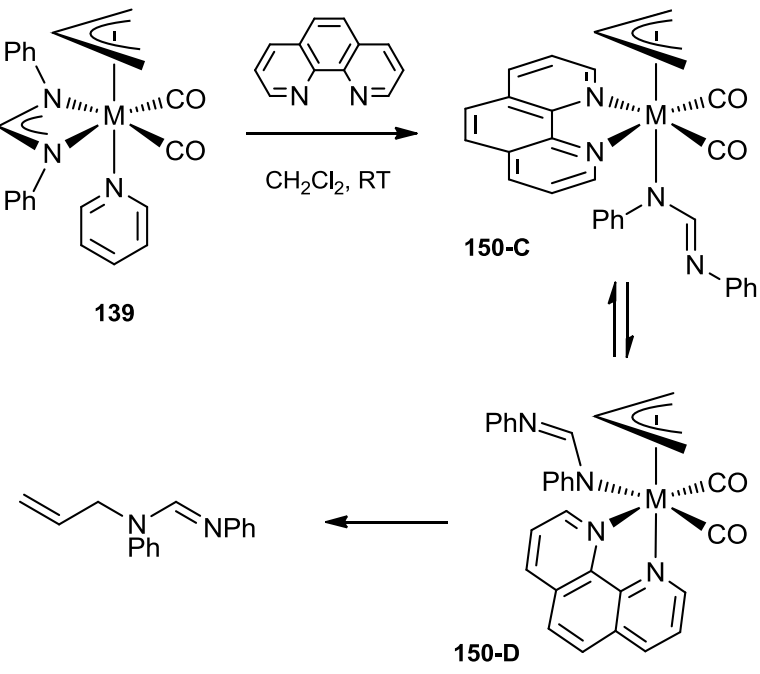
Scheme 51. Pyridine-substitution reactions of amidinato complexes $139(\mathrm{M}=\mathrm{Mo}, \mathrm{W})$ with 1,10-phenanthroline.

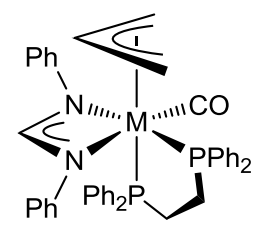

152-F

4

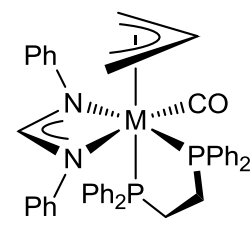

152-F' b)

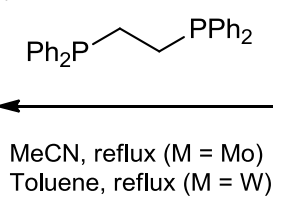

Toluene, reflux $(M=W)$

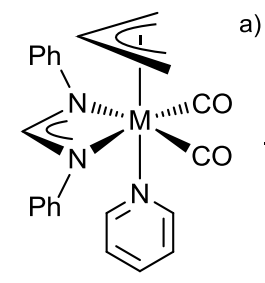

139 a)
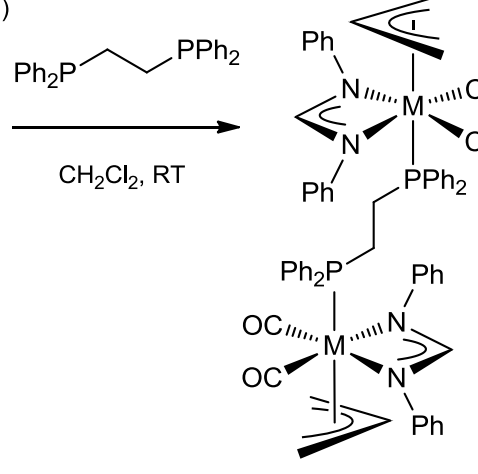

151

Scheme 52. Pyridine-substitution reactions of amidinato complexes $139(M=M o, W)$ with dppe. [244]

\section{Summary and outlook}

There has been much recent interest in allyl carbonyl complexes of the Group- 6 metals, including numerous studies of their catalytic activity. This activity has rendered timely an up-to-date survey of this large topic, including reactivity, dynamic behaviour, and structural features. Sections 3 and 4 have detailed many of the already extensive range of ligands that are found in association with the robust $\mathrm{M}(\mathrm{CO})_{2}\left(\eta^{3}\right.$-allyl) fragment, and the chemistry of such compounds. No review of such a vital, active area could hope to be comprehensive, and indeed many stimulating topics remain to date, unexplored. Within this class, compounds incorporating an $\alpha$-diimine motif have recently aroused great interest, not least because of their electrocatalytic activity, and significant role in affecting the cathodic behaviour. The wide range of $\alpha$-diimine ligands offers much scope for study; while chelating species, 
on account of their relative kinetic inertness, offer not only the possibility of varying steric and electronic factors, but also tethering to immobilised beds through backbone substitution, giving potential heterogeneous systems. This is also illustrated by amidinate complexes, where ligand backbone substitution has been shown to markedly affect the solution-borne dynamic behaviour (Section 4). The generation of active species in such significant processes as electrocatalytic reduction of carbon dioxide, may result from ligand loss, increasing further the interest in $\alpha$-diimine-containing species with electrochemically labile ligands.

The comparatively inert and frequently non-fluxional parent allyl ligand has been the subject of much less structural modification. It has been mentioned above, however, that the presence of mesomerically-active allyl substituents is frequently reflected at the metal centre, while sterically significant substituents almost invariably affect fluxionality. Further diversity is introduced by the incorporation of heteroatoms into the allyl ligand. While such compounds remain beyond the scope of the present article, the interested reader will find notable examples of such species in the following references: $\eta^{3}$-azaallyl [58-64], $\eta^{3}$-silaallyl [343-345], and silabenzyl [346-349] complexes, while the related $\eta^{3}$-bound benzyl species are detailed in [350-357]. The benzyl and related complexes offer an alternative route to coordinative unsaturation, via a relatively facile $\eta^{3} \rightarrow \eta^{1}$ haptotropic shift.

\section{Acknowledgements}

This work was jointly supported by the Reading Spectroelectrochemistry laboratory (Project D14-015 at the University of Reading) and the EPSRC - DTP Project F4044706.

\section{References}

[1] M. Cousins, M. L. H. Green, J. Chem. Soc. (1963) 889-894. 
[2] F. Hartl, H. Luyten, H. A. Nieuwenhuis, G. C. Schoemaker, Appl. Spectrosc. 48 (1994) $1522-$ 1528.

[3] F. P. A. Johnson, M. W. George, F. Hartl, J. J. Turner, Organometallics 15 (1996) 3374-3387.

[4] C. D. Nunes, M. J. Calhorda, Inorg. Chim. Acta 431 (2015) 122-131.

[5] M. L. H. Green, A. N. Stear, J. Organomet. Chem. 1 (1964) 230-234.

[6] T. E. Bitterwolf, J. Organomet. Chem. 689 (2004) 3939-3952.

[7] R. G. Hayter, J. Organomet. Chem. 13 (1968) P1-P3.

[8] D. W. Norman, M. J. Ferguson, J. M. Stryker, Organometallics 23 (2004) 2015-2019.

[9] P. M. Reis, C. A. Gamelas, J. A. Brito, N. Saffon, M. Gómez, B. Royo, Eur. J. Inorg. Chem. (2011) 666-673.

[10] D. P. Tate, W. R. Knipple, J. M. Augl, Inorg. Chem. 1 (1962) 433-434.

[11] R. P. A. Sneeden, Organochromium Compounds, Academic Press, New York, 1975, pp. 49.

[12] K. B. Shiu, K. S. Liou, C. P. Cheng, B. R. Fang, Y. Wang, G. H. Lee, W. J. Vong, Organometallics 8 (1989) 1219-1224.

[13] S. Trofimenko, J. Am. Chem. Soc. 91 (1969) 588-595.

[14] S. Trofimenko, J. Am. Chem. Soc. 89 (1967) 3904-3905.

[15] G. Wilke, B. Bogdanović, P. Hardt, P. Heimbach, W. Keim, M. Kröner, W. Oberkirch, K. Tanaka, E. Steinrücke, D. Walter, H. Zimmermann, Angew. Chem. Int. Ed. 5 (1966) 151-164.

[16] V. V. Krivykh, O. V. Gusev, M. I. Rybinskaya, J. Organomet. Chem. 362 (1989) 351-362.

[17] F. H. Allen, Acta Crystallogr., Sect. B: Struct. Sci. 58 (2002) 380-388.

[18] M. J. Calhorda, C. A. Gamelas, I. S. Gonçalves, E. Herdtweck, C. C. Romão, L. F. Veiros, Organometallics 17 (1998) 2597-2611. 
[19] M. J. Calhorda, L. F. Veiros, Coord. Chem. Rev. 185-186 (1999) 37-51.

[20] J. Honzíček, J. Vinklárek, M. Erben, J. Lodinský, L. Dostál, Z. Padělková, Organometallics 32 (2013) 3502-3511.

[21] R. B. King, Inorg. Chem. 5 (1966) 2242-2243.

[22] A. Davison, W. C. Rode, Inorg. Chem. 6 (1967) 2124-2125.

[23] D. R. van Staveren, T. Weyhermüller, N. Metzler-Nolte, Organometallics 19 (2000) 3730-3735.

[24] J. W. Faller, M. J. Incorvia, Inorg. Chem. 7 (1968) 840-842.

[25] F. A. Cotton, J. W. Faller, A. Musco, Inorg. Chem. 6 (1967) 179-182.

[26] R. W. Fish, W. P. Giering, D. Marten, M. Rosenblum, J. Organomet. Chem. 105 (1976) 101118.

[27] D. H. Gibson, W.-L. Hsu, A. L. Steinmetz, B. V. Johnson, J. Organomet. Chem. 208 (1981) 89102.

[28] A. Ariafard, S. Bi, Z. Lin, Organometallics 24 (2005) 2241-2244.

[29] B. E. R. Schilling, R. Hoffmann, J. W. Faller, J. Am. Chem. Soc. 101 (1979) 592-598.

[30] C. Limberg, A. J. Downs, T. M. Greene, T. Wistuba, Eur. J. Inorg. Chem. (2001) 2613-2618.

[31] S. Bi, A. Ariafard, G. Jia, Z. Lin, Organometallics 24 (2005) 680-686.

[32] I. S. Gonçalves, L. F. Veiros, C. A. Gamelas, C. Cabrita, M. J. Calhorda, C. F. G. C. Geraldes, J. Green, E. Packham, M. G. B. Drew, V. Félix, A. Gil Santos, C. C. Romão, J. Organomet. Chem. 792 (2015) 154-166.

[33] T. E. Bitterwolf, J. T. Bays, B. Scallorn, C. A. Weiss, M. W. George, I. G. Virrels, J. C. Linehan, C. R. Yonker, Eur. J. Inorg. Chem. (2001) 2619-2624.

[34] J. W. Faller, B. C. Whitmore, Organometallics 5 (1986) 752-755.

[35] N. W. Murrall, A. J. Welch, Acta Crystallogr., Sect. C: Cryst. Struct. Commun. 40 (1984) 401- 
403.

[36] D. S. Gill, P. K. Baker, M. Green, K. E. Paddick, M. Murray, A. J. Welch, J. Chem. Soc., Chem. Commun. (1981) 986.

[37] C.-Y. Cheng, G.-H. Lee, S.-M. Peng, R.-S. Liu, Organometallics 15 (1996) 1565-1571.

[38] V. B. Rybakov, L. A. Aslanov, V. M. Ionov, S. A. Eremin, J. Struct. Chem. 24 (1983) 414-427.

[39] M. Minelli, J. H. Enemark, R. T. C. Brownlee, M. J. O'connor, A. G. Wedd, Coord. Chem. Rev. 68 (1985) 169-278.

[40] J. T. Bailey, R. J. Clark, G. C. Levy, Inorg. Chem. 21 (1982) 2085-2087.

[41] N. F. Ramsey, Phys. Rev. 78 (1950) 699-703.

[42] C. J. Jameson, H. S. Gutowsky, J. Chem. Phys. 40 (1964) 1714-1724.

[43] J. Mason, Adv. Inorg. Chem. Radiochem. 22 (1979) 199-237.

[44] J. C. C. Chan, S. C. F. Au-Yeung, J. Chem. Soc., Faraday Trans. 92 (1996) 1121-1128.

[45] J. Mason, Chem. Rev. 87 (1987) 1299-1312.

[46] J. R. L. Priqueler, I. S. Butler, F. D. Rochon, Appl. Spectrosc. Rev. 41 (2006) 185-226.

[47] B. M. Still, P. G. A. Kumar, J. R. Aldrich-Wright, W. S. Price, Chem. Soc. Rev. 36 (2007) 66586.

[48] W. von Philipsborn, Chem. Soc. Rev. 28 (1999) 95-105.

[49] J. W. Faller, C.-C. Chen, M. J. Mattina, A. Jakubowski, J. Organomet. Chem. 52 (1973) 361386.

[50] C. M. Adams, G. Cerioni, A. Hafner, H. Kalchhauser, W. von Philipsborn, R. Prewo, A. Schwenk, Helv. Chim. Acta 71 (1988) 1116-1142.

[51] W. von Philipsborn, Pure Appl. Chem. 58 (1986) 513-528. 
[52] A. Fabrello, C. Dinoi, L. Perrin, P. Kalck, L. Maron, M. Urrutigoity, O. Dechy-Cabaret, Magn. Reson. Chem. 48 (2010) 848-856.

[53] M. A. Ortuño, L. Castro, M. Bühl, Organometallics 32 (2013) 6437-6444.

[54] A. C. Tsipis, I. N. Karapetsas, Dalton Trans. 43 (2014) 5409-5426.

[55] H. Bönnemann, W. Brijoux, R. Brinkmann, W. Meurers, R. Mynott, W. von Philipsborn, T. Egolf, J. Organomet. Chem. 272 (1984) 231-249.

[56] J. Malito, Annu. Rep. NMR Spectrosc. 33 (1996) 151-206.

[57] D. L. Bryce, R. E. Wasylishen, Phys. Chem. Chem. Phys. 4 (2002) 3591-3600.

[58] P. J. Daff, N. Kaltsoyannis, J. Chem. Soc., Dalton Trans. (1995) 1925-1932.

[59] U. Amador, P. J. Daff, M. L. Poveda, C. Ruiz, E. Carmona, J. Chem. Soc., Dalton Trans. (1997) $3145-3152$.

[60] P. J. Daff, A. Monge, P. Palma, M. L. Poveda, C. Ruiz, P. Valerga, E. Carmona, Organometallics 16 (1997) 2263-2275.

[61] E. Carmona, P. J. Daff, A. Monge, P. Palma, M. L. Poveda, C. Ruiz, J. Chem. Soc., Chem. Commun. (1991) 1503-1505.

[62] A. C. Filippou, W. Grünleitner, P. Kiprof, J. Organomet. Chem. 410 (1991) 175-210.

[63] G. M. Yang, G. H. Lee, S. M. Peng, R. S. Liu, Organometallics 10 (1991) 1305-1310.

[64] M. Green, R. J. Mercer, C. E. Morton, A. G. Orpen, Angew. Chem. Int. Ed. 24 (1985) 422-424.

[65] R. G. Kidd, J. Magn. Reson. 45 (1981) 88-93.

[66] P. S. Pregosin, NMR in Organometallic Chemistry, Wiley-VCH, Weinheim, 2012, pp. 35, 87, 179-196.

[67] R. J. Carbajo, L. Zhang, F. López-Ortiz, Magn. Reson. Chem. 36 (1998) 807-814.

[68] P. S. Pregosin, A. Macchioni, J. L. Templeton, P. S. White, S. Feng, Magn. Reson. Chem. 32 
(1994) 415-421.

[69] A. Macchioni, P. S. Pregosin, H. Rüegger, G. van Koten, P. A. van der Schaaf, R. A. T. M. Abbenhuis, Magn. Reson. Chem. 32 (1994) 235-241.

[70] L. A. Villanueva, Y. D. Ward, R. Lachicotte, L. S. Liebeskind, Organometallics 15 (1996) 41904200.

[71] D. S. Frohnapfel, P. S. White, J. L. Templeton, H. Rüegger, P. S. Pregosin, Organometallics 16 (1997) 3737-3750.

[72] D. W. Norman, R. McDonald, J. M. Stryker, Organometallics 24 (2005) 4461-4467.

[73] M. Brookhart, M. L. H. Green, G. Parkin, Proc. Natl. Acad. Sci. U. S. A. 104 (2007) 6908-6914.

[74] E. Clot, O. Eisenstein, Struct. Bonding 113 (2004) 1-36.

[75] W. Scherer, G. S. McGrady, Angew. Chem. Int. Ed. 43 (2004) 1782-1806.

[76] E. J. M. Hamilton, J. S. Park, X. Chen, S. Liu, M. R. Sturgeon, E. A. Meyers, S. G. Shore, Organometallics 28 (2009) 3973-3980.

[77] L. Brammer, B. J. Dunne, M. Green, G. Moran, A. G. Orpen, C. Reeve, C. J. Schaverien, J. Chem. Soc., Dalton Trans. (1993) 1747-1759.

[78] M. F. Asaro, S. R. Cooper, N. J. Cooper, J. Am. Chem. Soc. 108 (1986) 5187-5193.

[79] M. J. Shaw, W. E. Geiger, J. Hyde, C. White, Organometallics 17 (1998) 5486-5491.

[80] F. A. Cotton, T. LaCour, A. G. Stainislowski, J. Am. Chem. Soc. 96 (1974) 754-760.

[81] S. Trofimenko, Inorg. Chem. 9 (1970) 2493-2499.

[82] M. Brookhart, W. Lamanna, M. B. Humphrey, J. Am. Chem. Soc. 104 (1982) 2117-2126.

[83] M. Brookhart, W. Lamanna, A. R. Pinhas, Organometallics 2 (1983) 638-649.

[84] M. Brookhart, S. K. Noh, F. J. Timmers, Y. H. Hong, Organometallics 7 (1988) 2458-2465. 
[85] A. Castillo, M. A. Esteruelas, E. Oñate, N. Ruiz, J. Am. Chem. Soc. 119 (1997) 9691-9698.

[86] W. N. Palmer, T. Diao, I. Pappas, P. J. Chirik, ACS Catal. 5 (2015) 622-626.

[87] C. W. Spicer, C. F. Lovitt, G. S. Girolami, Organometallics 31 (2012) 4894-4903.

[88] A. Galindo, E. Gutiérrez, A. Monge, M. Paneque, A. Pastor, P. J. Pérez, R. D. Rogers, E. Carmona, J. Chem. Soc., Dalton Trans. (1995) 3801-3808.

[89] K. I. Galkin, S. E. Lubimov, I. A. Godovikov, F. M. Dolgushin, A. F. Smol'yakov, E. A. Sergeeva, V. A. Davankov, I. T. Chizhevsky, Organometallics 31 (2012) 6080-6084.

[90] M. A. Bennett, L. Y. Goh, I. J. McMahon, T. R. B. Mitchell, G. B. Robertson, T. W. Turney, Organometallics 11 (1992) 3069-3085.

[91] C. G. Kreiter, K. Lehr, G. Heeb, Z. Naturforsch. B 46 (1991) 941-949.

[92] A. Salzer, B. Buchmann, H. Schmalle, Acta Crystallogr., Sect. C: Cryst. Struct. Commun. 47 (1991) 275-279.

[93] K. Vrieze, H. C. Volger, P. W. N. M. van Leeuwen, Inorg. Chim. Acta Rev. 3 (1969) 109-128.

[94] D. R. van Staveren, E. Bill, E. Bothe, M. Bühl, T. Weyhermüller, N. Metzler-Nolte, Chem. Eur. J. 8 (2002) 1649-1662.

[95] W.-Q. Zhang, A. J. Atkin, I. J. S. Fairlamb, A. C. Whitwood, J. M. Lynam, Organometallics 30 (2011) 4643-4654.

[96] J.-T. Chen, Y.-K. Chen, J.-B. Chu, G.-H. Lee, Y. Wang, Organometallics 16 (1997) 14761483.

[97] J.-S. Fang, G.-H. Lee, S.-M. Peng, R.-S. Liu, Organometallics 19 (2000) 4458-4462.

[98] P. W. Jolly, R. Mynott, Adv. Organomet. Chem. 19 (1981) 257-304.

[99] K. E. Garrett, J. B. Sheridan, D. B. Pourreau, W. C. Feng, G. L. Geoffroy, D. L. Staley, A. L. Rheingold, J. Am. Chem. Soc. 111 (1989) 8383-8391. 
[100] T.-C. Yueh, S.-F. Lush, G.-H. Lee, S.-M. Peng, R.-S. Liu, Organometallics 15 (1996) 56695673.

[101] T. C. Coombs, W. Huang, E. C. Garnier-Amblard, L. S. Liebeskind, Organometallics 29 (2010) 5083-5097.

[102] C.-C. Chen, J.-S. Fan, G.-H. Lee, S.-M. Peng, S.-L. Wang, R. S. Liu, J. Am. Chem. Soc. 117 (1995) 2933-2934.

[103] I. Y. Wu, T. W. Tseng, Y. C. Lin, M. C. Cheng, Y. Wang, Organometallics 12 (1993) 478-485.

[104] T. W. Tseng, I. Y. Wu, Y. C. Lin, C. T. Chen, M. C. Chen, Y. J. Tsai, M. C. Chen, Y. Wang, Organometallics 10 (1991) 43-45.

[105] G.-M. Yang, G.-H. Lee, S.-M. Peng, R.-S. Liu, J. Chem. Soc., Chem. Commun. (1991) 478479.

[106] C. G. de Azevedo, M. J. Calhorda, M. A. A. F. de C. T. Carrondo, A. R. Dias, M. T. Duarte, A. M. Galvão, C. A. Gamelas, I. S. Gonçalves, F. M. da Piedade, C. C. Romão, J. Organomet. Chem. 544 (1997) 257-276.

[107] N. G. Connelly, G. A. Johnson, J. Organomet. Chem. 77 (1974) 341-344.

[108] J. K. Shen, J. W. Freeman, N. C. Hallinan, A. L. Rheingold, A. M. Arif, R. D. Ernst, F. Basolo, Organometallics 11 (1992) 3215-3224.

[109] R. D. Adams, D. F. Chodosh, J. W. Faller, A. M. Rosan, J. Am. Chem. Soc. 101 (1979) 25702578.

[110] J. W. Faller, A. M. Rosan, J. Am. Chem. Soc. 98 (1976) 3388-3389.

[111] J. W. Faller, C. Lambert, M. R. Mazzieri, J. Organomet. Chem. 383 (1990) 161-177.

[112] S. G. Davies, M. L. H. Green, D. M. P. Mingos, Tetrahedron 34 (1978) 3047-3077.

[113] M. Ephritikhine, B. R. Francis, M. L. H. Green, R. E. Mackenzie, M. J. Smith, J. Chem. Soc., 
Dalton Trans. (1977) 1131-1135.

[114] M. D. Curtis, O. Eisenstein, Organometallics 3 (1984) 887-895.

[115] J. W. Faller, K. H. Chao, J. Am. Chem. Soc. 105 (1983) 3893-3898.

[116] T. Suzuki, G. Okada, Y. Hioki, H. Fujimoto, Organometallics 22 (2003) 3649-3658.

[117] R. A. Baillie, P. Legzdins, Coord. Chem. Rev. 309 (2016) 1-20.

[118] L. F. Lindoy, S. E. Livingstone, Coord. Chem. Rev. 2 (1967) 173-193.

[119] H. D. Murdoch, R. Henzi, J. Organomet. Chem. 5 (1966) 552-558.

[120] H. D. Murdoch, J. Organomet. Chem. 4 (1965) 119-126.

The tris(halide) bridged dimeric compound is of tangential interest, alluded to in Section 3.1. Its synthesis is in line with the other syntheses discussed in Section 3.1, wherein oxidative addition of an allyl halide substrate is best achieved using a more nucleophilic anionic metal complex, rather than the neutral equivalent. Here, reaction of the $\left[\mathrm{M}(\mathrm{CO})_{6}\right](\mathrm{M}=\mathrm{Mo}$ and $\mathrm{W})$ precursors with allyl halides is unsuccessful, whilst the pentacarbonyl halide anions $\left[\mathrm{M}(\mathrm{CO})_{5} \mathrm{X}\right]^{-}$yield the tris(halide) bridged dimers. The dimeric structure is best described by two pentagonal bipyrimidal coordination spheres, which share a face delineated by the three halide ligands. The steric penalty associated with this apperently 7-coordinate topology around each metal centre is perhaps the cause for the failture to procure analogues that contain either iodine as the halide, or chromium as the metal centre.

[121] C. G. Hull, M. H. B. Stiddard, J. Organomet. Chem. 9 (1967) 519-525.

[122] M. H. B. Stiddard, J. Chem. Soc. (1962) 4712-4715.

[123] D. J. Stufkens, Coord. Chem. Rev. 104 (1990) 39-112.

[124] A. Vlček Jr., Coord. Chem. Rev. 230 (2002) 225-242.

[125] H. tom Dieck, H. Friedel, J. Organomet. Chem. 14 (1968) 375-385. 
[126] G. J. Kubas, L. S. Van Der Sluys, R. A. Doyle, R. J. Angelici, Tricarbonyltris(Nitrile) Complexes of Cr, Mo, and W, in: R. J. Angelici (Ed.), Inorganic Syntheses, Volume 28, John Wiley \& Sons Inc., Hoboken, New Jersey, 1990, pp. 29-33.

[127] M. V. Baker, M. R. North, J. Organomet. Chem. 565 (1998) 225-230.

[128] R. S. Dickson, J. Bowen, E. M. Campi, W. R. Jackson, C. A. M. Jonasson, F. J. McGrath, D. J. Paslow, A. Polas, P. Renton, S. Gladiali, J. Mol. Catal. A: Chem. 150 (1999) 133-146.

[129] F. Edelmann, P. Behrens, S. Behrens, U. Behrens, J. Organomet. Chem. 310 (1986) 333-355.

[130] A. T. T. Hsieh, B. O. West, J. Organomet. Chem. 112 (1976) 285-296.

[131] C. E. Holloway, J. D. Kelly, M. H. B. Stiddard, J. Chem. Soc. A (1969) 931-935.

[132] B. J. Brisdon, D. A. Edwards, J. W. White, J. Organomet. Chem. 156 (1978) 427-437.

[133] B. J. Brisdon, G. F. Griffin, J. Organomet. Chem. 76 (1974) C47-C49.

[134] T. Turki, T. Guerfel, F. Bouachir, Polyhedron 28 (2009) 569-573.

[135] Y. Oprunenko, S. Malyugina, A. Vasil'ko, K. Lyssenko, C. Elschenbroich, K. Harms, J. Organomet. Chem. 641 (2002) 208-214.

[136] J. A. Kaduk, A. T. Poulos, J. A. Ibers, J. Organomet. Chem. 127 (1977) 245-260.

[137] M. A. Cohen, T. L. Brown, Inorg. Chem. 15 (1976) 1417-1423.

[138] D. J. Darensbourg, J. D. Draper, D. L. Larkins, B. J. Frost, J. H. Reibenspies, Inorg. Chem. 37 (1998) 2538-2546.

[139] G. R. Dobson, K. J. Asali, J. L. Marshall, C. R. McDaniel, J. Am. Chem. Soc. 99 (1977) 81008102.

[140] R. J. Angelici, J. R. Graham, J. Am. Chem. Soc. 87 (1965) 5586-5590.

[141] J. A. S. Howell, P. M. Burkinshaw, Chem. Rev. 83 (1983) 557-599.

[142] F. Zingales, M. Graziani, U. Belluco, J. Am. Chem. Soc. 89 (1967) 256-260. 
[143] F.-W. Grevels, K. Kerpen, W. E. Klotzbücher, K. Schaffner, R. Goddard, B. Weimann, C. Kayran, S. Özkar, Organometallics 20 (2001) 4775-4792.

[144] J. W. Faller, D. Linebarrier, Organometallics 7 (1988) 1670-1672.

[145] D. L. Hughes, G. C. Lloyd-Jones, S. W. Krska, L. Gouriou, V. D. Bonnet, K. Jack, Y. Sun, D.J. Mathre, R. A. Reamer, Proc. Natl. Acad. Sci. U. S. A. 101 (2004) 5379-5384.

[146] S. W. Krska, D. L. Hughes, R. A. Reamer, D. J. Mathre, M. Palucki, N. Yasuda, Y. Sun, B. M. Trost, Pure Appl. Chem. 76 (2004) 625-633.

[147] A. Kuhl, J. A. Christopher, L. J. Farrugia, P. J. Kocienski, Synlett (2000) 1765-1768.

[148] G. C. Lloyd-Jones, S.W. Krska, D. L. Hughes, L. Gouriou, V. D. Bonnet, K. Jack, Y. Sun, R.A. Reamer, J. Am. Chem. Soc. 126 (2004) 702-703.

[149] J. A. R. Luft, Z.-X. Yu, D. L. Hughes, G. C. Lloyd-Jones, S. W. Krska, K. N. Houk, Tetrahedron: Asymmetry 17 (2006) 716-724.

[150] A. V. Malkov, L. Gouriou, G. C. Lloyd-Jones, I. Starý, V. Langer, P. Spoor, V. Vinader, P. Kocovský, Chem. Eur. J. 12 (2006) 6910-6929.

[151] A. Rubio, L. S. Liebeskind, J. Am. Chem. Soc. 115 (1993) 891-901.

[152] B. M. Trost, C. A. Merlic, J. Am. Chem. Soc. 112 (1990) 9590-9600.

[153] Y. D. Ward, L. A. Villanueva, G. D. Allred, L. S. Liebeskind, J. Am. Chem. Soc. 118 (1996) 897-898.

[154] J. W. Faller, J. T. Nguyen, W. Ellis, M. R. Mazzieri, Organometallics 12 (1993) 1434-1438.

[155] L. M. Wolf, W. Thiel, J. Org. Chem. 79 (2014) 12136-12147.

[156] D. M. Spencer, R. L. Beddoes, R. K. Dissanayake, M. Helliwell, M. W. Whiteley, J. Chem. Soc., Dalton Trans. (2002) 1009-1019.

[157] P. A. Evans, J. D. Nelson, J. Am. Chem. Soc. 120 (1998) 5581-5582. 
[158] M. P. T. Sjögren, H. Frisell, B. Åkermark, P. -O. Norrby, L. Eriksson, A. Vitagliano, Organometallics 16 (1997) 942-950.

[159] M. Arroyo, D. Miguel, F. Villafañe, E. C. B. Alegria, A. J. L. Pombeiro, Dalton Trans. 41 (2012) $7017-7025$.

[160] P. K. Baker, M. G. B. Drew, M. M. Meehan, E. E. Parker, A. E. Underhill, J. Organomet. Chem. 560 (1998) 191-196.

[161] G. L. Hillhouse, G. V. Goeden, B. L. Haymore, Inorg. Chem. 21 (1982) 2064-2071.

[162] C. E. Osterberg, A. M. Arif, T. G. Richmond, J. Am. Chem. Soc. 110 (1988) 6903-6904.

[163] S. D. Perera, J. J. Fernandez-Sanchez, B. L. Shaw, Inorg. Chim. Acta 325 (2001) 175-178.

[164] M. J. Poss, A. M. Arif, T. G. Richmond, Organometallics 7 (1988) 1669-1670.

[165] T. G. Richmond, M. A. King, E. P. Kelson, A. M. Arif, Organometallics 6 (1987) 1995-1996.

[166] T. G. Richmond, C. E. Osterberg, A. M. Arif, J. Am. Chem. Soc. 109 (1987) 8091-8092.

[167] J.-P. Sun, D.-W. Zhao, H.-B. Song, L.-F. Tang, Organometallics 33 (2014) 4425-4432.

[168] M. Wang, T. Weyhermüller, J. England, K. Wieghardt, Inorg. Chem. 52 (2013) 12763-12776.

[169] D.-W. Zhao, Y.-F. Xie, H.-B. Song, L.-F. Tang, J. Organomet. Chem. 718 (2012) 89-95.

[170] S. F. Lush, S. H. Wang, G. H. Lee, S. M. Peng, S. L. Wang, R. S. Liu, Organometallics 9 (1990) $1862-1871$.

[171] J. W. Faller, D. A. Haitko, R. D. Adams, D. F. Chodosh, J. Am. Chem. Soc. 101 (1979) 865876.

[172] J. R. Ascenso, C. G. de Azevedo, M. J. Calhorda, M. A. A. F. de C. T. Carrondo, P. Costa, A. R. Dias, M. G. B. Drew, V. Félix, A. M. Galvão, C. C. Romão, J. Organomet. Chem. 632 (2001) $197-208$.

[173] J. Honzíček, J. Vinklárek, Z. Padělková, L. Šebestová, K. Foltánová, M. Řezáčová, J. 
Organomet. Chem. 716 (2012) 258-268.

[174] A. J. Graham, R. H. Fenn, J. Organomet. Chem. 17 (1969) 405-422.

[175] J. Pérez, L. Riera, V. Riera, S. García-Granda, E. García-Rodríguez, J. Am. Chem. Soc. 123 (2001) 7469-7470.

[176] F.-C. Liu, P.-S. Yang, C.-Y. Chen, G.-H. Lee, S.-M. Peng, J. Organomet. Chem. 693 (2008) $537-545$.

[177] J. Pérez, L. Riera, V. Riera, S. García-Granda, E. García-Rodríguez, D. Miguel, Organometallics 21 (2002) 1622-1626.

[178] D. Bandarra, M. Lopes, T. Lopes, J. Almeida, M. S. Saraiva, M. Vasconcellos-Dias, C. D. Nunes, V. Félix, P. Brandão, P. D. Vaz, M. Meireles, M. J. Calhorda, J. Inorg. Biochem. 104 (2010) 1171-1177.

[179] C. W. Rodrigues, C. Limberg, H. Pritzkow, Chem. Commun. (2004) 2734-2735.

[180] P. M. F. J. Costa, M. Mora, M. J. Calhorda, V. Félix, P. Ferreira, M. G. B. Drew, H. Wadepohl, J. Organomet. Chem. 687 (2003) 57-68.

[181] L. Coue, L. Cuesta, D. Morales, J. A. Halfen, J. Pérez, L. Riera, V. Riera, D. Miguel, N. G. Connelly, S. Boonyuen, Chem. Eur. J. 10 (2004) 1906-1912.

[182] N. W. Murrall, A. J. Welch, J. Organomet. Chem. 301 (1986) 109-130.

[183] A. J. Graham, R. H. Fenn, J. Organomet. Chem. 25 (1970) 173-191.

[184] J. Pérez, L. Riera, V. Riera, S. García-Granda, E. García-Rodríguez, D. Miguel, Chem. Commun. (2002) 384-385.

[185] L. Eriksson, M. P. T. Sjögren, B. Åkermark, Acta Crystallogr., Sect. C: Cryst. Struct. Commun. 52 (1996) 77-80.

[186] E. Hevia, J. Pérez, L. Riera, V. Riera, I. Del Río, S. García-Granda, D. Miguel, Chem. Eur. J. 8 
(2002) 4510-4521.

[187] D. Morales, M. E. Navarro Clemente, J. Pérez, L. Riera, V. Riera, D. Miguel, Organometallics 21 (2002) 4934-4938.

[188] D. C. Gerbino, E. Hevia, D. Morales, M. E. N. Clemente, J. Pérez, L. Riera, V. Riera, D. Miguel, Chem. Commun. (2003) 328-329.

[189] D. Morales, M. E. Navarro Clemente, J. Pérez, L. Riera, V. Riera, D. Miguel, Organometallics 22 (2003) 4124-4128.

[190] D. Morales, J. Pérez, L. Riera, V. Riera, D. Miguel, M. E. G. Mosquera, S. García-Granda, Chem. Eur. J. 9 (2003) 4132-4143.

[191] D. Morales, J. Pérez, L. Riera, V. Riera, D. Miguel, Inorg. Chem. 41 (2002) 4111-4113.

[192] J. Pérez, E. Hevia, L. Riera, V. Riera, S. García-Granda, E. García-Rodríguez, D. Miguel, Eur. J. Inorg. Chem. 2003 (2003) 1113-1120.

[193] J. Lodinský, J. Vinklárek, L. Dostál, Z. Růžičková, J. Honzíček, RSC Adv. 5 (2015) 2714027153

[194] J. Tory, G. Gobaille-Shaw, A. M. Chippindale, F. Hartl, J. Organomet. Chem. 760 (2014) 3041.

[195] J. C. Alonso, P. Neves, M. J. Pires da Silva, S. Quintal, P. D. Vaz, C. Silva, A. A. Valente, P. Ferreira, M. J. Calhorda, V. Félix, M. G. B. Drew, Organometallics 26 (2007) 5548-5556.

[196] A. J. Graham, D. Akrigg, B. Sheldrick, Acta Crystallogr., Sect. C: Cryst. Struct. Commun. 41 (1985) 995-996.

[197] A. J. Graham, D. Akrigg, B. Sheldrick, Acta Crystallogr., Sect. C: Cryst. Struct. Commun. 5 (1967) 891-898.

[198] A.J. Graham, D. Akrigg, B. Sheldrick, Acta Crystallogr., Sect. C: Cryst. Struct. Commun. 39 (1983) 192-194. 
[199] J. C. Alonso, P. Neves, C. Silva, A. A. Valente, P. Brandão, S. Quintal, M. J. Villa de Brito, P. Pinto, V. Félix, M. G. B. Drew, J. Pires, A. P. Carvalho, M. J. Calhorda, P. Ferreira, Eur. J. Inorg. Chem. (2008) 1147-1156.

[200] H. Martínez-García, D. Morales, J. Pérez, M. Puerto, I. del Río, Chem. Eur. J. 20 (2014) 58215834.

[201] I. Honzíčková, J. Honzíček, J. Vinklárek, Z. Padělková, Polyhedron 81 (2014) 364-369.

[202] K.-B. Shiu, C.-J. Chang, S.-L. Wang, F.-L. Liao, J. Organomet. Chem. 407 (1991) 225-235.

[203] G. D. Gracey, S. J. Rettig, A. Storr, J. Trotter, Can. J. Chem. 65 (1987) 2469-2477.

[204] M. S. Saraiva, S. Quintal, F. C. M. Portugal, T. A. Lopes, V. Félix, J. M. F. Nogueira, M. Meireles, M. G. B. Drew, M. J. Calhorda, J. Organomet. Chem. 693 (2008) 3411-3418.

[205] L. Ion, D. Morales, S. Nieto, J. Pérez, L. Riera, V. Riera, D. Miguel, R. A. Kowenicki, M. McPartlin, Inorg. Chem. 46 (2007) 2846-2853.

[206] A. Mentes, R. D. W. Kemmitt, J. Fawcett, D. R. Russell, J. Organomet. Chem. 660 (2002) 9197.

[207] L. A. García-Escudero, D. Miguel, J. A. Turiel, J. Organomet. Chem. 691 (2006) 3434-3444.

[208] K. Heinze, V. Jacob, C. Feige, Eur. J. Inorg. Chem. (2004) 2053-2061.

[209] C. M. Alvarez, R. García-Rodríguez, D. Miguel, Dalton Trans. (2007) 3546-3554.

[210] C. M. Alvarez, R. García-Rodríguez, D. Miguel, J. Organomet. Chem. 692 (2007) 5717-5726.

[211] F.-C. Liu, T.-C. Tsai, Y.-L. Lin, C.-S. Lee, P.-S. Yang, J.-C. Wang, J. Organomet. Chem. 695 (2010) 423-430.

[212] F.-C. Liu, J.-E. Liang, J.-Y. Jin, Y.-L. Lin, Y.-J. Chu, P.-S. Yang, G.-H. Lee, S.-M. Peng, J. Organomet. Chem. 735 (2013) 1-9.

[213] J. Pérez, D. Morales, V. Riera, A. Rodríguez, S. García-Granda, Dalton Trans. (2003) 1641- 
1644.

[214] J. Pérez, V. Riera, A. Rodríguez, R. López, T. L. Sordo, S. García-Granda, E. García-Rodríguez, A. Galindo, Organometallics 22 (2003) 1540-1545.

[215] S. L. Wu, C. Y. Cheng, S. L. Wang, R. S. Liu, Inorg. Chem. 30 (1991) 311-316.

[216] J. W. Faller, P. P. Fontaine, J. Organomet. Chem. 691 (2006) 4667-4675.

[217] F.-C. Liu, Y.-L. Lin, P.-S. Yang, G.-H. Lee, S.-M. Peng, Organometallics 29 (2010) $4282-$ 4290.

[218] J. Jordanov, H. Behm, P. T. Beurskens, J. Crystallogr. Spectrosc. Res. 21 (1991) 657-659.

[219] J. W. Goodyear, C. W. Hemingway, R. W. Harrington, M. R. Wiseman, B. J. Brisdon, J. Organomet. Chem. 664 (2002) 176-181.

[220] F.-C. Liu, J.-H. Chen, J.-J. She, G.-H. Lee, S.-M. Peng, J. Organomet. Chem. 691 (2006) $3574-3580$.

[221] P. K. Baker, M. G. B. Drew, A. W. Johans, M. M. Meehan, J. Chem. Crystallogr. 28 (1998) 839-841.

[222] P. Paredes, D. Miguel, F. Villafañe, Eur. J. Inorg. Chem. (2003) 995-1004.

[223] M. Arroyo, M. T. García-de-Prada, C. García-Martín, V. García-Pacios, R. García-Rodríguez, P. Gómez-Iglesias, F. Lorenzo, I. Martín-Moreno, D. Miguel, F. Villafañe, J. Organomet. Chem. 694 (2009) 3190-3199.

[224] Y. Yamaguchi, K. Ogata, K. Kobayashi, T. Ito, Bull. Chem. Soc. Jpn. 77 (2004) 303-309.

[225] R. H. Fenn, A. J. Graham, J. Organomet. Chem. 37 (1972) 137-150.

[226] S. Quintal, S. Fedi, J. Barbetti, P. Pinto, V. Félix, M. G. B. Drew, P. Zanello, M. J. Calhorda, J. Organomet. Chem. 696 (2011) 2142-2152.

[227] B. J. Brisdon, M. Cartwright, A. G. W. Hodson, M. F. Mahon, K. C. Molloy, J. Organomet. 
Chem. 435 (1992) 319-335.

[228] P. Espinet, R. Hernando, G. Iturbe, F. Villafañe, A. G. Orpen, I. Pascual, Eur. J. Inorg. Chem. (2000) 1031-1038.

[229] B. J. Brisdon, A. A. Woolf, J. Chem. Soc., Dalton Trans. (1978) 291-295.

[230] J. W. Faller, N. Sarantopoulos, Cryst. Growth Des. 5 (2005) 2356-2361.

[231] Y. D. Ward, L. A. Villanueva, G. D. Allred, S. C. Payne, M. A. Semones, L. S. Liebeskind, Organometallics 14 (1995) 4132-4156.

[232] J. W. Faller, D. A. Haitko, R. D. Adams, D. F. Chodosh, J. Am. Chem. Soc. 99 (1977) $1654-$ 1655.

[233] B. J. Brisdon, J. Organomet. Chem. 125 (1977) 225-230.

[234] M. D. Fryzuk, B. Bosnich, J. Am. Chem. Soc. 99 (1977) 6262-6267.

[235] R. Nast, Angew. Chem. 72 (1960) 26-31.

[236] R. Nast, Coord. Chem. Rev. 47 (1982) 89-124.

[237] C. Elschenbroich, Organometallics, $3^{\text {rd }}$ ed., Wiley-VCH, Weinheim, 2006.

[238] C. H. Suresh, N. Koga, Organometallics 23 (2004) 76-80.

[239] C. H. Suresh, M. -H. Baik, Dalton Trans. (2005) 2982-2984.

[240] J. Pérez, V. Riera, A. Rodríguez, S. García-Granda, Angew. Chem. Int. Ed. 41 (2002) 14271429.

[241] L. Carlton, A. Emdin, A. Lemmerer, M. A. Fernandes, Magn. Reson. Chem. 46 (2008) S56S62.

[242] F. B. Ogilvie, J. M. Jenkins, J. G. Verkade, J. Am. Chem. Soc. 92 (1970) 1916-1923.

[243] K.-H. Yih, G.-H. Lee, J. Organomet. Chem. 693 (2008) 3303-3311. 
[244] Y. Yamaguchi, K. Ogata, K. Kobayashi, T. Ito, Dalton Trans. (2004) 3982-3990.

[245] J. P. Lomont, S. C. Nguyen, C. B. Harris, J. Phys. Chem. A 117 (2013) 2317-2324.

[246] D. Cullen, E. Meyer, T. S. Srivastava, M. Tsutsui, J. Chem. Soc., Chem. Commun. (1972) 584585.

[247] J. J. Bonnet, S. S. Eaton, G. R. Eaton, R. H. Holm, J. A. Ibers, J. Am. Chem. Soc. 95 (1973) $2141-2149$.

[248] M. Yamakawa, H. Ito, R. Noyori, J. Am. Chem. Soc. 122 (2000) 1466-1478.

[249] R. T. Jonas, T. D. P. Stack, J. Am. Chem. Soc. 119 (1997) 8566-8567.

[250] R. H. Holm, P. Kennepohl, E. I. Solomon, Chem. Rev. 96 (1996) 2239-2314.

[251] J. A. Bellow, M. Yousif, A. C. Cabelof, R. L. Lord, S. Groysman, Organometallics 34 (2015) $2917-2923$.

[252] S. A. Burgess, T. Bolaño, T. B. Gunnoe, M. Sabat, W. H. Myers, Eur. J. Inorg. Chem. (2015) $1041-1052$.

[253] J. F. Hartwig, Nature 455 (2008) 314-322.

[254] J. Zhao, A. S. Goldman, J. F. Hartwig, Science 307 (2005) 1080-1082.

[255] W. J. Tenn, K. J. H. Young, G. Bhalla, J. Oxgaard, W. A. Goddard, R. A. Periana, J. Am. Chem. Soc. 127 (2005) 14172-14173.

[256] J. R. Fulton, A. W. Holland, D. J. Fox, R. G. Bergman, Acc. Chem. Res. 35 (2002) 44-56.

[257] E. Hevia, J. Pérez, L. Riera, V. Riera, D. Miguel, Organometallics 21 (2002) 1750-1752.

[258] S. R. Su, A. Wojicicki, Inorg. Chem. 14 (1975) 89-98.

[259] J. J. Doney, R. G. Bergman, C. H. Heathcock, J. Am. Chem. Soc. 107 (1985) 3724-3726.

[260] E. R. Burkhardt, J. J. Doney, R. G. Bergman, C. H. Heathcock, J. Am. Chem. Soc. 109 (1987) 2022-2039. 
[261] C. Moberg, Top. Organomet. Chem. 38 (2012) 209-234

[262] S. W. Krska, D. L. Hughes, R. A. Reamer, D. J. Mathre, Y. Sun, B. M. Trost, J. Am. Chem. Soc. 124 (2002) 12656-12657.

[263] J. A. Brito, B. Royo, M. Gómez, Catal. Sci. Technol. 1 (2011) 1109-1118.

[264] B. M. Trost, J. R. Miller, C. M. Hoffman, J. Am. Chem. Soc. 133 (2011) 8165-8167.

[265] B. M. Trost, Y. Zhang, Chem. Eur. J. 17 (2011) 2916-2922.

[266] B. M. Trost, M. Lautens, Tetrahedron 43 (1987) 4817-4840.

[267] B. M. Trost, M. Lautens, J. Am. Chem. Soc. 104 (1982) 5543-5545.

[268] B. M. Trost, M. Lautens, Organometallics 2 (1983) 1687-1689.

[269] B. M. Trost, T. R. Verhoeven, J. Am. Chem. Soc. 98 (1976) 630-632.

[270] P. B. Mackenzie, J. Whelan, B. Bosnich, J. Am. Chem. Soc. 107 (1985) 2046-2054.

[271] D. Dvorak, I. Stary, P. Kocovsky, J. Am. Chem. Soc. 117 (1995) 6130-6131.

[272] R. J. Watts, J. S. Harrington, J. Van Houten, J. Am. Chem. Soc. 99 (1977) 2179-2187.

[273] B. J. Brisdon, G. F. Griffin, J. Chem. Soc., Dalton Trans. (1975) 1999-2002.

[274] L. A. MacAdams, W.-K. Kim, L. M. Liable-Sands, I. A. Guzei, A. L. Rheingold, K. H. Theopold, Organometallics 21 (2002) 952-960.

[275] D. W. Randall, S. D. George, P. L. Holland, B. Hedman, K. O. Hodgson, W. B. Tolman, E. I. Solomon, J. Am. Chem. Soc. 122 (2000) 11632-11648.

[276] P. G. Hayes, W. E. Piers, L. W. M. Lee, L. K. Knight, M. Parvez, M. R. J. Elsegood, W. Clegg, Organometallics 20 (2001) 2533-2544.

[277] N. B. Kazmina, M. Y. Antipin, S. V. Sereda, Y. T. Struchkov, E. I. Mysov, L. A. Leites, J. Fluorine Chem. 61 (1993) 57-83. 
[278] A. C. Jarvis, R. D. W. Kemmitt, D. R. Russell, P. A. Tucker, J. Organomet. Chem. 159 (1978) $341-355$.

[279] M. Méndez, J. M. Cuerva, E. Gómez-Bengoa, D. J. Cárdenas, A. M. Echavarren, Chem. Eur. J. 8 (2002) 3620-3628.

[280] M. E. Krafft, M. J. Procter, K. A. Abboud, Organometallics 18 (1999) 1122-1124.

[281] M. E. Krafft, M. J. Procter, Tetrahedron Lett. 41 (2000) 1335-1338.

[282] W.A. Thornley, T.E. Bitterwolf, Dalton Trans. 44 (2015) 8007-8012.

[283] S. K. Chowdhury, M. Nandi, V. S. Joshi, A. Sarkar, Organometallics 16 (1997) 1806-1809.

[284] X.-Y. Zhang, J. Hong, H.-B. Song, L.-F. Tang, Organometallics 26 (2007) 4038-4041.

[285] R. O. Day, W. H. Batschelet, R. D. Archer, Inorg. Chem. 19 (1980) 2113-2122.

[286] B. J. Brisdon, S. K. Enger, M. J. Weaver, R. A. Walton, Inorg. Chem. 26 (1987) 3340-3344.

[287] B. J. Brisdon, K. A. Conner, R. A. Walton, Organometallics 2 (1983) 1159-1163.

[288] C. W. Machan, S. A. Chabolla, C. P. Kubiak, Organometallics 34 (2015) 4678-4683.

[289] C. W. Machan, C. J. Stanton, J. E. Vandezande, G. F. Majetich, H. F. Schaefer, C. P. Kubiak, J. Agarwal, Inorg. Chem. 54 (2015) 8849-8856.

[290] K. A. Grice, C. P. Kubiak, Adv. Inorg. Chem. 66 (2014) 163-188.

[291] M. Bourrez, F. Molton, S. Chardon-Noblat, A. Deronzier, Angew. Chem. Int. Ed. 50 (2011) 9903-9906.

[292] J. M. Smieja, C. P. Kubiak, Inorg. Chem. 49 (2010) 9283-9289.

[293] B. P. Sullivan, C. M. Bolinger, D. Conrad, W. J. Vining, T. J. Meyer, J. Chem. Soc., Chem. Commun. (1985) 1414-1416.

[294] J. Hawecker, J.-M. Lehn, R. Ziessel, J. Chem. Soc., Chem. Commun. (1984) 328-330. 
[295] J. Tory, B. Setterfield-Price, R. A. W. Dryfe, F. Hartl, ChemElectroChem 2 (2015) 213-217.

[296] D. Sieh, D. C. Lacy, J. C. Peters, C. P. Kubiak, Chem. Eur. J. 21 (2015) 8497-8503.

[297] M. L. Clark, K. A. Grice, C. E. Moore, A. L. Rheingold, C. P. Kubiak, Chem. Sci. 5 (2014) 1894.

[298] F. Franco, C. Cometto, F. Sordello, C. Minero, L. Nencini, J. Fiedler, R. Gobetto, C. Nervi, ChemElectroChem 2 (2015) 1372-1379.

[299] J. Qiao, Y. Liu, F. Hong, J. Zhang, Chem. Soc. Rev. 43 (2014) 631-675.

[300] R. J. Lim, M. Xie, M. A. Sk, J. -M. Lee, A. Fisher, X. Wang, K. H. Lim, Catal. Today 233 (2014) 169-180.

[301] C. Finn, S. Schnittger, L. J. Yellowlees, J. B. Love, Chem. Commun. 48 (2012) 1392-1399.

[302] E. E. Benson, K. A. Grice, J. M. Smieja, C. P. Kubiak, Polyhedron 58 (2013) 229-234.

[303] M. S. Saraiva, C. D. Nunes, T. G. Nunes, M. J. Calhorda, J. Mol. Catal. A: Chem. 321 (2010) $92-100$.

[304] S. H. Hong, R. H. Grubbs, J. Am. Chem. Soc. 128 (2006) 3508-3509.

[305] B. D. Rossenaar, F. Hartl, D. J. Stufkens, C. Amatore, E. Maisonhaute, J. -N. Verpeaux, Organometallics 16 (1997) 4675-4685.

[306] C. W. Machan, M. D. Sampson, S. A. Chabolla, T. Dang, C. P. Kubiak, Organometallics 33 (2014) 4550-4559.

[307] E. E. Benson, C. P. Kubiak, Chem. Commun. 48 (2012) 7374-7376.

[308] L. H. Staal, A. Oskam, K. Vrieze, E. Roosendaal, H. Schenk, Inorg. Chem. 18 (1979) 16341640.

[309] A. Cebollada, M. E. Viguri, J. Pérez, J. Díaz, R. López, L. Riera, Inorg. Chem. 54 (2015) 25802590. 
[310] M. Brill, J. Díaz, M. A. Huertos, R. López, J. Pérez, L. Riera, Chem. Eur. J. 17 (2011) 85848595.

[311] J. Ruiz, B. F. Perandones, J. Am. Chem. Soc. 129 (2007) 9298-9299.

[312] M. A. Huertos, J. Pérez, L. Riera, J. Am. Chem. Soc. 130 (2008) 5662-5663.

[313] J. A. Keith, K. A. Grice, C. P. Kubiak, E. A. Carter, J. Am. Chem. Soc. 135 (2013) $15823-$ 15829.

[314] M. D. Sampson, J. D. Froehlich, J. M. Smieja, E. E. Benson, I. D. Sharp, C. P. Kubiak, Energy Environ. Sci. 6 (2013) 3748.

[315] P. Christensen, A. Hamnett, A. V. G. Muir, J. A. Timney, J. Chem. Soc., Dalton Trans. (1992) $1455-1463$.

[316] R. L. Beddoes, Z. I. Hussain, A. Roberts, C. R. Barraclough, M. W. Whiteley, J. Chem. Soc., Dalton Trans. (1996) 3629-3637.

[317] J. Li, J. Wu, C. Zhou, B. Han, X. Lei, R. Gordon, H. Cheng, Int. J. Quantum Chem. 109 (2009) $756-763$.

[318] M. W. Creswick, I. Bernal, Inorg. Chim. Acta 74 (1983) 241-269.

[319] I. Bernal, M. Creswick, H. Brunner, G. Agrifoglio, J. Organomet. Chem. 198 (1980) C4-C6.

[320] H. Brunner, W. Meier, J. Wachter, I. Bernal, E. Raabe, J. Organomet. Chem. 362 (1989) 95103.

[321] Y. Yamaguchi, K. Ogata, K. Kobayashi, T. Ito, Inorg. Chim. Acta 357 (2004) 2657-2668.

[322] O. M. El-Kadri, M. J. Heeg, C. H. Winter, J. Organomet. Chem. 694 (2009) 3902-3911.

[323] D. J. Bevan, R. J. Mawby, J. Chem. Soc., Dalton Trans. (1980) 1904-1909.

[324] M. G. B. Drew, G. F. Griffin, Acta Crystallogr., Sect. B: Struct. Crystallogr. Cryst. Chem. 35 (1979) 3036-3039. 
[325] O. M. El-Kadri, M. J. Heeg, C. H. Winter, Dalton Trans. (2006) 4506-4513.

[326] B. S. Lim, A. Rahtu, J. -S. Park, R. G. Gordon, Inorg. Chem. 42 (2003) 7951-7958.

[327] D. Matioszek, N. Saffon, J. -M. Sotiropoulos, K. Miqueu, A. Castel, J. Escudié, Inorg. Chem. 51 (2012) 11716-21.

[328] P. J. Tiong, A. Nova, E. Clot, P. Mountford, Chem. Commun. 47 (2011) 3147-3149.

[329] B. L. Yonke, J. P. Reeds, P. P. Fontaine, P. Y. Zavalij, L. R. Sita, Organometallics 33 (2014) $3239-3242$.

[330] L. R. Groom, A. D. Schwarz, A. Nova, E. Clot, P. Mountford, Organometallics 32 (2013) 7520 7539.

[331] G. R. Fulmer, A. J. M. Miller, N. H. Sherden, H. E. Gottlieb, A. Nudelman, B. M. Stoltz, J. E. Bercaw, K. I. Goldberg, Organometallics 29 (2010) 2176-2179.

[332] M. J. Hampden-Smith, H. Ruegger, Magn. Reson. Chem. 27 (1989) 1107-1111.

[333] S. R. Foley, G. P. A. Yap, D. S. Richeson, Inorg. Chem. 41 (2002) 4149-4157.

[334] S. Schmidt, S. Schulz, D. Bläser, R. Boese, M. Bolte, Organometallics 29 (2010) 6097-6103.

[335] T. Eisenmann, J. Khanderi, S. Schulz, U. Flörke, Z. Anorg. Allg. Chem. 634 (2008) 507-513.

[336] K. Ogata, Y. Yamaguchi, T. Kashiwabara, T. Ito, J. Organomet. Chem. 690 (2005) 5701-5709.

[337] D. A. Clark, D. L. Jones, R. J. Mawby, J. Chem. Soc., Dalton Trans. (1980) 565-569.

[338] D. J. Nelson, S. P. Nolan, in: S. P. Nolan (Ed.), N-Heterocyclic Carbenes, Wiley-VCH, Weinheim, 2014, pp. 8-12.

[339] K.-H. Yih, G.-H. Lee, S.-L. Huang, Y. Wang, Organometallics 21 (2002) 5767-5774.

[340] K.-H. Yih, G.-H. Lee, Y. Wang, Inorg. Chem. Commun. 3 (2000) 458-461.

[341] K.-H. Yih, G.-H. Lee, Y. Wang, Inorg. Chem. 42 (2003) 1092-1100. 
[342] K.-H. Yih, G.-H. Lee, S.-L. Huang, Y. Wang, Inorg. Chim. Acta 348 (2003) 271-278.

[343] H. Sakaba, H. Tonosaki, K. Isozaki, E. Kwon, Organometallics 34 (2015) 1029-1037.

[344] M. Yabe-Yoshida, C. Kabuto, K. Kabuto, E. Kwon, H. Sakaba, J. Am. Chem. Soc. 131 (2009) $9138-9139$.

[345] H. Sakaba, S. Watanabe, C. Kabuto, K. Kabuto, J. Am. Chem. Soc. 125 (2003) 2842-2843.

[346] Y. Kanno, T. Komuro, H. Tobita, Organometallics 34 (2015) 3699-3705.

[347] Y. Kanno, T. Komuro, H. Tobita, RSC Adv. 4 (2014) 19068-19071.

[348] T. Komuro, Y. Kanno, H. Tobita, Organometallics 32 (2013) 2795-2803.

[349] E. Suzuki, T. Komuro, Y. Kanno, H. Tobita, Organometallics 32 (2013) 748-751.

[350] B. M. Trost, L. C. Czabaniuk, Angew. Chem. Int. Ed. 53 (2014) 2826-2851.

[351] S. Lin, Y.-H. Chen, J. Chin. Chem. Soc. 45 (1998) 71-76.

[352] H. Adams, N. A. Bailey, M. J. Winter, S. Woodward, J. Organomet. Chem. 418 (1991) C39C42.

[353] D. Barratt, S. J. Davies, G. P. Elliott, J. A. K. Howard, D. B. Lewis, F. G. A. Stone, J. Organomet. Chem. 325 (1987) 185-201.

[354] R. B. King, A. Fronzaglia, J. Am. Chem. Soc. 88 (1966) 709-712.

[355] J. C. Jeffery, A. L. Ratermann, F. G. A. Stone, J. Organomet. Chem. 289 (1985) 367-376.

[356] M. D. Curtis, L. Messerle, J. J. D’Errico, W. M. Butler, M. S. Hay, Organometallics 5 (1986) $2283-2294$.

[357] J. A. K. Howard, J. C. Jeffery, S. Li, F. G. A. Stone, J. Chem. Soc., Dalton Trans. (1992) 627634. 